\title{
Niobium microalloyed rail steels
}
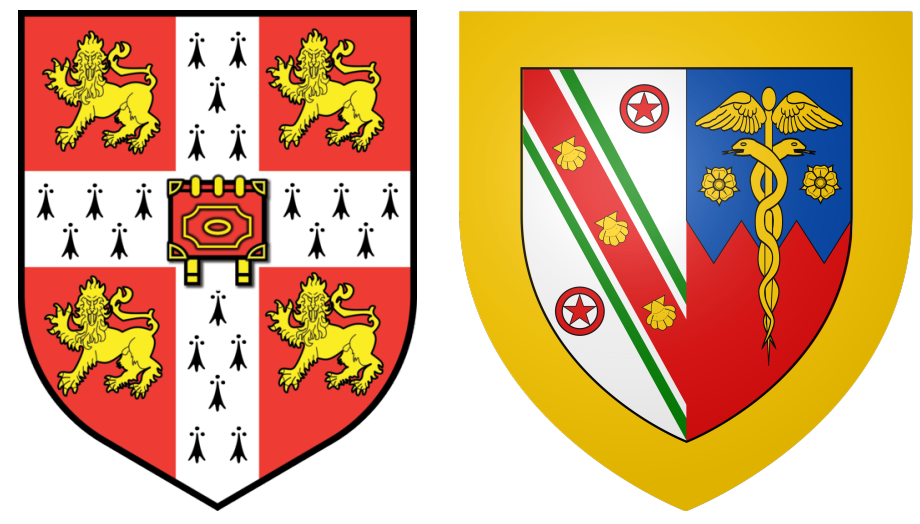

\section{Arunim Ray}

Darwin College

Department of Materials Science and Metallurgy

University of Cambridge

A dissertation submitted for the degree of

Doctor of Philosophy

April, 2017 



\section{Dissertation title: Niobium microalloyed rail steels. Author: Arunim Ray.}

\section{Abstract}

Rail steels rely primarily on possessing adequate wear and rolling contact fatigue resistance. These properties, together with the toughness, can in principle be optimized by implementing thermomechanical processing assisted by controlled niobium additions. The purpose of the current work is to develop a Nb-microalloying strategy in the context of high-carbon pearlitic and cementite-free bainitic steels. The conventional methods do not leave the critical regions of a rail section in a suitably processed state. An attempt has been made for the first time, to create a pancaked austenite grain structure, with an examination of the consequences on the final product. One of the major difficulties is to ensure that niobium does not segregate during manufacturing, since niobium is a strong carbide former and rail steels traditionally contain large carbon concentrations. Niobium solubility in austenite has been assessed critically and thermodynamic calculations for microsegregation have been taken into account. The aim is to ensure that any primary niobium carbide precipitated from solute-enriched liquid during non-equilibrium solidification, can be taken into solution in austenite during reheating, to mitigate potential effects of coarse precipitates on the final mechanical properties.

Rail steels containing 0.01-0.02 wt\% Nb have been designed and characterised. In as-cast condition, primary niobium carbides as large as $\sim 10 \mu \mathrm{m}$ can be observed, which dissolve slowly during reheating. An attempt has been made to develop a model to estimate the dissolution kinetics of the carbides. Dissolved niobium in reheated austenite precipitates during hot deformation as fine niobium carbides $(<50 \mathrm{~nm})$ which inhibit austenite recrystallisation by pinning the austenite grain boundaries. Nb-microalloying increases the 'no-recrystallisation temperature' of deformed austenite during multi-pass compression tests. The topology of grain deformation has been analysed in terms of stereological calculations and dilatometric experiments have shown that transformation kinetics tend to accelerate when the austenite is deformed below the no-recrystallisation temperature, however the effect is relatively small.

The microstructure and mechanical properties of the as-rolled Nb-microalloyed steels have been characterised along with their rolling-sliding wear performance 
and compared with their non-microalloyed counterparts. Increased austenite grain boundary area and increased dislocation activity due to pancaking, hinder bainite growth which leads to an increased retained austenite volume fraction. This in turn, leads to slightly improved ductility, improved toughness and improved wear resistance in Nb-microalloyed bainitic alloys. Microstructural refinement in Nbmicroalloyed pearlitic alloys does not have any significant effect on tensile and toughness properties, but wear resistance improves significantly. A Bayesian neural network model has been developed to estimate the wear of rails. Predicted trends have been found consistent with metallurgical experience and the perceived noise levels are consistent with reasonable repeatability of the wear testing method used. The model can be applied widely to estimate wear because of its capacity to indicate uncertainty, including both the perceived level of noise in the output, and an uncertainty associated with fitting the function in the local region of input space. 


\section{Declaration}

This dissertation is submitted for the degree of Doctor of Philosophy at the University of Cambridge. The research reported was conducted under the supervision of Professor H. K. D. H. Bhadeshia in the Department of Materials Science and Metallurgy, University of Cambridge, between January 2014 and December, 2016.

The is my own work and contains nothing that is the outcome of work done in collaboration with others, except where specifically indicated in the text. Neither this, nor any substantially similar work has been or is being submitted for any degree or diploma or other qualification at any other university or institution. The dissertation does not exceed the prescribed limit of 60,000 words.

Some part of the work has been published in the literature as follows:

- Ray, Arunim, \& Bhadeshia, H. K. D. H. (2015, October). Niobium in Microalloyed Rail Steels. In HSLA Steels 2015, Microalloying 2015 and Offshore Engineering Steels 2015 Conference Proceedings: Hangzhou, Zhejiang Province, China (p. 33). John Wiley \& Sons.

- Ray, Arunim. (2017). Niobium microalloying in rail steels. Materials Science and Technology, pp. 1-17, DOI: 10.1080/02670836.2017.1309111.

- Ray, Arunim, Ooi, S.W., \& Bhadeshia, H. K. D. H. (2017). Precipitation in niobium microalloyed pearlitic and cementite-free bainitic steels for rails. Submitted to Materials Science and Technology.

Arunim Ray

Cambridge, 2017. 


\section{Acknowledgments}

Words fail to express my indebtedness to my thesis supervisor Professor H.K.D.H. Bhadeshia for his invaluable guidance and sustained interest in successful completion of this dissertation. His encouragement and advice enables setting the right pace at every stage of this work and build up a momentum inside me which ensured a smooth sailing till the timely completion of the project. I gratefully acknowledge the generous financial support of CBMM, Brazil. I would like to express my sincere thanks to Mr. Leonardo Silvestre and Mr. Marcos Stuart for important discussions about this project.

I would also like to thank Professor Mark Blamire for the provision of laboratory facilities in the Department of Materials Science and Metallurgy at the University of Cambridge. I also thank Kevin Roberts, Sue Rhodes, Andrew Moss, David Nicol, Simon Griggs, Ken Thorn and Paul Stokes for assisting me in carrying out experiments in the heat treatment laboratory, X-ray, SEM and sample machining. I earnestly acknowledge the help provided by Dr. Arunansu Halder, Dr. Sandra Fretwell-Smith and Mr. Mike Baker with the rolling-sliding wear testing at Swinden Technology Centre, Tata Steel UK. I am thankful to the past and present members of the Phase Transformation and Complex Properties group for their help and friendship. Mathew Peet, Steve Ooi, Chris Hulme-Smith deserve special mention for much useful discussions and help with EBSD, TEM and neural networks. My sincere thanks to Neel, Joachim, Guo Lei, Wil, Gebril, Ailsa, Wendi, Zixin, Tim, Lin Sun, Subhankar, Shaumik, Appa, David and Surajit for their friendship. Anita and Anne needs a special mention on helping me over official matters.

I am indebted to Dr. Debalay Chakrabarti and Dr. S.B. Singh from IIT Kharagpur, for believing in me and providing me with the necessary references for my $\mathrm{PhD}$ application. I am thankful to my friends from BESU, IIT Kharagpur and Jamshedpur for their support and invaluable friendship. Special thanks to my facebook friends for providing me with all the necessary entertainments.

Finally, I express my profound gratitude to my parents for their support and good wishes, without which this venture would not have materialized. 


\section{Abstract}

Rail steels rely primarily on possessing adequate wear and rolling contact fatigue resistance. These properties, together with the toughness, can in principle be optimized by implementing thermomechanical processing assisted by controlled niobium additions. The purpose of the current work is to develop a Nb-microalloying strategy in the context of high-carbon pearlitic and cementite-free bainitic steels. The conventional methods do not leave the critical regions of a rail section in a suitably processed state. An attempt has been made for the first time, to create a pancaked austenite grain structure, with an examination of the consequences on the final product. One of the major difficulties is to ensure that niobium does not segregate during manufacturing, since niobium is a strong carbide former and rail steels traditionally contain large carbon concentrations. Niobium solubility in austenite has been assessed critically and thermodynamic calculations for microsegregation have been taken into account. The aim is to ensure that any primary niobium carbide precipitated from solute-enriched liquid during non-equilibrium solidification, can be taken into solution in austenite during reheating, to mitigate potential effects of coarse precipitates on the final mechanical properties.

Rail steels containing 0.01-0.02 wt\% Nb have been designed and characterised. In as-cast condition, primary niobium carbides as large as $\sim 10 \mu \mathrm{m}$ can be observed, which dissolve slowly during reheating. An attempt has been made to develop a model to estimate the dissolution kinetics of the carbides. Dissolved niobium in reheated austenite precipitates during hot deformation as fine niobium carbides $(<50 \mathrm{~nm})$ which inhibit austenite recrystallisation by pinning the austenite grain boundaries. Nb-microalloying increases the 'no-recrystallisation temperature' of deformed austenite during multi-pass compression tests. The topology of grain deformation has been analysed in terms of stereological calculations and dilatometric experiments have shown that transformation kinetics tend to accelerate when the austenite is deformed below the no-recrystallisation temperature, however the effect is relatively small.

The microstructure and mechanical properties of the as-rolled Nb-microalloyed 
steels have been characterised along with their rolling-sliding wear performance and compared with their non-microalloyed counterparts. Increased austenite grain boundary area and increased dislocation activity due to pancaking, hinder bainite growth which leads to an increased retained austenite volume fraction. This in turn, leads to slightly improved ductility, improved toughness and improved wear resistance in Nb-microalloyed bainitic alloys. Microstructural refinement in Nbmicroalloyed pearlitic alloys does not have any significant effect on tensile and toughness properties, but wear resistance improves significantly. A Bayesian neural network model has been developed to estimate the wear of rails. Predicted trends have been found consistent with metallurgical experience and the perceived noise levels are consistent with reasonable repeatability of the wear testing method used. The model can be applied widely to estimate wear because of its capacity to indicate uncertainty, including both the perceived level of noise in the output, and an uncertainty associated with fitting the function in the local region of input space. 


\section{Contents}

\begin{tabular}{lll}
\hline 1 & Introduction & 1
\end{tabular}

\begin{tabular}{|lll}
\hline 2 & Literature review & 4
\end{tabular}

$2.1 \quad$ Evolution of rail steels . . . . . . . . . . . . . . . . . . . . . . . . . . 4

2.1 .1 Pearlitic rail steels . . . . . . . . . . . . . . . . . . . . . 4

2.1 .2 Bainitic rail steels . . . . . . . . . . . . . . . . . . . . 7

2.2 Austenite grain structure in rail steels . . . . . . . . . . . . . . . . . . 11

2.3 Niobium in high-carbon steels . . . . . . . . . . . . . . . . . . . . . 14

2.4 Description of niobium carbide solubility in Fe-Nb-C system . . . . . 15

2.4 .1 Effect of alloying elements on Nb solubility in austenite . . . . 22

2.5 Primary niobium carbides . . . . . . . . . . . . . . . . . 22

$2.6 \quad$ Effect of niobium on prior austenite grain structure . . . . . . . . . . 24

$2.6 .1 \quad$ Effect of niobium during austenisation . . . . . . . . . . . 24

2.6 .2 Effect of niobium during austenite hot deformation . . . . . . 25

$2.7 \quad$ Effect of niobium on pearlitic microstructure and properties . . . . . 28

$2.7 .1 \quad$ Interlamellar spacing and strength . . . . . . . . . . . . . . . . 28

$2.7 .2 \quad$ Crystallographic unit size and toughness . . . . . . . . . . 33

$2.7 .3 \quad$ Wear resistance . . . . . . . . . . . . . . . . . . . 37

2.8 Effect of niobium on bainitic microstructures and properties . . . . . 38

2.9 Summary . . . . . . . . . . . . . . . . . . . . . . . . . 42

\begin{tabular}{|ll|}
\hline 3 & Statement of objectives
\end{tabular}

4 Thermodynamic calculations and microsegregation 44

4.1 Introduction . . . . . . . . . . . . . . . . . . . . . . . . . . . . . . . . 44

4.2 Thermodynamic calculations . . . . . . . . . . . . . . . . . . 44

4.3 Calculations for microsegregation . . . . . . . . . . . . . . . . . . 46

$4.3 .1 \quad$ Equilibrium or lever-rule model . . . . . . . . . . . . . . . . 46

4.3 .2 Scheil model . . . . . . . . . . . . . . . . . . . . . . . . . . 47

4.3 .3 Scheil model with carbon back-diffusion . . . . . . . . . . . . 47 
4.3 .4 Calculation results for segregated composition . . . . . . . . . 48

4.4 Summary . . . . . . . . . . . . . . . . . . . . . . . . . . . 51

$\begin{array}{lll}5 & \text { Experimental details } & 52\end{array}$

5.1 Alloys . . . . . . . . . . . . . . . . . . . 52

5.2 Dissolution kinetics of precipitates in austenite . . . . . . . . . . . 53

5.3 Microstructural characterisation . . . . . . . . . . . . . . 54

5.3 .1 Sample preparation for metallography . . . . . . . . . . . . 54

5.3 .2 Optical microscopy . . . . . . . . . . . . . . . . . . 54

5.3 .3 Scanning electron microscopy . . . . . . . . . . . . . . 55

5.3 .4 Electron back-scatter diffraction . . . . . . . . . . . . . . . 55

5.3 .5 Transmission electron microscopy . . . . . . . . . . . . . . 55

5.3 .6 X-ray diffraction $\ldots \ldots \ldots \ldots 5$

5.4 Thermomechanical experiments . . . . . . . . . . . . 56

5.5 Mechanical testing $\ldots \ldots \ldots \ldots . \ldots \ldots 57$

5.5 .1 Hardness measurement . . . . . . . . . . . . . . . . . . . 57

5.5 .2 Tensile and Charpy impact testing . . . . . . . . . . 57

5.5 .3 Rolling-sliding wear testing . . . . . . . . . . . . 58

$\begin{array}{lll}6 & \text { Precipitation and dissolution kinetics } & 62\end{array}$

6.1 Precipitates in as-cast material . . . . . . . . . . . . . . . . . . . 62

6.2 Precipitates in as-rolled material . . . . . . . . . . . . . . . . 65

6.3 Dissolution kinetics in a Nb-V-Ti microalloyed high C steel . . . . . . 70

6.4 Summary . . . . . . . . . . . . . . . . . . . . . . . . . . 74

\begin{tabular}{|lll}
\hline 7 & Modelling dissolution kinetics of precipitates & $\mathbf{7 6}$
\end{tabular}

7.1 Introduction . . . . . . . . . . . . . . . . . . . . . . 76

$7.2 \quad$ Kinetics of solute diffusion during precipitation or dissolution . . . . . 77

7.2 .1 Theory of multi-component diffusion . . . . . . . . . . . 80

7.2 .2 Capillarity effect . . . . . . . . . . . . . . . 81

7.3 The model . . . . . . . . . . . . . . . . . . . . . . . . . . . . . 82

7.4 Model results and discussion . . . . . . . . . . . . . . . . . . . . 86

$7.4 .1 \quad$ Effect of initial precipitate size . . . . . . . . . . . . . 87

7.4 .2 Effect of initial volume fraction and interfacial energy . . . . . 88

$7.4 .3 \quad$ Effect of precipitate size distribution . . . . . . . . . . . . 89

7.4 .4 Effect of temperature and composition . . . . . . . . . . . . 90

7.5 Summary . . . . . . . . . . . . . . . . . . . . . . 91 
\begin{tabular}{|lll}
8 & Hot deformation of austenite and dilatometry & 92
\end{tabular}

8.1 Introduction . . . . . . . . . . . . . . . . . . . . . . . . . 92

8.2 Determination of no-recrystallisation temperature . . . . . . . . . . 93

8.3 Topology of austenite grain deformation . . . . . . . . . . . . . 96

8.4 Two-stage compression tests . . . . . . . . . . . . . . . . . . . . . 98

8.5 Transformation temperature . . . . . . . . . . . . . . . . . 103

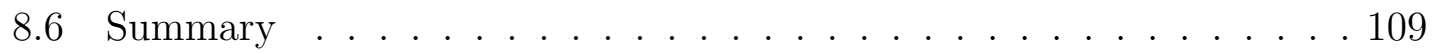

\begin{tabular}{|lll}
9 & Microstructure and mechanical properties of as-rolled material & 110
\end{tabular}

9.1 Introduction . . . . . . . . . . . . . . . . . . . . . . . . 110

9.2 Results and discussion . . . . . . . . . . . . . . . . . . . . . 111

$9.2 .1 \quad$ Microstructure and tensile properties . . . . . . . . . . . . . 111

9.2 .2 Charpy impact toughness . . . . . . . . . . . . . . . . . . . . 122

9.2 .3 Wear performance . . . . . . . . . . . . . . . . . . 129

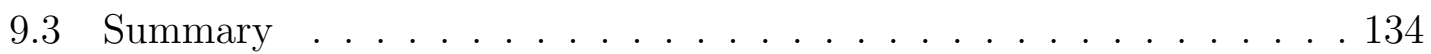

10 Neural network modelling of wear $\quad 135$

10.1 Introduction . . . . . . . . . . . . . . . . . . . 135

10.2 The technique . . . . . . . . . . . . . . . . . . . . 135

10.2 .1 Noise and uncertainty . . . . . . . . . . . . . . . 137

10.2 .2 Log predictive error . . . . . . . . . . . . . . . . . 137

10.2 .3 Committee . . . . . . . . . . . . . . . . . . . 138

10.3 The variables . . . . . . . . . . . . . . . . . . . . . . . . . . . . . . 138

10.4 Model training . . . . . . . . . . . . . . . . . . . . . . . . . 139

10.5 Committee formation and testing . . . . . . . . . . . . . 140

10.6 Maximum noise . . . . . . . . . . . . . . . . . . . . . . . . . . . . . . 142

10.7 Significance . . . . . . . . . . . . . . . . . . . . . . . . 142

10.8 Predictions . . . . . . . . . . . . . . . . . . . . . . . . . . . . . . 143

10.9 Summary $\ldots \ldots \ldots \ldots$. . . . . . . . . . . . . . . . . . . . . 147

\begin{tabular}{ll}
\hline 1 Conclusions and future work & 148
\end{tabular}

11.1 Scope for future work . . . . . . . . . . . . . . . . . . . 150 



\section{Chapter 1}

\section{Introduction}

There are several criteria which determine the suitability of a steel for rail track applications, the most important being wear and rolling contact fatigue resistance. Over the decades, the majority of research on rail steels has focused on improving the wear performance, resulting in a dramatic reduction in the rate of material loss. The cleanliness of the steels with respect to non-metallic inclusions has also been improved over the years, leading to a reasonable improvement in the rolling contact fatigue resistance. In addition to the wear and fatigue properties, the track material must also be capable of being manufactured into long rails with a high standard of straightness and flatness and must be weldable at the same time [1].

The structural integrity of rail steels can be compromised by localised plasticity during service. Resistance to brittle fracture as defined by the toughness of the steel is another prime property requirement for rail steels. Ordinary rail steels contain about high carbon (0.6-0.8 wt\%) contents and are pearlitic. Pearlite consists of a mixture of soft ferrite and a hard, relatively brittle iron carbide called cementite. The common way to increase the wear resistance of a pearlitic steel grade is to reduce the interlamellar spacing in the pearlite colonies, which hardens and strengthens the steel. It is well-known that an individual pearlite colony is an inter-penetrating bicrystal of cementite and ferrite [2]3]. Therefore, the crystallographic grain size, an aspect which determines toughness [1], is not necessarily refined by reducing the interlamellar spacing. It follows that pearlitic steels are hard but not particularly tough and therefore can be prone to brittle failure during service.

The pancaking of austenite grains 1 pinned with microalloy precipitates such as

\footnotetext{
${ }^{1}$ After hot deformation of austenite at temperatures below the no-recrystallisation temperature, the austenite remains as deformed and unrecrystallised grains, which are not equiaxed and elongated in shape of 'pancakes' in three dimensions.
} 
niobium carbide or carbonitride, during the hot rolling of steel, is a well-established thermo-mechanical processing route in the context of high strength low alloy structural steels $[4,5]$. But this aspect has not been explored in the context of rail sections which also suffer from the fact that the deformation experienced in different regions of the rail is not uniform because of the asymmetrical cross-section of the rails. A controlled addition of microalloying elements like niobium may lead to a substantial refinement of the microstructure even for the regions that experience low degrees of deformation, such as the head of the rail, if the austenite recrystallisation can be retarded. Refined prior austenite grains would in turn lead to refined pearlite colonies, which may improve the toughness. This is of particular importance in geographical locations where maintenance is likely to be sporadic.

Alternative steel technologies to pearlite have also been developed involving bainitic steels which are free from cementite, and have outstanding rolling contact fatigue performance [1]. Bainite is a non-lamellar aggregate of cementites and plateshaped ferrite. Each ferrite plate is about $10 \mu \mathrm{m}$ long and about $0.2 \mu \mathrm{m}$ thick. The fine scale of the microstructure is beneficial to strength but coarse cementite particles can degrade the toughness. The precipitation of cementite during the bainite transformation can be suppressed by alloying with about $1.5 \mathrm{wt} \%$ of silicon, which has a very low solubility in cementite and greatly retards its growth, resulting in a microstructure consists of fine plates of bainitic ferrite separated by carbon-enriched regions of austenite free from cementites [1].

However, there is a huge market for improved rail steels to cope with reduced maintenance, heavier traffic and structural integrity. It is in this light that the present work is formulated, to address the toughness of both pearlitic and cementitefree bainitic rails with the aim of achieving a new technology based on niobium microalloying. The proposed research will focus on:

- development of a niobium microalloying strategy in the context of standard rail production methods, including the fact that deformation through the rail section will not be homogeneous;

- development of a viable thermo-mechanical processing route for niobium microalloyed rail steels;

- creation of a pancaked austenite grain structure, with an examination of the consequences on the final product;

- creation of a refined pearlitic structure and possibly one containing fine $\mathrm{NbC}$ precipitates;

- cover the totally new area of microalloying the cementite-free high-silicon 
bainitic rails;

- development of a generic strategy for the use of niobium in high carbon steels.

The work begins with a description of the literature available on rail steel technologies. The evolution of rail steels to modern high strength and high wear resistant pearlitic steels and alternative cementite-free bainitic rail steels are described. The austenite grain structure in rail steels and the effect of niobium as an microalloying element in high carbon steels are also reviewed. The solubility of niobium in ternary Fe-Nb-C austenite is critically assessed to obtain accurate solubility information needed to address niobium segregation in high carbon steels. The effect of niobium on pearlitic and bainitic microstructures and mechanical properties are discussed. Calculations for micro-segregation are taken into account for optimizing the niobium content during alloy design so that niobium can be retained in solution during reheating in order to maximise precipitation during rolling ${ }^{2}$ An attempt has been made to model the dissolution kinetics of niobium carbide precipitates in as-cast steels to optimize the reheating temperature and time. Hot deformation of austenite and dilatometric studies have been carried out to analyze the recrystallisation and transformation kinetics of the microalloyed compositions. Finally, the mechanical properties and wear performance were evaluated to study the effect of niobium.

\footnotetext{
${ }^{2}$ Continuously cast steels are cut into slabs that are then reheated to $1200-1300^{\circ} \mathrm{C}$ for rolling into the appropriate shape.
} 


\section{Chapter 2}

\section{Literature review}

\subsection{Evolution of rail steels}

The first construction of guided transport can be dated back to the ancient Babylonian empire where grooves on roads were used for wagons with the aim of minimizing the resistance to rolling [6]. The concept was re-discovered in the 17 th century for mining transportation and eventually iron was established as the main load bearing surface used in the modern railway age. Initially, cast iron was used which is brittle and failures occurred frequently [7]. Steel rails became a practical choice and economically feasible by the second half of the 19th century when Henry Bessemer discovered the process for producing steel on an industrial scale in 1856. Ever since, all railway tracks have been made of steel, mostly pearlitic steel.

\subsubsection{Pearlitic rail steels}

The characteristic rail steel composition from the Bessemer era has been changed to the modern high-carbon pearlitic alloy as shown in Table 2.1]8]. With the advent of open hearth and basic oxygen furnace processes, the concentration of impurities such as sulphur and phosphorus were reduced through longer refining times and the use of lime-based slag which allows a greater partitioning of the impurities into the slag from the liquid steel. Longer refining times also allowed individual ferroalloy additions to achieve an accurate rail composition, for example, the $\mathrm{Mn}$ and $\mathrm{Si}$ contents for strengthening purposes. 
Table 2.1: Evolution of rail steel composition (wt\%) 8

\begin{tabular}{cccccc}
\hline Year / Type of steelmaking & $\mathrm{C}$ & $\mathrm{Mn}$ & $\mathrm{Si}$ & $\mathrm{P}$ & $\mathrm{S}$ \\
\hline 1890 / Bessemer Converter & 0.58 & 1.33 & 0.08 & 0.074 & 0.072 \\
\hline 2013 / Electric Furnace & 0.84 & 1.00 & 0.40 & 0.010 & 0.008 \\
\hline
\end{tabular}

The carbon content is substantially increased to develop fully pearlitic microstructures or even hyper-eutectoid rail steels. 'Grade-700' rails were the main product for the early 20 th century rail roads which contained $0.5 \mathrm{wt} \% \mathrm{C}$ and had a microstructure of about $30 \%$ proeutectoid ferrite and $70 \%$ pearlite within the rail-head [9]. Due to the rather slow cooling of the rail-head after rolling, the pearlite was relatively coarse. To increase the hardness, and consequently the wear-resistance, 'Grade-900' rails were developed richer in carbon $(0.7-0.8 \mathrm{wt} \%)$ to achieve a fully pearlitic microstructure. Welding techniques were developed to replace fishplate connections and 'Grade-900' became the standard material for main lines. 'Grade-900' had a coarse pearlitic microstructure with sufficient ductility and toughness for general applications. Nevertheless, on narrow curves, mountainous regions and for heavy-haul ore and coal transportation, strengths greater than that exhibited by 'Grade-900' rails were needed $[9]$.

Further strengthening of pearlitic rails to 1100-1200 MPa tensile strength was accomplished by refining the interlamellar spacing of the ferrite and cementite in pearlite colonies. Based on the continuous cooling transformation (CCT) diagram of 'Grade-900' steel, two strategies were adopted for refining pearlite. First, as shown in Figure 2.1 3 , the hardenability was increased through additions of chromium and other alloying elements, so that on air cooling, the rail-head transformed into fine pearlite with a narrow interlamellar spacing [10]. This type was the high-strength and high wear-resistant alloy 'Grade-1100-1200', which cools in still air after rolling. The second way was to accelerate the cooling rate of the rail-head so that the austenite to pearlite transformation of 'Grade-900' can be suppressed to lower temperatures in order to generate fine pearlite $(\sim 90 \mathrm{~nm})$ with $1100-1200 \mathrm{MPa}$ tensile strength using the same steel composition, as shown in Figure 2.1] [11]. This is the head-hardened rail ('Grade-1100HH'). With the advent of the head-hardening processes, rail producers are now able to increase the hardness and strength of pearlitic rails well beyond that of the standard air-cooled rail while maintaining adequate ductility. 

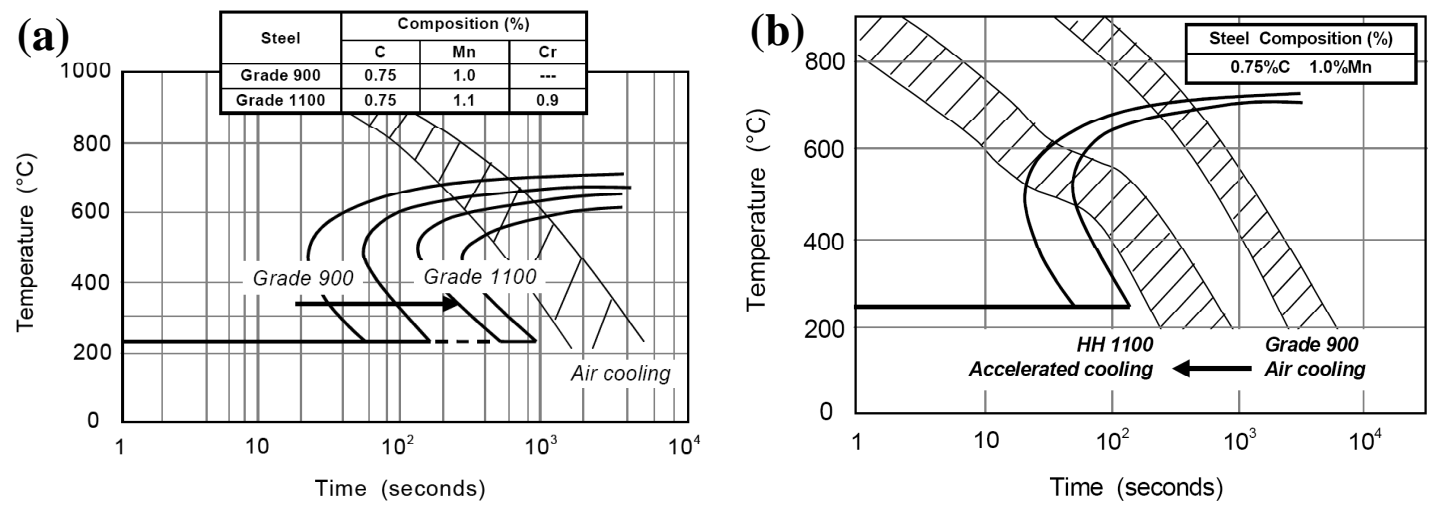

Figure 2.1: Continuous cooling transformation (CCT) diagrams showing the effect of different parameters on pearlite refinement (a) effect of alloying elements; (b) effect of cooling rate. Compositions are in wt\%. 9

However, other steels have been developed and used as well, albeit in small niche applications such as switches and crossings 3 where the stress states differ a great deal from those associated with straight track. Impact loads can become very high when wheels have to pass from one rail to another at switches and crossings. Austenitic steels with high-manganese contents such as the Hadfield steels, have properties better suited to handle repeated impacts. Martensitic steels are not used to a significant extent in railway tracks, but they have found niche applications as parts of crossings and switches [6]. Figure 2.2 and Table 2.2 list some typical microstructures and compositions of pearlitic, austenitic and martensitic rail steels.

\footnotetext{
${ }^{3}$ Rail switches and crossings guide trains from one track to another and enable lines to cross paths, thus creating multi-lined and multi-routed rail networks.
} 

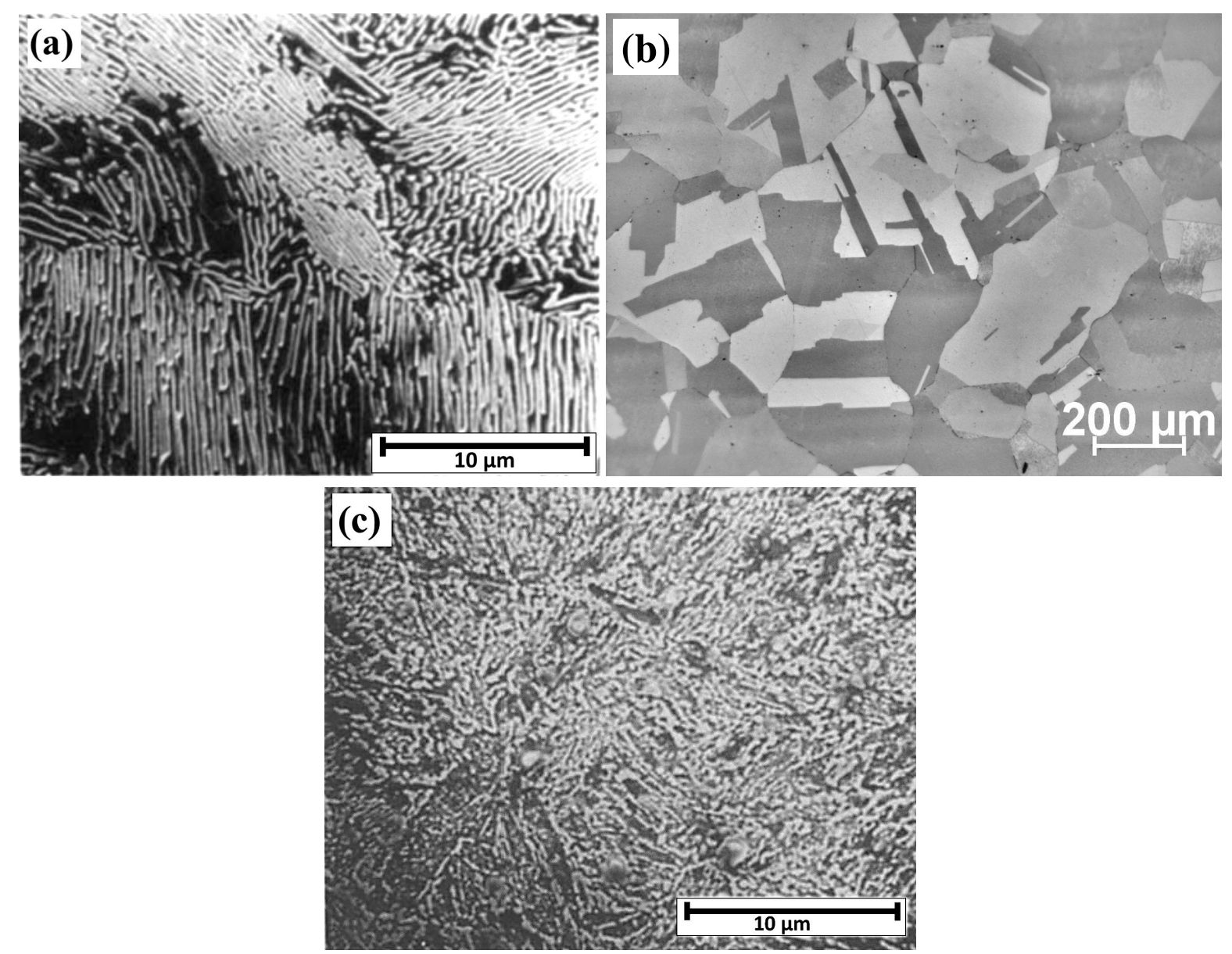

Figure 2.2: Typical rail steel microstructures: (a) pearlitic [12], (b) austenitic [6 13 and (c) martensitic [12]. Reproduced with permission from Elsevier.

\subsubsection{Bainitic rail steels}

The most successful alternatives to pearlitic steels are carbide-free bainitic rails which have an excellent combination of wear-resistance and rolling-contact-fatigue properties [1]. The evolution of bainitic rails in terms of morphology, transformation characteristics and properties (e.g strength, ductility, wear and fatigue resistance, toughness, weldability) have been reviewed over time by several authors [1 14 15]. Early conventional bainitic steels contained carbides in a microstructure mixed of pearlite and bainite and showed inferior mechanical properties than pearlitic rails in terms of wear, rolling-contact-fatigue and toughness [16]. Some bainitic steels were developed with higher tensile and fatigue properties compared to pearlitic rails at same hardness, but subsequent service trials reported faster wear for bainitic rails and also welding related issues which were unspecified [1,17, 18. Further research on low-carbon bainitic grades showed similar trends with mixed microstruc- 
ture being less wear-resistant than those that are fully pearlitic [19 20] though there were few encouraging results. Clayton et al. 21] reported comparable or superior wear-resistance (pin-ring wear test) of low-carbon bainitic steels compared to pearlitic steels of identical hardness (>300 VHN 4). Lower carbon concentrations contribute to better ductility, toughness and weldability [15]. Contradicting results were reported by Garnham [1] for carbide-free bainitic steels (0.04C-0.2Si-0.75Mn$2.0 \mathrm{Ni}-0.25 \mathrm{Mo}-2.8 \mathrm{Cr} / \mathrm{wt} \%$, Table 2.2 which showed poor wear performance relative to pearlite during rolling-sliding wear, a scenario more representative of service conditions. More systematic wear studies by Devanathan and Clayton [22] suggested that low-carbon $(0.07 \mathrm{wt} \%)$ bainitic steels with rapid work hardening and greater ductility, can outperform pearlitic rail steels at the same hardness levels. Whereas medium-carbon $(0.10 \mathrm{wt} \%)$ steels showed comparable wear to pearlite and highcarbon (0.30 wt\%) bainitic steel had poor wear due to chemical segregation, leading to high-carbon martensite separated by bainite with cracking initiated at the interface between these bands.

Bhadeshia et al. 23] attributed some of the inferior mechanical properties of high-strength bainitic rail steels to coarse carbides associated with the bainite microstructure and developed an interesting carbide-free bainitic microstructure by suppressing cementite precipitation during bainite transformation by alloying with silicon (about $1.5 \mathrm{wt} \% \mathrm{Si}$ ) 123 . Silicon has low solubility in cementite and greatly retards its growth. When the Si-alloyed steel is transformed to upper-bainite, the carbon is rejected into the residual austenite and instead of precipitating as cementite, remains in the austenite and stabilises it down to ambient temperature. The resulting microstructure consists of fine plates of bainitic ferrite separated by carbon-enriched regions of austenite (Figure 2.3 a). Several potential advantages of this kind of mixed microstructure of bainitic ferrite and austenite, were reported by Bhadeshia [1] including high hardness and toughness, improved stress-corrosion resistance, simple and cheap processing routes etc. The possibility of poor toughness was also reported due to the presence of relatively large 'blocky' austenite between bainite sheaves (Figure 2.3b). The less stable austenite blocks transformed into highcarbon martensite under the influence of a small applied stress and this untempered, hard martensite embrittled the steel. With careful thermodynamic calculations [1], the composition of alloying elements (like Mn, $\mathrm{Si}, \mathrm{Cr}, \mathrm{Mo}$ ) were critically adjusted to manipulate the thermodynamic limit to permit more bainitic ferrite to form. The

\footnotetext{
${ }^{4}$ VHN or, HVN represents Vickers hardness number.
} 
large blocks of austenite were eliminated whilst still retaining the films of stable austenite.
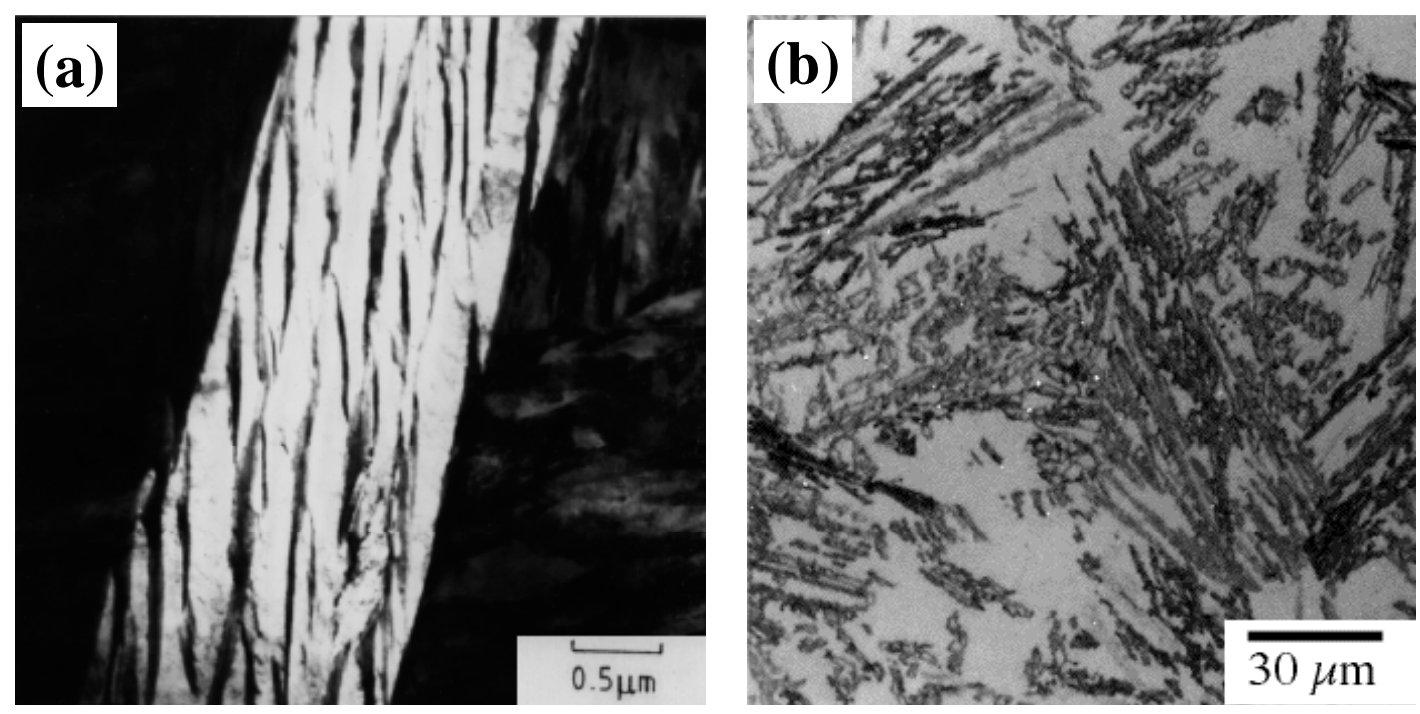

Figure 2.3: (a) Transmission electron micrograph of a sheaf of bainite, consisting of fine ferrite platelets separated by films of carbon-enriched retained austenite; (b) Blocks of retained austenite between sheaves of bainite 123 .

Collaborative work between British steel (later Corus steel and now Tata steel) and University of Cambridge integrated all these theories into a mechanism based model and developed a novel composition specific for rail steels (Table 2.2) with a tough, wear-resistant carbide-free bainitic microstructure [24].

Table 2.2 summarises some typical rail steel compositions. 


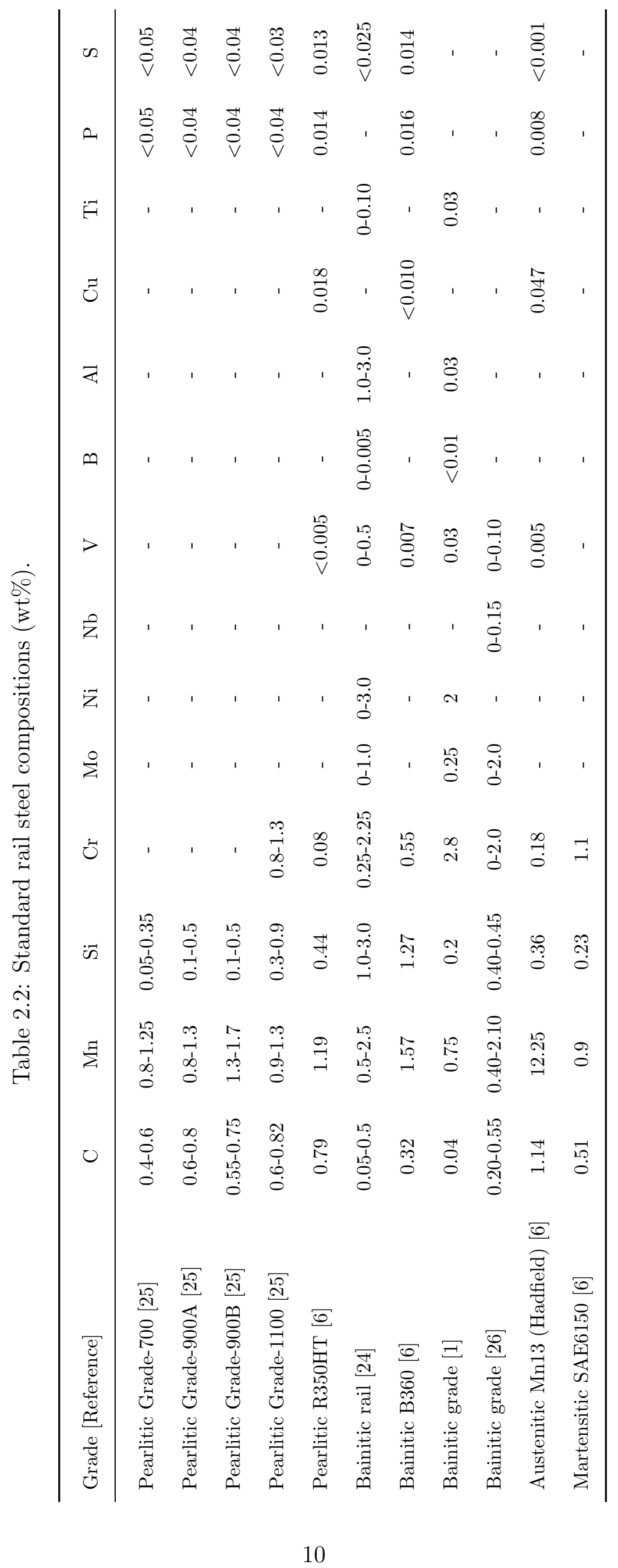




\section{$2.2 \quad$ Austenite grain structure in rail steels}

Austenite grain size, defined as a mean lineal intercept $\bar{L}_{\gamma}$, is important for the following reasons:

(i) a small $\bar{L}_{\gamma}$ leads in general to an even smaller length scale in the transformation product; the reasons for this are attributed to an associated increase in the number density of nucleation sites, limiting the size of displacive transformation products.

(ii) Impurities can segregate to austenite grain surfaces or even prior-austenite grain boundaries if they are not disrupted by phase transformation. The amount of surface per unit volume varies with $\bar{L}_{\gamma}^{-1}$ so the finer the grain size, the smaller the impurity concentration at the grain boundary for a given average value. Thus, boundary-related embrittlement phenomena diminish as $\bar{L}_{\gamma}$ is reduced.

(iii) The thickness of cementite films or size of cementite particles at austenite grain surfaces is reduced as $\bar{L}_{\gamma}$ decreases. These two cementite-dimensions in many circumstances determine the initiation of cleavage fracture [27]. Films of proeutectoid cementite at the prior-austenite grain boundaries are particularly important to avoid or minimise in rail steels.

Rails are hot-rolled starting with reheated slabs and then are deformed into the required profile in less than about twenty rolling passes. Table 2.3 lists some railsection rolling conditions during industrial manufacture and laboratory hot-rolling trials, as published in the open literature \begin{tabular}{|l|l|l|l|l|l|l|}
\hline 14 & 24 & 26 & 28 & 31 &
\end{tabular} . 
Table 2.3: Rolling of rail-sections

\begin{tabular}{|c|c|c|c|c|c|}
\hline $\begin{array}{l}\text { Manufacturing } \\
\text { scale }\end{array}$ & $\begin{array}{c}\text { Ingot } \\
\text { cross-section } \\
(\mathrm{mm} \times \mathrm{mm})\end{array}$ & $\begin{array}{c}\text { Reheating } \\
\text { temperature } \\
\left({ }^{\circ} \mathrm{C}\right)\end{array}$ & $\begin{array}{c}\text { Final } \\
\text { section-size/ } \\
\text { Final thickness }\end{array}$ & $\begin{array}{c}\text { Finish-rolling } \\
\text { temperature } \\
\left({ }^{\circ} \mathrm{C}\right)\end{array}$ & Reference \\
\hline Industrial & $360 \times 270$ & 1250 & UIC60* & $900-950$ & 14 \\
\hline Industrial & $400 \times 610$ & 1288 & $\begin{array}{l}\text { AREMA } \\
\text { 136-RE* }\end{array}$ & 882 & 28 \\
\hline Industrial & $210 \times 270$ & 1160 & KL60* & $880,930-960$ & 29 \\
\hline Laboratory & $45 \times 50$ & 1250 & $15-20 \mathrm{~mm}$ & $>940 / 950$ & 14 \\
\hline Laboratory & $125 \times 125$ & - & $30 \mathrm{~mm}$ & 1000 & 24 \\
\hline Laboratory & $127 \times 127$ & 1200 & $32 \mathrm{~mm}$ & 1050 & 30 \\
\hline Laboratory & - & 1288 & $76 \mathrm{~mm}$ & $882,940-954$ & 28 \\
\hline Laboratory & $75 \times 75$ & 1200 & $24 \mathrm{~mm}$ & - & 31 \\
\hline Laboratory & - & 1250 & $12 \mathrm{~mm}$ & 980 & 26 \\
\hline
\end{tabular}

The initial austenite grain size in a slab held at $1200^{\circ} \mathrm{C}$ for four hours is greater than $460 \mu \mathrm{m}$ [33], and decreases to about $50 \mu \mathrm{m}$ during the first two rolling passes, after which it remains at that value during subsequent reductions. The lack of microalloying elements leads to the coarse structure at the reheating temperature, and all of the subsequent deformation leaves the steel in a recrystallised state between passes. Conventional rails have an austenite grain size which varies dramatically as a function of position within the rail (Figure 2.4), and with the processing parameters. Furthermore, it is particularly noticeable that the base of the web has a much more uniform and relatively fine austenite grain size, presumably because this is the portion which has had the most work done during shape forming. The temperature and strain-distribution in the rail-head are critical parameters and their effect on the final austenite grains are shown in Figure 2.5 [34]. 


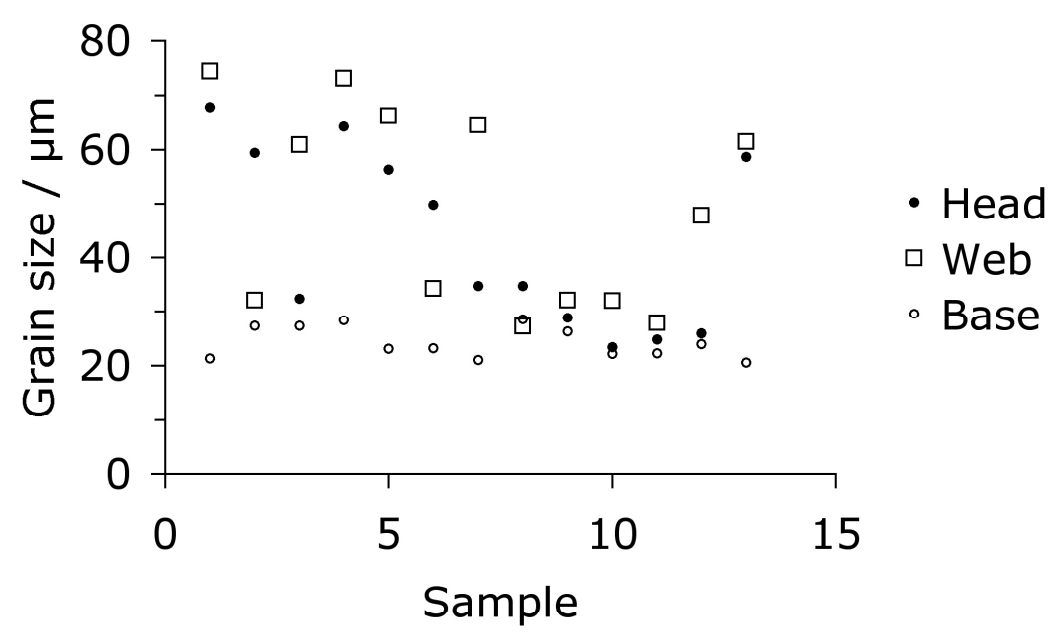

Figure 2.4: Variation in prior-austenite grain diameter within rails. [7]
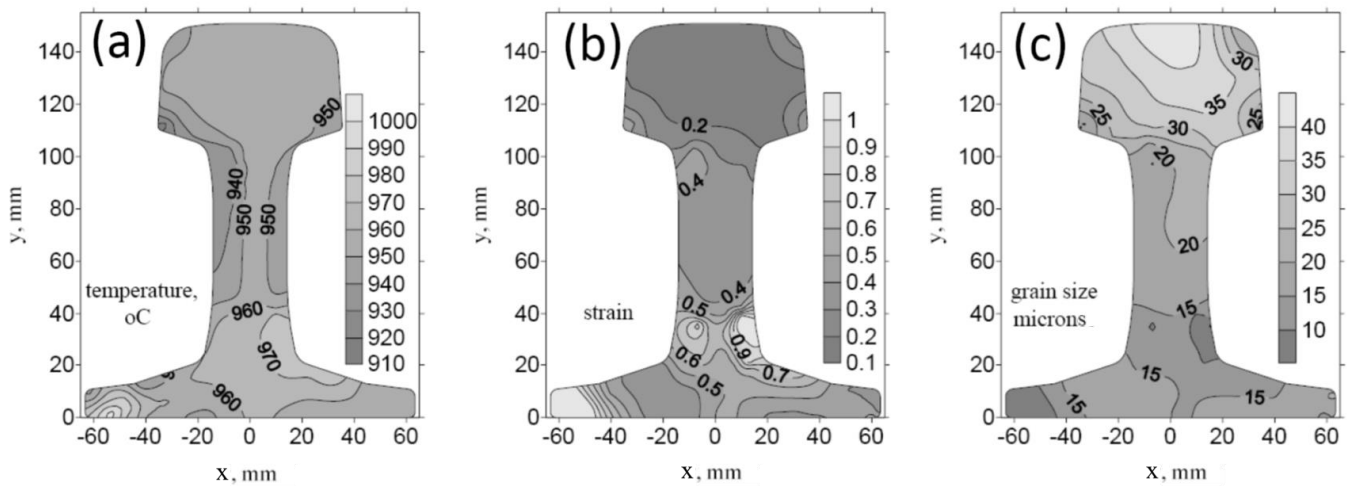

Figure 2.5: Distribution of (a) temperature, (b) effective strain and (c) austenite grain size at the cross-section of a rail after exit from the last pass in a hot-rolling mill [34]. 
It seems obvious that a controlled addition of microalloying elements could lead to substantial grain refinement for the lower degrees of deformation experienced by the rail-head, if the austenite recrystallisation process can be retarded. Such retardation is common in the controlled rolling of large quantities of lower strength materials so the technology is well-established, albeit for the low-carbon alloys. There is an interesting aspect which has never before been explored, i.e., the creation of a pancaked austenite grain structure, especially in the rail-head. Pancaking would lead to a dramatic increase in the amount of grain surface per unit volume because of the highly anisotropic grain shape [35] and hence a more pronounced reduction in $\bar{L}_{\gamma}$ than if equiaxed grains are made finer. Similarly, there is the possibility of further refinement due to shear band formation in unrecrystallised austenite. It is noteworthy that niobium present in solution, for example at the slab reheating temperature, would in itself retard recrystallisation during subsequent deformation if the latter stimulates precipitation [36].

\subsection{Niobium in high-carbon steels}

Niobium is used as an microalloying element for precipitation strengthening and grain refinement in low carbon high strength steels such as those used in manufacturing automotive, pipe steels etc. Whether controlling austenite grain coarsening during reheating or inhibiting austenite recrystallisation during hot deformation by pinning the grain boundaries by fine niobium carbide precipitates, the theory and thermo-mechanical processing technology is well established for low carbon steels (0.01-0.2 wt\% C) [4].5]. There are hardly any niobium microalloyed high carbon steel products commercially available. The major issue is severe niobium segregation in high carbon steels because of low solubility of niobium in high carbon austenite. So the key is to optimise the niobium content so that the niobium can be taken into solution during reheating so that fine niobium carbides can be precipitated during deformation. Alternatively if the niobium carbide cannot be dissolved during reheating, the carbide size must be fine enough and the number density of carbide particles large enough to pin austenite grain boundaries. The literature on the microalloying of high-carbon steels is limited [37.38, but the indications are that niobium additions would be beneficial in the context of rail steels. The benefits are related to both in limiting the austenite grain size, and in modifying the subsequent development of pearlite. There are a number of difficulties not addressed in the available literature.

(i) The data reported are usually for alloys investigated in relatively small scale 
laboratory experiments.

(ii) Full scale trials of the manufacture and testing of rails containing niobium do not seem to have been conducted, or alternatively, such trials have not been reported in accessible literature.

(iii) Issues due to segregation of niobium added to large melts and the formation of coarse deposits of $\mathrm{NbC}$ (which remain as a permanent feature in the steel), are seldom discussed.

To use niobium as an effective microalloying element in high carbon steels, the solubility of niobium carbide is an important parameter to determine the amount of effective microalloying in steel. To maximize precipitate pinning of grain boundaries, it is necessary to dissolve the carbides or nitrides completely at the reheating temperature and precipitate them in the form of fine dispersions and stable particles during rolling. Though the decrease in niobium solubility in austenite with increasing carbon content is a well-established fact but the possibility of an increased niobium solubility at very high carbon contents has been reported by Ohtani et al. [39] and Balasubramanian et al. [40]. To address this anomaly, the description of niobium carbide solubility in ternary $\mathrm{Fe}-\mathrm{Nb}-\mathrm{C}$ austenite is reviewed and compared against thermodynamic databases. The effect of niobium on pearlitic and bainitic microstructures and mechanical properties is discussed thereafter.

\subsection{Description of niobium carbide solubility in Fe-Nb-C system}

There have been many experimental determinations as well as thermodynamic predictions of the solubility of niobium carbide precipitates in ternary Fe-Nb-C austenite [41 50]. The results have been reviewed over time and sometimes reassessed to provide a more suitable thermodynamic description of $\mathrm{NbC}$ solubility in austenite 39 40 49 52]. The early experimental measurements and thermodynamic calculations of carbide solubility were based on the assumption that carbides (or nitrides) of transition elements such as $\mathrm{Ti}, \mathrm{Nb}, \mathrm{V}$ are stoichiometric in composition and that the austenite is devoid of any ternary solute interactions. The methodology considers the austenite- $\mathrm{NbC}$ equilibrium as follows:

$$
\begin{gathered}
{[\mathrm{Nb}]+[\mathrm{C}] \rightleftharpoons \mathrm{NbC}} \\
R T \ln \left[a_{\mathrm{Nb}} a_{\mathrm{C}}\right]=\Delta^{\circ} G_{\mathrm{NbC}}
\end{gathered}
$$


where $[\mathrm{Nb}]$ and $[\mathrm{C}]$ are elements dissolved in austenite, $a_{\mathrm{Nb}}$ and $a_{\mathrm{C}}$ are the activities of the elements, $\Delta^{\circ} G_{\mathrm{NbC}}$ is the standard free energy of formation of the stoichiometric carbide from $1 \mathrm{wt} \%$ austenite solution. Assuming dilute solutions in austenite, the solubility product can be defined as:

$$
\begin{gathered}
R T \ln [\% \mathrm{Nb}][\% \mathrm{C}]=\Delta^{\circ} G_{\mathrm{NbC}} \\
\log [\% \mathrm{Nb}][\% \mathrm{C}]=A+B / T
\end{gathered}
$$

where $[\% \mathrm{Nb}]$ and $[\% \mathrm{C}]$ are the weight percents of niobium and carbon dissolved in austenite respectively, $A$ and $B$ are approximate constants related to the enthalpy and entropy of carbide formation respectively. A summary of various investigations up to 1980s on $\mathrm{NbC}$ solubility is given in terms of $A$ and $B$ values in Table 2.4. Some investigations showed an improved prediction with the experimental solubility data for carbides by assuming the carbide composition to be $\mathrm{NbC}_{0.87}$ instead of perfect stoichiometry.

\begin{tabular}{|c|c|c|c|}
\hline \multirow{2}{*}{$\begin{array}{c}\text { Temperature } \\
\text { Range }\end{array}$} & \multicolumn{2}{|c|}{ Solubility Product } & \multirow[t]{2}{*}{ Reference } \\
\hline & $A$ & $B(\mathrm{~K})$ & \\
\hline $1173-1473 \mathrm{~K}$ & 2.90 & -7500 & De Kazinczy, 196341 \\
\hline $1273-1573 \mathrm{~K}$ & 3.18 & -7700 & Mori, 196442 \\
\hline $1323-1573 \mathrm{~K}$ & 3.42 & -7900 & Narita, 1966 43. \\
\hline $1173-1573 \mathrm{~K}$ & 3.04 & -7290 & Meyer, 196744 \\
\hline $1273-1573 \mathrm{~K}$ & 3.70 & -9100 & Smith, 1966 45 \\
\hline $1223-1323 \mathrm{~K}$ & 4.37 & -9290 & Johansen, 196746 \\
\hline $1173-1473 \mathrm{~K}$ & 3.11 & -7520 & Nordberg, $1968 * 47$ \\
\hline $1323-1423 \mathrm{~K}$ & 3.31 & -7970 & Koyama, 197148 \\
\hline $1273-1523 \mathrm{~K}$ & 3.40 & -7920 & Lakshmanan, $1977 *$ \\
\hline $1173-1473 \mathrm{~K}$ & 2.81 & -7020 & Sharma, $1984 * 50$ \\
\hline
\end{tabular}

Table 2.4: Solubility of niobium carbide in austenite [40].

Balasubramanian [40], reported two drawbacks in calculating NbC solubility by the above methodology.

(i) Transition elements like $\mathrm{Ti}, \mathrm{Nb}, \mathrm{V}$ are strong carbide and nitride formers. So interactions between solutes need to be accounted for.

(ii) $\mathrm{NbC}$ is non-stoichiometric and hence its composition can vary when precipitated in steels. This rules out a simplified analysis. 
An increase in Nb solubility in austenite has been reported at high-carbon concentrations by Balasubramanian [40]. A solubility-minimum was observed (around 0.4-0.5 wt\% C) at $1273-1473 \mathrm{~K}$. This was attributed to the strong solute interactions in austenite and non-stoichiometry of the carbides. It was argued that earlier investigations $41-50]$ were performed at low-carbon concentrations (below $0.2 \mathrm{wt} \%$ ) without addressing the solute interactions and carbide non-stoichiometry and hence are not capable of predicting the solubility at higher carbon levels where the effects of solute interactions become significant. The classical solubility product expression (equation 2.4) was modified by incorporating an additional term for the concentration dependence on carbon [40].

$$
\log [\% \mathrm{Nb}][\% \mathrm{C}]=A+B / T+(C / T-D) \cdot[\% \mathrm{C}]
$$

Thus, raising the carbon content increases the solubility product of $\mathrm{NbC}$ and more niobium can be retained in solution.

Parallel but independent work by Ohtani et al. [39] also suggested an increase in $\mathrm{NbC}$ solubility at high-carbon concentrations by taking account of strong interactions between niobium and carbon atoms in austenite. Table 2.5 and Figure 2.6 compare the two separate thermodynamically calculated solubility data in [40] and [39], both reporting an increase in Nb solubility at high-carbon concentrations. Both groups showed fair agreement at lower temperatures $(\leq 1373 \mathrm{~K})$ but the difference widens with increasing temperatures. Different values for the free energy of dissolution of niobium in austenite are the cause of this anomaly in NbC solubility data. 
Table 2.5: Solubility limit and ternary interaction in Fe-Nb-C system [40]. Composition and temperature are in wt\% and K respectively. $\gamma_{\mathrm{Nb}}^{0}$ is the activity co-efficient of dissolved niobium in austenite.

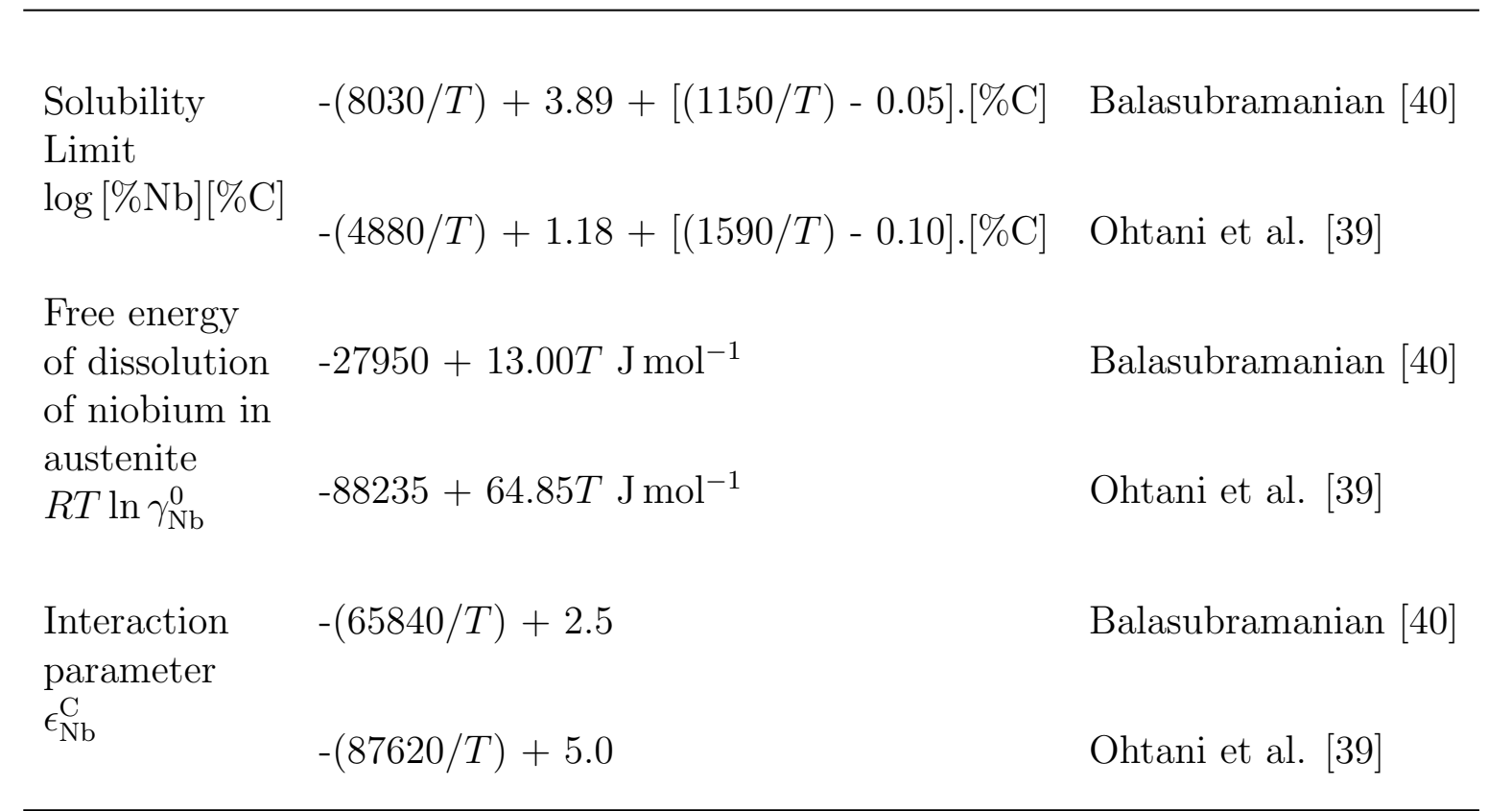
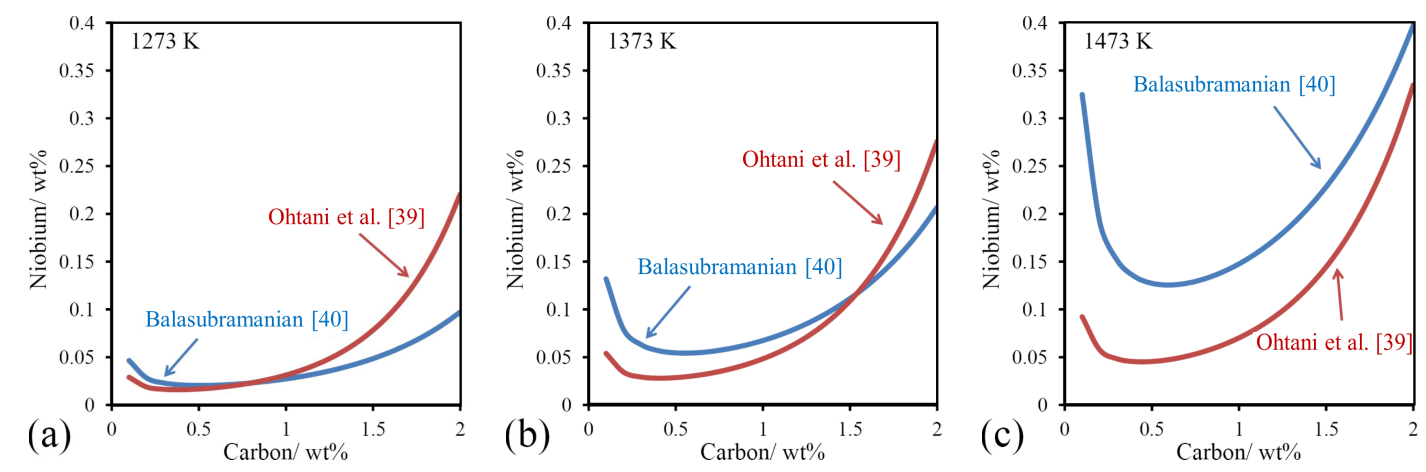

Figure 2.6: Comparison between thermodynamically calculated solubility data by Balasubramanian [40] and Ohtani et al. [39]: (a) $1273 \mathrm{~K}$, (b) $1373 \mathrm{~K}$, (c) $1473 \mathrm{~K}$.

Complete original experimental data for NbC solubility from Ohtani's work have not been possible to trace. Only one instance of experimental data from Ohtani's work (experimental data points up to $1.0 \mathrm{wt} \% \mathrm{C}$ ) can be found from [53. The corresponding complete original references ( $[54 \mid 55$ cited in $[53]$ ) could not be obtained. Figure 2.7 compares their experimental data with those of Balasubramanian [40] (experimental data up to $2.0 \mathrm{wt} \% \mathrm{C}$ ) and an earlier experimental investigation by Lakshmanan [49] which was limited to only $0.2 \mathrm{wt} \% \mathrm{C}$. There is no apparent solubilityminimum in the experimental data from Ohtani et al. [39]. This contradicts the 
solubility-minimum at about $0.4-0.5 \mathrm{wt} \% \mathrm{C}$ in the thermodynamically fitted curve on the same solubility data of Ohtani et al. from Figure2.6c. Also, experimental data from Ohtani et al. agree well with those of Lakshmanan [49 for carbon concentrations up to $0.2 \mathrm{wt} \%$. But there remains a discrepancy with the experimental data from Balasubramanian [40] where a clear solubility-minimum can be observed (Figure2.7).

The NbC solubility in Fe-Nb-C austenite was measured by Balasubramanian [40] from the deflection in equilibrated carbon content variation with $\mathrm{Nb}$ additions at constant carbon activity during dynamic gas-equilibration experiments [40]. The reported error is calculated by assuming negligible error in the determination of $\mathrm{wt} \% \mathrm{C}$ and equating the absolute error in the solubility product to the relative error in determination of wt $\% \mathrm{Nb}$. As shown in Figure 2.8 a, at high carbon levels $(>1.0 \mathrm{wt} \% \mathrm{C})$, the change of slope in the iso-activity curves is significant and hence the error in the determination of $\mathrm{C}$ and $\mathrm{Nb}$ compositions are small. However, at lower carbon levels $(<1.0 \mathrm{wt} \% \mathrm{C})$ (Figure $2.8 \mathrm{~b}-\mathrm{c})$, the error should be relatively higher due to a less pronounced change in slope and error in measured $\mathrm{wt} \% \mathrm{C}$ should not be neglected. So in Figure 2.7, the experimental NbC solubility data at high carbon levels ( $>1.0 \mathrm{wt} \% \mathrm{C}$ ) due to Balasubramanian 40 may be accurate, but the solubility at lower carbon contents $(<1.0 \mathrm{wt} \% \mathrm{C})$ should contain a larger amount of error than reported.
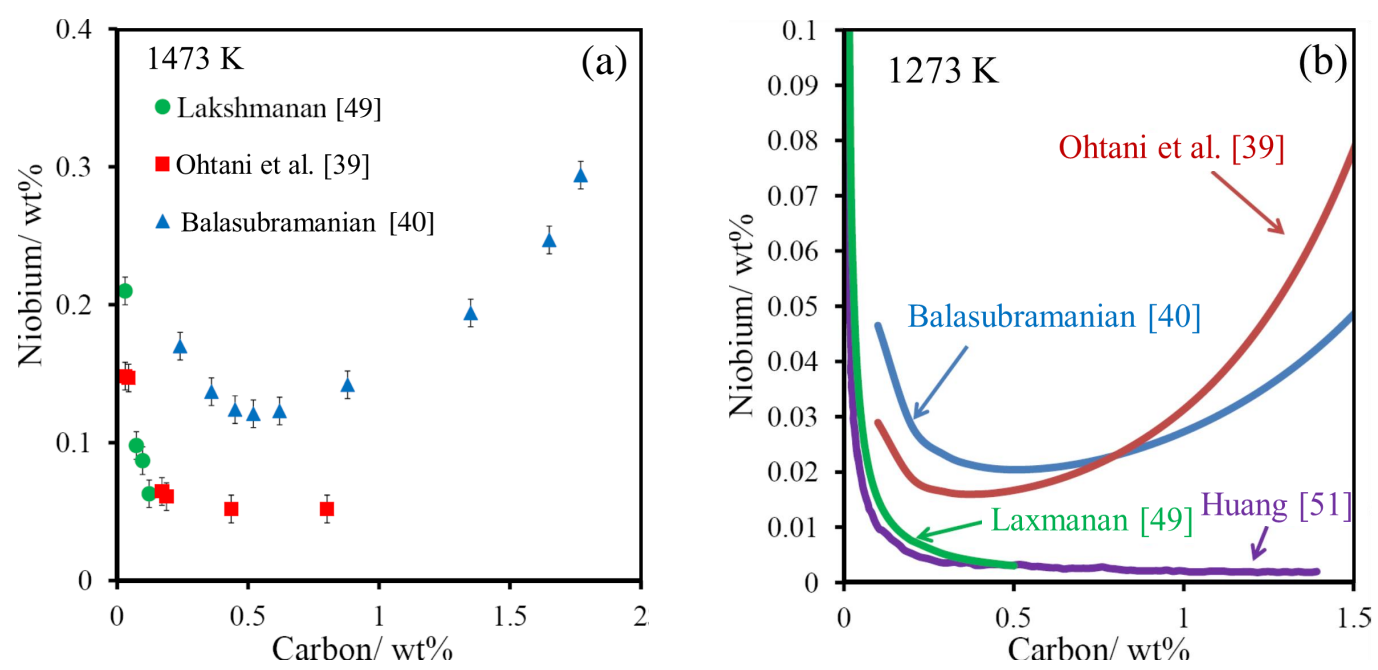

Figure 2.7: NbC solubility in austenite as a function of the carbon concentration: (a) experimentally measured at $1473 \mathrm{~K}$, (b) thermodynamically calculated at $1273 \mathrm{~K}$. 

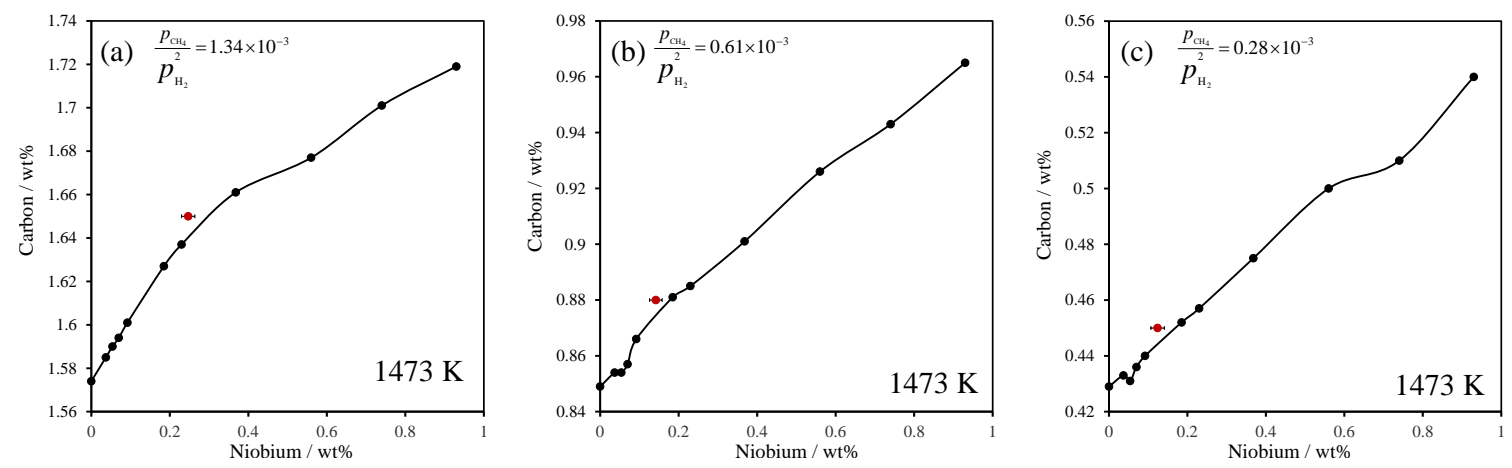

Figure 2.8: The carbon content of equilibrated Fe-Nb-C alloys at $1473 \mathrm{~K}$ for different carbon potentials: (a) high carbon potential [gas ratio $\left(p_{\mathrm{CH}_{4}} / p_{\mathrm{H}_{2}}^{2}\right)=1.34 \times 10^{-3}$ ], (b) medium carbon potential $\left(p_{\mathrm{CH}_{4}} / p_{\mathrm{H}_{2}}^{2}=0.61 \times 10^{-3}\right)$, (c) low carbon potential $\left(p_{\mathrm{CH}_{4}} / p_{\mathrm{H}_{2}}^{2}=0.28 \times 10^{-3}\right)$. Red circles indicate the measure solubility data at the corresponding carbon potential [40].

Huang [51], optimized the thermodynamic description for Fe-Nb-C ternary system by using $\mathrm{Nb}-\mathrm{C}$ and $\mathrm{Fe}-\mathrm{Nb}$ data and the Fe-C description by Gustafson [56]. This work was reviewed by Lee [52], along with the other earlier experimental investigations on $\mathrm{NbC}$ solubility including the anomaly between Ohtani et al. [39] and Balasubramanian [40]. The calculated solubility using Huang's description [51] is too low, especially at low temperature $(1273 \mathrm{~K})$, when compared with data from [39] and [40] as shown in Figure 2.7b. In contrast, no increase in solubility can be observed at large carbon contents in [51]. These differences were attributed to a more positive value of the interaction energy parameter $L_{\mathrm{Fe}, \mathrm{Nb}}\left(-4784 \mathrm{~J} \mathrm{~mol}^{-1}\right)$ in Huang's calculations [51] than in [39] and [40]. The value of the ternary interaction parameter was calculated in [51] as $\epsilon_{\mathrm{Nb}}^{\mathrm{C}}=-38276 / T+3.1$ which is more positive and does not correspond to the strong mutual solute interaction as compared with those of [39] and [40] (Table 2.5). It was also argued by Huang [51] that the calculated activity of carbon from Balasubramanian's 40 experimental data on NbC solubility in austenite, could show a large error since the carbon activities of the Fe-C binary obtained by [40] show poor agreement with the well-established data by Gustafson [56]. Balasubramanian et al. [57] also acknowledged this fact that some uncertainty still exists in the description of Fe-Nb-C system.

But the data from Huang's calculation [51] were consistent with earlier investigations [41 50] in the same range of temperature (1273 to $1473 \mathrm{~K}$ ). Lee [52] developed a self-consistent thermodynamic description for the Fe-Nb-Ti-C-N quinary system and on the way reassessed Huang's work [51] on Fe-Nb-C ternary systems in terms of its sub-binary systems i.e. Fe-Nb, Nb-C and Fe-C. In particular the Fe-Nb descrip- 
tion was revised by making $L_{\mathrm{Fe}, \mathrm{Nb}}$ temperature dependent instead keeping constant. A slight change in $\mathrm{Nb}-\mathrm{C}$ description was also required but the revision was made in a way that does not change the temperature dependence of the enthalpy of formation of $\mathrm{NbC}$ carbides. Thus Fe-Nb phase becomes more stable in austenite at low temperatures which in turn improves the agreement between calculated and experimentally measured slopes of solubility product for $\mathrm{NbC}$.

Commercial software like Thermo-Calc, MTDATA, MatCalc, JMatPro etc. have been developed, which, together with appropriate data, can be used to calculate phase-equilibria and thermodynamic properties in multicomponent, multiphase systems. For steel and Fe-based alloys, TCFE is the most common database which has been continuously developed and improved over the years by Thermo-Calc Software AB [58]. It has also been translated and tested for use with MTDATA [58. MatCalc has been developed with 'mc_fe'; 'mc_steel' and 'mc_sample_fe' thermodynamic databases for steel and Fe-based alloys [59]. Detailed review of the database references reveals that the Fe-Nb-C description for TCFE and 'mc_sample_fe' databases have been developed based on the assessment by Lee [52] while for 'mc_fe_v2.009' and 'mc_steel', thermodynamic calculations by Huang [51] have been taken into account in addition to that of Lee [52]. Figure 2.9 compares the NbC solubility calculated by different commercial software and databases. There clearly is considerable uncertainty in calculating the appropriate niobium solubility for a given carbon concentration.

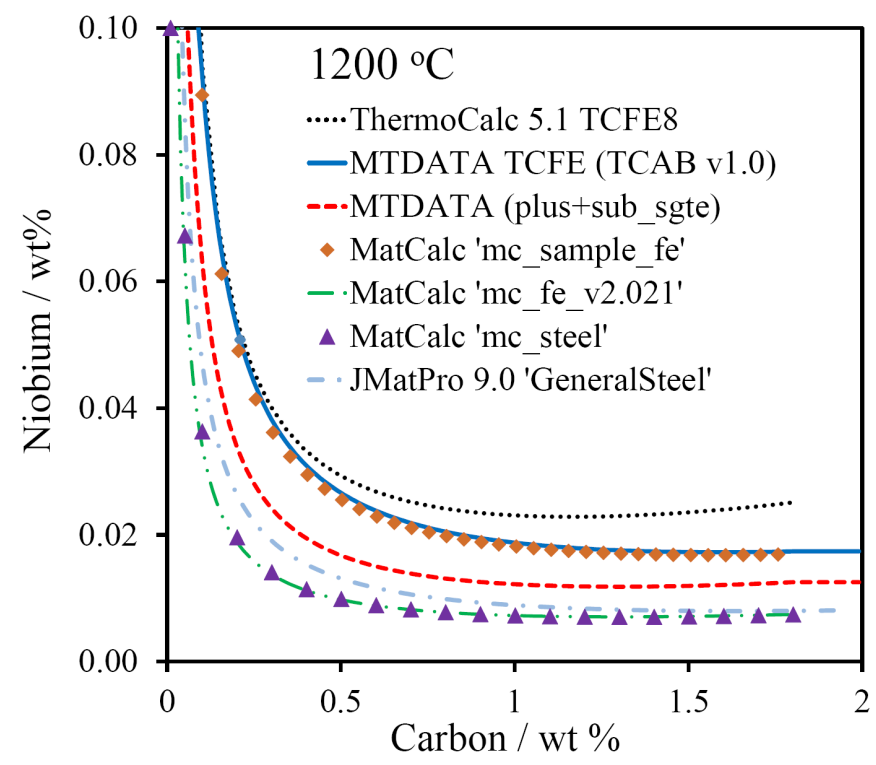

Figure 2.9: Comparison between thermodynamically calculated solubility data by different commercial software with different databases. 


\subsubsection{Effect of alloying elements on $\mathrm{Nb}$ solubility in austenite}

Koyama et al. [48] studied the influence of $\mathrm{Mn}, \mathrm{Si}, \mathrm{Cr}$ and $\mathrm{Ni}$ on the solubility of $\mathrm{NbC}$ in $\mathrm{Fe}-\mathrm{Nb}-\mathrm{C}$ austenite by the method of equilibration with methane-hydrogen mixture gas. $\mathrm{Mn}$ and $\mathrm{Cr}$ increased $\mathrm{NbC}$ solubility in austenite remarkably whereas $\mathrm{Ni}$ increased the solubility at $1050-1100^{\circ} \mathrm{C}$. But the effect was weak at higher temperatures $\left(\sim 1150^{\circ} \mathrm{C}\right)$. In contrast, Si drastically decreased the solubility of $\mathrm{NbC}$ in austenite. This will have an important effect for Nb-microalloyed cementite-free bainitic compositions where the Si content is quite high (1.5-2.0 wt\% $\mathrm{Si}$ ) to suppress cementite precipitation. Such effects are attributed to the effect of each element on the activity of $\mathrm{Nb}$ as well as that of carbon. The effect on the NbC solubility product was described by the following equations based on experimental data. Composition and temperatures are in wt\% and $\mathrm{K}$ respectively.

$$
\begin{array}{r}
\log [\% \mathrm{Nb}][\% \mathrm{C}]=-7970 / T+3.31+(1371 / T-0.900)[\% \mathrm{Mn}]-(75 / T-0.0504)[\% \mathrm{Mn}]^{2} \\
\log [\% \mathrm{Nb}][\% \mathrm{C}]=-7970 / T+3.31-(735 / T-0.348)[\% \mathrm{Si}] \\
\log [\% \mathrm{Nb}][\% \mathrm{C}]=-7970 / T+3.31+(1113 / T-0.691)[\% \mathrm{Cr}]-(38 / T-0.0228)[\% \mathrm{Cr}]^{2} \\
\log [\% \mathrm{Nb}][\% \mathrm{C}]=-7970 / T+3.31+(148 / T-0.0904)[\% \mathrm{Ni}]-(8.5 / T-0.0068)[\% \mathrm{Ni}]^{2}
\end{array}
$$

\subsection{Primary niobium carbides}

The majority of articles on Nb-microalloyed high-carbon steels do not address the role of primary niobium carbides, i.e., those which may precipitate from the last liquid to solidify. The solubility of $\mathrm{NbC}$ is also low in liquid steel with high carbon compositions and due to micro-segregation during solidification, there is a probability of primary $\mathrm{NbC}$ formation from liquid. Kestenbach et al. 60 studied quantity, distribution and effectiveness of eutectic carbides in $0.75 \mathrm{C}-0.9 \mathrm{Mn}-0.16 \mathrm{Si}$ $(0.04-0.07) \mathrm{Nb}$ (wt\%) steels. The particles were heterogeneously distributed and seemed to be ineffective in promoting microstructural refinement. Primary precipitates were reported even for low carbon (0.15-0.2 wt\%) compositions. Bernetič et al. 61] observed coarse niobium carbo-nitride particles (Figure 2.10a) in 0.15C-1.1Mn$0.49 \mathrm{Si}-0.022 \mathrm{Nb}-0.0071 \mathrm{~N}$ (wt\%) as constituents of the degenerated $\mathrm{Fe}-\mathrm{Nb}(\mathrm{C}, \mathrm{N})$ that forms because of the centerline segregation of niobium. The location of the eu- 
tectic in the centre of the slab and the composition of the steel suggest that its formation is an improper solidification process related to a high casting temperature, a high slab solidification rate or a deficiency in the secondary slab cooling. The stability of the precipitates at slab-soaking temperatures even higher than stoichiometric $\mathrm{Nb}\left(\mathrm{C}_{0.9} \mathrm{~N}_{0.1}\right)$ solution temperature, was attributed to high nitrogen contents in the eutectic precipitates. Vodopivec et al. [62 observed eutectic NbC formation in mild steel containing niobium [0.19C-1.46Mn-0.42Si-0.045Nb-0.053V0.047Al-0.014N (wt\%)] under special solidification conditions and the precipitates caused internal hot cracks in steel slabs. The isothermal dissolution kinetics of the precipitates in austenite was reported to be very slow (Figure 2.10 b) which was attributed to slow diffusion transport at the precipitate/austenite interface rather than slow diffusion rate of $\mathrm{Nb}$ in austenite. But even the diffusion controlled dissolution kinetics of such precipitates is also quite slow owing to the coarse carbide sizes (average NbC size $2 \pm 1 \mu \mathrm{m}$ for Figure 2.10a).

Some more examples of primary niobium carbide formation from liquid steel are given in 63 68]. During industrial continuous casting of steel, with the advent of technologies like electro-magnetic stirring, dynamic soft reduction etc. and due to faster cooling rates during solidification, it may be possible to inhibit the formation of primary precipitates. Also by controlling the niobium addition, the size of the coarse carbides may be refined so that they are not harmful to the mechanical properties.
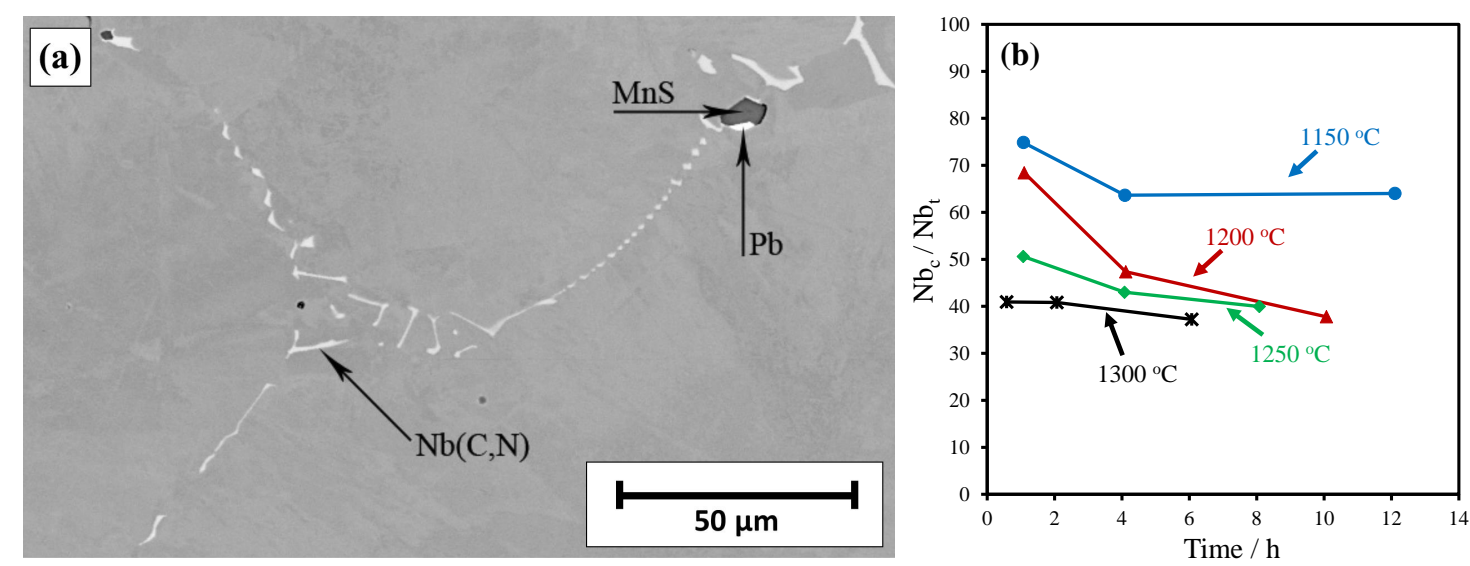

Figure 2.10: (a) Primary eutectic $\mathrm{Nb}(\mathrm{C}, \mathrm{N})$ precipitates in as-cast Nb-microalloyed steel. Reproduced with permission [61]. (b) Kinetics of dissolution of niobium carbonitride in austenite at different temperatures. $\mathrm{Nb}_{\mathrm{c}}$ is niobium in carbonitrides and $\mathrm{Nb}_{\mathrm{t}}$ is total niobium content in steel [62]. 


\subsection{Effect of niobium on prior austenite grain struc- ture}

Niobium generally has two main effects on prior austenite grain size (PAGS):

(i) during soaking at austenisation temperatures, fine niobium precipitates (nitrides, carbides or carbo-nitrides) delay austenite grain growth retaining fine austenite grain size;

(ii) during hot rolling, strain-induced niobium precipitates pin austenite boundaries and delay or inhibit austenite recrystallisation, thus producing a pancaked austenite structure.

\subsubsection{Effect of niobium during austenisation}

The majority of work on Nb-microalloyed high carbon steels is focussed on the first effect i.e. austenite grain growth during soaking 60.68 71]. Coladas et al. 69 have shown for Nb-microalloyed (0.03-0.09 wt\% Nb) medium to high carbon (0.4$0.81 \mathrm{wt} \% \mathrm{C})$ steels, that there is a critical austenisation temperature $\left(T_{c}\right)$ [Figure 2.11a], below which the change in grain size remains small. At $T>T_{c}$, the size increases rapidly with temperature. In contrast, for non-microalloyed steels, the austenite grain size increases monotonically with temperature. For medium carbon steels with $0.4-0.5 \mathrm{wt} \% \mathrm{C}, T_{c}$ decreases with increasing niobium [Figure 2.11 b] but for higher carbon contents $(0.7-0.8 \mathrm{wt} \% \mathrm{C})$, it is not significantly affected by increasing $\mathrm{Nb}$. This is because the austenite grains are only affected by the fine niobium precipitates which precipitate during the hot deformation and air cooling stages preceding the final austenitising treatment. Adding more $\mathrm{Nb}$ than that which can be dissolved during reheating prior to hot deformation, will produce coarse precipitates $(\geq 480 \mathrm{~nm})[69$ which do not affect the austenite grain growth kinetics. Liu et al. 68 showed $0.035 \mathrm{wt} \% \mathrm{Nb}$ in a $\mathrm{U} 74$ rail $(0.67-0.80 \mathrm{wt} \% \mathrm{C})$ is most effective in refining austenite grains during $860^{\circ} \mathrm{C}-40 \mathrm{~min}$ austenisation. Niobium in solution can have a beneficial effect even when $T>T_{c}$ as can be seen in Figure 2.11a. Kestenbach et al. 72 reported that $0.01 \mathrm{wt} \% \mathrm{Nb}$ can be dissolved in austenite during reheating at $1200{ }^{\circ} \mathrm{C}-30 \mathrm{~min}$ for a $0.76 \mathrm{C}-0.04 \mathrm{Nb}(\mathrm{wt} \%)$ steel and reduced the austenite grain size from 360 to $220 \mu \mathrm{m}$. 

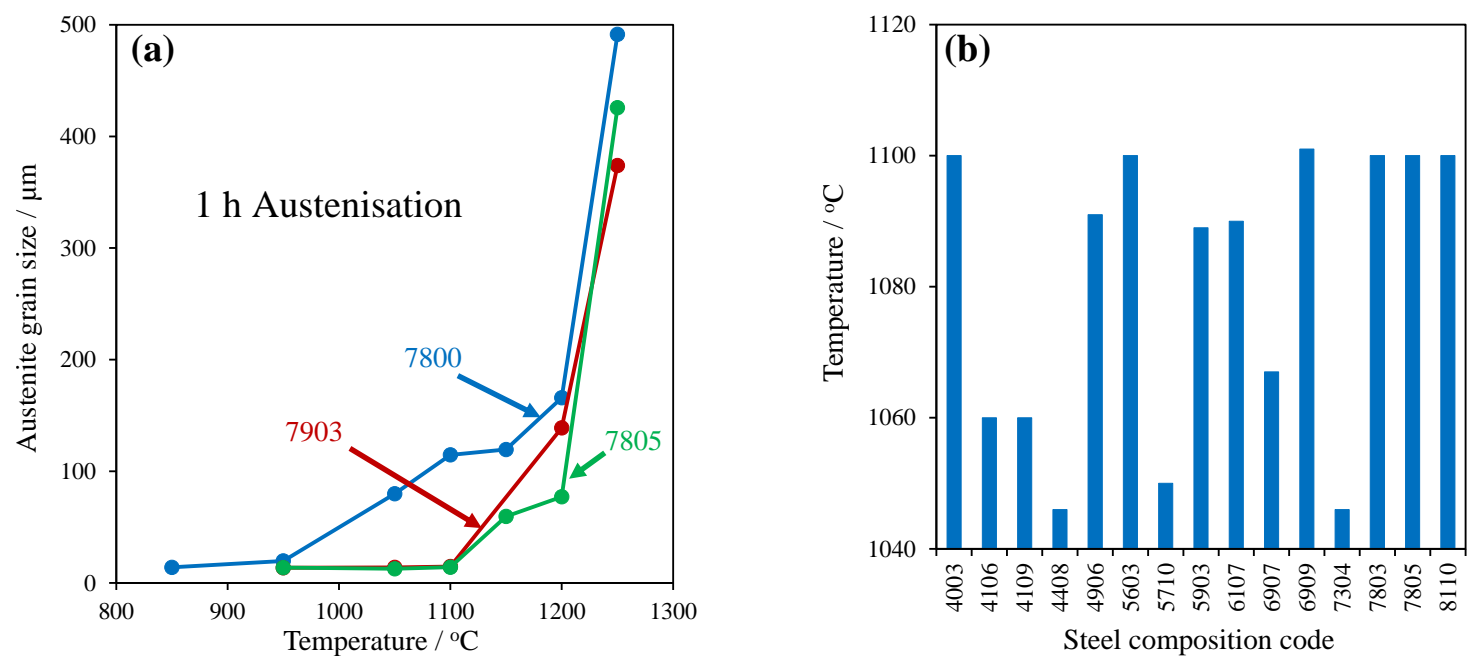

Figure 2.11: (a) Comparison of austenite grain size for ordinary and microalloyed steels. (b) $T_{c}$ for a variety of steel $[69]$. The first two digits of the alloys identified numerically represent wt $\% \mathrm{C} \times 100$ and the last two digits give the $\mathrm{wt} \% \mathrm{Nb} \times 100$.

For optimal niobium addition in high carbon steels, CBMM, the world's largest producer of niobium, has developed a strategy, defined as "Micro-Niobium Alloy Approach ${ }^{\circledR} " 7377$ which is being successfully applied in several Nb-bearing medium and high carbon steel products including eutectoid rails and reinforcing bars for pre-stressed concrete, high alloy tool steels, spring steels, automotive fasteners, seismic and fire resistant rebars etc [75 77]. Both the metallurgical properties and processability such as wire drawability or formability during manufacturing, are reported to be improved, thereby reducing the operational cost per tonne by 10 to $15 \%$. The key elements of the approach can be summarised as:

(i) addition of $0.005-0.020 \mathrm{wt} \% \mathrm{Nb}$ across $0.20-0.95 \mathrm{wt} \% \mathrm{C}$ steels to retard austenite grain coarsening by $\mathrm{Nb}$-pinning during soaking in reheating furnaces prior to hot deformation;

(ii) reduced total activity-based operational cost per tonne in energy and quality;

(iii) offsets operational reheat furnace combustion variations and thermal excursions;

\subsubsection{Effect of niobium during austenite hot deformation}

Kestenbach et al. 72 reported that just $0.01 \mathrm{wt} \% \mathrm{Nb}$, dissolved in $0.76 \mathrm{wt} \% \mathrm{C}$ austenite reheated at $1200^{\circ} \mathrm{C}$, can precipitate and delay recrystallisation during hot 
deformation by pinning the austenite grain boundaries. As shown in Figure 2.12, austenite recrystallisation is virtually complete at $950^{\circ} \mathrm{C}$ for the non-microalloyed steel (Nb-0) whereas the niobium-bearing steel (Nb-1) can be deformed without any sign of recrystallisation at temperatures up to $900^{\circ} \mathrm{C}$. Coladas et al. 72.78] also reported a strong delaying effect of $0.022 \mathrm{wt} \% \mathrm{Nb}$ dissolved in reheated austenite on the static recrystallisation of a $0.4 \mathrm{wt} \% \mathrm{C}$ steel after hot rolling.

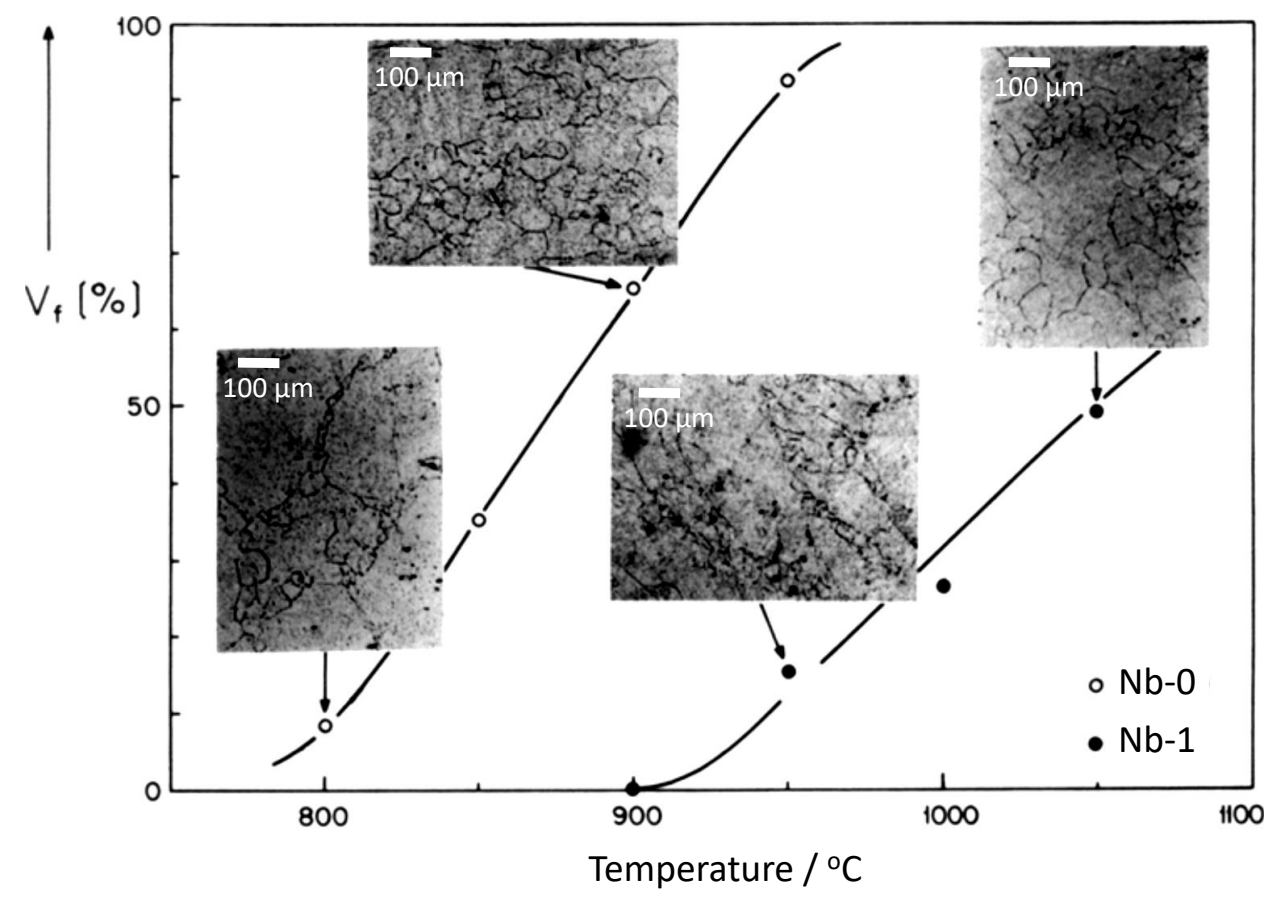

Figure 2.12: Effect of $\mathrm{Nb}$ on the recrystallised volume percent of austenite, $V_{f}$, as a function of the deformation temperature. Micrographs show the partially recrystallised austenite grain structures quenched immediately after hot deformation. Reproduced with permission from Springer $[72$.

Due to the competing effect of recrystallisation and austenite grain boundary pinning at the onset of deformation induced $\mathrm{NbC}$ precipitation, partial recrystallisation occur during hot deformation 37 79. Hot torsion testing of C-Mn-Cr-Nb rail steel at BHP Melbourne Research Laboratories, Australia (Ref 23 in [37]) indicated that austenite recrystallisation becomes sluggish during deformations at $1000{ }^{\circ} \mathrm{C}$ starting from 0.015-0.035 wt\% Nb, dissolved in 0.4-0.8 wt\% C steels reheated at $1260-1300^{\circ} \mathrm{C}$. And during deformation below $950{ }^{\circ} \mathrm{C}$, strain-induced NbCN severely retard recrystallisation. In-between recrystallisation may not occur uniformly along the length of the rail or through the section of the rail and these variations can lead to shape problems. It was suggested to confine the rolling to $T>1000^{\circ} \mathrm{C}$ to minimize these 
problems. More recently, Cui et al. [79] also showed partial recrystallisation of hot deformed austenite at finish deformation temperatures of $950-1000^{\circ} \mathrm{C}$ for $0.6 \mathrm{C}$ $0.018 \mathrm{Nb}(\mathrm{wt} \%)$ steel.

Niobium addition is said to increase the no-recrystallisation temperature $\left(T_{n R}\right)$. Wada et al. [80 carried out a detailed analysis for the effect of $0.02 \mathrm{wt} \% \mathrm{Nb}$ microalloying and controlled finish rolling at low temperature $\left(710-960{ }^{\circ} \mathrm{C}\right)$ austenite region for eutectoid rail steel compositions. Increased $T_{n R}$ at $870-890^{\circ} \mathrm{C}$ for $\mathrm{Nb}-$ microalloyed steels $(\mathrm{Nb}, \mathrm{Cr}+\mathrm{Nb}, \mathrm{Si}+\mathrm{Nb}$ in ref [80]) were reported compared to $760-800^{\circ} \mathrm{C} T_{n R}$ for the non-microalloyed steels (BA, Cr, Si steels in ref [80]). Cotrina et al. [81] carried out multi-pass hot torsion tests on $0.78 \mathrm{C}-0.03 \mathrm{Nb}$ (wt\%) steels and showed recrystallised austenite grains of size $60-80 \mu \mathrm{m}$ with finish rolling temperature (FRT) of $1060^{\circ} \mathrm{C}$ while austenite remains un-recrystallised for FRT $870^{\circ} \mathrm{C}$. Figure 2.13 attempts to summarise the $T_{n R}$ temperatures reported in literature with increasing niobium content. Strain at each pass is very critical for recrystallisation but the effect of strain is not considered while constructing Figure 2.13a.

The Nippon Steel Corporation in 1979, developed the NS-II rail composition [0.76C-0.82Mn-0.82Si-0.49Cr-0.005Nb (wt\%)] so as to start the pearlite transformation at about $600{ }^{\circ} \mathrm{C}$ in the rail-head during cooling in rail-production or after flashbutt welding [38,82. The purpose was to address the problem of a high degree of inhomogeneity in hardness distribution at HAZ of weld-joints. Nb was added to refine the austenite grain size and increase the hardenability. Figure $2.13 \mathrm{~b}$ compares austenite grain size distribution through the rail sections of NS-II and ordinary carbon steel rails. NS-II rail exhibits a finer grain size than that of ordinary carbon steel rails in as-rolled condition, and the grain size becomes much finer by headhardening. The austenite grain size was measured in terms of ASTM grain size number by an ultrasonic device and converted to mean linear intercept. 

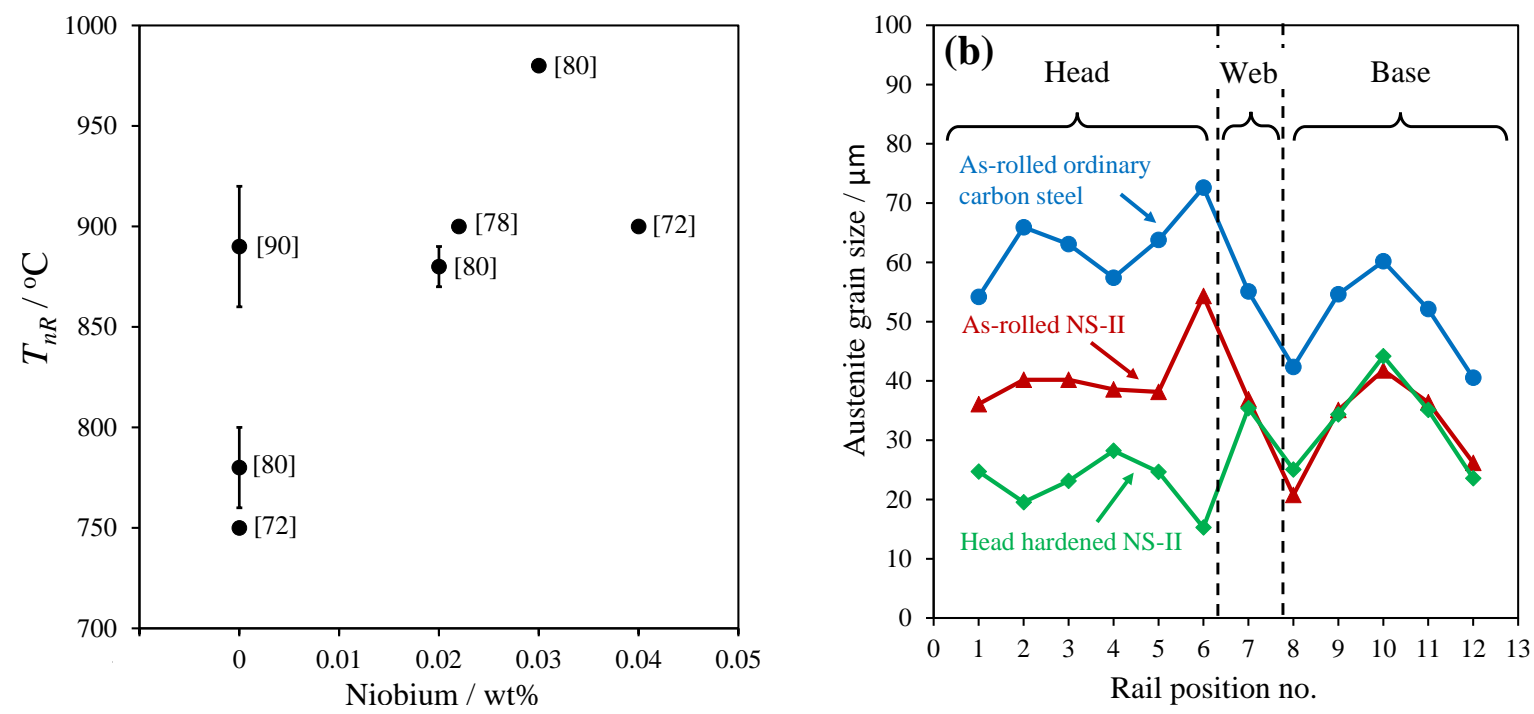

Figure 2.13: (a) Reported $T_{n R}$ for different $\mathrm{Nb}$ content in high carbon (0.6-0.8 wt\%) steels. (b) Austenite grain size distribution in ordinary carbon steel and NS-II rail sections [38].

\subsection{Effect of niobium on pearlitic microstructure and properties}

\subsubsection{Interlamellar spacing and strength}

During continuous cooling, pearlite can begin forming at a higher temperature in fine or unrecrystallised austenite due to greater density of nucleation sites. A higher transformation temperature is associated with a coarse interlamellar spacing in the pearlite. Therefore, for refined or unrecrystallised austenite, strength may decrease due to the coarsening of the lamellar spacing [72]. This trend is confirmed as illustrated in Figure 2.14 by Wada et al. [80] for non-microalloyed $0.78 \mathrm{C}-1 \mathrm{Mn}$ (wt\%) steel. But for the Nb-microalloyed 0.81C-1Mn-0.018Nb (wt\%), though the transformation temperature increases with decreasing finish rolling temperature, the yield strength tends to increase. Strain induced precipitation of niobium carbo-nitride $(\mathrm{NbCN})$ was attributed to the strength increase despite coarser lamellar spacing due to higher transformation temperature [80]. Liu et al. [68] observed fine niobium rich precipitates in both ferrite and cementite lamellae of pearlite (Figure 2.15) and suggested $0.024 \mathrm{wt} \% \mathrm{Nb}$ in $0.67-0.80 \mathrm{wt} \% \mathrm{C}$ rails for effective control of lamellar spacing during normalizing from $860^{\circ} \mathrm{C}-40 \mathrm{~min}$ austenisation. 

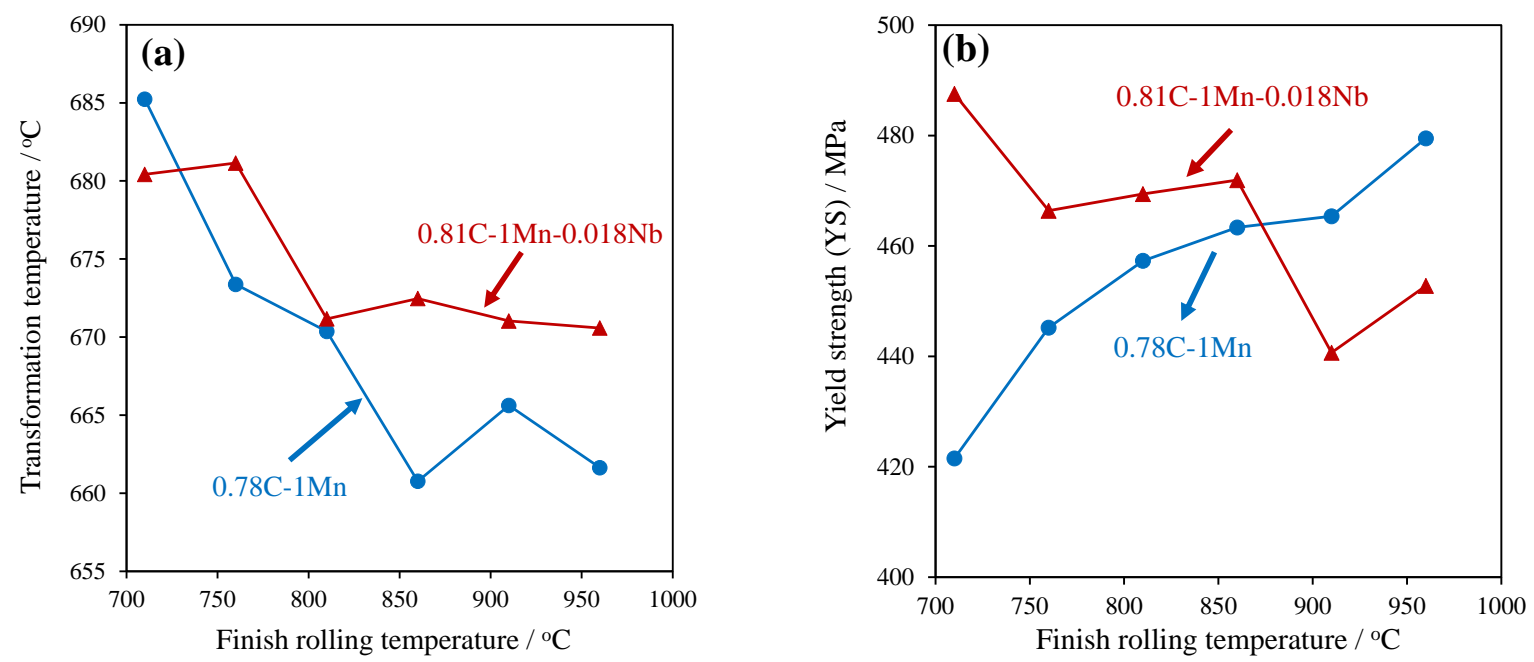

Figure 2.14: Variation of (a) austenite to pearlite transformation temperature, (b) yield strength (YS) with different finish rolling temperatures and compositions (wt\%) [80.
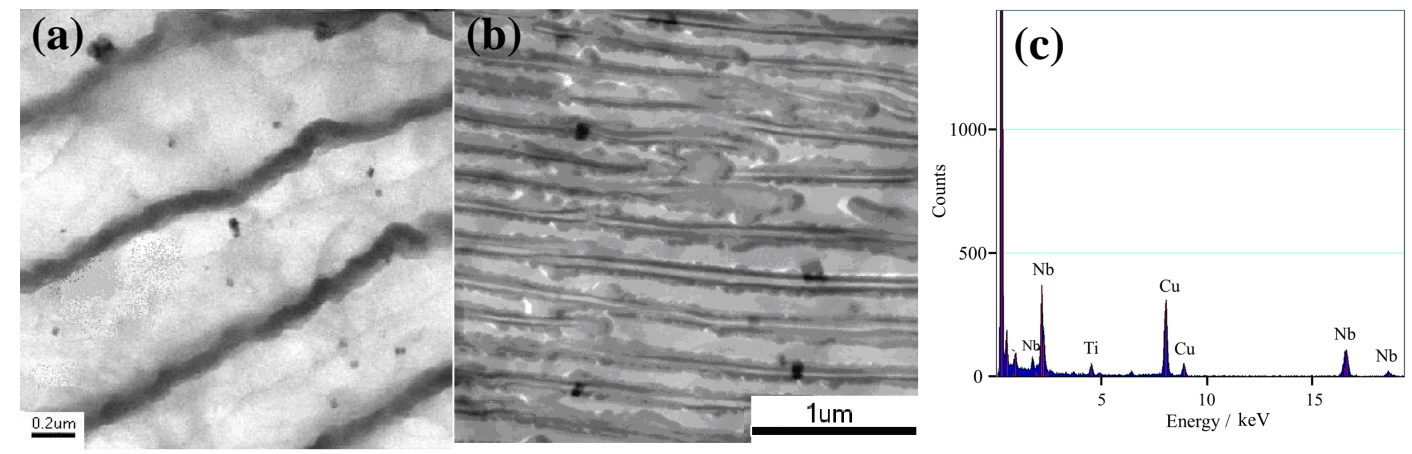

Figure 2.15: Transmission electron micrographs of niobium-rich precipitates in pearlite: (a) in ferrite, (b) in cementite, (c) corresponding EDS spectra. Reproduced with permission of Trans Tech Publications [68].

Yang et al. 83] also reported increasing interlamellar spacing (ILS) with increasing niobium content [Steel 6700: $148 \mathrm{~nm}$, Steel 6704: $178 \mathrm{~nm}$, Steel 6910: $193 \mathrm{~nm}]^{5}$ during normalizing from $850^{\circ} \mathrm{C}$. For similar heat-treated austenite grain sizes, Gomes et al. 71 reported about $10 \%$ increase in mean true ILS for $0.76 \mathrm{C}-0.045 \mathrm{Nb}$ (wt\%) steel compared to its non-microalloyed counterpart. In some cases, ILS was reported to be independent of austenite grain size. Cotrina et al. [81 observed decreasing ILS with increasing cooling rate but found no specific correlation with the austenite

\footnotetext{
${ }^{5}$ The first two digits of the alloys identified numerically, represent wt $\% \mathrm{C} \times 100$ and the last two digits give $\mathrm{wt} \% \mathrm{Nb} \times 100$.
} 
grain size or state (recrystallised or not). But the number of tests were too few to conclude no correlation as such. Williams et al. [37] reported reduced pearlite colony size but similar lamellar spacing in $0.72 \mathrm{C}-1.07 \mathrm{Mn}-0.86 \mathrm{Cr}-0.05 \mathrm{Nb}$ (wt\%) in comparison to the non-microalloyed steel. In contrast to the discussion thus far, soluble niobium in austenite that is not thermomechanically processed, increases its hardenability. Therefore, it would lead to a lower transformation temperature, finer pearlite and stronger steel [72]. Jansto $[77]$ evaluated $0.02 \mathrm{wt} \% \mathrm{Nb}$ in eutectoid compositions to be optimum to produce finest inter-lamellar spacing.

Williams et al. [37] also studied the effect of finish rolling temperature (FRT) on the state of $\mathrm{Nb}$ in austenite and corresponding effect on austenite recrystallisation and strength properties. At a given level of soluble Nb, the FRT essentially controls the extent to which strain-induced precipitation in austenite and subsequent precipitation strengthening in the ferrite take place. High FRT promotes retention of $\mathrm{Nb}$ in solution in austenite thereby raising the capacity for precipitation strengthening of ferrite. On the other hand, a low FRT enhances strain-induced precipitation of NbCN in austenite, which causes a reduced strengthening effect, but refines the pearlite colony size. As shown in Figure 2.16a, both yield and tensile strength decrease steadily with decreasing FRT below about $1000^{\circ} \mathrm{C}$ for $0.55 \mathrm{wt} \% \mathrm{C}$ steels with $\mathrm{Nb}$ content ranging from 0.02 to $0.06 \mathrm{wt} \% \mathrm{Nb}$. This would be consistent with an increase in strain induced precipitation of $\mathrm{NbCN}$ in austenite with decreasing FRT at the expense of precipitation strengthening in the ferrite. The effect of FRT on the strength of $0.70 \mathrm{wt} \% \mathrm{C}$ steels with $0.02-0.06 \mathrm{wt} \% \mathrm{Nb}$, is less pronounced probably on account of the lower level of $\mathrm{Nb}$ in solution and the likelihood that little remaining $\mathrm{Nb}$ would be available for precipitation hardening in the ferrite. As shown in Figure $2.16 \mathrm{~b}$, irrespective of carbon content, strength benefits occur upto $0.03 \mathrm{wt} \% \mathrm{Nb}$ addition in $0.4-0.8 \mathrm{wt} \% \mathrm{C}$ steels 37.38 . 

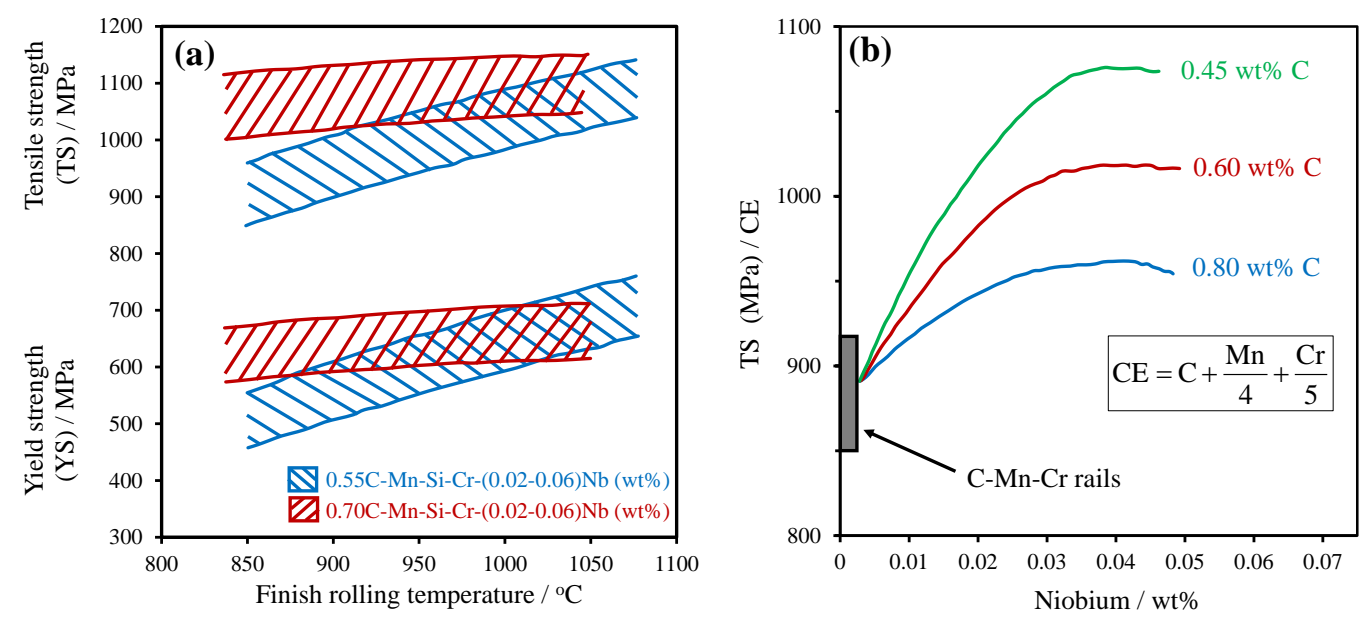

Figure 2.16: (a) Effect of finish rolling temperature and carbon content on strength of C-Mn-Cr-Nb rails. (b) Effect of $\mathrm{Nb}$ content on tensile strength (TS) normalized by carbon equivalent $(\mathrm{CE})$ to take account of variation in composition 3738]. All compositions are in wt\%.

Williams et al. [37] and later de Boer et al. 38 gave a comprehensive compilation of strength improvements and other benefits achieved by adding $\mathrm{Nb}$ in high carbon steels like rails. One of the early and most important contribution to Nb-microalloyed rail steels was the development of Niobras-200 in Brazil [70]. $0.03 \mathrm{wt} \% \mathrm{Nb}$ was microlloyed to $0.75 \mathrm{C}-1.25 \mathrm{Mn}-0.8 \mathrm{Si}$ (wt\%) which resulted in fine microstructural features and improved mechanical properties (610-625 MPa yield strength, 1080-1090 MPa tensile strength with 11-12\% elongation) along with good toughness, wear resistance and weldability. The other examples are summarised in Table2.6. 
Table 2.6: Some examples of Nb addition in commercial rails 37.38. Compositions are in wt\%. YS and TS is yield strength and tensile strength respectively. FRT is finish rolling temperature.

Organization/Author Findings

Domnarvets Jernverk, Swe- Increased TS of UIC rails by $98 \mathrm{MPa}$ by Nb-microalloying den (1970) which improved the wear resistance.

Belgium (1972)

Crane rails: $\quad(0.1-0.3) \mathrm{C}-(1.7-1.9) \mathrm{Mn}-(0.4-0.6) \mathrm{Si}-(0.4-$ $0.6) \mathrm{Cr}-(1.1-1.3) \mathrm{Cu}-(0.8-1.0) \mathrm{Ni}-(0.04-0.06) \mathrm{Nb}-(0.04-0.1) \mathrm{Al}$ : $\mathrm{YS}=590-785 \mathrm{MPa}, \mathrm{TS}=1080 \mathrm{MPa}$, elongation $=12 \%$.

0.69C-1.03Mn-0.5Si-0.7Cr-0.05Nb: Improved toughness ISCOR, South Africa (1977) with as high as 735MPa YS and $1215 \mathrm{MPa}$ TS and $14 \%$ elongation

0.43C-1.52Mn-0.17Si-0.29Cr-(0.025-045)Nb: YS and TS improves by $39 \%$ and $7 \%$ respectively with significantly Australian Iron and Steel better elongation and reduction-of-area values. $\mathrm{Nb}$ miPty. Ltd. (AIS) (1977) croalloyed rail sections (47, 53, 68, $192 \mathrm{~kg} / \mathrm{m}$ ) showed atleast 2-6 fold increase in rail life compared to conventional rail steels in service.

0.67C-(0.61-0.88)Mn-(0.51-0.82)Cr-(0.24-0.30)Mo-0.02Nb:

Ductility improved due to $\mathrm{Nb}$ addition at low Mo contents but no improvement in $0.3 \mathrm{wt} \%$ Mo steels. In the latter

Climax Molybdenum Co., case, the mechanical properties were largely influenced by USA (1978) the proportion of bainite in the microstructure, this being increased by faster cooling rates and higher $\mathrm{Nb}$ contents leading to predominantly bainitic structures and relatively low strengths.

Molycorp and The Colorado

0.74C-0.80Mn-0.14Si-(0.015-0.047)Nb: Increased YS $(11.4 \%)$ and TS $(4.0 \%)$ and better toughness. However, in-track tests showed no significantly improved performance over the basic rails.

Grade 900 rail steel $(0.70$ wt\% C) microalloyed with 0.06 wt\% $\mathrm{Nb}$ showed slight increase in TS at higher FRT $\left(1070^{\circ} \mathrm{C}\right)$ but negligible strength change at lower FRT $\left(1000^{\circ} \mathrm{C}\right)$. The toughness improved significantly. Weldability remain unaffected.

TS improved by $40 \mathrm{MPa}$ for $\mathrm{Mn}-\mathrm{Cr}-\mathrm{Nb}$ rail steel through pearlite colony interlamellar spacing refinement without any deleterious effect on weldability. 


\subsubsection{Crystallographic unit size and toughness}

Definition of a pearlite nodule or colony varies in literature and procedural information on their size measurement is lacking [86]. The metallograph of pearlite microstructure is also very rough and tumble and it is difficult to determine the nodule or colony size using metallography images [87]. From toughness and crackpropagation point of view, the 'crystallographic unit' grain for pearlite is visualised as an interpenetrating bi-crystal of cementite and ferrite [2 88], bounded by high angle misorientation boundaries. Cementite orientation can change inside a single unit [3] which is composed of ferrite regions with nearly the same crystallographic misorientation 86 89]. Different critical misorientation angle criteria have been adopted in bibliography [90], ranging from $10^{\circ}$ misorientation criterion in plain eutectoid steels by Park and Bernstein [91], to $15^{\circ}$ in Nb-microalloyed steels [81] and $12^{\circ}$ in the case of $\mathrm{V}$ eutectoid steels $[92]$.

As discussed in section 2.6, $\mathrm{Nb}$ addition can produce a fine prior austenite grain size during soaking or pancaked austenite grains during hot deformation - both leading to refined 'crystallographic unit' size. Figure 2.17 compares the orientation maps of transformed microstructures for two different finish deformation temperature (FDT) ${ }^{6}$ in a $0.78 \mathrm{C}-0.03 \mathrm{Nb}(\mathrm{wt} \%)$ steel [81]. The 'crystallographic unit' size was refined for lower FDT $\left(=870^{\circ} \mathrm{C}\right)$ where the transformation occurred from unrecrystallised austenite whereas for higher $\operatorname{FDT}\left(=1060^{\circ} \mathrm{C}\right)$, the austenite was recrystallised.

\footnotetext{
${ }^{6}$ Finish rolling temperature (FRT) refers to hot deformation by rolling whereas finish deformation temperature (FDT) refers to other hot deformation experiments like hot torsion, hot compression tests etc.
} 

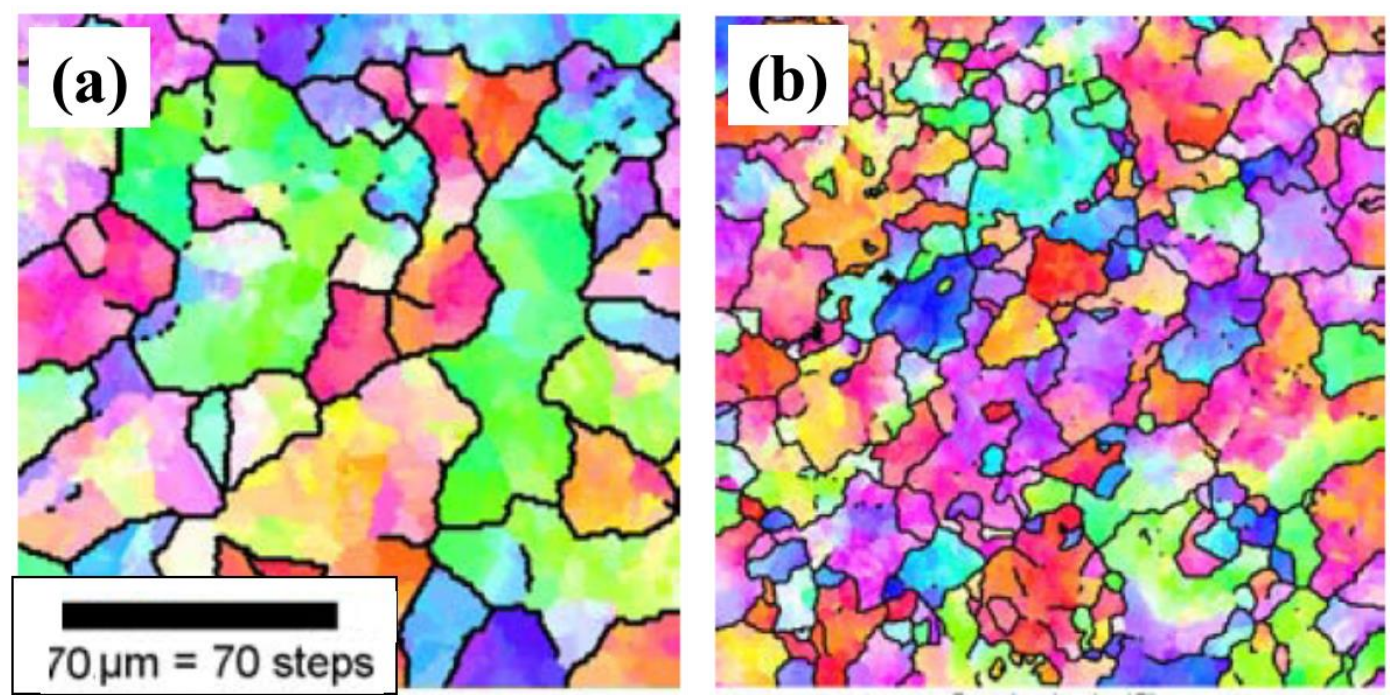

Figure 2.17: Orientation maps corresponding to (a) $\mathrm{FDT}=1060^{\circ} \mathrm{C}$, (b) $\mathrm{FDT}=870^{\circ} \mathrm{C}$, showing refined 'crystallographic unit' size at lower FDT. Copyright 2003 by The Minerals, Metals \& Materials Society. Reproduced with permission [81.

Cotrina et al. [81 has observed that the cleavage fracture facet size correlates better with the 'crystallographic unit' size ( $>15^{\circ}$ misorientation) than austenite grain size as shown in Figure 2.18a. The state of austenite grains ('ReX' i.e. recrystallised or 'UnReX' i.e. un-recrystallised) affects the crystallographic unit size and hence the cleavage facet size. Un-recrystallised ('UnReX') austenite grains produce finer 'crystallographic unit' grains and inturn finer facet sizes which indicate toughness improvement as shown in Figure $2.18 \mathrm{~b}$ and c. 

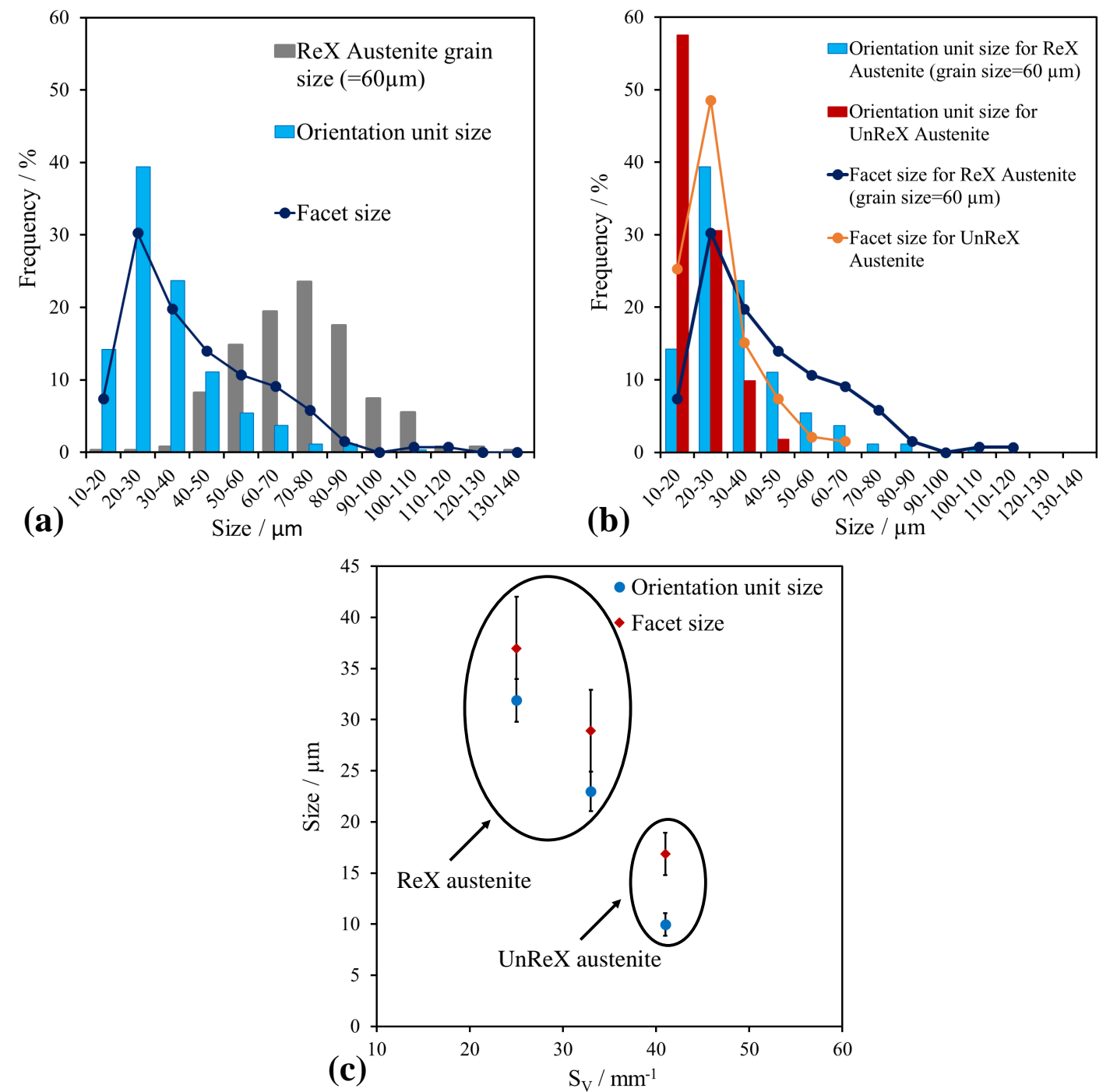

Figure 2.18: (a) Recrystallised (ReX) austenite grain size, crystallographic unit size and cleavage facet size distribution for finish deformation temperature $(\mathrm{FDT})=1060^{\circ} \mathrm{C}$. (b) Comparison of crystallographic unit and facet size distribution for different FDT and austenite state. (c) Variation of crystallographic unit and facet size with specific grain boundary area $\left(\mathrm{S}_{\mathrm{V}}\right)$ [81].

Wada et al. 80] reported negligible impact toughness improvement (8 J to $10 \mathrm{~J}$ ) for $0.021 \mathrm{wt} \% \mathrm{Nb}$ addition in 0.79C-1.05Mn-1.0Si steel at $860^{\circ} \mathrm{C}$ FRT [Figure 2.19]. Impact toughness properties at higher and lower FRTs are comparable for the base and microalloyed grades. But the fracture toughness improvement by upto $8 \mathrm{MPam}^{1 / 2}$ was possible due to $\mathrm{Nb}$ addition as shown in Figure 2.19b 7 . These improvements may be attributed to refined microstructure from un-recrystallised

${ }^{7}$ units are converted to $\mathrm{MPam}^{1} / 2$ from $\mathrm{kgfmm}^{-3 / 2}$ from the original reference by Wada et al. 80 
austenite grains due to $\mathrm{Nb}$ addition as discussed in section 2.6.
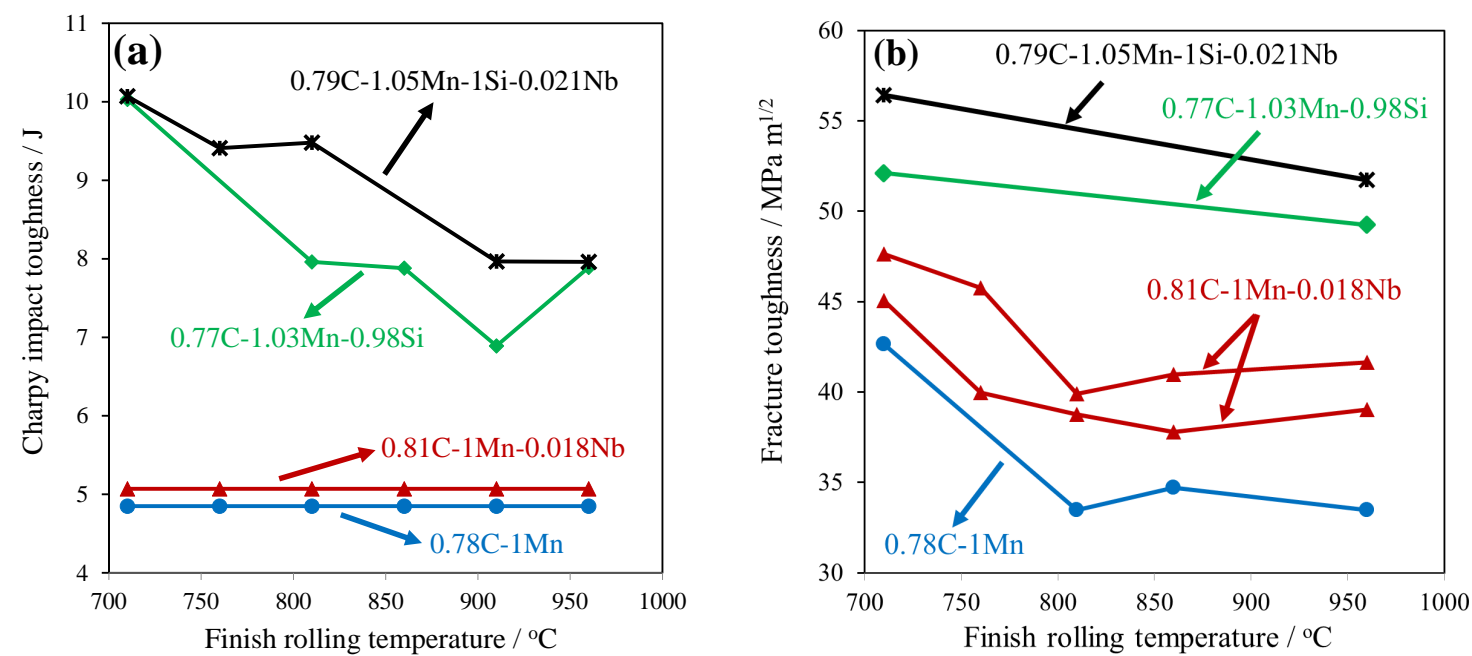

Figure 2.19: Variation of toughness with finish rolling temperature for different compositions (wt\%) (a) Charpy impact toughness, (b) fracture toughness. Test temperature is $20^{\circ} \mathrm{C}[80]$.

Liu et al. 68 reported increased fracture toughness with increasing $\mathrm{Nb}$ content for U74 (0.67-0.80 wt\% C) heavy rail steels and the maximum toughness reported is $50 \mathrm{MPa} \mathrm{m}^{1 / 2}\left(20^{\circ} \mathrm{C}\right)$ at $0.053 \mathrm{wt} \% \mathrm{Nb}$ [Figure 2.20]. The improvement is attributed to austenite grain size refinement by fine niobium precipitates. But when the niobium content exceeds $0.073 \mathrm{wt} \%$, both the amount and size of precipitates are increased in the pearlite and the coarse inclusion like precipitates [Figure 2.20 b-c] act as cleavage fracture nucleation triggers, thus the fracture toughness is decreased rapidly. 


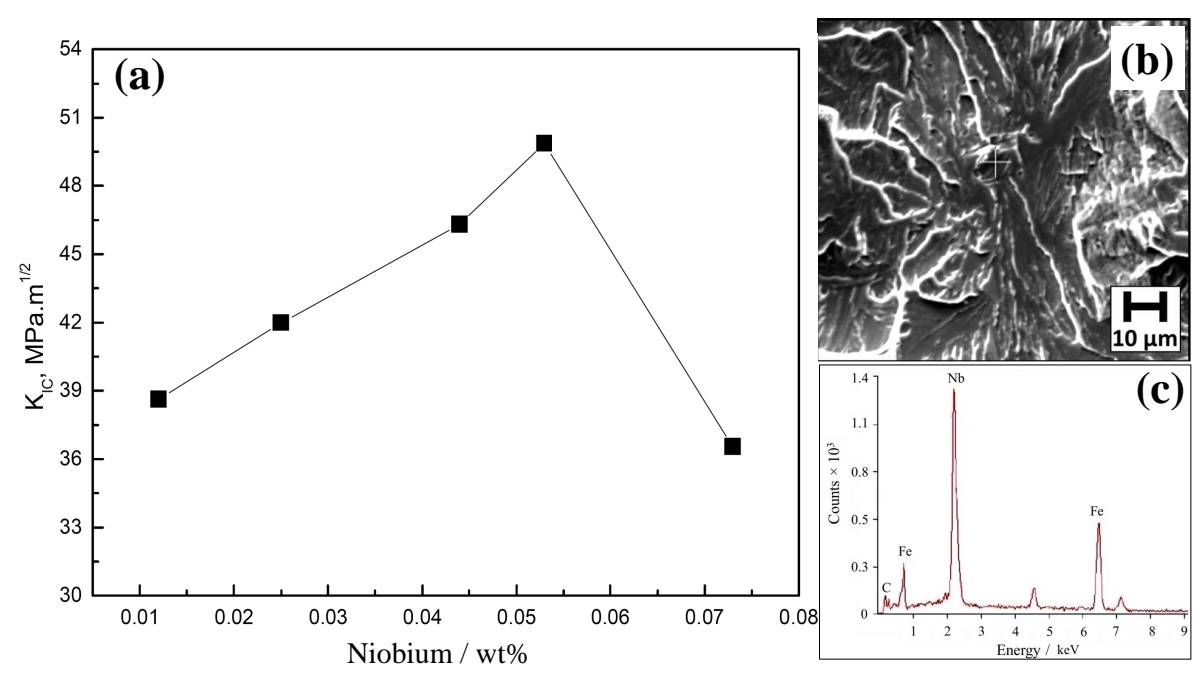

Figure 2.20: (a) Variation of fracture toughness with niobium content (wt\%), (b) coarse precipitate at fracture initiation point for U74-0.073Nb (wt\%) steel, (c) corresponding EDS spectra showing Nb-rich precipitates. Reproduced with permission of Trans Tech Publications [68].

\subsubsection{Wear resistance}

Figure 2.21 compares the wear performance of Niobras-200 [0.73C-1.38Mn-0.76Si (wt\%); hardness: $314 \mathrm{BHN}$ ] with other non-microalloyed rail compositions [70]. Weight loss of Niobras-200 was reduced by a factor of two as compared to the softer ASTM-A-1 [0.78C-0.9Mn-0.14Si (wt\%); hardness: $269 \mathrm{BHN}]$ steel with similar fully pearlitic microstructure. The good wear behavior of Niobras-200 compared to other composition and microstructures, was attributed to its higher hardness due to refined pearlite morphology. Figure 2.21b shows the hardness variation across a transverse section of the specimens after wear testing. Plastic flow in similar amounts was found for Niobras-200 compared to the Cr-Mn-Si steel [0.69C-0.98Mn0.54Si-1.1Cr (wt\%); hardness: $314 \mathrm{BHN}]$ and the tempered martensitic rail steel [0.64C-1.1Mn-0.22Si (wt\%); hardness: $327 \mathrm{BHN}$. 

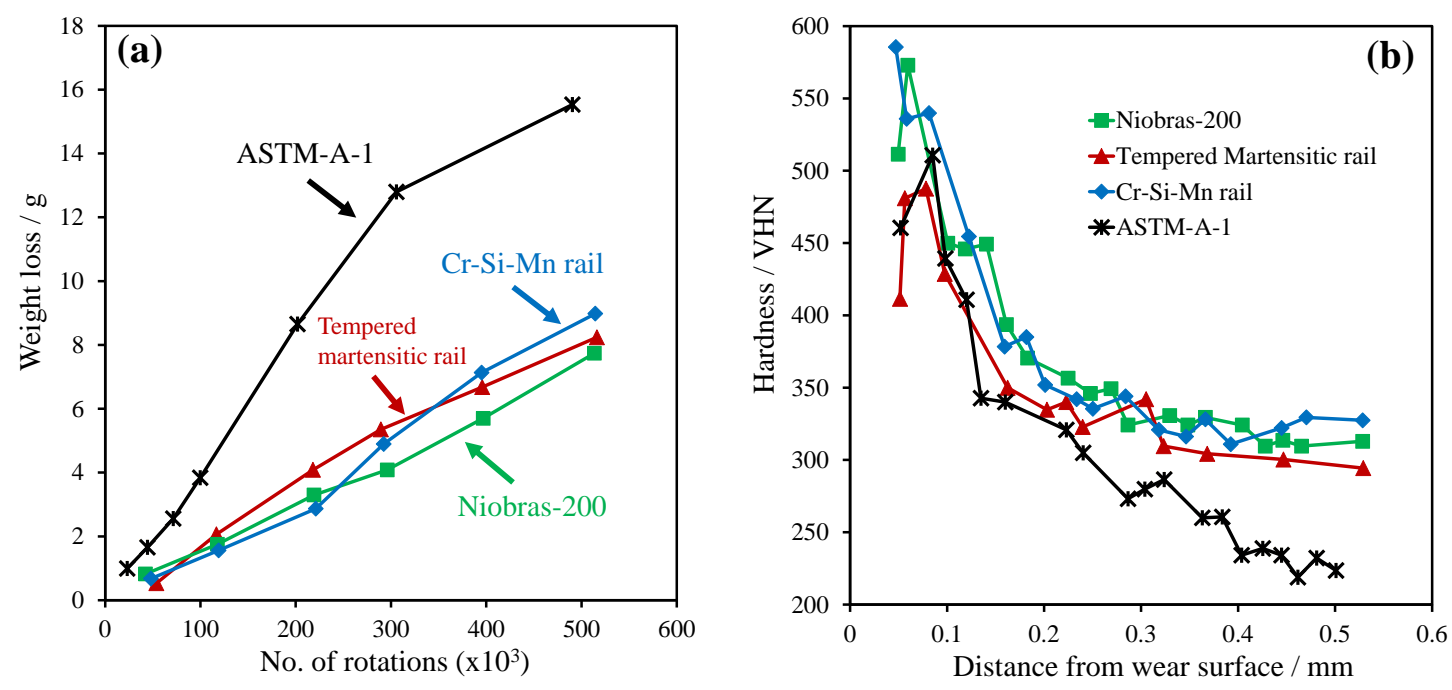

Figure 2.21: Wear performance of different rail steels. (a) Weight loss (g) v/s no. of rotations $\left(\times 10^{3}\right)$, (b) Hardness variation across tranverse section of the wear specimens 70 .

The NS-II rails [0.76C-0.82Mn-0.82Si-0.49Cr-0.005Nb (wt\%)] developed by Nippon Steel Corporation (NSC), including flash butt welded joints, were tested in actual track on the FAST track (Facility for Accelerated Service Testing) [38 93]. It exhibited the lowest gauge face wear rates, smallest deformation at the weld-joints and the best performance against corrugation without grinding even after $35 \mathrm{M}$ gross ton of traffic [38 94]. The good performance was attributed to a good combination of tensile strength (1127-1324 MPa) and ductility (14-19\%) due to austenite grain refinement by dilute niobium addition $(0.005 \mathrm{wt} \%)$ as discussed in section 2.6.2). Due to such improved properties, the NS-II rail was widely used not only as the wear resistant rail with good weldability, but also a rail for use in cold climate countries such as Canada and Russia [38].

\subsection{Effect of niobium on bainitic microstructures and properties}

The direct effect of niobium on bainitic microstructures is seldom explored in the literature 26 38 385 97 but the effect of prior austenite grain size (PAGS) and recrystallisation on bainite transformation is well reviewed [15]. Reduction in PAGS should lead to an accelerated nucleation rate because of increased grain boundary nucleation sites during isothermal transformation of bainite. If the sheaf volume remains smaller than the maximum possible sheaf volume, the reaction is limited 
by slow growth rate and the overall transformation rate is accelerated with reduction in PAGS. Conversely, for rapid growth from a limited number of nucleation sites, a reduction in PAGS reduces the total volume transformed per nucleus and hence retards the overall reaction rate. The two circumstances are illustrated in Figure2.22,

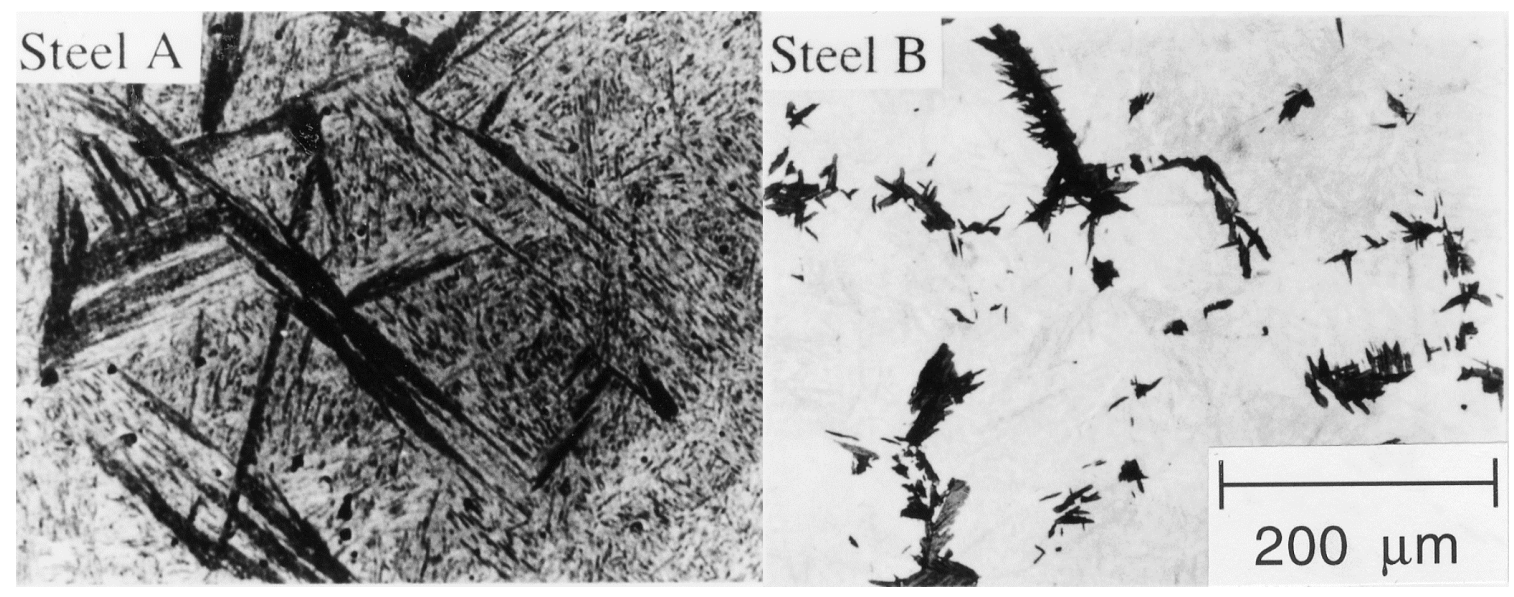

Figure 2.22: (a) Bainite in a steel A [0.12C-2.96Mn-2.03Si (wt\%)] with sparse nucleation and rapid sheaf-growth, austenite grains constrain the transformation amount that each nucleus can cause. Reducing the austenite grain size causes a net reduction in the overall transformation rate. (b) Bainite in a steel B [0.96C-0.21Si-0.38Mn$1.26 \mathrm{Cr}(\mathrm{wt} \%)]$ with small growth rate, reducing austenite grain size imply promote the nucleation rate 15 98]. Reproduced with permission from Taylor and Francis.

The typical cementite-free bainite compositions for rails eg. 0.2C-2Mn-2Si (wt\%) can be expected to follow Figure 2.22 i.e. with Nb-microalloying, a reduced PAGS would retard overall bainite transformation. Increased $\mathrm{Nb}$ as solute in austenite can also retard bainite nucleation for slow cooling rates i.e. when the driving force for transformation is low [95]. While significant, the effect is rather small. But it was indicated that a small amount of niobium carbide precipitation, if allowed, can significantly enhance bainite transformation by acting as new nucleation sites [95].

Nb-microalloying retards austenite recrystallisation and unrecrystallised austenite is susceptible to mechanical stabilisation during martensitic or bainitic transformation i.e. during growth, the motion of the glissile transformation interface is hindered by the accumulation of dislocation debris in the austenite 99 100]. A comprehensive review of the theoretical basis and experimental evidences of the effect of mechanical stabilisation on the bainitic transformation are given in 'Bainite in Steels' by Bhadeshia 15]. Heterogeneous nucleation becomes more frequent as 
defects are introduced in the austenite but the growth by a displacive mechanism is stifled as the interface encounters forests of dislocations. The transformation start may accelarate but the overall transformation kinetics becomes slower. The maximum attainable fraction of bainite decreases but the platelets are refined. In Nb-microalloyed steels, the strain-induced niobium-rich precipitates along with the dislocation forest, can also hinder the movement of the austenite to bainite transformation interface [96]. The recovery of dislocation structure in austenite may also be modified due to strain-induced precipitation and the precipitates may in turn influence bainite nucleation [15].

Figure $2.23 \mathrm{a}-\mathrm{b}$ shows optical micrographs of bainite transformed isothermally from undeformed and deformed austenite in a non-microalloyed composition [0.45C2.08Si-2.69Mn (wt\%)] but demonstrates the large effect of mechanical stabilisation in the refining the microstructure and in reducing the amount of bainite 15. The bainitic ferrite inherits the parent dislocation structure and there are corresponding changes in its crystallographic orientation and growth direction as well. This is illustrated in the optical micrograph shown in Figure2.23c, where the bainite sheaves appear on a macroscopic scale to be curved. They are in fact following the deformation-induced misorientations within the austenite grains 97 . 


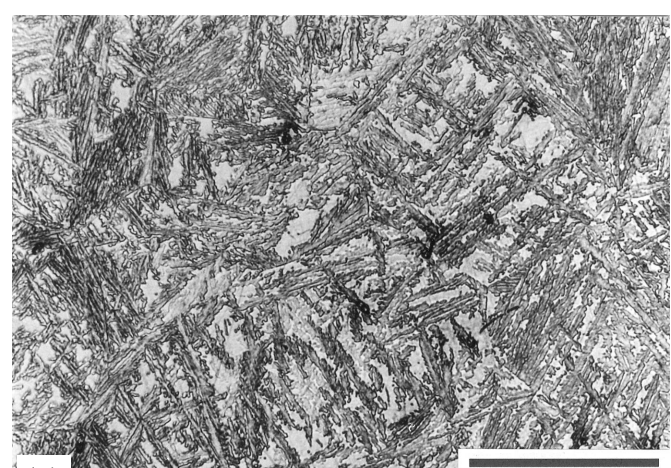

(a)

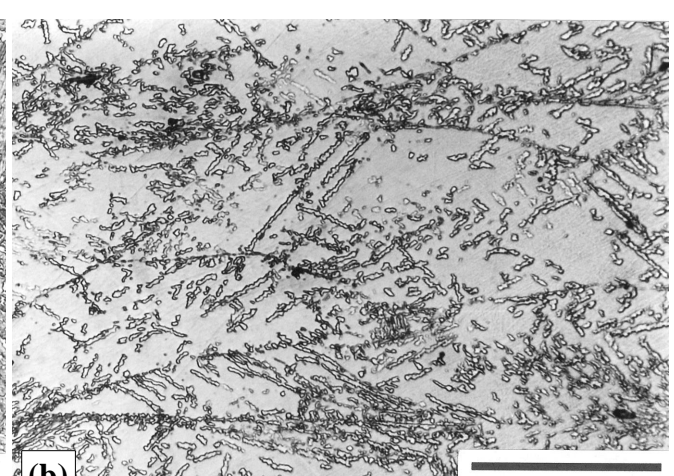

(b) 00 m

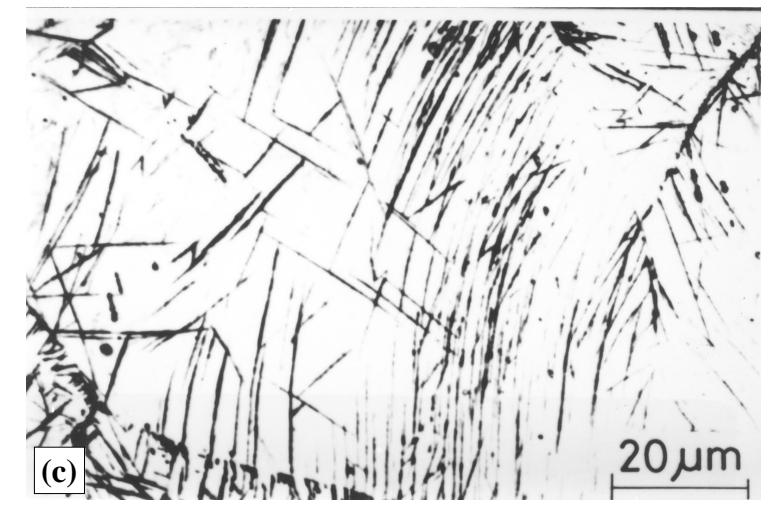

Figure 2.23: Mechanical stabilization of bainite (a) transformation from undeformed austenite, (b) transformation from deformed austenite. Reproduced with permission from Taylor and Francis. (c) 'Curved' bainite growth in deformed austenite 15 , 97 99 100]. Printed in Hot Workability of Steels and Light AlloysComposites and reproduced with permission from the Canadian Institute of Mining, Metallurgy and Petroleum.

De Boer et al. 38 reviewed the experimental results on Nb-microalloyed bainitic rails $[(0.2-0.55) \mathrm{C}-(0.4-0.45) \mathrm{Si}-(0.4-2.1) \mathrm{Mn}-(0-2.0) \mathrm{Cr}-(0-0.15) \mathrm{Nb}-(0-0.1) \mathrm{V}$ (wt\%)] developed by NKK, Japan [26]. Niobium addition is considered to improve not only strength by precipitation hardening, but also toughness by microstructural refinement. Tensile strengths varied from 810 to $1430 \mathrm{MPa}$ depending upon the composition. U-notch charpy impact toughness of a $1420 \mathrm{MPa}$ bainitic steel ( $\sim 40 \mathrm{~J}$ at $20^{\circ} \mathrm{C}$ ) was reported twice of that of a $1300 \mathrm{MPa}$ pearlitic steel $\left(\sim 20 \mathrm{~J}\right.$ at $\left.20^{\circ} \mathrm{C}\right)$. The wear resistance was comparable under $1.4 \mathrm{GPa}$ contact pressure. Other properties like shelling and flaking resistance, rolling contact fatigue performance, plane strain fracture toughness $\left(\mathrm{K}_{1 \mathrm{c}} \sim 98 \mathrm{MPam}^{1 / 2}\right)$ of the Nb-microalloyed bainitic rails were reported superior to head-hardened premium pearlitic rails and expected to exhibit excellent performance in heavy haul railroads. 


\subsection{Summary}

The important findings from this review are:

- Pearlitic steels with fine interlamellar spacing are hard but not necessarily tough as the pearlite colony size controls toughness. Cementite-free bainitic rails are hard as-well-as tough owing to fine bainitic ferrite plates and cementitefree retained austenite films.

- The solubility of niobium decreases with increasing carbon concentrations even at higher carbon levels $(>0.8 \mathrm{wt} \% \mathrm{C})$ in austenite in contradiction to some analysis reporting increased niobium solubility at high carbon levels. Silicon decreases niobium solubility in austenite which affect high silicon cementitefree bainitic compositions.

- Due to low niobium solubility in high carbon austenite and high silicon low carbon austenite at reheating temperatures, there may be undissolved coarse carbides which coarsen rapidly. Nb composition must be adjusted so that the coarse carbides can be taken into solution during reheating. Even if carbides remain undissolved, they should not be harmful if NbC precipitates are small in size.

- A controlled addition of niobium leads to substantial grain refinement for the lower degrees of deformation experienced by the head of the rail. Strength levels are improved by precipitation strengthening and/or microstructure refinement which in turn improves the wear-resistance.

- Though some fundamental research have been carried out to study the effect of niobium on bainitic rail compositions, industrial scale studies on low silicon Nb-microalloyed bainitic rails are very rare. For high silicon cementite-free bainitic rails, it is more unlikely that any commercial Nb-microalloyed rails have been produced and studied till date. 


\section{Chapter 3}

\section{Statement of objectives}

The present work is formulated, to address the microstructure and mechanical properties of both pearlitic and cementite-free bainitic rails with the aim of achieving a new technology based on niobium microalloying. The proposed research will focus on:

- development of a niobium microalloying strategy in the context of standard rail production methods, including the fact that deformation through the rail section will not be homogeneous;

- development of a viable thermo-mechanical processing route for niobium microalloyed rail steels;

- creation of a pancaked austenite grain structure, with an examination of the consequences on the final product;

- creation of a refined pearlitic structure and possibly one containing fine $\mathrm{NbC}$ precipitates;

- cover the totally new area of microalloying the cementite-free high-silicon bainitic rails;

- development of a generic strategy for the use of niobium in high carbon steels. 


\section{Chapter 4}

\section{Thermodynamic calculations and microsegregation}

\subsection{Introduction}

To add niobium as a microalloying element in high carbon (0.6-0.8 wt\% C) pearlitic steels and low carbon (0.2-0.4 wt\%) cementite-free bainitic steels, thermodynamic and microsegregation calculations are carried out to investigate optimum niobium addition. In particular, the goal is to ensure that any niobium carbide precipitated from solute-enriched liquid due to segregation, can be taken into solution in austenite that is reheated to temperatures upto $1300^{\circ} \mathrm{C}$ prior to hot rolling. Sometimes, a more energy efficient process limits the reheating temperature to $1200^{\circ} \mathrm{C}$, which imposes greater restrictions on the permitted niobium concentration.

\subsection{Thermodynamic calculations}

The commercial software MatCalc with 'mc_sample_fe.tdb' database, which is similar to MTDATA TCFE database (Figure 2.9), is utilised where Fe-Nb-C description for the database is based on the assessment by Lee [52]. The base compositions used for this study are enlisted in Table 4.1 with $\mathrm{Nb}$ concentrations varying from 0.005-0.03 wt\%. Figure 4.1 shows typical equilibrium phase fraction diagrams and Table 4.2 lists the transformation temperatures. Depending upon the reheating temperatures, the maximum soluble niobium in austenite for the pearlitic and bainitic compositions are summarized in Table 4.3 . 
Table 4.1: Base compositions for calculation (wt\%)

\begin{tabular}{ccccccc}
\hline Steel & C & Mn & Si & Cr & Mo & Nb \\
\hline Pearlitic & 0.78 & 1.0 & 0.4 & 0.55 & - & \\
\hline Bainitic & 0.22 & 2.0 & 1.9 & 0.55 & 0.5 & \\
\hline
\end{tabular}
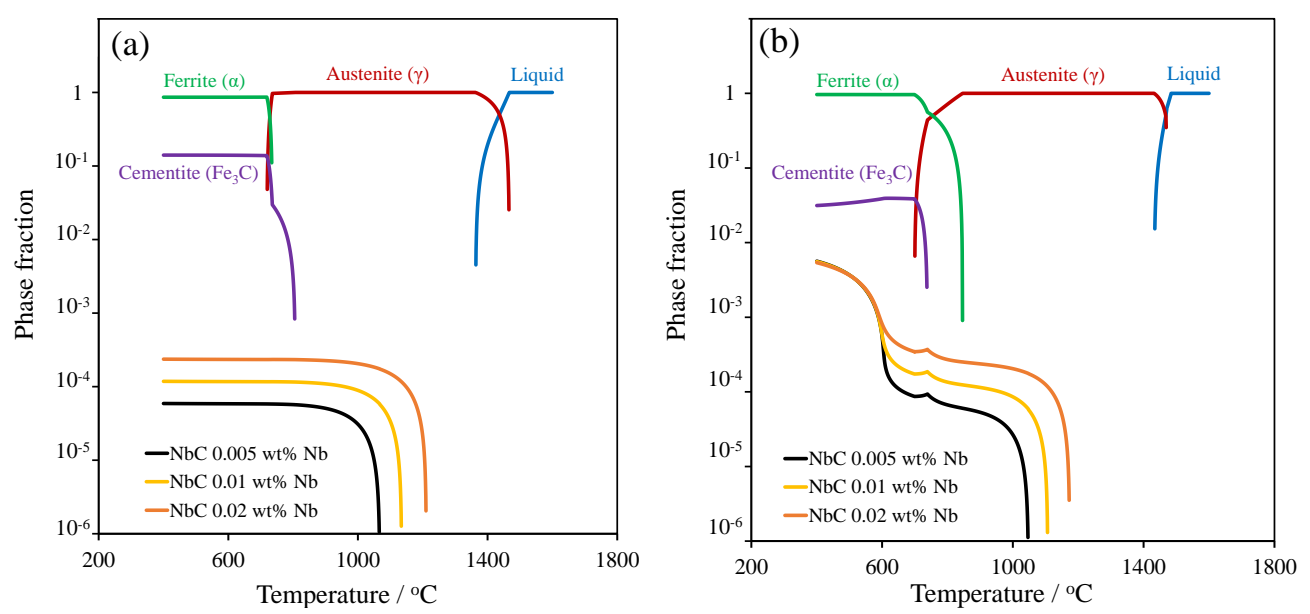

Figure 4.1: Equilibrium phase fraction calculation for (a) pearlitic steel, (b) bainitic steel.

Table 4.2: Equilibrium transformation temperatures $\left({ }^{\circ} \mathrm{C}\right): T_{L}$ : Liquidus, $T_{S}$ : Solidus, $T_{\mathrm{NbC}}$ : Equilibrium NbC precipitation/ dissolution temperature and $V_{\mathrm{NbC}}$ is equilibrium $\mathrm{NbC}$ mass fraction at $A_{e_{3}}$

\begin{tabular}{cccccccc}
\hline Steel & $\mathrm{Nb} / \mathrm{wt} \%$ & $T_{L} /{ }^{\circ} \mathrm{C}$ & $T_{S} /{ }^{\circ} \mathrm{C}$ & $A_{e_{3}} /{ }^{\circ} \mathrm{C}$ & $A_{e_{1}} /{ }^{\circ} \mathrm{C}$ & $T_{\mathrm{NbC}} /{ }^{\circ} \mathrm{C}$ & $V_{\mathrm{NbC}}$ \\
\hline \multirow{3}{*}{ Pearlitic } & 0.005 & & & & & 1068 & 0.0000568 \\
& 0.01 & \multirow{2}{*}{1467} & \multirow{2}{*}{1363} & 806 & 719 & 1136 & 0.000115 \\
& 0.02 & & & & & 1213 & 0.000233 \\
& 0.04 & & & & & 1296 & 0.000467 \\
\hline \multirow{3}{*}{ Bainitic } & 0.005 & & & & & 1047 & 0.0000602 \\
& 0.02 & \multirow{2}{*}{1484} & \multirow{2}{*}{1432} & \multirow{2}{*}{846} & 699 & 1174 & 0.000251 \\
& 0.06 & & & & & 1216 & 0.000377 \\
& & & & & 1294 & 0.000756 \\
\hline
\end{tabular}


Table 4.3: Maximum niobium (wt\%) soluble in austenite for pearlite and bainitic compositions at different reheat temperatures.

\begin{tabular}{llll}
$\begin{array}{l}\text { Steel } / \\
\text { Reheat } \\
\text { tempera- } \\
\text { ture }\end{array}$ & $1200{ }^{\circ} \mathrm{C}$ & $1250{ }^{\circ} \mathrm{C}$ & $1300{ }^{\circ} \mathrm{C}$ \\
\hline Pearlitic & 0.19 & 0.029 & 0.04 \\
\hline & 0.025 & 0.036 & 0.06 \\
\hline
\end{tabular}

\subsection{Calculations for microsegregation}

The basic methodology for estimating microsegregation is to calculate the composition of the last solidifying residual liquid during cooling from the liquid state. This is assumed to correspond to the solute enriched region due to microsegregation. Now, considering the composition of residual liquid, the dissolution temperature, written $T_{\mathrm{NbC}}^{s e g}$ with the superscript denoting the solute enriched region, of the niobium carbides in the solute enriched regions has been calculated. Ideally, the optimum $\mathrm{Nb}$ concentration should be decided based on the condition that $T_{\mathrm{NbC}}^{\text {seg }}$ must be less than the reheating temperature $\left(1200-1300^{\circ} \mathrm{C}\right)$ if all the $\mathrm{Nb}$ is to be taken into solution. The different solidification models which have been considered for the calculations are described below.

\subsubsection{Equilibrium or lever-rule model}

The lever-rule model involves equilibrium solidification. It assumes complete diffusion to equilibrium of all alloying elements in both the liquid and the solid phases. The model is represented as 101]:

$$
C_{L, i}=\frac{C_{0, i}}{1-\left(1-k_{i}\right) f_{s}}
$$

where $C_{L, i}$ is the concentration of a given solute ' $i$ ' in the liquid, $C_{0, i}$ is the initial concentration in the liquid, $k_{i}$ is the equilibrium partition coefficient for that element, and $f_{S}$ is the solid fraction.

In MatCalc, the 'mc_sample_fe.tdb' database and 'Fe, C, Mn, Si, Cr, Mo, Nb, 
Va' system with 'Liquid, FCC_A1, BCC_A2, Cementite' phases are considered for calculations. The compositions in Table 4.1 are given as input. The equilibrium is calculated at $1600^{\circ} \mathrm{C}$ and set as start values. Then the 'stepped equilibrium calculation' is done by varying the temperature from $1600^{\circ} \mathrm{C}$ to $1000^{\circ} \mathrm{C}$ in steps of $1^{\circ} \mathrm{C}$. The composition of the last solidifying liquid reflects the segregated region composition.

\subsubsection{Scheil model}

The Scheil equation or the 'non-equilibrium lever rule' assumes that there is no diffusion in the solid phase, but complete mixing in the liquid and local equilibrium at solid-liquid interface. This is represented as [101]:

$$
C_{L, i}=\frac{C_{0, i}}{\left(1-f_{s}\right)^{1-k_{i}}}
$$

In MatCalc, the 'Scheil calculation' dialog box is utilised with 'liquid' as the dependent phase. The temperature is varied from $1600{ }^{\circ} \mathrm{C}$ to $1000^{\circ} \mathrm{C}$ in steps of $1^{\circ} \mathrm{C}$. The composition of the residual liquid will depend on the terminating liquid fraction. In order to be able to remove the equilibrium content of solid phases from the system after each temperature step, MatCalc creates copies of all phases except the dependent ('liquid') phase. The new phases have the name of the original phase plus the suffix ' $S$ ' which denotes that the corresponding phase is a 'solid' phase 102 .

\subsubsection{Scheil model with carbon back-diffusion}

In the classical Scheil approach, the assumption is made that the diffusion of elements in the liquid is infinitely fast while that in the solid is negligibly slow. These assumptions may be reasonable for the conditions during solidification, if only substitutional elements are considered. For interstitial elements, however, the second assumption is hardly valid since they are fast diffusers. After being rejected into the liquid phase within each solidification step of Scheil calculations, elements, such as $\mathrm{C}$ and $\mathrm{N}$, are capable of diffusing rapidly also in the solid phase and establish partial equilibrium between the liquid and solid phases. This process is known as back-diffusion 101 102. Brody and Flemings 103 derived the following equation to deal with this:

$$
C_{L, i}=C_{0, i}\left[1-\left(1-2 \alpha k_{i}\right) f_{s}\right]^{\frac{\left(k_{i}-1\right)}{\left(1-2 \alpha k_{i}\right)}}
$$


where the back-diffusion coefficient $\alpha$ is defined as:

$$
\alpha=\frac{D_{i} t_{f}}{(0.5 \lambda)^{2}}
$$

where $D_{i}$ is the diffusion coefficient of solute ' $i$ ' in the transformed solid phase in $\mathrm{cm}^{2} \mathrm{~s}^{-1}, t_{f}$ is the solidification time in seconds and $\lambda$ is the secondary dendritic arm-spacing in $\mathrm{cm}$.

In MatCalc, the allowance is made by checking 'yes' for carbon back diffusion in the 'Scheil calculation' dialog box [102]. The rest of the procedure is similar to that of section 4.3.2. After each temperature step, MatCalc sets up a para-equilibrium calculation, where all elements without back-diffusion have fixed composition variables and only the elements with back-diffusion are unconstrained. By that means, carbon is always brought back into equilibrium with regard to the solid and liquid phases after a regular Scheil simulation step is carried out.

As mentioned in section 4.3.2, the composition of the residual liquid will depend on the terminating liquid fraction. MatCalc recommends a $3 \%$ residual liquid criterion in case of faster cooling rates during solidification and $1 \%$ residual liquid for slow cooling conditions such as during the casting of heavy components [102]. Back-diffusion of slowly diffusing substitutional species becomes more prominent if the residual liquid fraction becomes rather small. Also, back-diffusion generally limits the maximum amount of liquid enrichment. For practical simulations, this effect can be accounted for by assuming final solidification at slightly larger residual liquid fraction, i.e. at values between $3 \%$ and $5 \%$ [104. Other literature $105-107$ reported $5-10 \%$ as residual liquid fractions to calculate the segregated composition.

\subsubsection{Calculation results for segregated composition}

Figure 4.2 compares the calculations by different solidification models in MatCalc for $0.03 \mathrm{wt} \% \mathrm{Nb}$ concentrations. Figure 4.2 a compares the fraction solidified with temperature while Figures $4.2 \mathrm{~b}$ and $4.2 \mathrm{c}$ compare the variation of composition of $\mathrm{C}$ and $\mathrm{Nb}$ in liquid with temperature during solidification. The downward bend of $\mathrm{Nb}$ concentration in Figure 4.2 for Scheil model calculations with or without carbon back-diffusion is due to the occurrence of primary precipitation of $\mathrm{NbC}$ in 'liquid+austenite' region during solidification. 

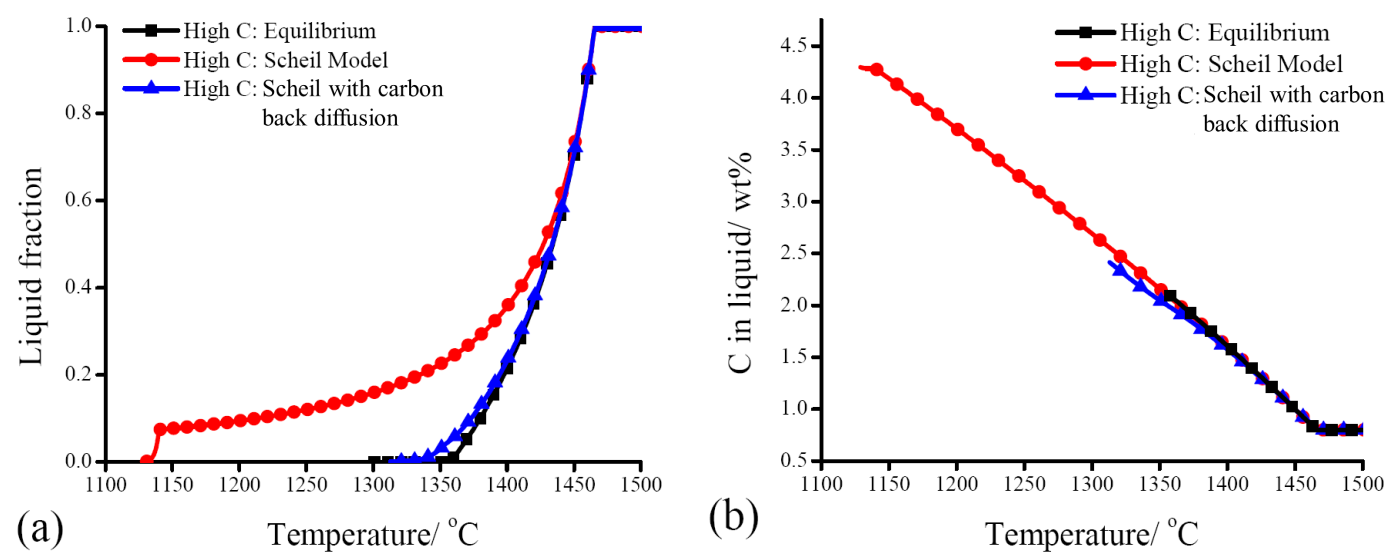

(b)

Temperature $/{ }^{\circ} \mathrm{C}$

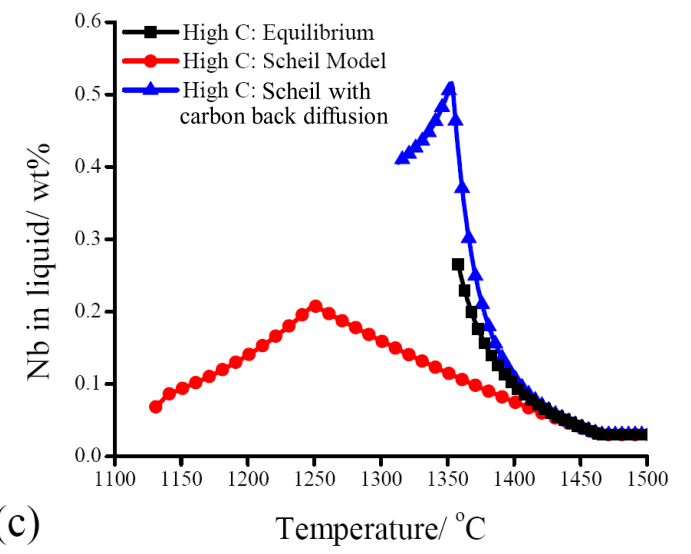

Figure 4.2: MatCalc calculations for pearlitic (high C) steel with $0.03 \mathrm{wt} \% \mathrm{Nb}$. (a) Liquid fraction versus temperature, (b) $\mathrm{C}$ in liquid versus temperature, (c) $\mathrm{Nb}$ in liquid versus temperature.

From Figure 4.2 a, the opposite limiting characteristics of the two solidification models i.e. 'equilibrium or lever-rule' and 'Scheil' models can be clearly observed. The former calculates the lowest level of segregation and the latter represents the highest level of segregation possible in the system. In order to predict microsegregation during steel solidification, finite non-zero diffusion must be considered, at least in the solid phase and allowing for carbon back-diffusion enables a more practical calculation by creating a balance between the above mentioned two models. As soon as final solidification has completed, the fast diffusers rapidly establish partial equilibrium again, which practically means that the fast elements diffuse away from the previous residual liquid regions because their solubility is now comparable to the surrounding regions. In a first and rough approximation, this effect can be accounted for by assuming that the fast diffusers like carbon distribute homogeneously in the segregated microstructure and the segregated carbon composition is replaced by the nominal carbon composition 104.

Tables 4.4 and 4.5 list the carbon homogenized segregated composition at differ- 
ent residual liquid fraction and corresponding $\mathrm{NbC}$ dissolution temperature $\left(T_{\mathrm{NbC}}^{\text {seg }}\right)$ at segregated regions.

Table 4.4: Pearlitic steel segregated region composition (wt\%) after carbon homogenization. $T_{P}$ and $L_{P}$ denotes, respectively, the temperature $\left({ }^{\circ} \mathrm{C}\right)$ and residual liquid (mass\%) at which the primary precipitation of $\mathrm{NbC}$ from liquid, starts. $W_{P}$ denotes the mass fraction of primary carbides.

\begin{tabular}{cccccccccc}
\hline $\begin{array}{c}\text { Bulk Nb/ } \\
\text { wt\% }\end{array}$ & $\begin{array}{c}\text { Residual } \\
\text { liquid }\end{array}$ & $\mathrm{C}$ & $\mathrm{Mn}$ & $\mathrm{Si}$ & $\mathrm{Cr}$ & $\mathrm{Nb}$ & $T_{\mathrm{NbC}}^{\text {seg }}$ & $W_{P}$ & $T_{P}\left(L_{P}\right)$ \\
\hline \multirow{2}{*}{0.005} & $10 \%$ & 0.78 & 1.91 & 0.71 & 0.92 & 0.03985 & 1300 & - & \\
& $5 \%$ & 0.78 & 2.27 & 0.77 & 1.11 & 0.07234 & 1349 & - & $1337(0.5 \%)$ \\
& $1 \%$ & 0.78 & 3.35 & 0.81 & 1.78 & 0.31455 & 1390 & - & \\
\hline \multirow{2}{*}{0.01} & $10 \%$ & 0.78 & 1.90 & 0.70 & 0.92 & 0.07863 & 1354 & - & \\
& $5 \%$ & 0.78 & 2.28 & 0.77 & 1.12 & 0.14698 & 1370 & - & $1344(1.2 \%)$ \\
& $1 \%$ & 0.78 & 3.30 & 0.79 & 1.75 & 0.46699 & 1403 & $8.55 \times 10^{-6}$ & \\
\hline \multirow{2}{*}{0.02} & $10 \%$ & 0.78 & 1.90 & 0.70 & 0.92 & 0.15886 & 1375 & - & \\
& $5 \%$ & 0.78 & 2.26 & 0.76 & 1.11 & 0.28786 & 1392 & - & $1351(2.5 \%)$ \\
& $1 \%$ & 0.78 & 3.31 & 0.78 & 1.76 & 0.46912 & 1403 & $8 \times 10^{-5}$ & \\
\hline
\end{tabular}

Table 4.5: Bainitic steel segregated region composition (wt\%) after carbon homogenization. $T_{P}$ and $L_{P}$ denotes, respectively, the temperature $\left({ }^{\circ} \mathrm{C}\right)$ and residual liquid (mass\%) at which the primary precipitation of NbC from liquid, starts. $W_{P}$ denotes the mass fraction of primary carbides.

\begin{tabular}{ccccccccccc}
\hline $\begin{array}{c}\text { Bulk Nb/ } \\
\text { wt\% }\end{array}$ & $\begin{array}{c}\text { Residual } \\
\text { liquid }\end{array}$ & $\mathrm{C}$ & $\mathrm{Mn}$ & $\mathrm{Si}$ & $\mathrm{Cr}$ & $\mathrm{Mo}$ & $\mathrm{Nb}$ & $T_{\mathrm{NbC}}^{\text {seg }}$ & $W_{P}$ & $T_{P}\left(L_{P}\right)$ \\
\hline \multirow{3}{*}{0.005} & $10 \%$ & 0.22 & 2.57 & 2.97 & 0.61 & 1.40 & 0.03487 & 1275 & - & \\
& $5 \%$ & 0.22 & 2.55 & 3.25 & 0.74 & 2.06 & 0.06352 & 1359 & - & $1370(0.4 \%)$ \\
& $1 \%$ & 0.22 & 2.49 & 3.68 & 0.83 & 4.43 & 0.23924 & 1385 & - & \\
\hline \multirow{2}{*}{0.01} & $10 \%$ & 0.22 & 2.57 & 2.97 & 0.61 & 1.39 & 0.06894 & 1354 & - & \\
& $5 \%$ & 0.22 & 2.54 & 3.24 & 0.74 & 2.03 & 0.12397 & 1386 & - & $1377(0.9 \%)$ \\
& $1 \%$ & 0.22 & 2.47 & 3.64 & 0.84 & 4.42 & 0.47088 & 1403 & - & \\
\hline \multirow{2}{*}{0.02} & $10 \%$ & 0.22 & 2.57 & 2.97 & 0.61 & 1.41 & 0.14019 & 1399 & - & \\
& $5 \%$ & 0.22 & 2.53 & 3.22 & 0.75 & 2.02 & 0.24697 & 1400 & - & $1385(1.8 \%)$ \\
& $1 \%$ & 0.22 & 2.45 & 3.60 & 0.84 & 4.41 & 0.53635 & 1405 & $4.34 \times 10^{-5}$ & \\
\hline
\end{tabular}


Even if $10 \%$ residual liquid is taken to be the point where segregation is assessed i.e. the least level of segregation is considered, to maintain the $T_{\mathrm{NbC}}^{\text {seg }}$ below $1300^{\circ} \mathrm{C}$, the $\mathrm{Nb}$ concentration must be less than $0.005 \mathrm{wt} \%$ for both the pearlitic and bainitic steel. The NbC volume fraction may not then be significant to affect the austenite grain size. Greater concentrations may lead to $\mathrm{NbC}$ in the segregated regions that do not dissolve during reheating at $1200-1300^{\circ} \mathrm{C}$, causing potential problems in rolling contact fatigue. However, this can be mitigated if the size of the undissolved carbides remains small.

\subsection{Summary}

Niobium addition is limited by the maximum niobium that can be soluble in austenite at reheating temperatures. This can be calculated by commercial thermodynamic software and database. Any niobium concentration beyond that, will form carbides that can not be dissolved in austenite at corresponding reheating temperatures. Even when the niobium addition is less than the maximum soluble niobium in austenite, microsegregation leads to solute enrichment in liquid and eventually formation of primary niobium carbides that precipitate from liquid. To dissolve these primary carbides in the segregated austenite, the dissolution temperature required is way higher than the standard $1200-1300^{\circ} \mathrm{C}$ reheating temperatures and the carbides will remain undissolved. To mitigate potential problems in rolling contact fatigue, it is essential to either avoid the formation of the primary carbides or to control their size fine enough by controlling casting parameters so that the undissolved carbides cannot be harmful to the mechanical properties. 


\section{Chapter 5}

\section{Experimental details}

\subsection{Alloys}

Based on the alloy design considerations in Chapter 4 , the following steel melts were manufactured on our behalf at OCAS, Belgium, using a vacuum induction furnace. The final compositions (Table 5.1) in the cast were analyzed by spark source optical emission spectroscopy and by combustion analysis for C, S, N and O. The alloys are identified using the characters ' $\mathrm{P}$ ' or ' $\mathrm{B}$ ' to represent pearlitic or bainitic steels respectively, followed by two digits representing wt $\% \mathrm{C} \times 100$ and final two digits representing wt $\% \mathrm{Nb} \times 100$.

Table 5.1: Composition of experimental alloys (wt\%)

\begin{tabular}{ccccccccc}
\hline Alloy & C & Mn & Si & Cr & Mo & Nb & P & S \\
\hline P7802 & 0.78 & 1.0 & 0.42 & 0.55 & - & 0.02 & 0.0026 & 0.0013 \\
P7901 & 0.79 & 0.98 & 0.41 & 0.57 & - & 0.011 & 0.0022 & 0.0005 \\
P7600 & 0.76 & 1.0 & 0.42 & 0.53 & - & - & 0.0023 & 0.0007 \\
\hline B4002 & 0.40 & 2.0 & 1.5 & 1.0 & 0.36 & 0.023 & 0.0037 & 0.0026 \\
B4101 & 0.41 & 1.96 & 1.52 & 1.01 & 0.31 & 0.011 & 0.0021 & 0.0007 \\
\hline B2102 & 0.21 & 2.0 & 1.9 & 0.54 & 0.52 & 0.019 & 0.0023 & 0.0007 \\
B2200 & 0.22 & 2.0 & 1.9 & 0.54 & 0.47 & - & 0.0026 & 0.001 \\
\hline
\end{tabular}

Each cast weighed $100 \mathrm{~kg}$, but after removal of the 'head' of the ingot (which contained porosity), approximately $55-60 \mathrm{~kg}$ of material remained available. After casting and cutting off the 'head', 4 blocks of $125 \times 125 \times 95 \mathrm{~mm}^{3}$ were cut from each cast and hot rolled to $30 \mathrm{~mm}$ (reduction ratio 0.68). Table 5.2 lists the rolling schedule. 
A slice of $125 \times 125 \times 10 \mathrm{~mm}^{3}$ was cut from each ingot to analyse the cast material. Cooling rates for $30 \mathrm{~mm}$ thick plates are close to those at the centre of a rail-head [24].

Table 5.2: Hot rolling schedule

\begin{tabular}{|c|c|c|c|c|c|c|c|c|c|}
\hline Alloy & $\begin{array}{l}\text { Reheating } \\
\text { temperature } \\
\text { and time }\end{array}$ & Hot Rolling & Initial & Pass 1 & Pass 2 & Pass 3 & Pass 4 & Pass 5 & \\
\hline \multirow{3}{*}{$\begin{array}{l}\text { P7802 } \\
\text { B4002 }\end{array}$} & \multirow{3}{*}{$\begin{array}{l}1300^{\circ} \mathrm{C} \\
-2 \mathrm{~h}\end{array}$} & Reduction/ \% & - & 15 & 20 & 22 & 22 & 23 & \multirow{9}{*}{$\begin{array}{c}\text { Air } \\
\text { Cooling }\end{array}$} \\
\hline & & Temperature $/{ }^{\circ} \mathrm{C}$ & 1300 & 1280 & 1250 & 1200 & 1150 & 980 & \\
\hline & & Thickness/ mm & 95 & 81 & 64 & 50 & 39 & 30 & \\
\hline \multirow{3}{*}{$\begin{array}{l}\text { P7901 } \\
\text { B4101 }\end{array}$} & \multirow{3}{*}{$\begin{array}{l}1200^{\circ} \mathrm{C} \\
-2 \mathrm{~h}\end{array}$} & Reduction/ \% & - & 10 & 23 & 23 & 22 & 20 & \\
\hline & & Temperature/ ${ }^{\circ} \mathrm{C}$ & 1200 & 1180 & 1150 & 1100 & 1050 & 950 & \\
\hline & & Thickness/ mm & 95 & 85 & 66 & 51 & 39 & 31 & \\
\hline \multirow{3}{*}{$\begin{array}{l}\text { P7901 } \\
\text { P7600 } \\
\text { B2102 } \\
\text { B2200 }\end{array}$} & \multirow{3}{*}{$\begin{array}{l}1200^{\circ} \mathrm{C} \\
-2 \mathrm{~h}\end{array}$} & Reduction/\% & - & 11 & 24 & 24 & 22 & 22 & \\
\hline & & Temperature $/{ }^{\circ} \mathrm{C}$ & 1200 & 1180 & 1150 & 1100 & 1020 & 870 & \\
\hline & & Thickness/ mm & 95 & 85 & 64 & 49 & 38 & 30 & \\
\hline
\end{tabular}

\subsection{Dissolution kinetics of precipitates in austen- ite}

A steel not designed for rails (Table 5.3), coded as 'SB02', was studied initially to evaluate the dissolution kinetics of coarse niobium carbide precipitates in a high carbon $(0.83 \mathrm{wt} \% \mathrm{C})$ and high niobium $(0.019 \mathrm{wt} \% \mathrm{Nb})$ composition. The material was received in the form of a $150 \mathrm{~mm}$ diameter steel shaft made by Tata steel Europe for Rolls-Royce plc, and was cooled slowly through the temperature range of $700{ }^{\circ} \mathrm{C}$ $550^{\circ} \mathrm{C}$ to ensure that the initial microstructure is pearlitic in order to avoid possible cracking associated with martensitic transformation.

Table 5.3: Composition (wt\%) of 'SB02' steel

\begin{tabular}{cccccccccccc}
\hline $\mathrm{C}$ & $\mathrm{Mn}$ & $\mathrm{Si}$ & $\mathrm{Cr}$ & $\mathrm{Mo}$ & $\mathrm{Al}$ & $\mathrm{Cu}$ & $\mathrm{Co}$ & $\mathrm{Sn}$ & $\mathrm{V}$ & $\mathrm{Ti}$ & $\mathrm{Nb}$ \\
\hline 0.83 & 2.39 & 1.76 & 1.456 & 0.224 & 0.046 & 0.12 & 1.55 & 0.027 & 0.112 & 0.013 & 0.019 \\
\hline
\end{tabular}

To study the dissolution kinetics of the precipitates, samples were cut from asreceived material and sealed in quartz tubes. The tubes were heated at $1300{ }^{\circ} \mathrm{C}$ in a muffle furnace for different time intervals i.e. 0.5, 1, 2, 4, 8, 16 and $32 \mathrm{~h}$ followed by water quenching. 
In a similar fashion, selected as-cast alloys from Table 5.1 were also sectioned and sealed in quartz tubes and heated at $1200-1300^{\circ} \mathrm{C}$ depending upon their respective reheating temperatures, for different time intervals followed by water quenching. The heat-treated and quenched samples were metallographically polished, etched and observed using scanning electron microscopy to study the precipitates.

\subsection{Microstructural characterisation}

\subsubsection{Sample preparation for metallography}

Cross-sectional samples from the as-cast and as-rolled materials, were hot-mounted in conductive bakelite and prepared for metallographic study by grinding using silicon carbide emery papers (800-grade to 4000-grade), followed by polishing with $1 \mu \mathrm{m}$ paste on a polishing cloth. Samples were etched with $2 \%$ nital (2\% nitric acid, $98 \%$ methanol) to reveal the microstructure. Optical microscopy and scanning electron microscopy (SEM) together with energy dispersive spectroscopy (EDS) have been used to analyse the microstructures and to identify the precipitates and measure their size distributions.

Unmounted sections were prepared in a similar fashion and final polished with $0.25 \mu \mathrm{m}$ colloidal silica on a polishing cloth, before ultrasonically cleaning with acetone and then using for X-ray analysis and electron back-scatter diffraction study.

Thin foil samples for transmission electron microscopy were prepared from $3 \mathrm{~mm}$ diameter discs, punched out from $200 \mathrm{~mm}$ thick foils. The discs were ground down to $\sim 50 \mu \mathrm{m}$ thickness using 1200-2500 grade silicon carbide emery papers and then, thinned by electropolishing using a twin jet electropolisher set to $26-27 \mathrm{~V}$ at $7-10{ }^{\circ} \mathrm{C}$. The electrolyte consisted of $5 \%$ perchloric acid, $15 \%$ glycerol and $80 \%$ methanol by volume.

\subsubsection{Optical microscopy}

All of the optical microscopy work, with magnification in the range 50-500X, was performed in both Olympus BH optical microscope and Leica Microsystems DM2500M upright light microscope. Both the microscopes are attached with DFC295 cameras for recording the micrographs. Leica Application Suite software and ImageJ were used for minor digital enhancements (e.g. cropping, addition of scale bars, brightness and contrast adjustments) and quantitative analysis (e.g. precipitate and grain size measurements). 


\subsubsection{Scanning electron microscopy}

Scanning electron microscopy (SEM) was carried out using a Camscan MX 2600 field-emission gun (FEG) microscope, fitted with an Oxford Instruments detector for energy dispersive X-ray spectroscopy (EDS), to characterise the niobium containing precipitates in back-scatter electron mode as well as to study the fracture surface morphology of the mechanically tested (tensile and impact test) samples in secondary electron mode. The pearlitic and baintic microstructures were studied using a Phenom ProX desktop SEM with a back-scatter detector and an integrated EDS system for chemical analysis.

\subsubsection{Electron back-scatter diffraction}

Electron back-scatter diffraction (EBSD) was carried out using a FEI Nova NanoSEM, fitted with a Bruker EBSD camera. A voltage of $20 \mathrm{kV}$ and a working distance of $15 \mathrm{~mm}$ were used. The post-processing analysis was carried out using AZtecHKL Channel 5 software.

\subsubsection{Transmission electron microscopy}

A FEI Tecnai Osiris 80-200, fitted with EDS detectors, was used for scanning transmission electron microscopy (STEM) in bright field (BF), high-angle annular dark field (HAADF) imaging mode and selected area diffraction (SAD) mode with an accelerating voltage of $200 \mathrm{kV}$.

\subsubsection{X-ray diffraction}

A Bruker D8 DAVINCI X-ray diffractometer was used with the Bragg-Brentano geometry under continuous scanning mode over a range of $2 \theta=25^{\circ}-120^{\circ}$ with unfiltered $\mathrm{CuK}_{\alpha}$ radiation. The machine was operated at $40 \mathrm{kV}$ and $30 \mathrm{~mA}$ with a scan step of $0.05^{\circ}$ and dwell time of $14 \mathrm{~s}$ per step. Either of HighScore Plus or MAUD X-ray diffraction analysis software was utilised to identify peak positions and phases and for peak fitting. Quantitative phase analysis was performed using Rietveld refinement and the retained austenite volume fraction in the cementite-free bainitic samples was calculated from the integrated austenite and ferrite peaks, 


\subsection{Thermomechanical experiments}

To study the effect of hot deformation on Nb-microalloyed austenite, uniaxial compression tests were carried out using $\phi 8 \mathrm{~mm} \times 12 \mathrm{~mm}$ cylindrical samples in a Thermecmastor Z thermomechanical simulator. Some experiments were carried out using $\phi 5 \mathrm{~mm} \times 10 \mathrm{~mm}$ cylindrical samples in a DIL805D dilatometer (Make: TA instruments) (Figure 5.1 a) to control the deformation strain, strain rate, cooling rate, sample dimensions and load, more accurately. The cylindrical samples were prepared from the as-rolled materials and reheated at $1200^{\circ} \mathrm{C}$ for $2 \mathrm{~h}$ and helium-cooled at high cooling rate $\left(\sim 50^{\circ} \mathrm{Cs}^{-1}\right)$ thereafter to take as much as niobium into solution before hot deformation. Typical thermomechanical processing schedules are shown schematically in Figure 5.1b. Depending on double-pass or multi-pass testing (Chapter 8), the typical parameters are: heating rate $=10^{\circ} \mathrm{Cs}^{-1}$, strain per pass $=0.15-0.5$, strain rate $=5 \mathrm{~s}^{-1}$, cooling rate between deformations $=1-5^{\circ} \mathrm{C} \mathrm{s}^{-1}$ and inter-pass time $=50 \mathrm{~s}$ etc.
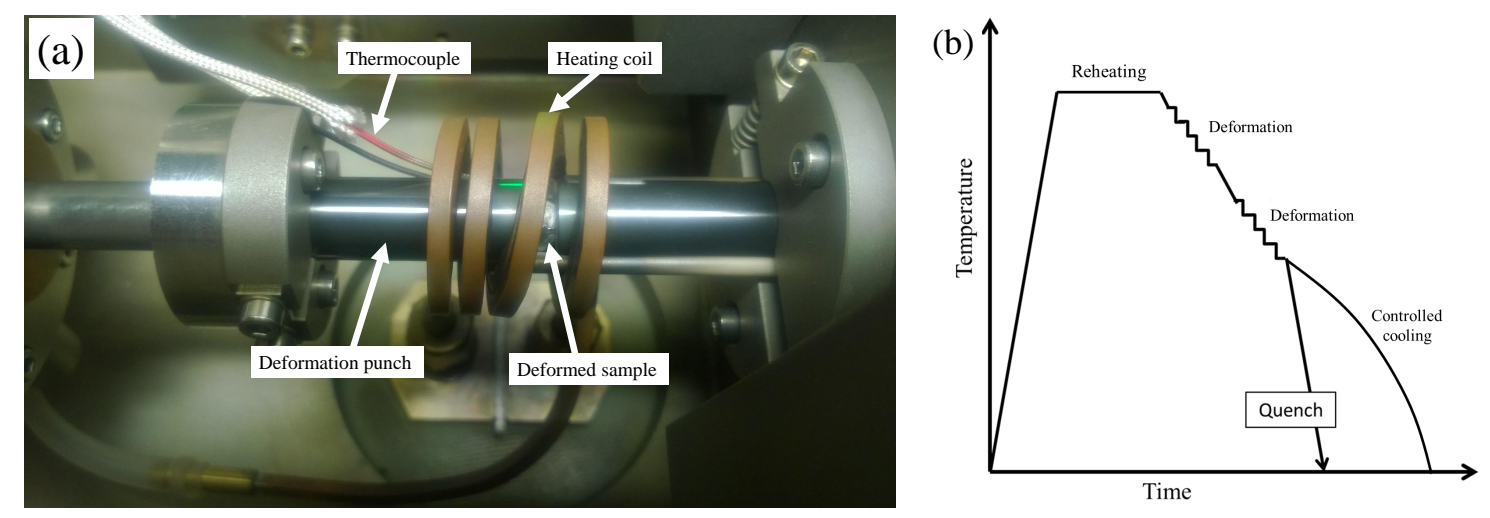

Figure 5.1: (a) Inside DIL805D deformation dilatometer and (b) Schematic representation of thermo-mechanical schedules.

To study the austenite grain structure after deformation, the quenched samples were tempered at $500^{\circ} \mathrm{C}$ for $24 \mathrm{~h}$ before preparing for metallographic study by standard grinding and polishing techniques. Austenite grain boundaries were revealed by etching with Marshall's reagent (Stock solution A: $100 \mathrm{ml} \mathrm{H}_{2} \mathrm{O}+8 \mathrm{~g}$ oxalic acid $+5 \mathrm{ml} \mathrm{H}_{2} \mathrm{SO}_{4}$ mixed with equal parts of stock solution B: $15 \% \mathrm{H}_{2} \mathrm{O}_{2}$ ). $2 \%$ nital were used to reveal the transformed pearlitic and bainitic microstructures. 


\subsection{Mechanical testing}

\subsubsection{Hardness measurement}

Bulk hardness was measured using Vickers hardness tester applying $30 \mathrm{~kg}$ dead load. The average of the two diagonal lengths of the projected square indentation made by the pyramidal indenter was measured optically and the hardness was measured under constant load using equation 5.1 :

$$
H V \sim \frac{0.1891 F}{d^{2}}
$$

where, $F$ is the applied load in newtons and $d$ is the measured diagonal length of the indentation in mm. A gap equal to at least $2.5 d$ between two nearest indentations were maintained in order to avoid the increase in hardness due to the work-hardening of the deformed structure due to indentation. At least ten indentations were taken for each structure, readings of which were averaged out during reporting. The standard deviation (S.D.) of the measurement was taken to calculate the statistical standard error $(S . D . / \sqrt{N})$, where, $N$ is the number of indentations made.

\subsubsection{Tensile and Charpy impact testing}

The tensile properties and Charpy impact toughness values for selected alloys are evaluated according to EN 13674-1 [108] and ASTM E-23 [109] respectively. The standard sample designs are shown in Figures 5.2 and 5.3 . The longitudinal (L) and transverse $(\mathrm{T})$ orientation of the tensile and Charpy V-notch samples are shown schematically in Figure 5.4 .

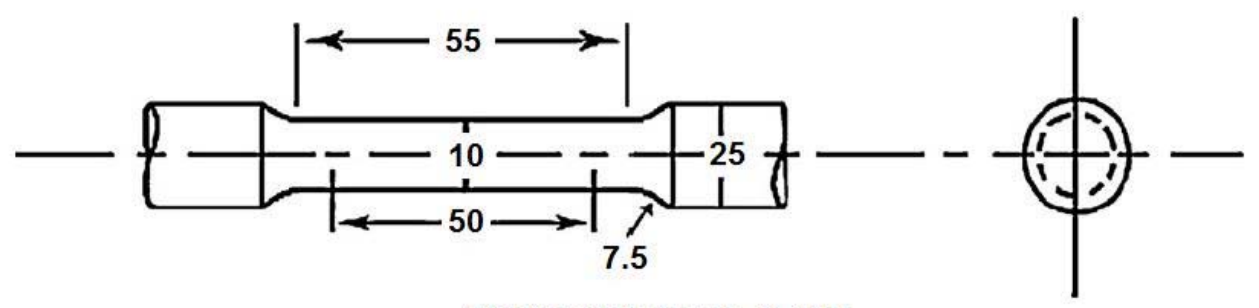

All dimensions are in $\mathrm{mm}$.

Figure 5.2: Standard cylindrical tensile specimen according to EN 13674-1 108. 

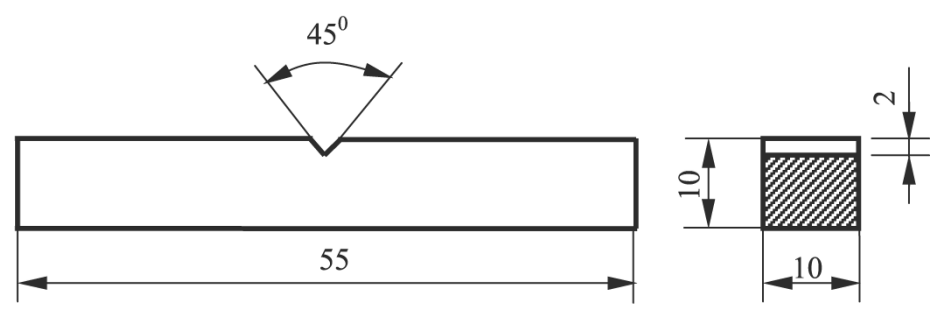

All dimensions are in $\mathrm{mm}$.

Figure 5.3: Standard Charpy impact specimen according to ASTM E-23 [109].
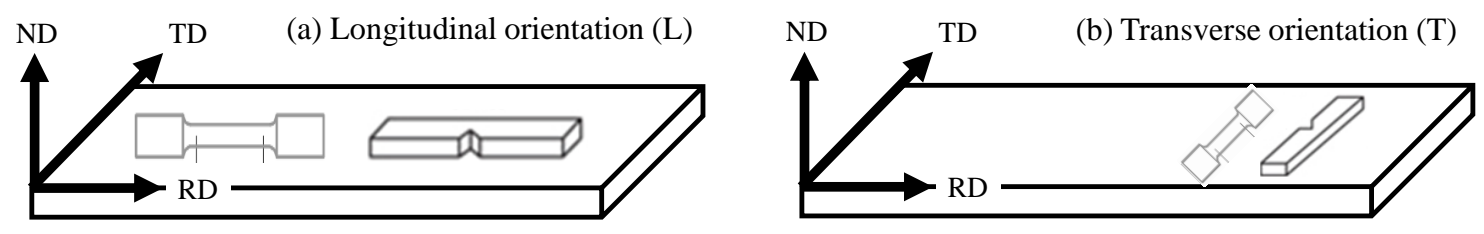

Figure 5.4: (a) Longitudinal orientation (L) and (b) transverse orientation (T). RD, ND, TD denote the rolling direction, normal and transverse to rolling direction, respectively.

\subsubsection{Rolling-sliding wear testing}

A twin-disk rolling contact machine was used to evaluate the wear performance of the investigated compositions. The rail and the wheel specimens (Figure 5.5) were mounted on the top and lower shaft respectively, which were driven by a motor and a combination of gears, as shown in Figure 5.6. The twin-disk configuration produces a situation similar to acceleration in a wheel-rail system, in that the motion of the contact point and shear traction were in opposite directions for the rail specimen and in the same direction for the wheel specimen [12]. For a given specimen, the relative direction of motion of the counterface defined the direction of the traction force. The variable number of teeth at gear F (Figure 5.6) allows the test to be carried out at different slip ratios.

For a bottom shaft speed $\left(v_{W}\right)$ measured at 135 rotations per minute (rpm), the slip ratio and slip distance calculations are summarised in Table 5.4. The top shaft speed $\left(v_{R}\right)$ is calculated as:

$$
v_{R}=v_{W} \times \frac{n_{D}}{n_{F}}
$$


where $n_{F}$ is the variable number of teeth at gear ' $\mathrm{F}$ ' and $n_{D}$ is number of teeth at gear ' $\mathrm{D}$ ' $(=80)$. The slip ratio is calculated as:

$$
\text { Slip ratio }=\frac{\pi}{1000}\left(v_{W} D_{W}-v_{R} D_{R}\right)
$$

where $D_{W}$ and $D_{R}$ are the wheel and rail disk diameters respectively.

The composition and heat treatment for standard wheel specimens are listed in Table 5.5. The wear tests were carried out at $25 \%$ slip ratio without any lubrication. The Vickers hardness (HV 30) of each disc was measured at three positions and the average of these measurements was used as the disc hardness. The contact stress was $560 \mathrm{MPa}$ for hardness up to $320 \mathrm{HV} 30$ and $750 \mathrm{MPa}$ for hardness above 320 HV 30. The discs were weighed accurately before and after the test. Each test was run initially for 213 cycles to have a common reference point for initial weight measurement and then run to 2130 cycles i.e. total $2130-213=1917$ cycles of wear. The output is weight loss in $\mathrm{mg} \mathrm{m}^{-1}$ of slip. 

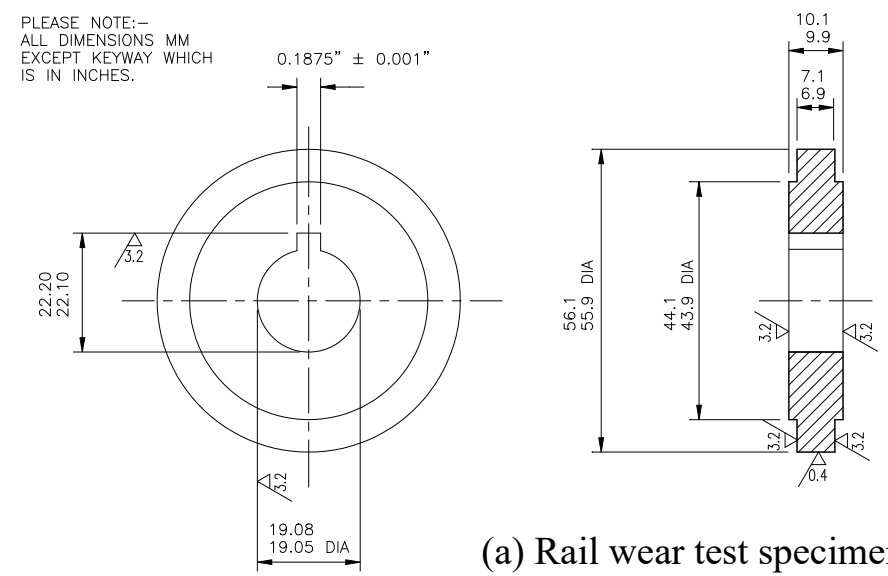

(a) Rail wear test specimen

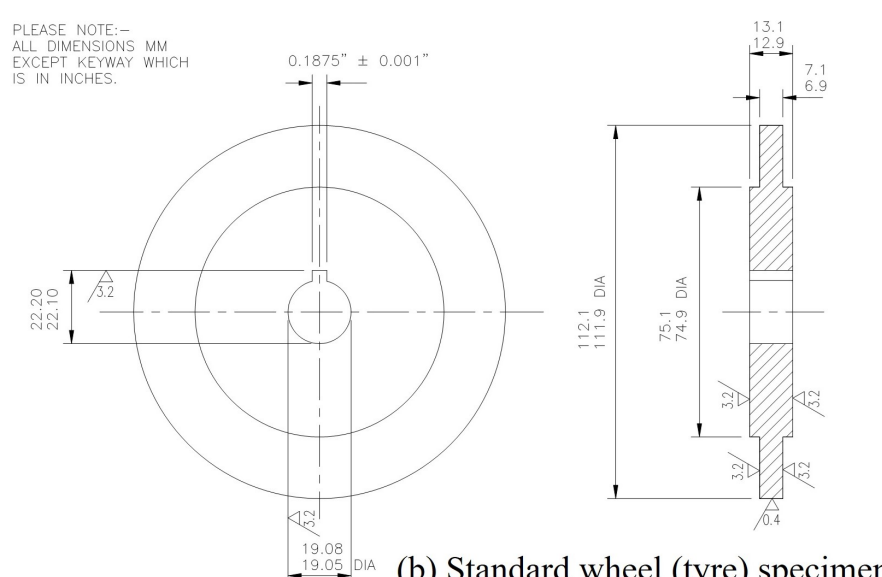

(b) Standard wheel (tyre) specimen

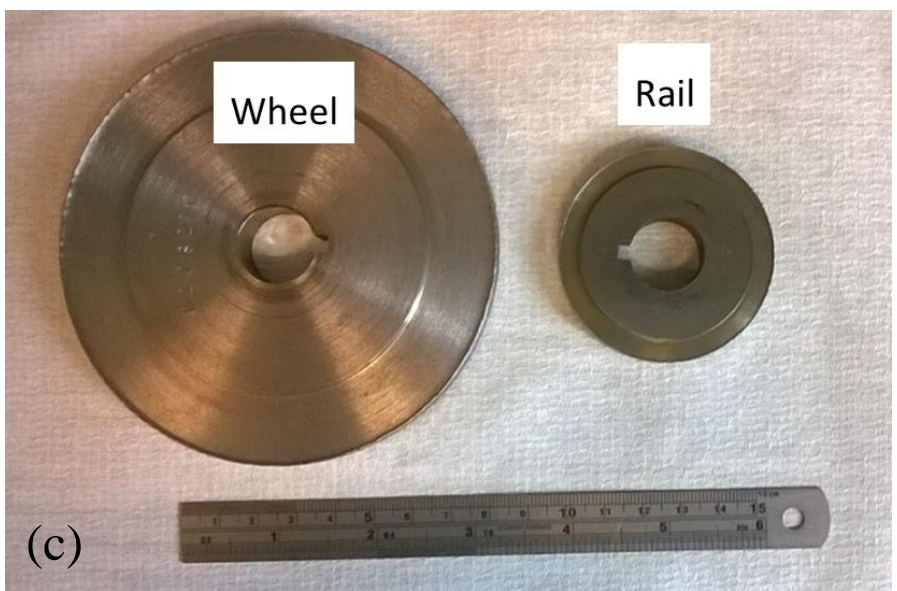

Figure 5.5: Engineering drawing for (a) rail wear test specimen, (b) standard wheel (tyre) specimen. (c) Actual rail and wheel test specimen. 
(a) Plan view

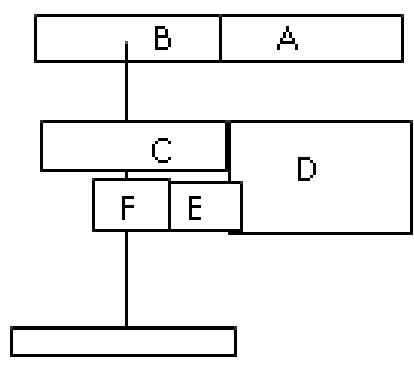

Gears

A on motor shaft $=80$ Teeth

$\mathrm{B}=140$ Teeth

$\mathrm{C}=\mathrm{D}=80$ Teeth

$\mathrm{E}=$ Idler

$\mathrm{F}=$ variable no of teeth

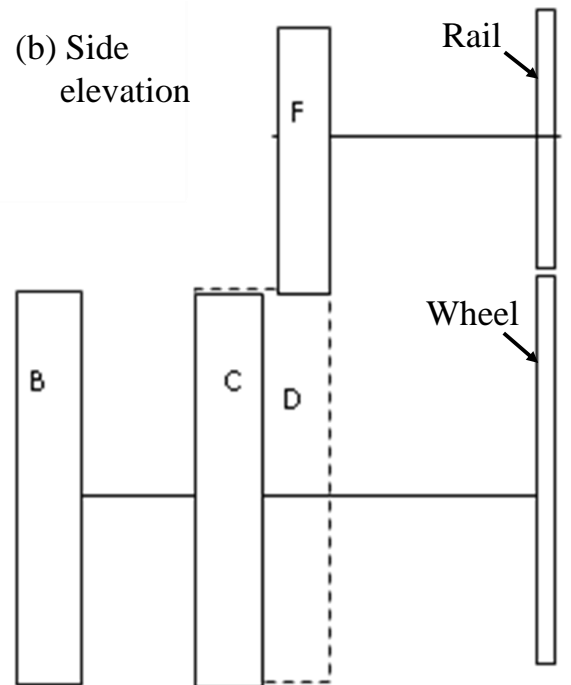

Figure 5.6: Schematic configuration of gears in twin-disk wear test machine: (a) plan view, (b) side elevation.

Table 5.4: Top shaft speed and slip ratio for different teeth number at gear ' $\mathrm{F}$ ' at $135 \mathrm{rpm}$ bottom shaft speed.

\begin{tabular}{ccc} 
Teeth on 'F' & Slip ratio / \% & Top shaft speed / rpm \\
42 & 5 & 257.1 \\
44 & 10 & 245.5 \\
46 & 15 & 234.8 \\
48 & 20 & 225 \\
50 & 25 & 216 \\
\hline
\end{tabular}

Table 5.5: Standard wheel (tyre) disk composition and heat treatment.

\begin{tabular}{|c|c|c|c|c|c|c|c|c|c|c|}
\hline $\mathrm{C}$ & $\mathrm{Mn}$ & $\mathrm{Si}$ & $\mathrm{Cr}$ & $\mathrm{Ni}$ & Mo & $\mathrm{Cu}$ & $\mathrm{Sn}$ & $\mathrm{P}$ & $\mathrm{S}$ & Heat treatment \\
\hline 0.51 & 0.74 & 0.27 & 0.14 & 0.16 & 0.04 & 0.20 & 0.02 & 0.014 & 0.029 & $\begin{array}{l}820^{\circ} \mathrm{C}-1 \mathrm{~h} \\
\text { holding and } \\
\text { air-cooled in } \\
150 \mathrm{~mm} \text { diame- } \\
\text { ter }\end{array}$ \\
\hline
\end{tabular}




\section{Chapter 6}

\section{Precipitation and dissolution kinetics}

\subsection{Precipitates in as-cast material}

Figure 6.1 shows low magnification scanning electron micrographs of the representative pearlitic and bainitic alloys in the as-cast condition. The dark and light patches due to chemical segregation are clearly visible in Figure6.1b for $\mathrm{Mn}$ and $\mathrm{Si}$ rich bainitic alloys but not as apparent in the case of the pearlitic alloy. This is because the entire cast transforms into pearlite, whereas in the case of the bainitic steels, the solute enriched regions are likely to contain some martensite and hence etch lighter. The arrows mark the niobium carbides in the segregated regions and the high magnification SEM micrographs of such carbides are shown in Figure6.2. The corresponding energy-dispersive spectra (Figure 6.1 c) show only Nb peaks associated with the precipitates. The eutectic or dendritic type of morphology of the precipitates indicates that these niobium carbides form directly from the residual liquid during solidification. These are henceforth termed as 'primary precipitates'. As shown in Tables 3.3 and 3.4, theoretical calculations require Scheil solidification to terminate within 1-3\% residual liquid fraction to start forming primary niobium carbides from residual liquid. 


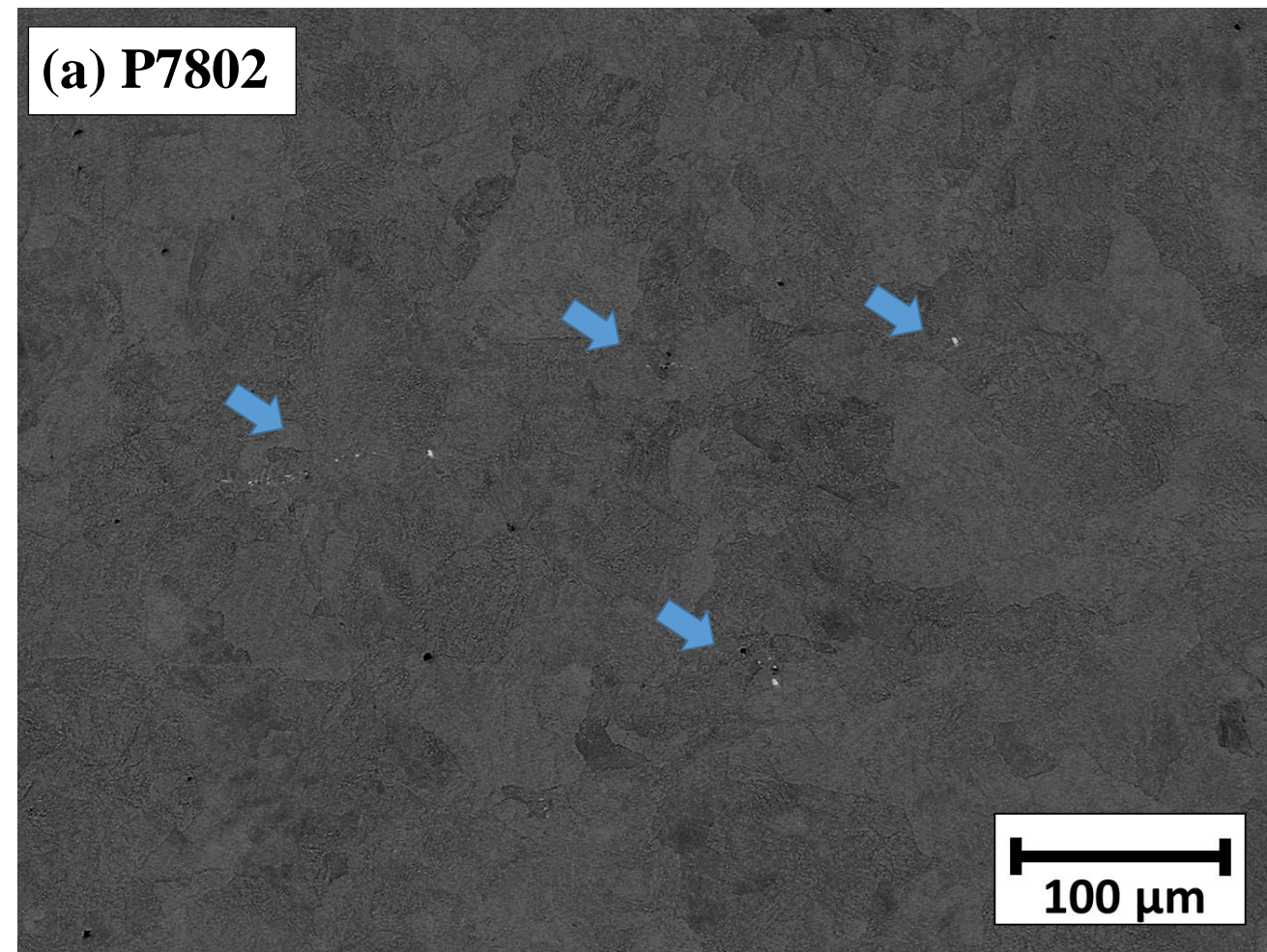

\section{(b) B2202}

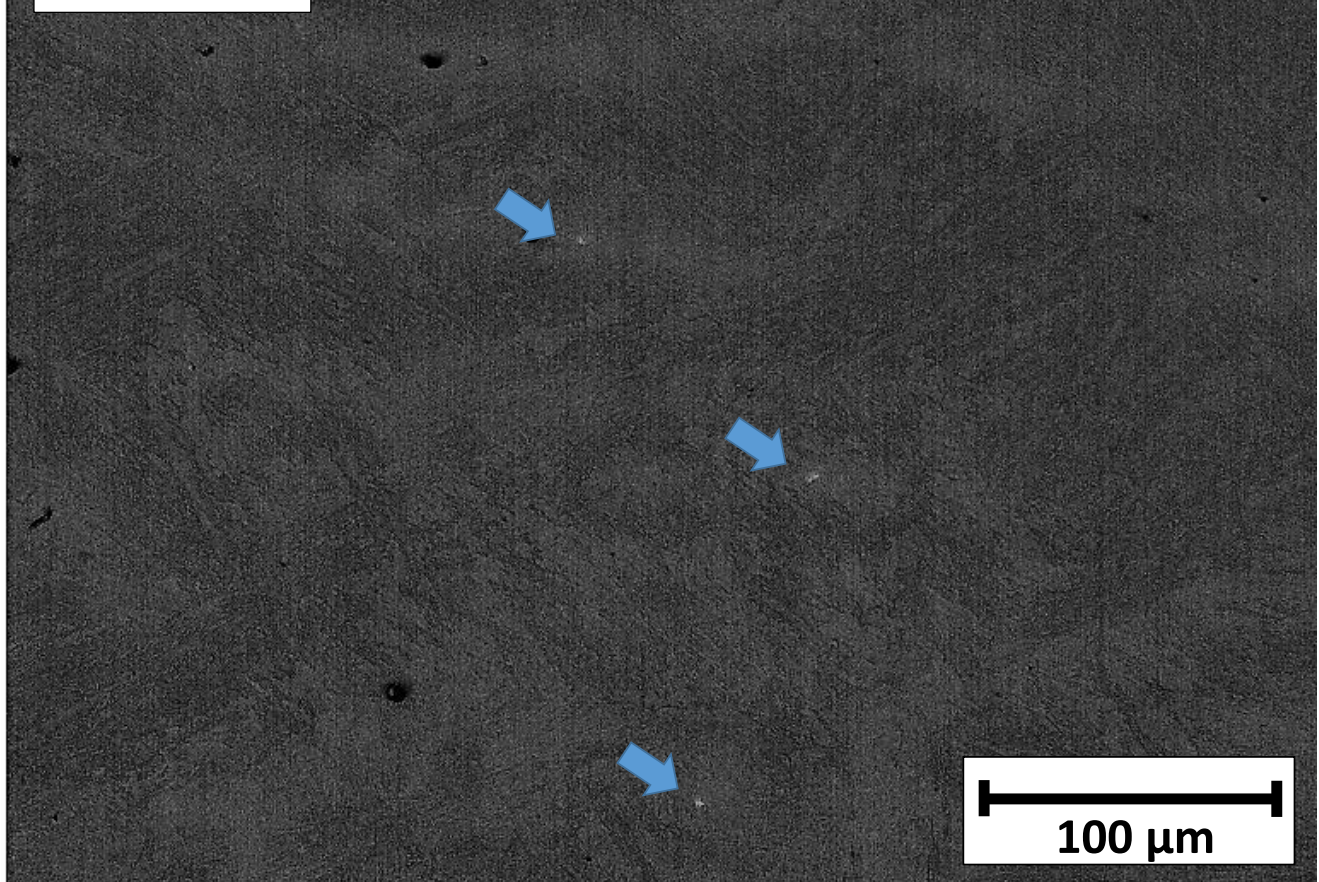

Figure 6.1: As-cast microstructure (a) P7802, (b) B2202. The arrows mark niobium carbides. 

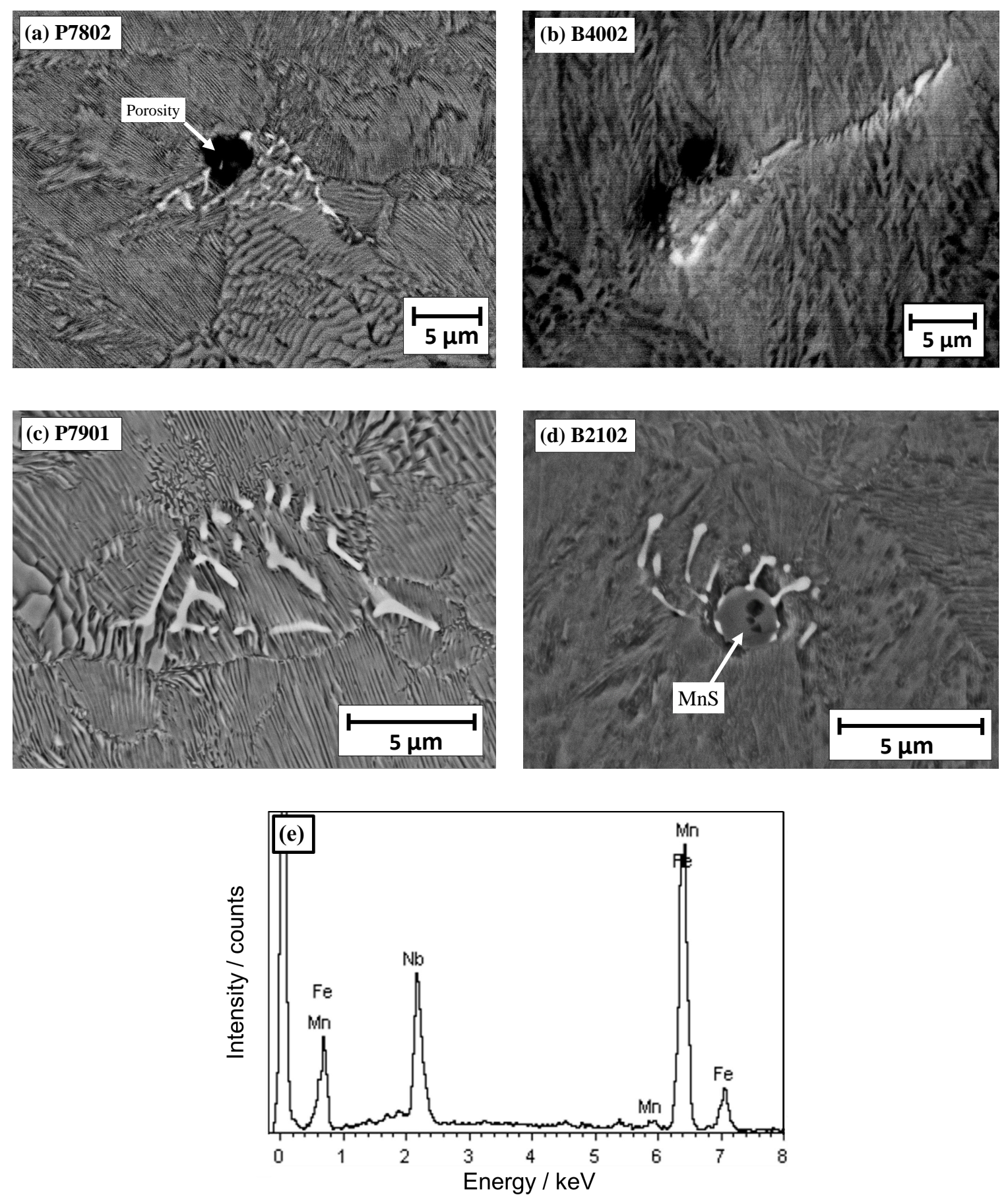

Figure 6.2: Primary niobium carbides in as-cast (a) P7802, (b) B4002, (c) P7901, (d) B2102. (e) A representative EDS spectrum showing Nb rich precipitates. Porosity can be observed in (a) and (b) and primary niobium carbides tend to precipitate on a $\mathrm{MnS}$ inclusion in (d). 
The primary precipitate size distribution was measured based on the largest dimension and compared in Figure 6.3. For each sample, approximately 200 precipitates containing niobium, were measured in order to determine statistically meaningful size distributions. The arrows indicate the largest precipitate size measured. The error bars represent the standard error (SE) of a population count $(N)$, calculated as $\mathrm{SE}=\sqrt{N}$.
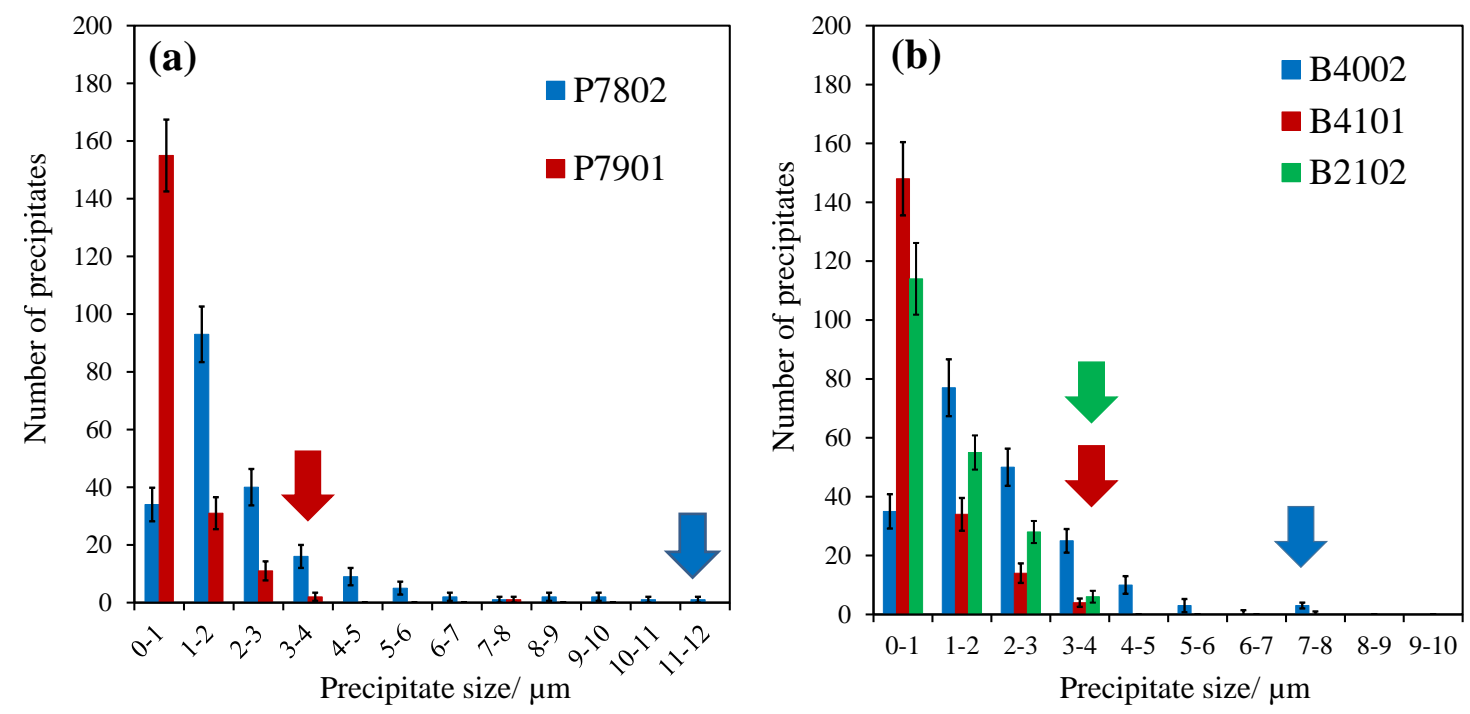

Figure 6.3: Primary niobium carbide size distribution in as-cast alloys: (a) pearlitic, (b) bainitic.

The average primary precipitate size varied between $0.5-2 \mu \mathrm{m}$ but the largest observed precipitate size decreased with reduction in the niobium content for alloys with identical carbon content. Though precipitates as long as $10-11 \mu \mathrm{m}$ are observed, the thickness of these plate-like morphologies were not more than 3-4 $\mu \mathrm{m}$, the dimension which affects the dissolution kinetics of the precipitates more than the length.

\subsection{Precipitates in as-rolled material}

In spite of reheating for $2 \mathrm{~h}$ at temperatures greater than the equilibrium dissolution temperatures for niobium carbides, undissolved primary precipitates are observed in the as-rolled material (Figure 6.4). Unlike the dendritic as-cast precipitates, niobium carbides in the as-rolled materials are more spherical in shape. This is due to slow dissolution kinetics of the coarse as-cast precipitates during reheating and eventual fragmentation during hot deformation. The number density and volume fraction of 
the undissolved precipitates after rolling are small and sufficient precipitates could not be detected and measured for a statistically meaningful size distribution.
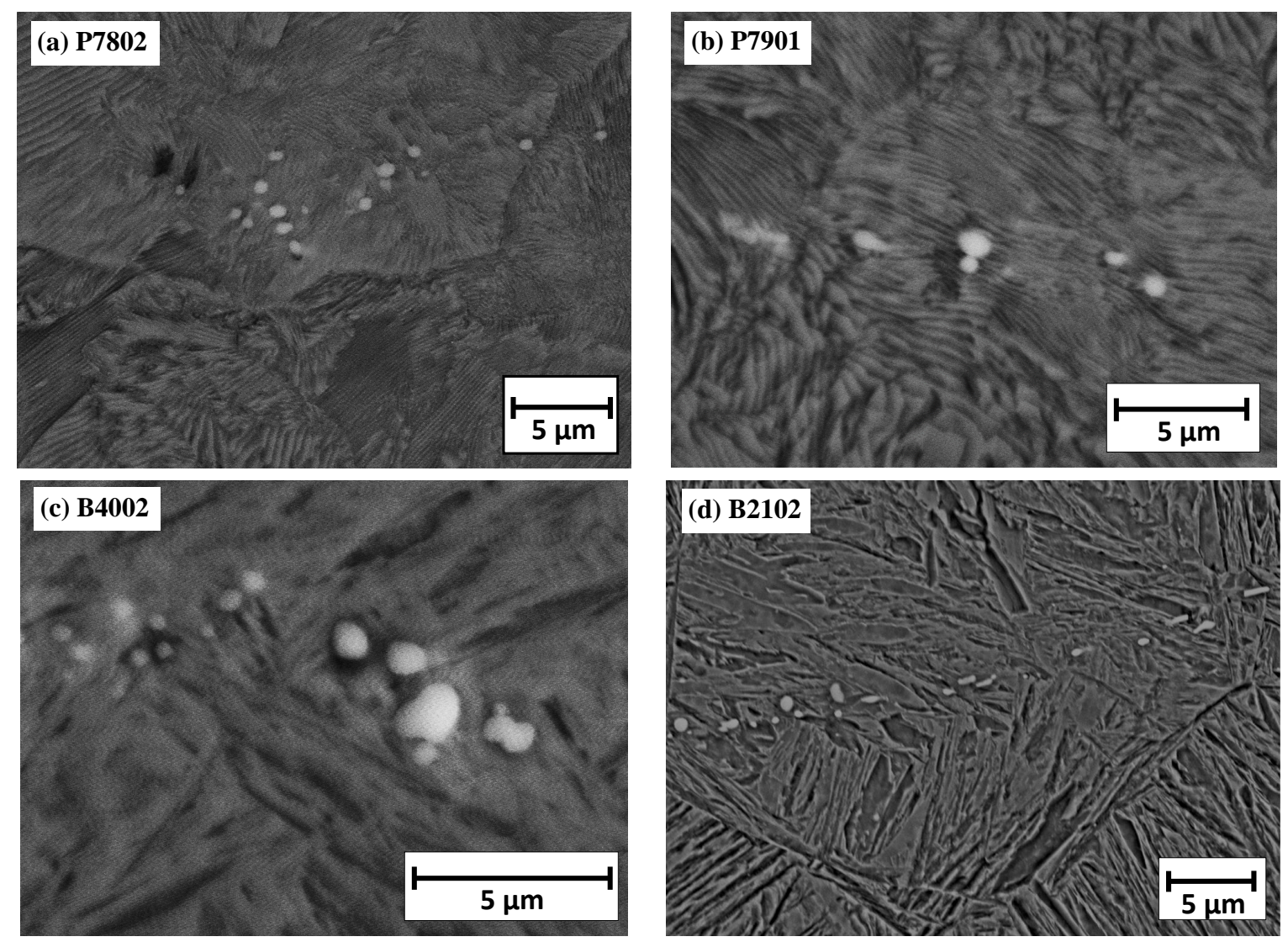

Figure 6.4: Precipitates in as-rolled material (a) P7802, (c) B4002 after $1300{ }^{\circ} \mathrm{C}-2 \mathrm{~h}$ reheating and (b) P7901, (d) B2102 after $1200^{\circ} \mathrm{C}-2 \mathrm{~h}$ reheating.

As shown schematically in Figure 6.5 $[110]$, the as-cast dendrite-like niobium carbides undergo multiple necking along the length of the particle due to diffusion controlled dissolution. Dissolution rate is high in the thinnest sections due to GibbsThompson capillarity effect [111], eventually leading to leading to fragmentation during reheating itself. Figure 6.5b shows precipitates in a sample reheated to $1200^{\circ} \mathrm{C}$ for $30 \mathrm{~min}$ and quenched, showing that the fragmentation is not due to hot deformation alone. But due to slow dissolution kinetics of the coarse precipitates and also due to other factors as discussed in Chapter 7, the time for complete dissolution is very long compared to standard reheating times of $2 \mathrm{~h}$. 

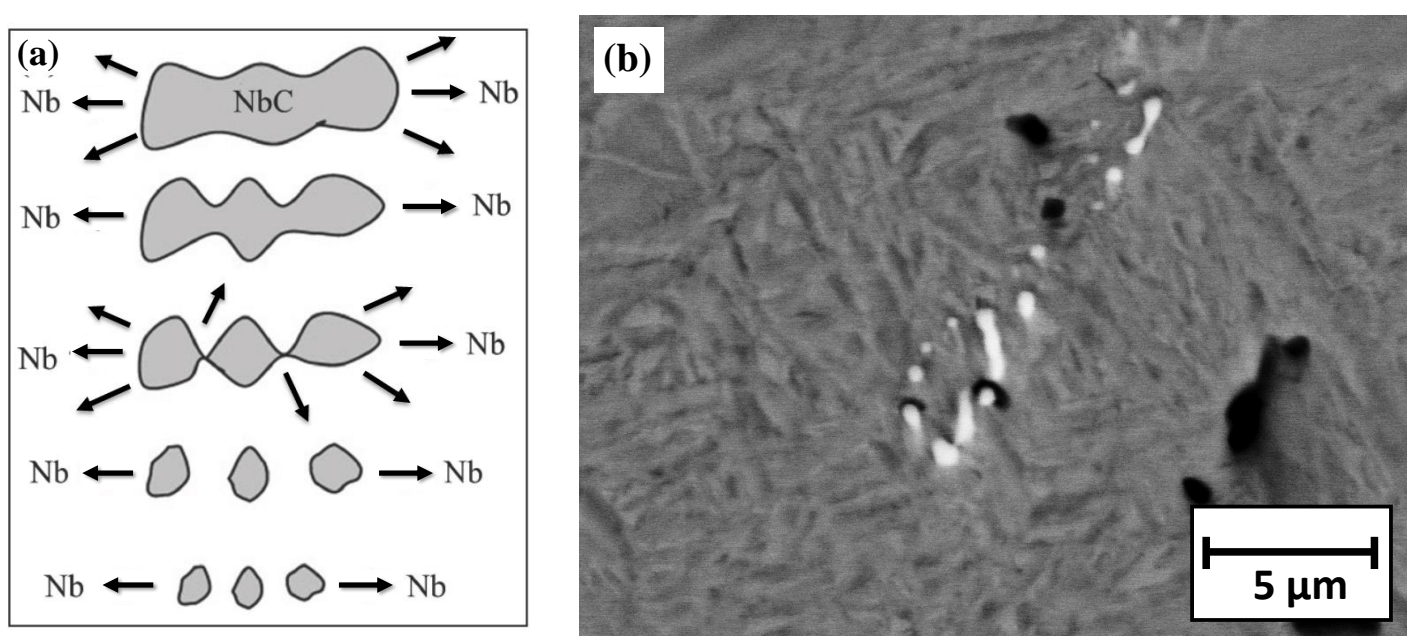

Figure 6.5: (a) Schematic showing dissolution of a primary $\mathrm{NbC}$ and (b) dissolution of primary $\mathrm{NbC}$ in as-cast B2102 during $1200^{\circ} \mathrm{C}$ for $30 \mathrm{~min}$ and quenched thereafter.

TEM investigation has shown Nb-containing precipitates having size less than $50 \mathrm{~nm}$ in as-rolled pearlitic alloys e.g. P7901 as shown in Figure6.6 a along with corresponding EDS spectrum (Figure6.6p). The orientation relationship between the NbC and ferrite $\alpha$ can be calculated from indexing the selected area electron diffraction (SAED) pattern (Figure6.6 ) : $[113]_{\alpha} \|[001]_{\mathrm{NbC}}$. The fine size of these precipitates and the absence of Baker-Nutting orientation relationship [112 115] between the precipitates and ferrite, indicate that they precipitate from the dissolved niobium in austenite during hot-rolling. The dark field image corresponding to $200_{\mathrm{NbC}}$ is shown in Figure 6.6d. For the as-rolled bainitic alloys e.g. B2102, such fine precipitates are difficult to identify due to high dislocation density in bainitic ferrite (Figure 6.7 a). Still some Nb-containing fine precipitates can be identified as shown in Figure6.7bc with corresponding EDS spectrum (Figure6.7d) and SAED pattern (Figure6.7e) but the volume fraction of such strain-induced precipitates seem to be less than that of the pearlitic alloy. 

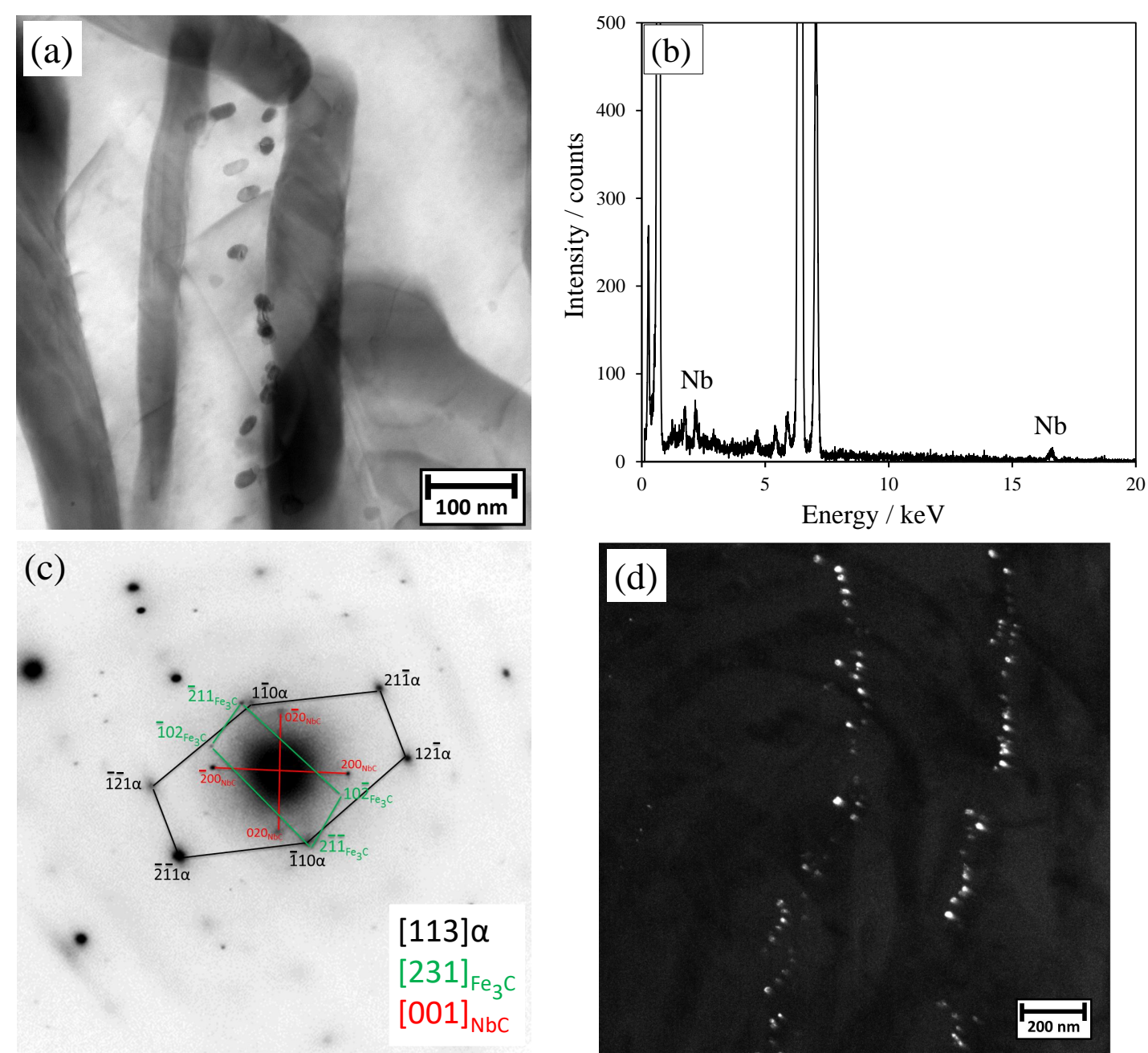

Figure 6.6: (a) Strain-induced niobium carbides in as-rolled P7901, (b) representative EDS spectrum, (c) selected area electron diffraction pattern (zone axes in the inset), (d) dark field image from $200_{\mathrm{NbC}}$ diffraction spot. 

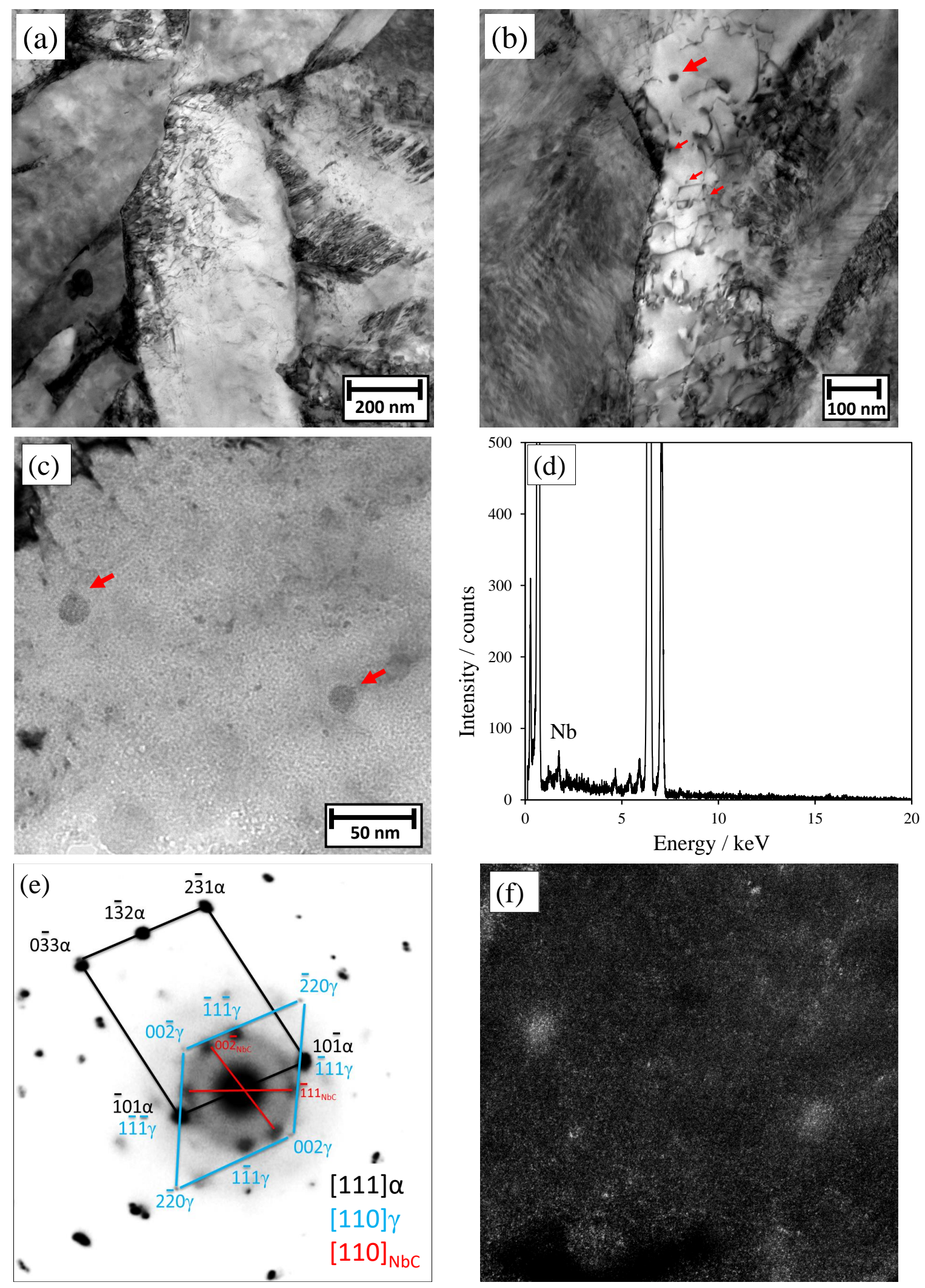

Figure 6.7: TEM study of as-rolled B2102: (a) dislocation cells in bainitic ferrite, (b) and (c) strain-induced precipitates indicated by arrows, (d) representative EDS spectrum, (e) selected area electron diffraction pattern (zone axes in the inset), (d) dark field image of the precipitates. 


\subsection{Dissolution kinetics in a Nb-V-Ti microalloyed high C steel}

As introduced in the Chapter 4 on experimental details, a steel composition (Table 6.1), coded as 'SB02', was initially studied to evaluate the dissolution kinetics of coarse niobium carbide precipitates in a high carbon $(0.83 \mathrm{wt} \%)$ and high niobium (0.019 wt\%) composition. To study the dissolution kinetics of the precipitates, samples were cut from as-received material and sealed in quartz tubes. The tubes were heated at $1300{ }^{\circ} \mathrm{C}$ in a muffle furnace for different time intervals i.e. 0.5, 1, 2, 4, 8, 16 and $32 \mathrm{~h}$ followed by water quenching. The heat-treated and quenched samples were metallographically polished, etched and observed using scanning electron microscopy to study the precipitates. Here also, for each time period, approximately 200 precipitates containing niobium, were measured to determine statistically meaningful size distributions.

Table 6.1: Composition (wt\%) of 'SB02' steel

\begin{tabular}{cccccccccccc}
\hline $\mathrm{C}$ & $\mathrm{Mn}$ & $\mathrm{Si}$ & $\mathrm{Cr}$ & $\mathrm{Mo}$ & $\mathrm{Al}$ & $\mathrm{Cu}$ & $\mathrm{Co}$ & $\mathrm{Sn}$ & $\mathrm{V}$ & $\mathrm{Ti}$ & $\mathrm{Nb}$ \\
\hline 0.83 & 2.39 & 1.76 & 1.456 & 0.224 & 0.046 & 0.12 & 1.55 & 0.027 & 0.112 & 0.013 & 0.019 \\
\hline
\end{tabular}

Figure 6.8 shows $(\mathrm{Ti}, \mathrm{Nb}, \mathrm{V}) \mathrm{C}$ complex precipitates in the segregated regions of asreceived 'SB02' material. During solidification, Ti being the least soluble of microalloying elements in austenite, precipitated first with niobium carbides and vanadium carbides forming subsequently on the Ti-based precipitates with decreasing temperatures. The majority of the paricles were not spherical, some being cuboidal and some elliptical in shape. The size distributions were calculated based on the largest dimensions measured for the cuboidal and elliptical precipitates. Figure 6.9 represents the size distribution of the niobium containing precipitates for different holding times at $1300{ }^{\circ} \mathrm{C}$. For clarity, data for $8 \mathrm{~h}$ have been compared with $0.5 \mathrm{~h}$ and $16 \mathrm{~h}$ in Figures $6.10 \mathrm{a}$ and $\mathrm{b}$ respectively. With increasing holding time the mode of the distribution shifted towards lower precipitate sizes. The maximum precipitate size measured decreased. While precipitates greater than $20 \mu \mathrm{m}$ were observed after heating for half hour, the $16 \mathrm{~h}$ holding treatment resulted in a maximum precipitate size of $8.3 \mu \mathrm{m}$. 


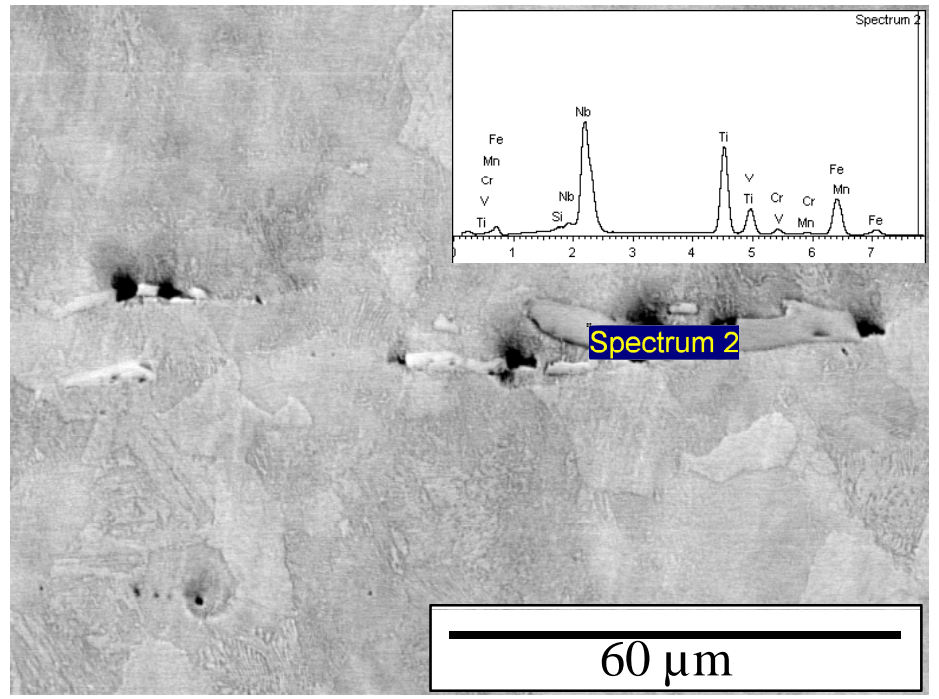

Figure 6.8: Segregated precipitates in as-received 'SB02' material and corresponding EDS spectrum.

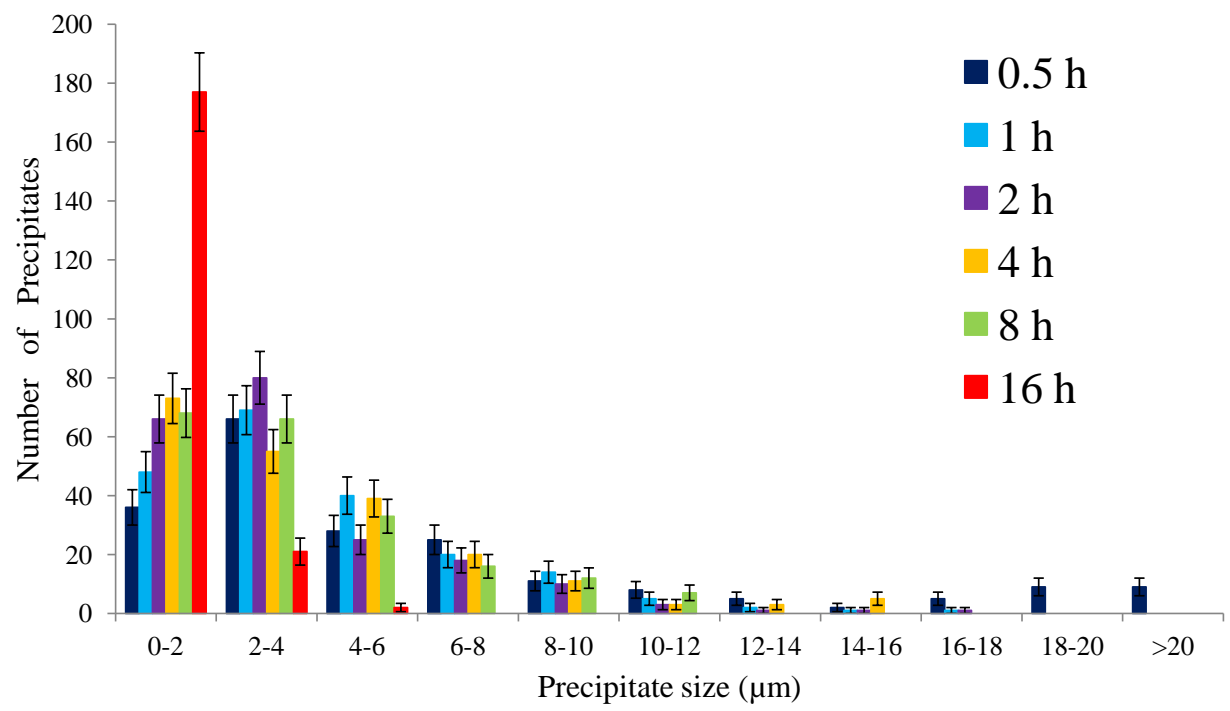

Figure 6.9: Precipitate size distribution in alloy 'SB02'. For each heat treated sample, about 200 precipitates, containing niobium, were measured to determine statistically meaningful size distribution. 

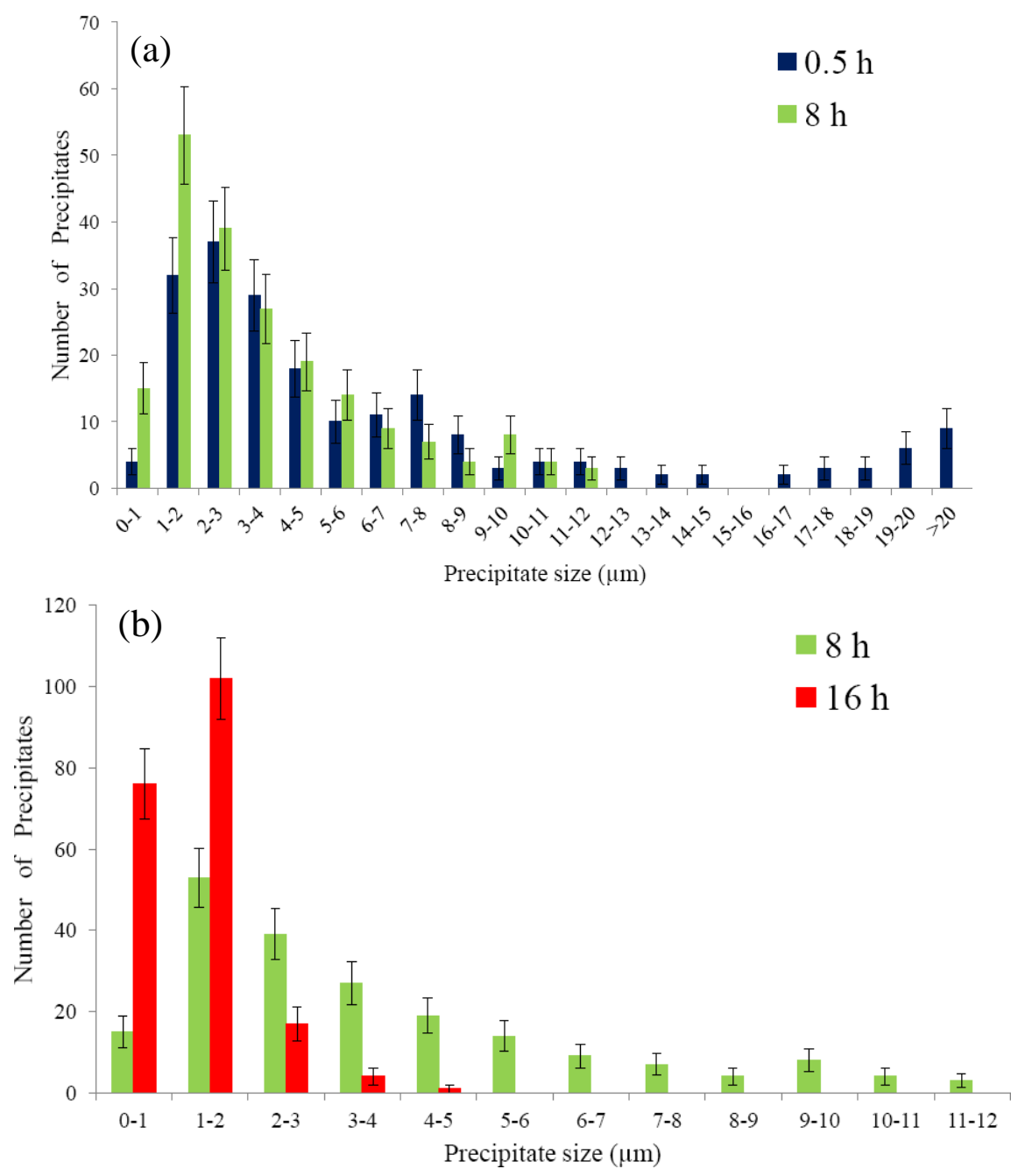

Figure 6.10: Comparison of precipitate size distributions in 'SB02' (a) $0.5 \mathrm{~h}$ and $8 \mathrm{~h}$, (b) $8 \mathrm{~h}$ and $16 \mathrm{~h}$.

As indicate by the blue arrows in Figure 6.11, the undissolved precipitates in the heat treated samples are present as segregated patches similar to the particles in the as-received condition (The black features are quenching cracks formed due to water quenching high carbon steels like SB02). For the samples heated for $32 \mathrm{~h}$, precipitates are also observed in regions containing chemical segregation but EDS analysis revealed those as Ti-precipitates with negligible traces of niobium (Figure6.12 ). Even the EDS spectra for the precipitates from $16 \mathrm{~h}$ holding are quite different from the EDS spectra obtained from the samples heated for 0.5-8 h (Figure6.12 a and b). The primary intensity peaks of $\mathrm{Nb}$ are relatively higher than for Ti for the latter set of samples. However, for the $16 \mathrm{~h}$ samples, the niobium intensity is low compared to that of $\mathrm{Ti}$ peaks, indicating dissolution of $\mathrm{NbC}$ from the complex $(\mathrm{Ti}, \mathrm{Nb}, \mathrm{V}) \mathrm{C}$ precipitates. Titanium in particular is known to stabilise NbC and hence retard its 
dissolution [116. For the samples heated for more than $32 \mathrm{~h}$, apparently no niobium containing precipitates could be observed; it is likely that the niobium is completely dissolved in austenite.
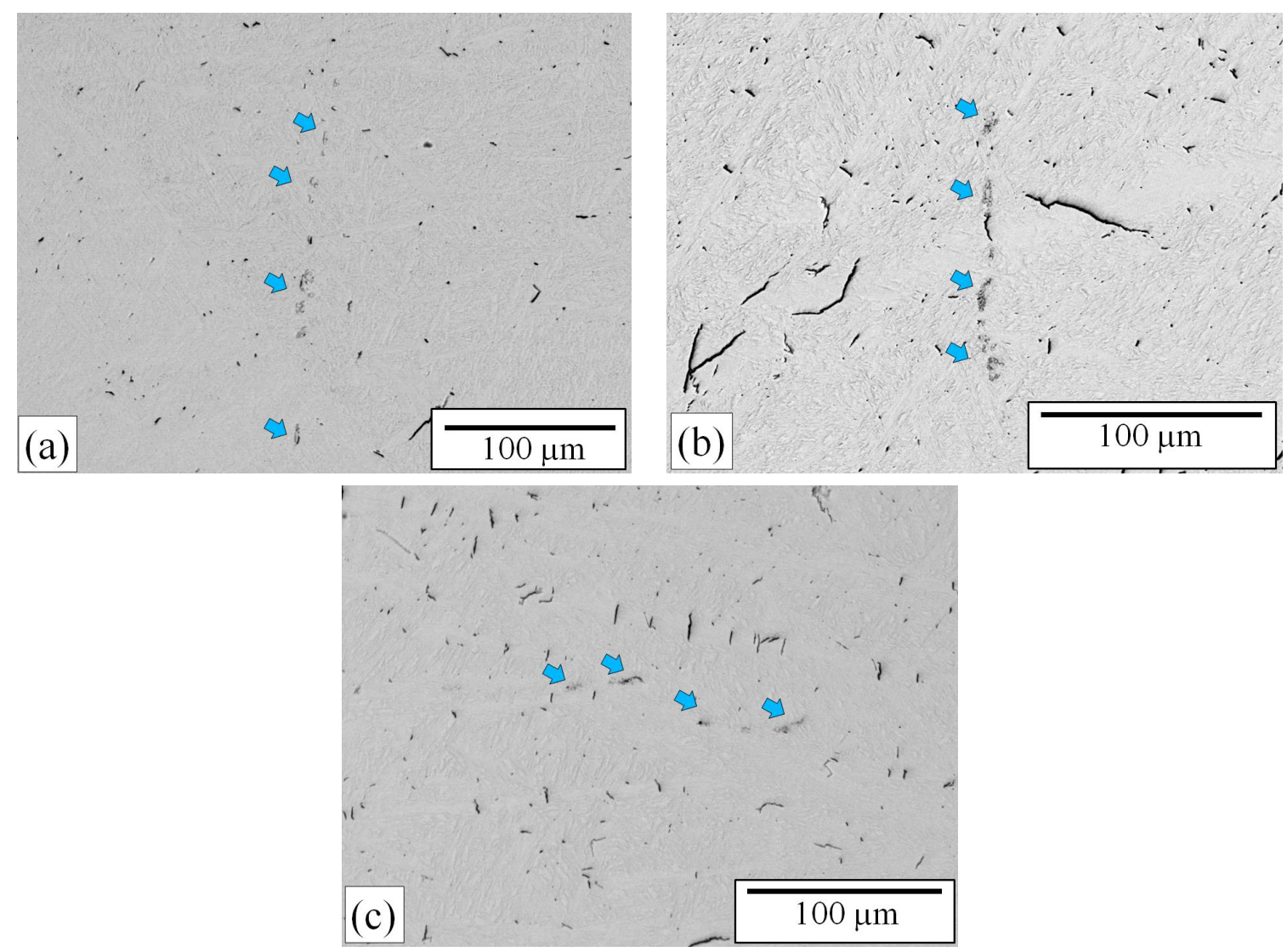

Figure 6.11: Undissolved precipitates in heat treated 'SB02' samples : (a) 8 h, (b) $16 \mathrm{~h},(\mathrm{c}) 32 \mathrm{~h}$. 

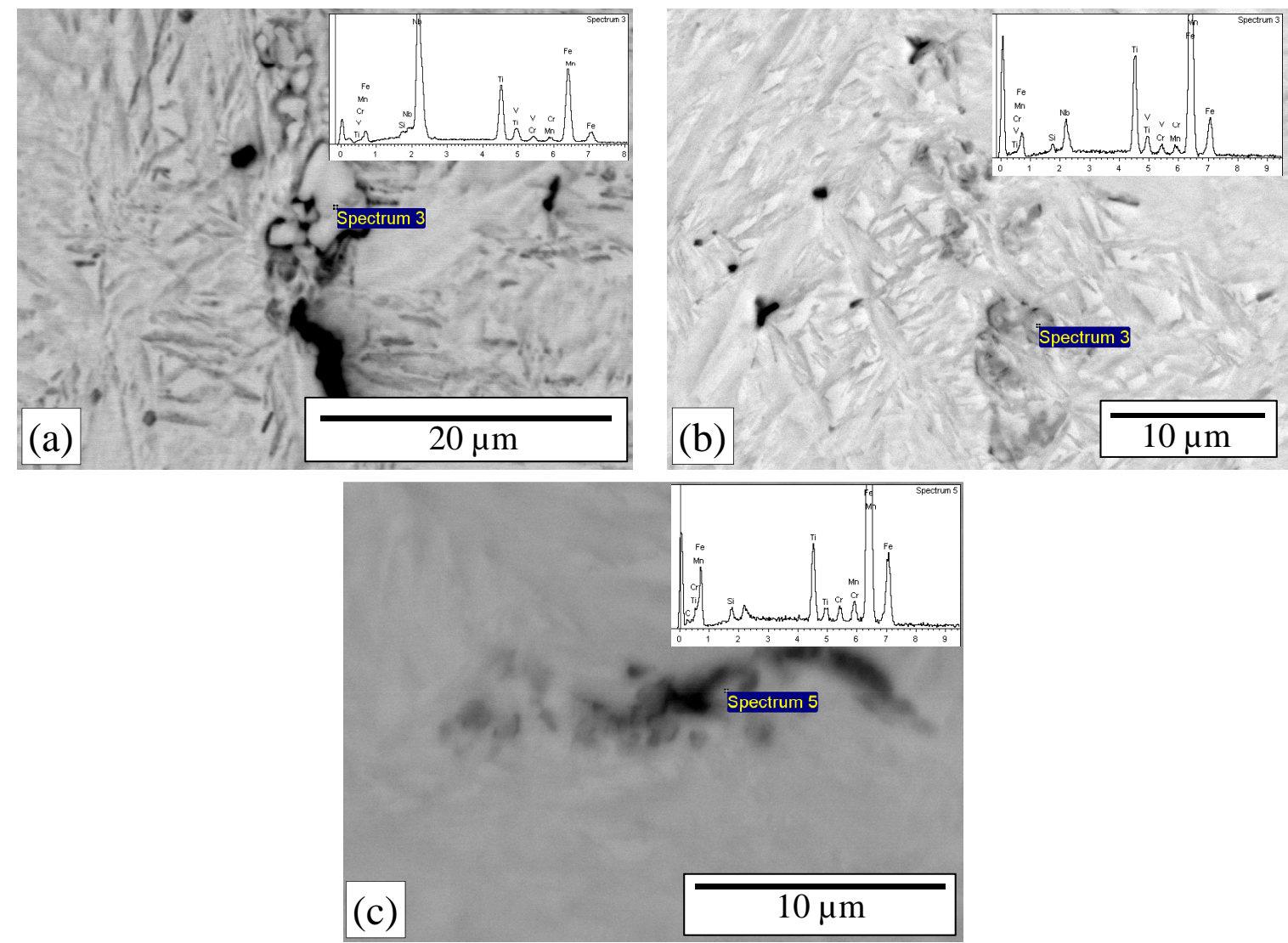

Figure 6.12: EDS for undissolved precipitates in heat treated 'SB02' samples (a) $8 \mathrm{~h}$, (b) $16 \mathrm{~h}$, (c) $32 \mathrm{~h}$.

\subsection{Summary}

Due to the low solubility of niobium and microsegregration during solidification, coarse primary niobium carbides (as large as $\sim 10 \mu \mathrm{m}$ ) precipitate from liquid in the as-cast high carbon pearlitic steels and silicon-rich low-carbon bainitic steels. The largest observed precipitate size decrease with decreasing niobium concentration. To dissolve these primary precipitates in austenite, the reheating temperatures must be atleast greater than the equilibrium NbC solution temperatures. But due to the coarse nature of the primary $\mathrm{NbC}$ precipitates, the dissolution rate is slow and the standard reheating time of $2 \mathrm{~h}$ is not sufficient to dissolve all the precipitates. The dendritic morphology of the precipitates breaks down into spheroids during reheating and hot rolling and the average diameter of the as-rolled precipitates in the investigated alloys is $3 \pm 1 \mu \mathrm{m}$ which is similar to the thickness of the as-cast dendritic precipitates. The dissolved niobium in austenite precipitate during hot rolling and fine in size $(<50 \mathrm{~nm})$ which are suitable to affect austenite recrystallisation. Ideally, 
it is essential to avoid the formation of the primary carbides to mitigate potential problems in brittle fracture and rolling contact fatigue, because once formed, it is very difficult to dissolve these carbides into austenite. During industrial continuous casting of steel, with the advent of technologies like electro-magnetic stirring, dynamic soft reduction etc, the severity of segregation can be expected to be low which may result in undissolved carbides to be more finer and easily dissolvable. 


\section{Chapter 7}

\section{Modelling dissolution kinetics of precipitates}

\subsection{Introduction}

Dissolution of second phase precipitates has been analysed extensively by Thomas and Whelan 117 118 and Aaron 119 120 and reviewed in 121 for different precipitate morphologies (sphere or plate) considering different approximations (exact solution, invariant-size, invariant-field and linearized-gradient approximations) to solve the diffusion field around a dissolving precipitate and also accounting for the interface reaction controlled dissolution 120122 . For virtually all cases of practical interest, it was demonstrated that the invariant-size approximation is the most accurate one 121. The approximation requires a stationary matrix-precipitate interface which restricts the diffusion field to have no memory of the past motion of the interface i.e. the diffusion field around the precipitate is assumed to be the same as that which would exist if the precipitate-matrix interface had been fixed at origin from the start and ignores the effect on the diffusion field of interface motion.

In this chapter, the theoretical aspects of modelling the kinetics of precipitate dissolution are reviewed in the context of dissolution of spherical niobium carbides in austenite at reheating temperatures. The kinetics of solute diffusion in a multicomponent system have been taken into account including capillarity effects due to the spherical shape of the precipitates. 


\subsection{Kinetics of solute diffusion during precipita- tion or dissolution}

The equation for diffusion-controlled dissolution or growth of a spherical precipitate, is given by:

$$
\frac{\partial c}{\partial t}=D\left(\frac{\partial^{2} c}{\partial r^{2}}\right)+\frac{2 D}{r}\left(\frac{\partial c}{\partial r}\right)
$$

where $c=c(r, t)$ is the solute concentration profile ahead of the precipitate as a function of time $t$ and radius $r$. D is the diffusion coefficient of the solute in the matrix 123 124]. The distribution of solute in the matrix for a precipitate of radius $r \geq r^{*}$ is given by 123 :

$$
c(r, t)=c^{m}+\left(c^{\gamma \omega}-c^{m}\right) \frac{r^{*}}{r} \operatorname{erfc}\left(\frac{r-r^{*}}{2 \sqrt{D t}}\right)
$$

where $c^{m}$ is the matrix composition away from the precipitate-matrix interface, $c^{\gamma \omega}$ is the equilibrium matrix composition at the interface. The complementary error function is defined as 123:

$$
\operatorname{erfc}(x)=\frac{2}{\sqrt{\pi}} \int_{x}^{\infty} \exp \left(-t^{2}\right) d t
$$

Thomas and Whelan 117 118 have suggested that dissolution is merely the reverse of growth and the interface velocity of a dissolving spherical precipitate can be calculated from the flux balance at the interface. Due to mass conservation of the solute in the matrix, the flux of solute at the interface is equal to the rate of loss (or, gain in case of precipitate growth) of solute in the precipitate. Flux balance at the interface can be written as:

$$
-4 \pi r^{2}\left(c^{\omega \gamma}-c^{\gamma \omega}\right) \cdot d r=-\left.4 \pi r^{2} D \cdot \frac{\partial c}{\partial r}\right|_{r=r^{*}} . d t
$$

where $c^{\omega \gamma}$ is the carbide composition. $c^{m}$ and $c^{\gamma \omega}$ are the austenite matrix compositions away from the interface and in equilibrium with the carbides, respectively as defined earlier and shown schematically in Figure 7.1][123]. The interface velocity can be calculated as 118]:

$$
\frac{d r}{d t}=-\frac{\Omega D}{r}-\Omega \sqrt{\frac{D}{\pi t}}
$$


The negative sign is for dissolution and $\Omega$ is a supersaturation factor, defined as:

$$
\Omega=\frac{c^{\gamma \omega}-c^{m}}{c^{\omega \gamma}-c^{\gamma \omega}}
$$
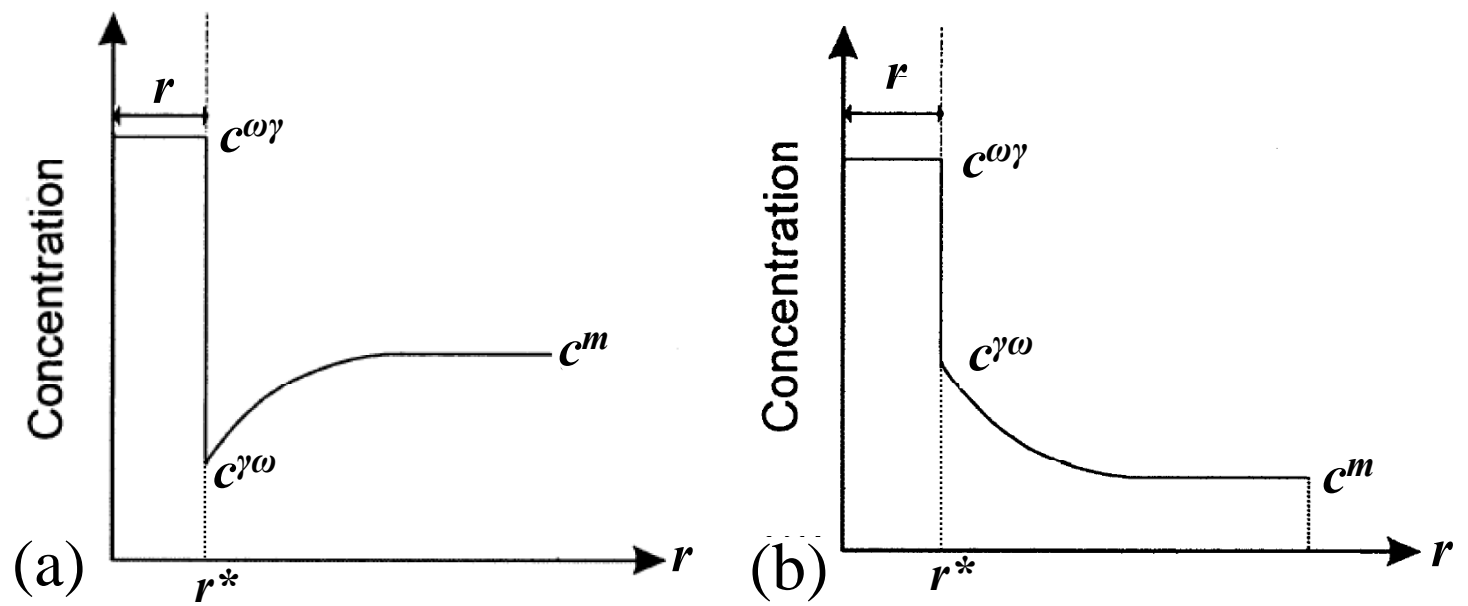

Figure 7.1: Schematic diagram of the solute concentration in the vicinity of (a) a growing precipitate and (b) a dissolving precipitate [123].

When $c^{m}>c^{\gamma \omega}, \Omega$ is negative. So $d r / d t$ is positive and precipitation occurs i.e. $r$ increases (Figure 7.17).

When $c^{m}<c^{\gamma \omega}, \Omega$ is positive. So $d r / d t$ is negative and dissolution occurs i.e. $r$ decreases (Figure 7.1b).

For time $t \equiv\left(t_{1}, t_{2}\right)$, radius $r \equiv\left(r_{1}, r_{2}\right)$ and $\left(t_{2}-t_{1}\right)=\Delta t>0$, equation 7.5 can be numerically solved as:

$$
r_{2}-r_{1}=\Delta r=\left(-\frac{\Omega D}{r}-\Omega \sqrt{\frac{D}{\pi t}}\right) \Delta t
$$

Depending on the sign of $\Omega$; either $r_{2}>r_{1}$ (i.e. precipitation) or $r_{2}<r_{1}$ (i.e. dissolution).

The term in $t^{-1 / 2}$ in equations 7.5 and 7.7 arises from the transient part of the diffusion field in equation 7.2 . At longer times, the transient part becomes negligible and the dissolution process becomes steady state.

$$
\frac{d r}{d t}=-\frac{\Omega D}{r}
$$

Aaron's approach [119 to dissolution kinetics of particles was essentially based on 
the transient part of the diffusion field equation 7.2. Aaron [119 characterized precipitate dissolution by:

$$
\begin{gathered}
\frac{d r}{d t}=-\Omega \sqrt{\frac{D}{t}} \\
r_{2}-r_{1}=\Delta r=-\Omega \sqrt{\frac{D}{t}} \Delta t
\end{gathered}
$$

The term in $t^{1 / 2}$ in equation 7.5 is essentially the same as Aaron's result in equation 7.9 as the discrepancy factor $(1 / \sqrt{\pi})$ in the multiplying factor is very negligible for $\Omega \ll 1$ which is the case in practice. But, Aaron's solution is strictly for a onedimensional diffusion field based on the assumption that the dissolution kinetics of a spherical precipitate in the limit of the early stages of dissolution is the same as that of a planar precipitate, so cannot be applicable for longer times during precipitate dissolution.

According to some other approaches like Fujita [124, Robson [125], Sourmail et al. [126], the interface velocity is given as:

$$
\frac{d r}{d t}=\frac{\alpha_{3}}{2} \sqrt{\frac{D}{t}} \simeq \sqrt{2 \Omega} \sqrt{\frac{D}{t}}
$$

where $\alpha_{3} \simeq \sqrt{2 \Omega}$ is considered to be a three dimensional parabolic rate constant for spherical geometries and defined as:

$$
\begin{aligned}
& \text { For precipitation; } \alpha_{3} \simeq \sqrt{2} \frac{\left(c^{m}-c^{\gamma \omega}\right)^{\frac{1}{2}}}{\left(c^{\omega \gamma}-c^{m}\right)^{\frac{1}{2}}} \\
& \text { For dissolution; } \alpha_{3} \simeq-\sqrt{2} \frac{\left(c^{\gamma \omega}-c^{m}\right)^{\frac{1}{2}}}{\left(c^{\omega \gamma}-c^{m}\right)^{\frac{1}{2}}}
\end{aligned}
$$

For time $t \equiv\left(t_{1}, t_{2}\right)$, radius $r \equiv\left(r_{1}, r_{2}\right)$ and $\left(t_{2}-t_{1}\right)=\Delta t>0$, equation 7.11 can also be numerically solved as:

$$
r_{2}-r_{1}=\Delta r=\frac{\alpha_{3}}{2} \sqrt{\frac{D}{t}} \Delta t
$$

Depending on the sign of $\alpha_{3}$; either $r_{2}>r_{1}$ (i.e. precipitation) or $r_{2}<r_{1}$ (i.e. dissolution). 


\subsubsection{Theory of multi-component diffusion}

During isothermal diffusion-controlled carbide precipitation or dissolution in binary alloys, the local equilibrium compositions are given by an unique tie-line which passes through average solute concentration $(\bar{c})$ in the alloy (Figure $7.2 \mathrm{a}$ ). The concentration profile just ahead of the precipitating/dissolving carbides is already shown in Figure 7.1. The conservation condition for local equilibrium to be maintained is given by:

$$
\left(c^{\omega \gamma}-c^{\gamma \omega}\right) \frac{d r}{d t}=-\left.D\left(\frac{\partial c}{\partial r}\right)\right|_{r^{*}}
$$

where $\frac{d r}{d t}$ is the interface velocity and $\left.\left(\frac{\partial c}{\partial r}\right)\right|_{r^{*}}$ is the solute concentration gradient at the interface at position $r^{*} 111$.

For ternary systems like $\mathrm{Fe}-\mathrm{Nb}-\mathrm{C}$ alloy, the tie-line will not in general pass through $\bar{c}$ because it is necessary to simultaneously satisfy two conservation equations at the interface, one each for niobium and carbon which diffuse at very different rates:

$$
\begin{aligned}
& \left(c_{\mathrm{C}}^{\omega \gamma}-c_{\mathrm{C}}^{\gamma \omega}\right) \frac{d r}{d t}=-\left.D_{\mathrm{C}}\left(\frac{\partial c}{\partial r}\right)\right|_{r^{*}} \\
& \left(c_{\mathrm{Nb}}^{\omega \gamma}-c_{\mathrm{Nb}}^{\gamma \omega}\right) \frac{d r}{d t}=-\left.D_{\mathrm{Nb}}\left(\frac{\partial c}{\partial r}\right)\right|_{r^{*}}
\end{aligned}
$$

However, according to the phase rule there is an additional degree of freedom in a ternary alloy which allows many tie-lines at any given temperature (Figure $7.2 \mathrm{~b}$ ). It is then possible to select an unique tie-line which is able to satisfy both the solute conservation equations in spite of the fact that $D_{\mathrm{C}} \gg D_{\mathrm{Nb}}$, while at the same time maintaining local equilibrium. For a practically relevant solution, partitioning local equilibrium (PLE) condition prevails. The tie-line is selected in a way that the gradient of carbon is reduced to such an extent that the flux of carbon is reduced to a level consistent with that of niobium and $c_{\mathrm{C}}^{\gamma \omega} \approx c_{\mathrm{C}}^{m}$. The corresponding $c_{\mathrm{Nb}}^{\gamma \omega}$ value can be calculated from the solubility data. Detailed description of tie-line selection and the construction of Figure $7.2 \mathrm{~b}$ is given in 111 124]. 

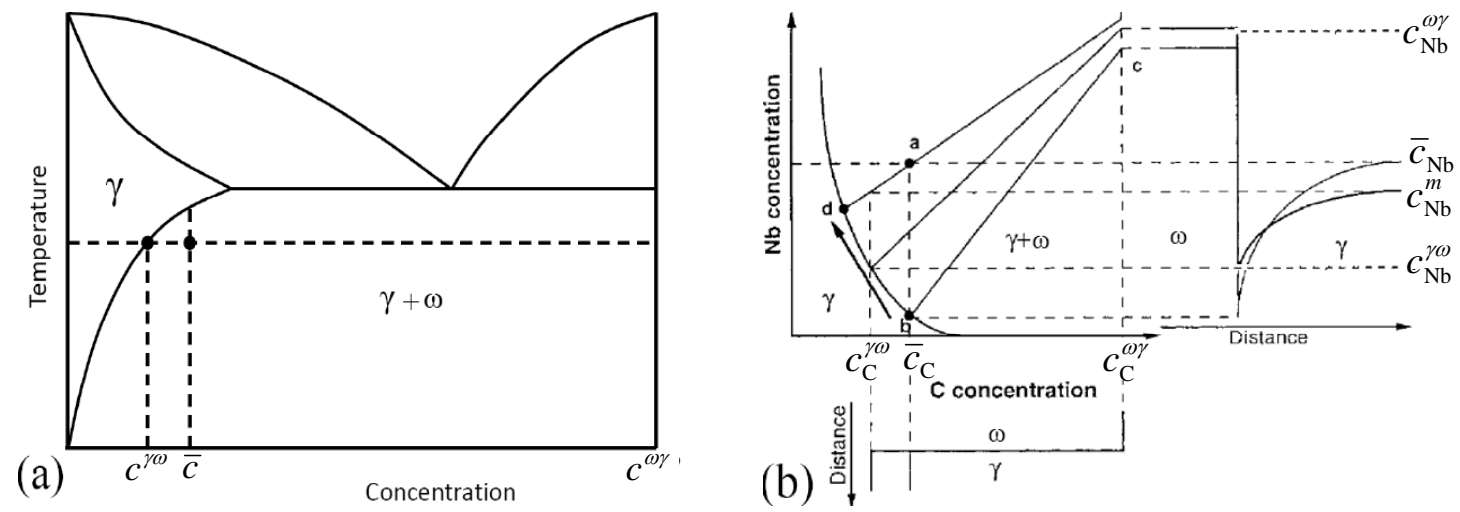

Figure 7.2: Schematic diagram for tie-line selection during precipitate growth for (a) binary system and (b) Fe-Nb-C ternary system 111 124].

It must be noted that at the beginning of precipitation, $\bar{c}=c^{m}$. As precipitation progress and the volume fraction $V$ increases, solute is depleted from the matrix during 'soft impingement' and $c^{m}$ decreases. The mean field approximation 111 , 124 125 is used to calculate the instantaneous matrix composition as:

$$
\begin{gathered}
c_{\mathrm{C}}^{m}=\bar{c}_{\mathrm{C}}-\frac{V\left(c_{\mathrm{C}}^{\omega \gamma}-\bar{c}_{\mathrm{C}}\right)}{(1-V)} \\
c_{\mathrm{Nb}}^{m}=\bar{c}_{\mathrm{Nb}}-\frac{V\left(c_{\mathrm{Nb}}^{\omega \gamma}-\bar{c}_{\mathrm{Nb}}\right)}{(1-V)}
\end{gathered}
$$

But at the begining of dissolution, $c^{m}<\bar{c}$ as there is a certain volume of precipitates already present. As dissolution proceeds, $V$ decreases and $c^{m}$ increases. At the end of complete dissolution, $c^{m}=\bar{c}$.

Thomas and Whelan's [117] and Aaron's [121 treatments were essentially based on dissolution into infinite matrix which resulted in a constant supersaturation $\Omega$ throughout the dissolution process and the interface velocity equations 7.5 and 7.9 was integrated to calculate the final precipitate size. But if 'soft-impingement' is taken into account, then $\Omega$ is no longer constant and the velocity equations are to be solved numerically as in equations $7.7,7.10$ and 7.13 .

\subsubsection{Capillarity effect}

To account for the Gibbs-Thompson effect due to curved interface of spherical precipitates, the equilibrium austenite composition changes as:

$$
\left(c_{\mathrm{Nb}}^{\gamma \omega}\right)_{r}=c_{\mathrm{Nb}}^{\gamma \omega}\left[1+\frac{\sigma}{k_{B} T} \frac{2 V_{M}^{\omega}}{r} \frac{1-c_{\mathrm{Nb}}^{\gamma \omega}}{c_{\mathrm{Nb}}^{\omega \gamma}-c_{\mathrm{Nb}}^{\gamma \omega}}\right]
$$


where $\sigma=$ interfacial energy of the carbides in $\mathrm{J} \mathrm{m}^{-2}, k_{B}=$ Boltzmann constant in $\mathrm{J} \mathrm{K}^{-1}, V_{M}^{\omega}=$ volume per unit NbC molecule in $\mathrm{m}^{3}$ per molecule, $r=$ radius in $\mathrm{m}$ [111] when the concentrations are in terms of mole fraction. So to incorporate the capillarity effect, $\Omega$ in equation 7.6 should be defined as:

$$
\Omega=\frac{c_{\mathrm{Nb}}^{m}-\left(c_{\mathrm{Nb}}^{\gamma \omega}\right)_{r}}{c_{\mathrm{Nb}}^{\omega \gamma}-\left(c_{\mathrm{Nb}}^{\gamma \omega}\right)_{r}}
$$

For microalloyed carbides like $\mathrm{NbC}$, it can be reasonably assumed that changes in the carbide composition $c_{\mathrm{Nb}}^{\omega \gamma}$ due to capillarity can be neglected because the composition range of a carbide is limited. Also, $\left(c_{\mathrm{Nb}}^{\gamma \omega}\right)_{r} \ll c_{\mathrm{Nb}}^{\omega \gamma}$. So, the denominator in equation 7.18 is effectively constant and the supersaturation $\Omega$ will depend on the competition between matrix niobium content away from the interface, $c_{\mathrm{Nb}}^{m}$ and the equilibrium niobium content at the interface adjusted for capillarity, $\left(c_{\mathrm{Nb}}^{\gamma \omega}\right)_{r}$.

\subsection{The model}

A theoretical model for dissolution of niobium carbides in austenite during isothermal heat-treatment above the equilibrium dissolution temperature, is developed based upon the equations outlined in the previous section for a set of identical precipitates with similar initial radius. The flowchart of the computer program developed is shown in Figure 7.3 . The input variables are explained as follows:

- Average alloy composition: $\bar{c}(\mathrm{wt} \%)=\left(\bar{c}_{\mathrm{C}}, \bar{c}_{\mathrm{Nb}}\right)$ where $\bar{c}_{\mathrm{C}}=\mathrm{wt} \%$ carbon; $\bar{c}_{\mathrm{Nb}}$ $=\mathrm{wt} \%$ niobium. The calculations require the compositions to be used in terms of mole-fraction for unit compatibility. The conversion between weightpercentages and mole-fractions can be calculated as follows:

$$
\bar{x}_{\mathrm{C}}=\text { mole fraction carbon }=\frac{\frac{\bar{c}_{\mathrm{C}}}{A_{\mathrm{C}}}}{\frac{\bar{c}_{\mathrm{C}}+\frac{\bar{c}_{\mathrm{Nb}}}{A_{\mathrm{C}}}+\frac{100-\bar{c}_{\mathrm{C}}-\bar{c}_{\mathrm{Nb}}}{A_{\mathrm{Fe}}}}{\bar{x}_{\mathrm{Nb}}=\text { mole fraction niobium }=\frac{\frac{\bar{c}_{\mathrm{Nb}}}{A_{\mathrm{Nb}}}}{\frac{\bar{c}_{\mathrm{C}}}{A_{\mathrm{C}}}+\frac{\bar{c}_{\mathrm{Nb}}}{A_{\mathrm{Nb}}}+\frac{100-\bar{c}_{\mathrm{C}}-\bar{c}_{\mathrm{Nb}}}{A_{\mathrm{Fe}}}}}}
$$

where $\bar{x}=\left(\bar{x}_{\mathrm{C}}, \bar{x}_{\mathrm{Nb}}\right)$ is the average alloy composition in mole-fractions, $A_{\mathrm{Fe}}$ $=55.845, A_{\mathrm{C}}=12.01, A_{\mathrm{Nb}}=92.91$ are the atomic weights of $\mathrm{Fe}, \mathrm{C}, \mathrm{Nb}$ respectively. 


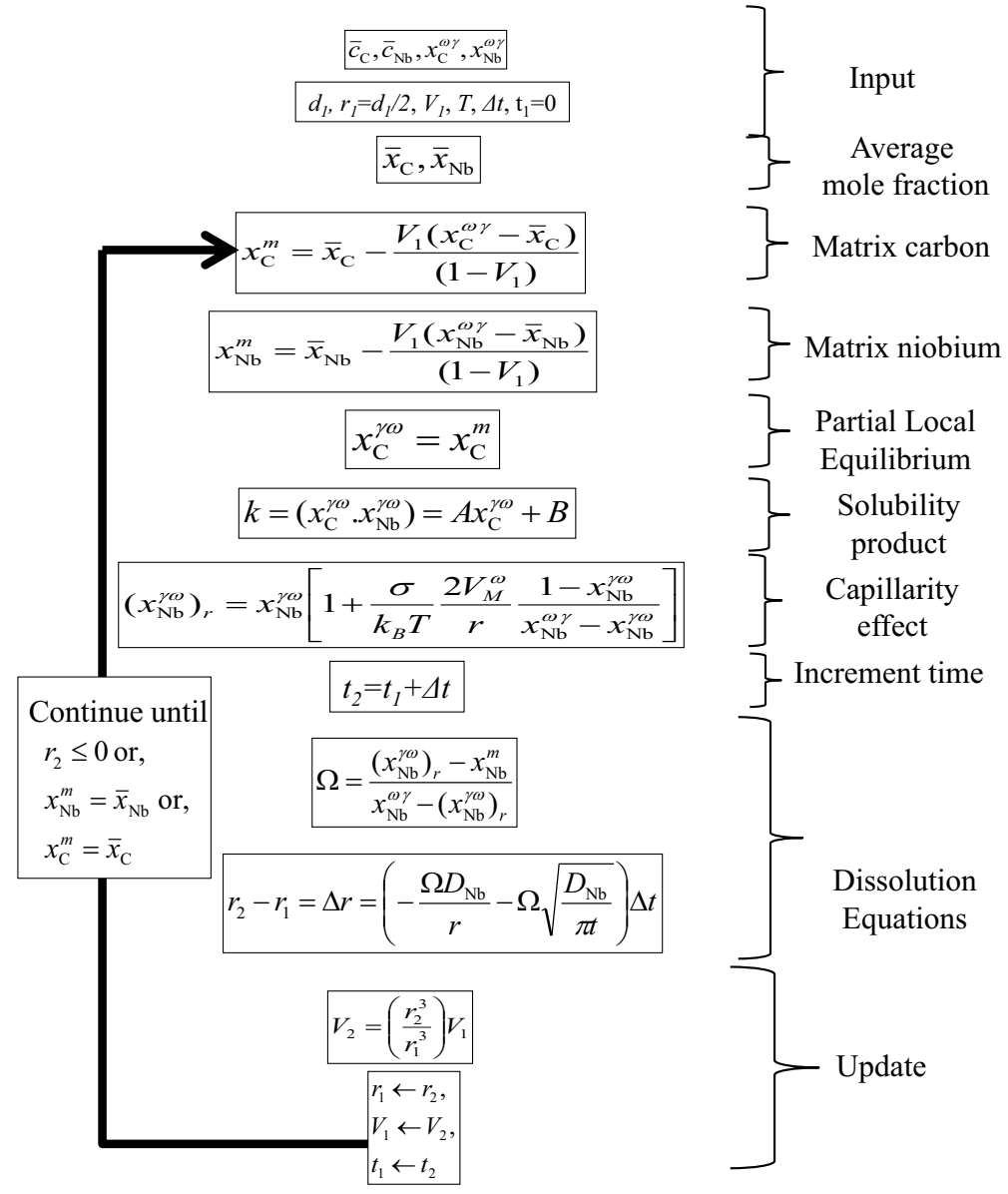

Figure 7.3: Flowchart of the computer program for the dissolution kinetics of identical sized precipitates.

- Carbide composition: $x^{\omega \gamma}=\left(x_{\mathrm{C}}^{\omega \gamma}, x_{\mathrm{Nb}}^{\omega \gamma}\right)$ where $x_{\mathrm{C}}^{\omega \gamma}$ and $x_{\mathrm{Nb}}^{\omega \gamma}$ are the molefractions of $\mathrm{C}$ and $\mathrm{Nb}$ respectively in NbC. Superscript ' $\omega \gamma$ ' denotes composition in carbide equilibrium with austenite.

- Temperature $T$ in Kelvin.

- Solubility product: The solubility product data are calculated from MatCalc 'mc_sample_fe.tdb' database. When dealing with mole-fraction compositions, the solubility product also needs to be expressed in terms of equilibrium molefractions in austenite, $x^{\gamma \omega}=\left(x_{\mathrm{C}}^{\gamma \omega}, x_{\mathrm{Nb}}^{\gamma \omega}\right)$ where $x_{\mathrm{C}}^{\gamma \omega}$ and $x_{\mathrm{Nb}}^{\gamma \omega}$ are mole-fractions of $\mathrm{C}$ and $\mathrm{Nb}$ respectively in equilibrium austenite. For the present model, the solubility product $k_{T}$ is defined as a function of carbon content at a constant temperature $T$. 


$$
k_{T}=\left[x_{\mathrm{C}}^{\gamma \omega}\right]\left[x_{\mathrm{Nb}}^{\gamma \omega}\right]=A\left[x_{\mathrm{C}}^{\gamma \omega}\right]+B
$$

where $A$ and $B$ are constants. As shown earlier in section 2.4.1, the $\mathrm{NbC}$ solubility in austenite depends on the composition and so, $A$ and $B$ values for the investigated alloys are listed in Table 7.1. The Fe-C-Nb composition indicates solubility in only ternary $\mathrm{Fe}-\mathrm{C}-\mathrm{Nb}$ austenite without other alloying elements.

Table 7.1: Solubility product constants for different alloys at $T=1300^{\circ} \mathrm{C}$.

\begin{tabular}{ccccc}
\hline Composition & Temperature $/{ }^{\circ} \mathrm{C}$ & Valid range $(w t \% \mathrm{C})$ & $\mathrm{A}($ mole-fraction) & $\mathrm{B}$ (mole-fraction $)^{2}$ \\
\hline Fe-C-Nb & 1300 & $0.7-0.9$ & $1.196 \times 10^{-4}$ & $5.107 \times 10^{-6}$ \\
P7802 & 1300 & $0.7-0.9$ & $1.065 \times 10^{-4}$ & $4.591 \times 10^{-6}$ \\
P7901 & 1200 & $0.7-0.9$ & $5.016 \times 10^{-5}$ & $2.109 \times 10^{-6}$ \\
B4002 & 1300 & $0.3-0.5$ & $6.690 \times 10^{-5}$ & $3.484 \times 10^{-6}$ \\
B4101 & 1200 & $0.3-0.5$ & $2.950 \times 10^{-5}$ & $1.418 \times 10^{-6}$ \\
B2102 & 1200 & $0.1-0.3$ & $3.079 \times 10^{-5}$ & $1.191 \times 10^{-6}$ \\
\hline
\end{tabular}

- Initial precipitate diameter, $d_{1}$ (in $\mathrm{m}$ ), so radius, $r_{1}=d_{1} / 2$ (in $\mathrm{m}$ ) and initial precipitate volume fraction, $V_{1}$. $V_{1}$ can be measured experimentally or can be approximated as the maximum equilibrium volume-fraction possible for the precipitate in austenite as calculated from MatCalc. If $N_{r}$ is the total number of precipitates of radius $r$ per unit volume; then the volume fraction for spherical particles becomes:

$$
V=N_{r}\left(\frac{4}{3} \pi r^{3}\right)
$$

As all $N_{r}$ number of precipitates have similar initial radius $r_{1}$, their dissolution behaviour will be similar and $N_{r}$ will remain constant during dissolution. After time $t$, volume fraction $V_{t}$ and radius $r_{t}$ is given by:

$$
\frac{V_{t}}{V_{1}}=\frac{r_{t}^{3}}{r_{1}^{3}}
$$

- Time step $d t$ in seconds.

- Diffusion coefficient of niobium in austenite, $D_{\mathrm{Nb}}\left(\right.$ in $\left.\mathrm{m}^{2} \mathrm{~s}^{-1}\right)$ at temperature $T$ is defined by:

$$
D_{\mathrm{Nb}}=D_{0} \exp \left(-\frac{Q}{R T}\right)
$$


where $D_{0}=$ Diffusion pre-exponent factor for niobium (in $\left.\mathrm{m}^{2} \mathrm{~s}^{-1}\right), Q=$ Diffusion activation energy for niobium (in $\mathrm{J} \mathrm{mol}^{-1}$ ) and $R$ is the Gas constant $(=8.314$ $\mathrm{J} \mathrm{mol}^{-1} \mathrm{~K}^{-1}$ ). Table 7.2 lists $D_{0}$ and $Q$ values reported in different literature for niobium diffusion in austenite and corresponding complete dissolution time for precipitates of $2 \mu \mathrm{m}$ diameter at $1300{ }^{\circ} \mathrm{C}$ as calculated by the described model. Values used by Fujita et al. [127] (reference [11] of [111]) deviates substantially from the rest of the literature reported values as shown in Figure 7.4. The calculated complete dissolution times are about similar for the other reported diffusion coefficient values. For representative purpose, the values reported by San Martin et al. [128] are used for the current study.

Table 7.2: Diffusion coefficient parameters for niobium diffusion in austenite and corresponding complete dissolution time for precipitates of $2 \mu \mathrm{m}$ diameter at 1300 ${ }^{\circ} \mathrm{C}$.

\begin{tabular}{lcccc}
\hline Reference & $D_{0} / \mathrm{m}^{2} \mathrm{~s}^{-1}$ & $Q / \mathrm{J} \mathrm{mol}^{-1}$ & $D_{\mathrm{Nb}} / \mathrm{m}^{2} \mathrm{~s}^{-1}$ at $1300^{\circ} \mathrm{C}$ & Dissolution time $/ \mathrm{h}$ \\
\hline Gladman, 1997 113 & 0.053 & 344600 & $1.91 \times 10^{-13}$ & 1.93 \\
Fujita, 2001 127 & 0.000056 & 286000 & $1.78 \times 10^{-14}$ & 20.61 \\
San Martin, 2004 128] & 0.00093 & 291966 & $1.87 \times 10^{-13}$ & 1.96 \\
Oikawa, 1983 129 & 0.00056 & 286000 & $1.78 \times 10^{-13}$ & 2.06 \\
Subramanian, 1985 130] & 0.000492 & 285000 & $1.69 \times 10^{-13}$ & 2.18 \\
Lechuk, 2000 131] & 0.053 & 343000 & $2.16 \times 10^{-13}$ & 1.70 \\
Kurokawa, 1983 132] & 0.000075 & 264000 & $1.28 \times 10^{-13}$ & 2.87 \\
Xu, 2011 133] & 0.000083 & 266500 & $1.17 \times 10^{-13}$ & 3.14 \\
\hline *Values used in the current study.
\end{tabular}

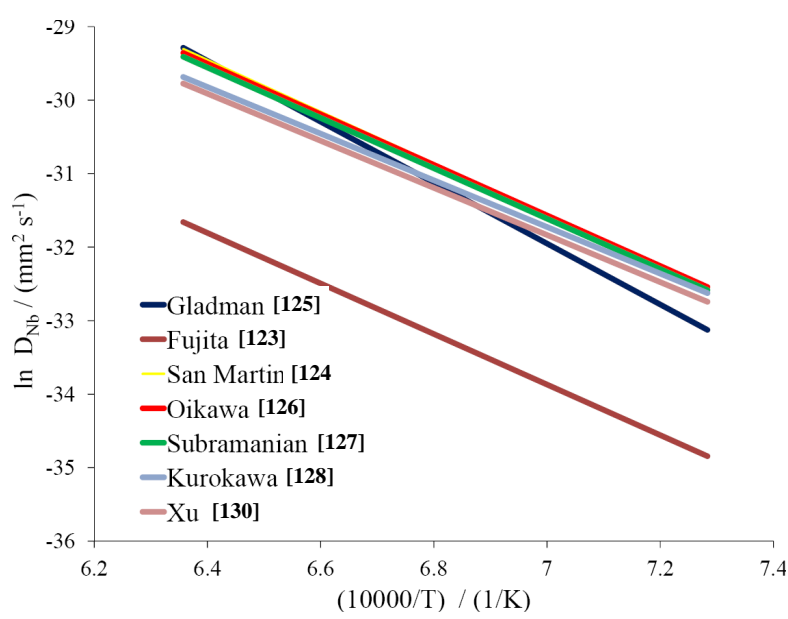

Figure 7.4: Different values for diffusion coefficient of niobium in austenite in literature. 


\subsection{Model results and discussion}

Figure 7.5 compares dissolution kinetics for $\mathrm{NbC}$ precipitates of initial radius $r_{1}=2 \mu \mathrm{m}$ and volume fraction $V_{1}=0.0002$ in Fe- $0.78 \mathrm{C}-0.02 \mathrm{Nb}$ (wt\%) system at $1300{ }^{\circ} \mathrm{C}$ for different approaches discussed in section 7.2 . The other input values are:

$$
\begin{aligned}
& d t(\mathrm{~s})=10 ; \\
& D_{0}\left(\mathrm{~m}^{2} \mathrm{~s}^{-1}\right)=0.00093, Q\left(\mathrm{~J} \mathrm{~mol}^{-1}\right)=291966 ; \\
& \sigma\left(\mathrm{J} \mathrm{m}^{-2}\right)=1 ; V_{M}^{\omega}\left(\mathrm{m}^{3} \text { per molecule }\right)=2.23 \times 10^{-29} \\
& x^{\omega \gamma}(\text { mole fraction }) \equiv\left(x_{\mathrm{C}}^{\omega \gamma}, x_{\mathrm{Nb}}^{\omega \gamma}\right) \equiv(0.5,0.5) ; \\
& \text { solubility product (in terms of mole fraction): } \\
& \qquad k_{T}=\left[x_{\mathrm{C}}^{\gamma \omega}\right]\left[x_{\mathrm{Nb}}^{\gamma \omega}\right]=1.1969 \times 10^{-4}\left[x_{\mathrm{C}}^{\gamma \omega}\right]+4.5912 \times 10^{-6} ; \\
& \text { Constants: } R=8.314 \mathrm{~J} \mathrm{~mol}^{-1} \mathrm{~K}^{-1} ; k_{B}=1.3806488 \times 10^{-23} \mathrm{~J} \mathrm{~K}^{-1}
\end{aligned}
$$
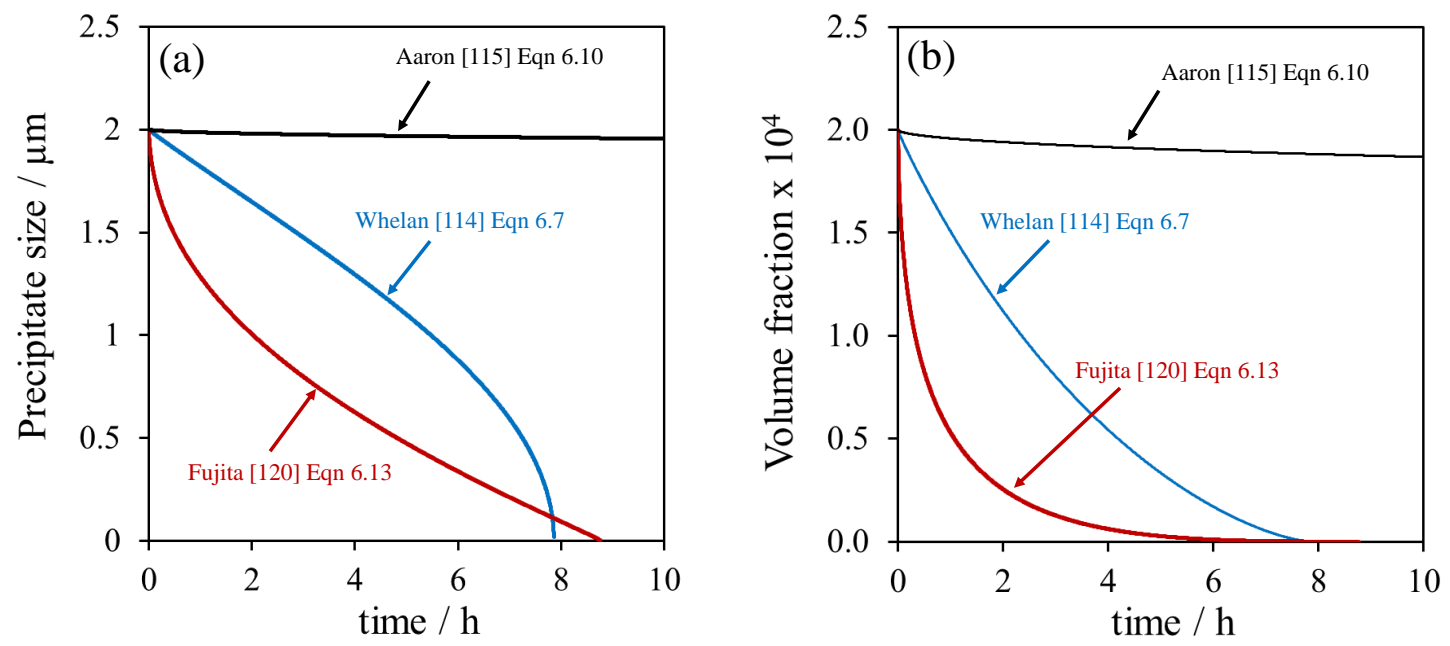

Figure 7.5: Comparison of different dissolution kinetics models for precipitates with initial radius $r_{1}=2 \mu \mathrm{m}$ and initial volume fraction $V_{1}=0.0002$ in Fe-0.78C-0.02Nb (wt\%) system at $1300^{\circ} \mathrm{C}$. Evolution of (a) precipitate size and (b) precipitate volume fraction during dissolution. Total number of precipitates $N_{r}$ remains constant during dissolution.

As discussed earlier, Aaron's solution is strictly for a one-dimensional diffusion field based on the assumption that the dissolution kinetics of a spherical precipitate in the limit of the early stages of dissolution is the same as that of a planar precipitate, so cannot be applicable for longer times during precipitate dissolution. Both Fujita's and Whelan's solutions are for three dimensional spherical precipitates, but the kinetics are different. Now, onwards the results are discussed in terms of diffu- 
sion controlled dissolution kinetics of spherical precipitates according to Whelan's approach using equation 7.5. Figure 7.6 shows the variation of different parameters during dissolution of a precipitate of $2 \mu \mathrm{m}$ radius and initial volume fraction $V_{1}=0.0002$. Initially, supersaturation $\Omega$ decrease as dissolution progresses and the matrix solute content $\left(x^{m}\right)$ increases. The increase in equilibrium matrix composition at interface $\left(x^{\gamma \omega}\right)_{r}$ with decreasing precipitate size due to capillarity effect, is negligible initially. But when the precipitate size is sufficiently small towards the end of dissolution, $\left(x^{\gamma \omega}\right)_{r}$ increases rapidly and as a result $\Omega$ starts to increase. This increases the dissolution rate of the precipitates and finer precipitates dissolve much faster.

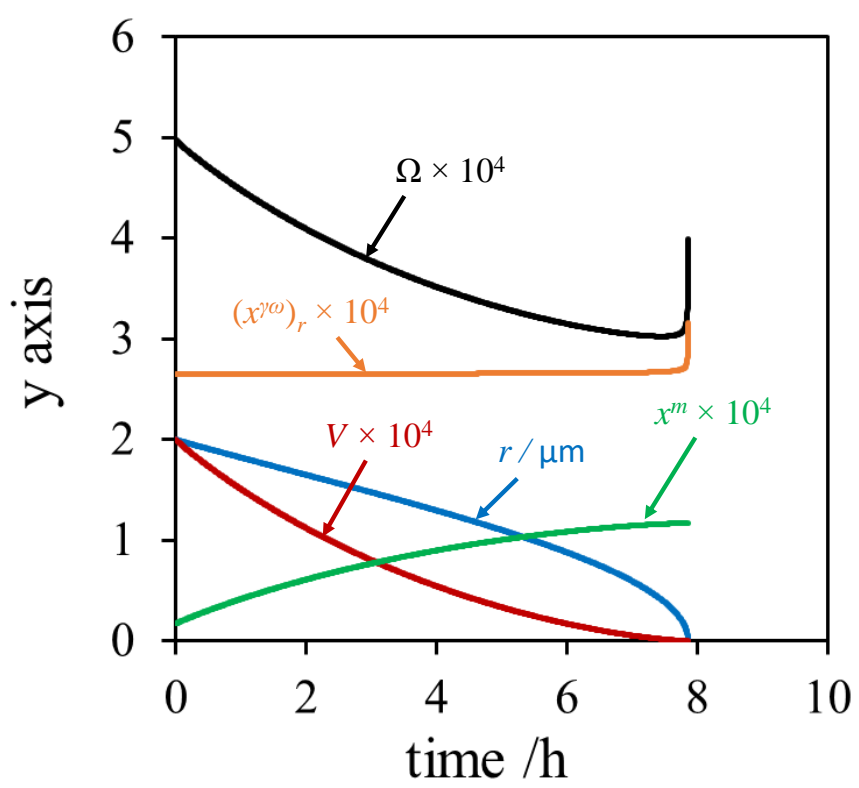

Figure 7.6: Variation of radius $(r)$ in $\mu \mathrm{m}$, volume fraction $(V)$, supersaturation $(\Omega)$, niobium composition in austenite ( $x^{m}$ in mol fraction) and equilibrium niobium at the interface $\left[\left(x^{\gamma \omega}\right)_{r}\right.$ in mol fraction] for precipitates of $2 \mu \mathrm{m}$ radius and initial volume fraction $V_{1}=0.0002$ in Fe- $0.78 \mathrm{C}-0.02 \mathrm{Nb}$ (wt\%) system.

\subsubsection{Effect of initial precipitate size}

For a similar initial volume fraction of precipitates $\left(V_{1}=0.0002\right)$, the complete dissolution time increases with increasing precipitate size as shown in Figure 5.13. This is the direct result of the interface velocity being inversely proportional to precipitate size. Before dissolution starts, as the initial radius $r_{1}$ is different in each case, total number of precipitates $N_{r}$ will also be different for each initial radius to keep the initial volume fraction identical for each scenario. During dissolution of similar sized precipitates, $N_{r}$ remains constant and precipitate volume fraction decrease. 

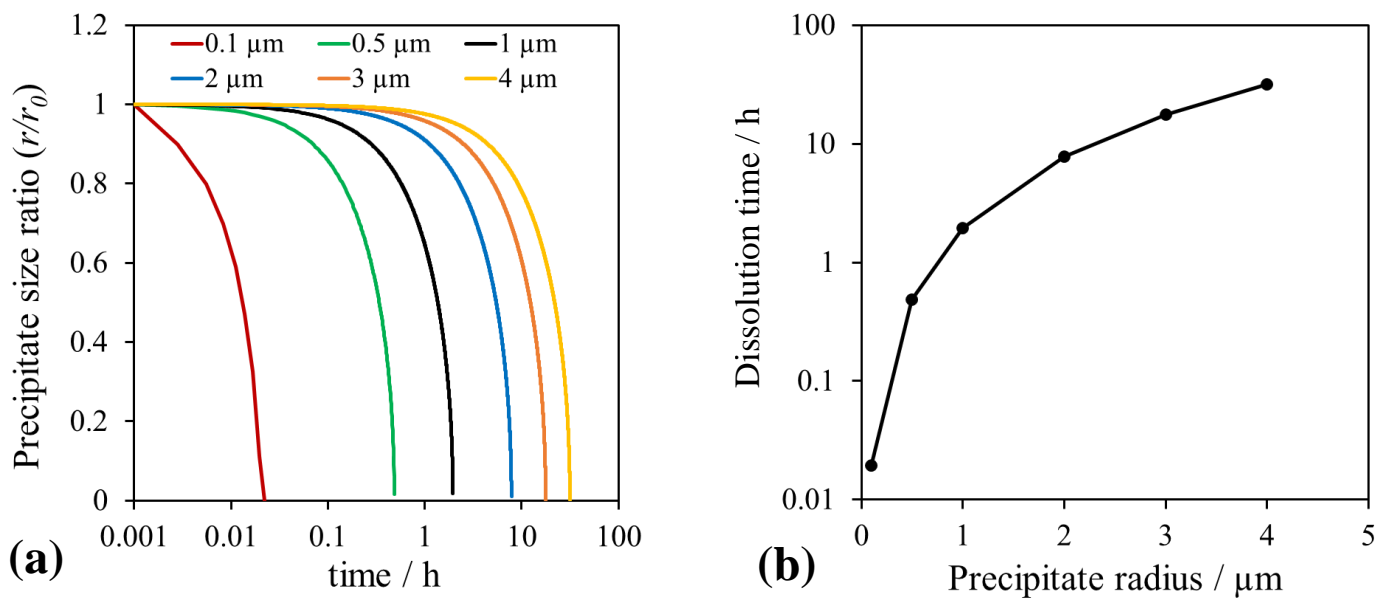

Figure 7.7: (a) Evolution of precipitate size ratio with dissolution time, (b) complete dissolution time for different initial precipitate sizes with similar initial volume fraction $\left(V_{1}=0.0002\right)$. For each initial radius $r_{1}$ with similar $V_{1}$, total number of precipitates $N_{r}$ is different which remains constant during dissolution.

\subsubsection{Effect of initial volume fraction and interfacial energy}

For precipitates with identical initial size $\left(r_{1}=2 \mu \mathrm{m}\right)$, the complete dissolution time decreases with increasing initial precipitate volume fraction $V_{1}$ as shown in Figure 5.14a. This can be explained by the fact that precipitation removes solute from the matrix. So at large volume fraction, there will be a greater supersaturation for dissolution. For each initial volume fraction, $N_{r}$ will be different which remains constant during the course of dissolution. The maximum initial volume fraction is limited by the total diffusing solute i.e. niobium content in the system. Interface energy $(\sigma)$ values have a small effect on the dissolution kinetics as shown in Figure $5.14 \mathrm{~b}$. 

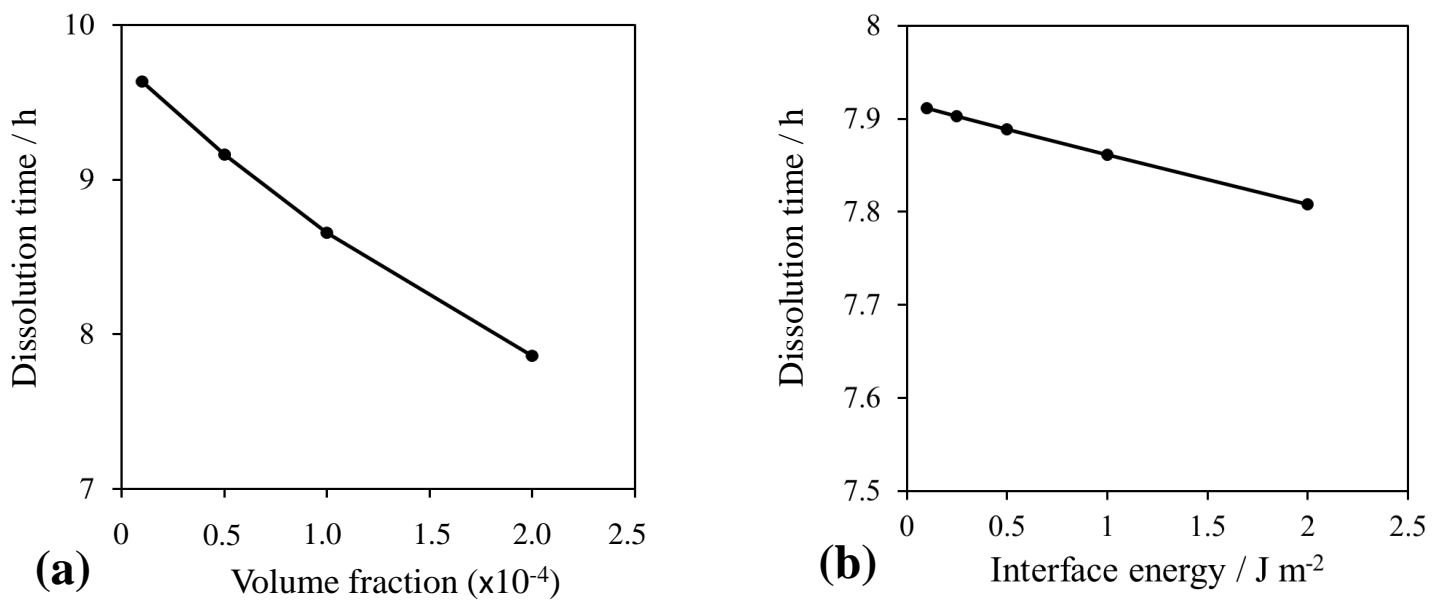

Figure 7.8: (a) Complete dissolution time for different initial volume fraction $\left(V_{1}\right)$ of precipitates with similar initial size $\left(r_{1}=2 \mu \mathrm{m}\right)$. For each $V_{1}$ with similar $r_{1}$, total number of precipitates $N_{r}$ is different which remains constant during dissolution. (b) Effect of interfacial energy $(\sigma)$ on dissolution time for $V_{1}=0.0002$ and $r_{1}=2 \mu \mathrm{m}$.

\subsubsection{Effect of precipitate size distribution}

The model can be modified to take account of a size distribution of precipitates instead of a single precipitate size-class by the following equations. A normal distribution of precipitates can be defined as [123]:

$$
\begin{gathered}
\rho_{n_{i}}=\frac{V}{\frac{4}{3} \pi \sum\left(\rho_{n_{i}}^{*} r_{i}^{3}\right)} \rho_{n_{i}}^{*} \\
\rho_{n_{i}}^{*}=\frac{1}{\sqrt{2 \pi} \sigma_{n} r_{i}} \exp \left(-\frac{\left(r_{i}-\bar{r}\right)^{2}}{2 \sigma_{n}^{2}}\right)
\end{gathered}
$$

where $r_{i}$ is the radius of $i$ th particle, $\rho_{n_{i}}$ is the probability density of a normal particle size distribution with volume fraction $V, \bar{r}$ is the arithmetic mean of the distribution and $\sigma_{n}$ is the standard deviation.

But the experimentally measured precipitate sizes are not in normal distribution but develop a log-normal distribution (Figure 5.3) which can be defined as [123]:

$$
\begin{gathered}
\rho_{l_{i}}=\frac{V}{\frac{4}{3} \pi \sum\left(\rho_{l_{i}}^{*} r_{i}^{3}\right)} \rho_{l_{i}}^{*} \\
\rho_{l_{i}}^{*}=\frac{1}{\sqrt{2 \pi} \sigma_{l} r_{i}} \exp \left(-\frac{\left(\ln r_{i}-\mu\right)^{2}}{2 \sigma_{l}^{2}}\right)
\end{gathered}
$$

where $\rho_{l}$ is the probability density of a log-normal particle size distribution, $\mu$ is the arithmetic mean of the distribution of $\ln r_{i}$ and $\sigma_{l}$ is the standard deviation 
of the normal distribution of $\ln r_{i}$. Figure 5.15 shows a representative probability density distribution calculated from the experimental precipitate size measurement (Figure 5.3) for P7901. The experimentally measured size was based on the largest dimension of the precipitates so the radius is calculated as half of the experimentally measured size.

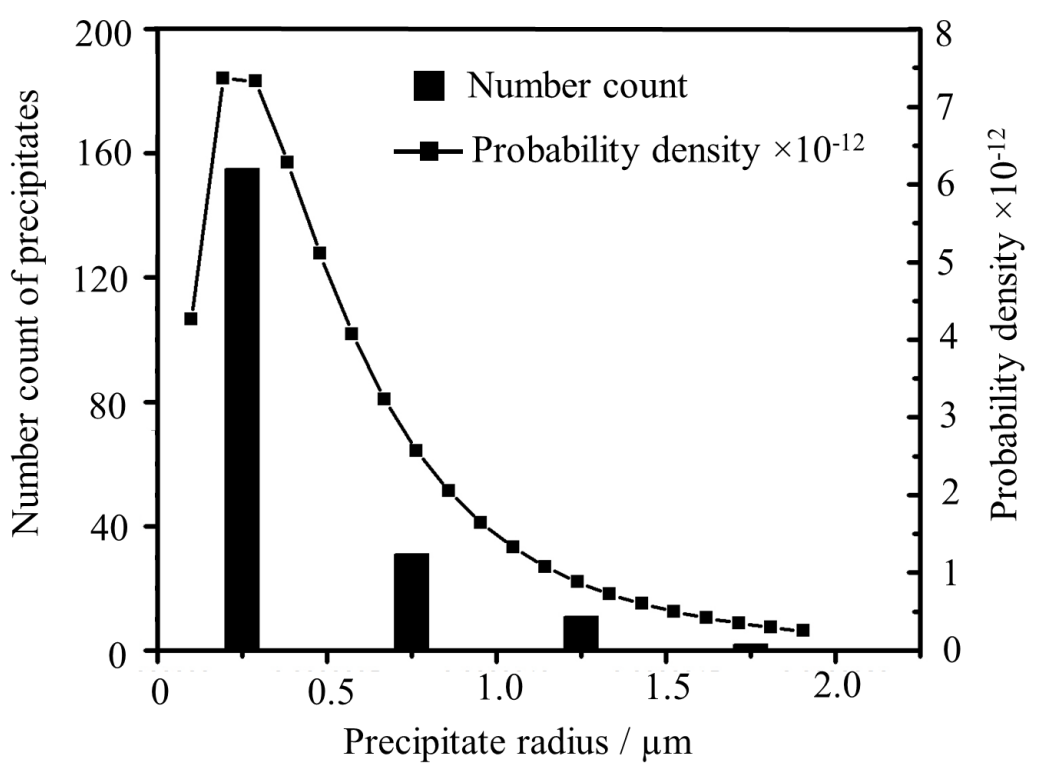

Figure 7.9: Probability density distribution calculated from experimentally measured size distribution for P7901 with initial volume fraction $V_{1}=0.0001$.

As the dissolution rate is inversely proportional to the radius and also due to capillarity effect, the finer precipitates dissolve faster and niobium in austenite increases. Thus, the already slowly dissolving coarser precipitates gradually dissolve under decreasing supersaturation. The complete dissolution time for all the precipitates is eventually controlled by the maximum size in the distribution.

\subsubsection{Effect of temperature and composition}

The dissolution temperature must be higher than the equilibrium niobium carbide formation temperature in the alloys. Higher the temperature, higher is niobium solubility in austenite and higher will be the supersaturation. The alloying elements also affect niobium solubility in austenite and in turn affect the supersaturation. Solubility data from Table 5.1 and the calculated size distribution from equation 5.23 are utilised to predict the dissolution kinetics in the investigated alloys and showed in Figure 5.16. The initial precipitate volume fraction is limited by the equilibrium niobium carbide volume fraction in the alloys. 

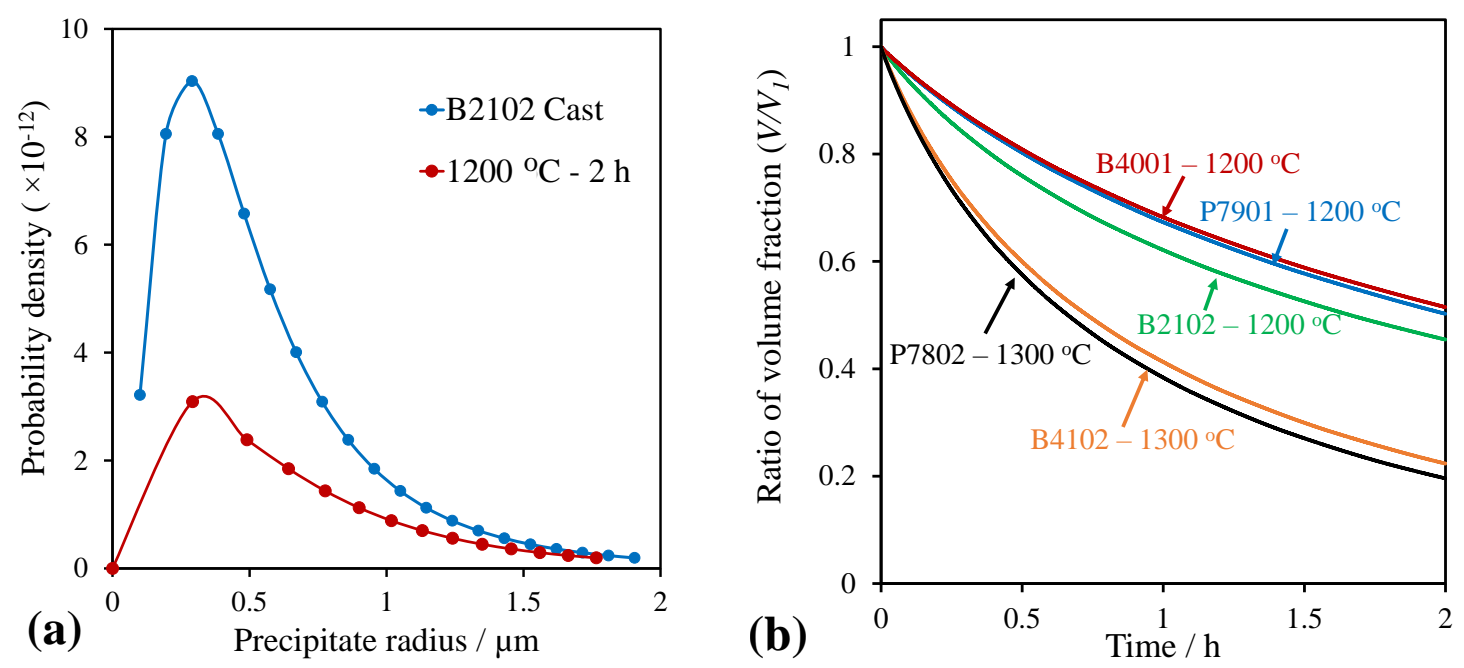

Figure 7.10: (a) Evolution of precipitate size distribution for B2102 cast, (b) Evolution of precipitate volume fraction during dissolution of precipitates with log-normal size distribution.

\subsection{Summary}

A theoretical model can be formulated to analyse the multi-component diffusion controlled dissolution kinetics of the niobium carbides and to study the evolution of niobium carbide volume fraction during dissolution which is otherwise experimentally difficult to study because of very low volume fractions involved. The dissolution rate is inversely proportional to the precipitate size and more coarse is the precipitate, lower is the dissolution rate. The primary carbide volume fraction is small which results in austenite being less depleted of niobium. This decreases the supersaturation i.e. the diffusion gradient ahead of the precipitate-matrix interface is shallow which also reduces the dissolution rate. 


\section{Chapter 8}

\section{Hot deformation of austenite and dilatometry}

\subsection{Introduction}

The no-recrystallisation temperature $\left(T_{n R}\right)$ is critical in investigating the effect of niobium on austenite hot deformation in high carbon pearlitic and Si-rich cementitefree bainitic alloys. In theory, dissolved niobium in reheated austenite would precipitate during subsequent hot rolling and inhibit austenite recrystallisation by pinning the austenite grain boundaries. $T_{n R}$ is the temperature below which deformed austenite grains will not recrystallise for any given holding time 113. Several empirical equations are available to predict $T_{n R}$ temperatures 134 137 as well as recrystallisation kinetics of microalloyed austenite 138 141 but most of these equations are based on low to medium carbon $(0.01-0.5 \mathrm{wt} \% \mathrm{C})$ steels and also seldom applicable for high silicon $(>1 \mathrm{wt} \% \mathrm{Si})$ compositions. Some articles 34 138 142 have reported equations for austenite recrystallisation kinetics in non-microalloyed pearlitic rail compositions. Laboratory methods like double-hit deformation testing, multipass hot torsion or, multipass plane-strain compression testing, stress relaxation testing, tension-compression testing etc $[90,134$ 143 150 can be utilised to determine $T_{n R}$ experimentally. The advantage of multistep hot torsion [90] or plane-strain compression [150 testing is that single experiments can approximate the $T_{n R}$ for a given deformation schedule as shown in Figure 8.1.

In this chapter, uniaxial compression tests are carried out on selected alloys from Table 5.1. The general experimental details are summarised in Chapter 5. The cylindrical samples are prepared from the as-rolled materials and reheated at $1200^{\circ} \mathrm{C}$ for $2 \mathrm{~h}$ and helium-cooled at a fast rate $\left(\sim 50^{\circ} \mathrm{C}\right)$ thereafter to take as much niobium into solution before hot deformation. 

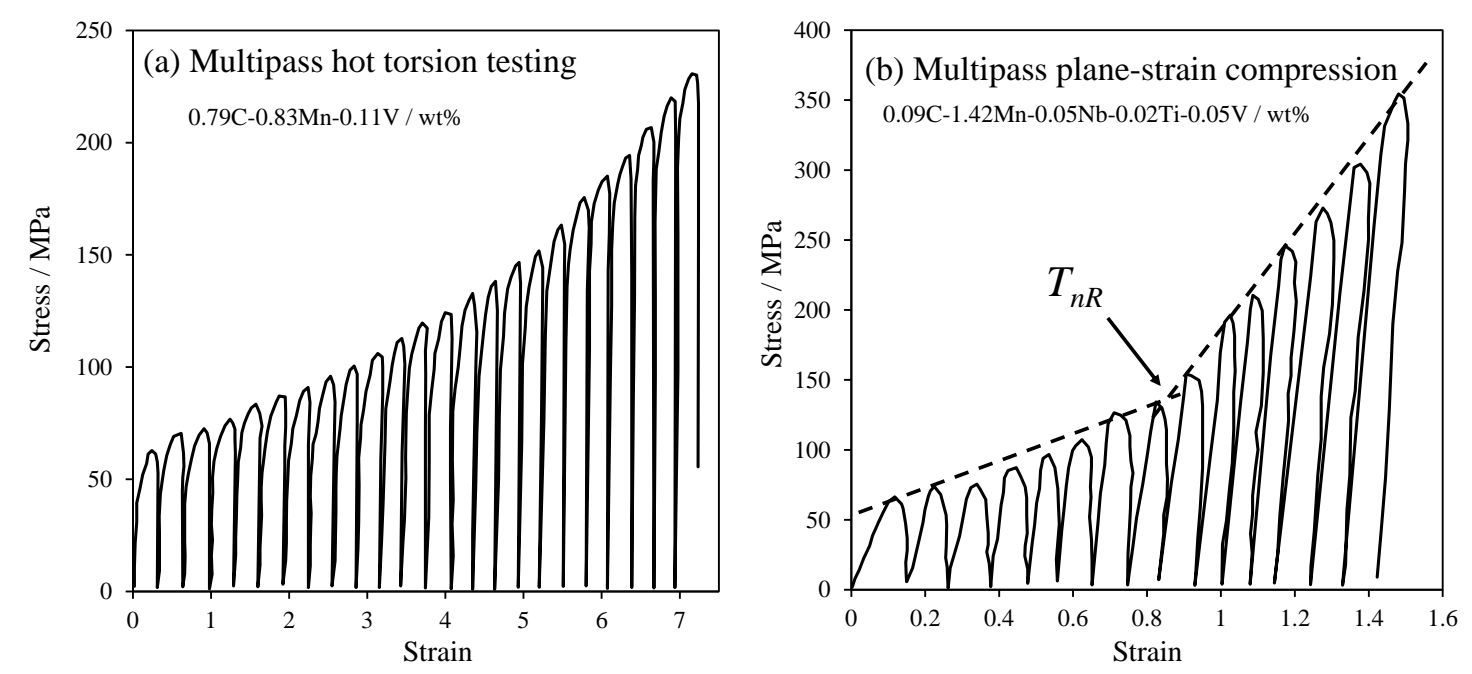

Figure 8.1: $T_{n R}$ determination by (a) multipass hot torsion testing [90], (b) multipass plane-strain compression testing [150].

\subsection{Determination of no-recrystallisation temper- ature}

In order to approximate the no-recrystallisation temperature $\left(T_{n R}\right)$, multipass axisymmetric compression tests were carried out on the water-quenched cylindrical samples according to the schedule illustrated in Figure 8.2. The deformation temperature ranges from $1100^{\circ} \mathrm{C}$ to $800^{\circ} \mathrm{C}$, soaking temperature and time are $1200{ }^{\circ} \mathrm{C}$ for $2 \mathrm{~min}$. The other parameters are: strain per pass $=0.15$, strain rate $=5 \mathrm{~s}^{-1}$, cooling rate between deformations $=1^{\circ} \mathrm{Cs}^{-1}$ and inter-pass time $=50 \mathrm{~s}$. 


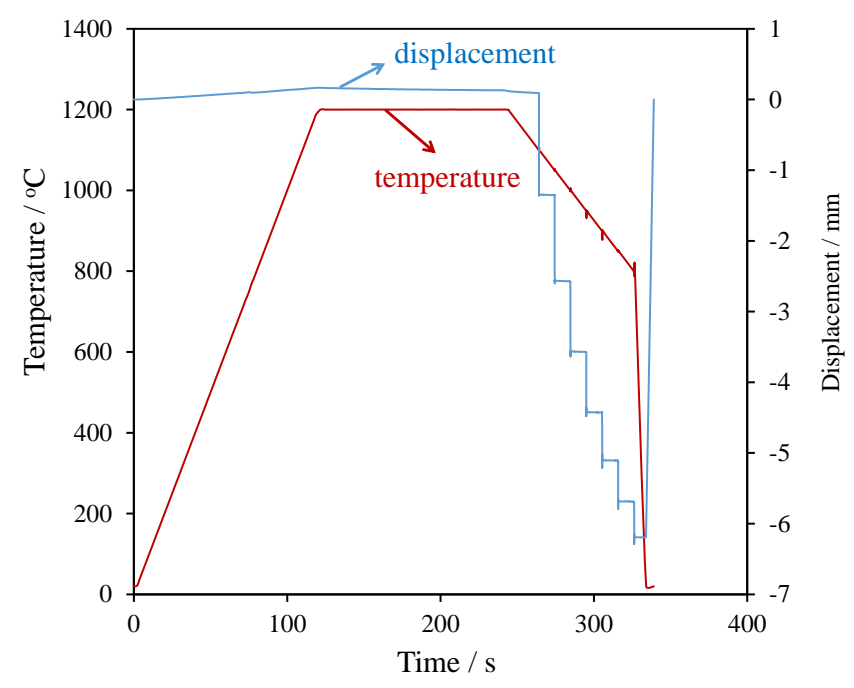

Figure 8.2: Deformation schedule to determine $T_{n R}$.

The $T_{n R}$ is calculated from the determination of mean flow stress (MFS) which is calculated from equations 8.1 applied on the flow curves at each reduction pass [151. The MFS at initial high temperature deformations are small and as the deformation temperature reduces with each pass, MFS increases. At deformation temperatures below $T_{n R}$, un-recrystallised austenite cause MFS to increase at a higher rate per each reduction pass. $T_{n R}$ can be approximated from the inflexion point as illustrated in Figure 8.1 .

$$
\begin{gathered}
\mathrm{MFS}=\frac{1}{\epsilon_{b}-\epsilon_{a}} \int_{\epsilon_{a}}^{\epsilon_{b}} \sigma d \epsilon \\
\sigma=\frac{4 P h}{\pi D_{0}^{2} h_{o}}
\end{gathered}
$$

where $\epsilon$ is true plastic strain, $\sigma$ is the true compressive stress, $P$ is the compressive load, $h$ is the instantaneous length, $h_{0}$ is the initial length and $D_{0}$ is the initial diameter of the cylinder.

Figure 8.3 and 8.4 compare flow curves and calculated mean flow stress for the alloys P7600, P7901 and B2200, B2102. The inflexion point in Figure 8.3b for P7901 and in Figure $8.4 \mathrm{~b}$ for B2102, indicate $T_{n R}$ for the respective alloys. 

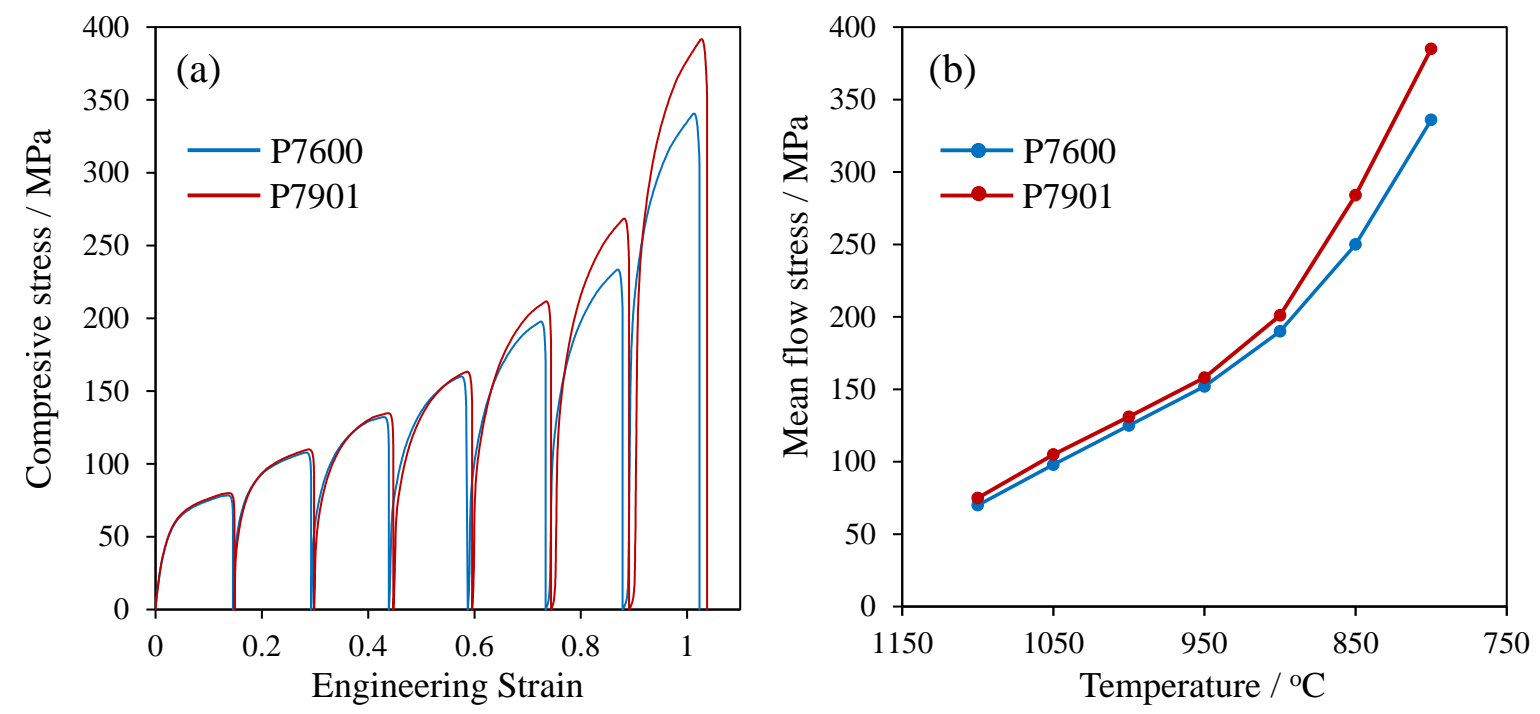

Figure 8.3: (a) Flow curves for the compression tested samples at each deformation step, (b) variation of mean flow stress (MFS) with deformation tempeature for the pearlitic alloys.
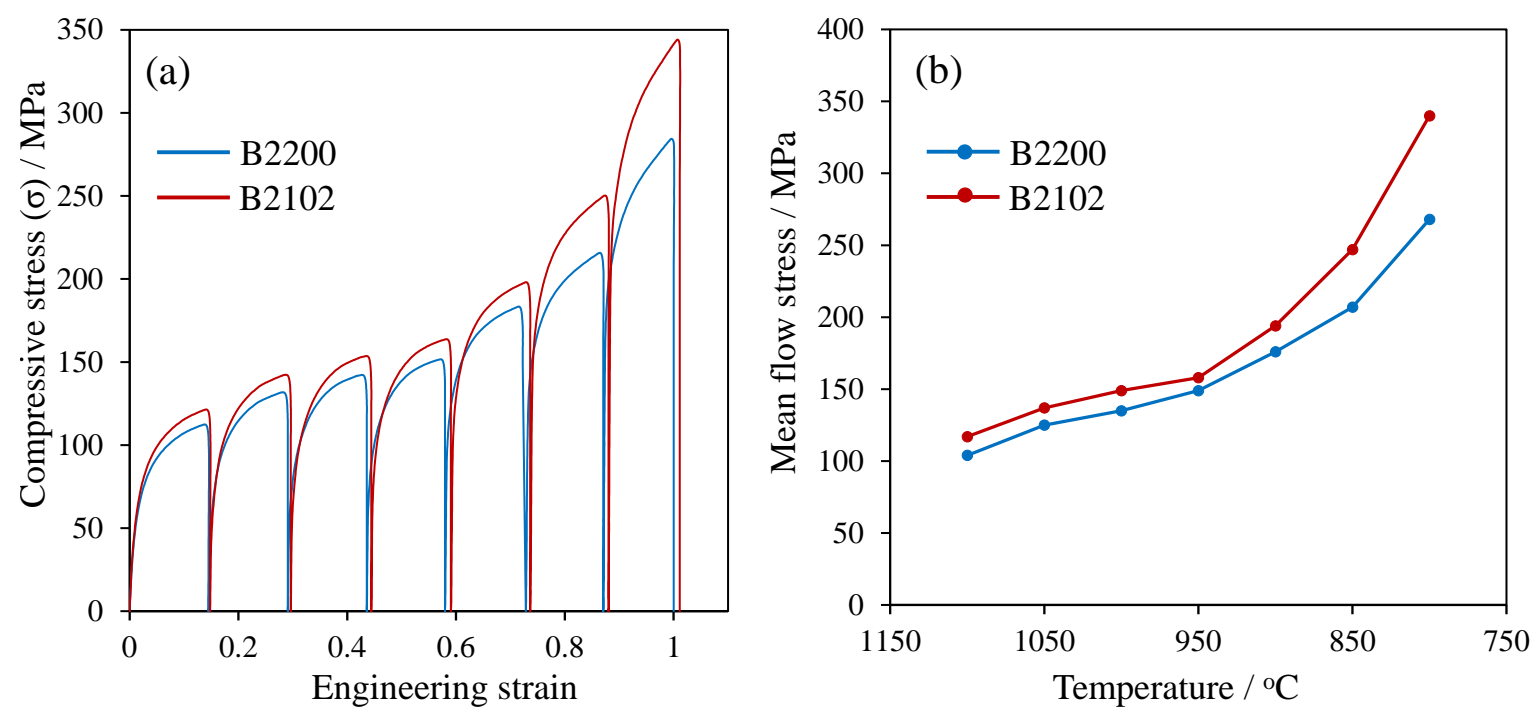

Figure 8.4: (a) Flow curves for the compression tested samples at each deformation step, (b) variation of mean flow stress (MFS) with deformation tempeature for the pearlitic alloys.

For both the pearlitic and bainitic alloys, the flow stress for the Nb-microalloyed alloys tend to be higher than the non-microalloyed alloys. This is possibly due to deformation induced NbC precipitation which strengthen the austenite. Figure 8.5 summarises the measured $T_{n R}$ for the investigated alloys along with the $T_{n R}$ tempera- 
tures collected from the literature for Nb-microalloyed pearlitic steels. This indicates that $T_{n R}$ increases with increasing niobium contents in high carbon pearlitic steels and the present experimental data fits reasonably into a linear trend.

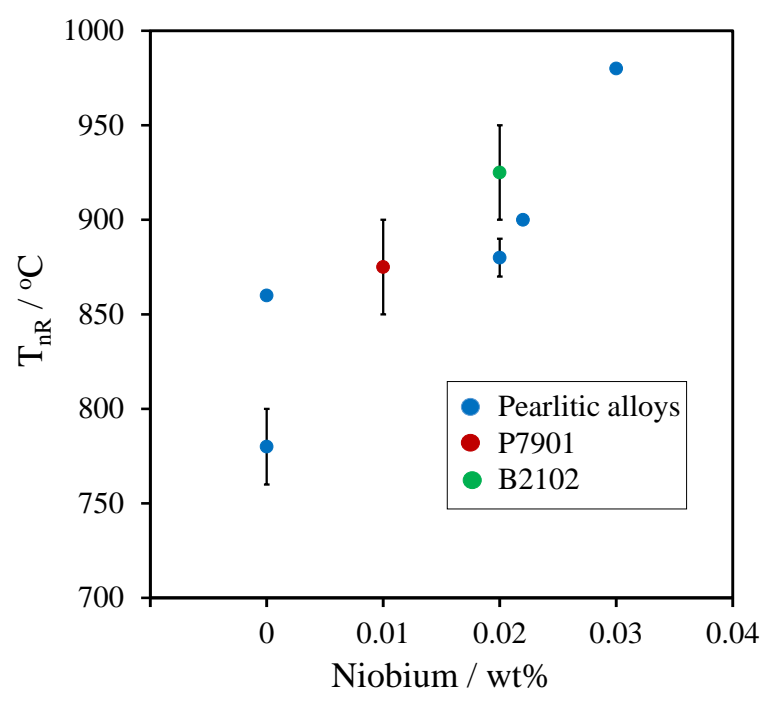

Figure 8.5: Experimentally determined $T_{n R}$ for P7901 and B2102 along with reported $T_{n R}$ for different $\mathrm{Nb}$ contents in pearlitic compositions.

\subsection{Topology of austenite grain deformation}

In the context of axisymmetric compression of tetrakaidecahedron shape of grains (Figure 8.6), the effect of plastic deformation on the austenite grain boundary per unit volume in the last deformation pass can be analysed using equations 8.2 and 8.3. Equation 8.2 is derived by applying homogeneous deformations to tetrakaidecahedra in a variety of orientations and the equation 8.3 is by using the principles of stereology $35[152$.

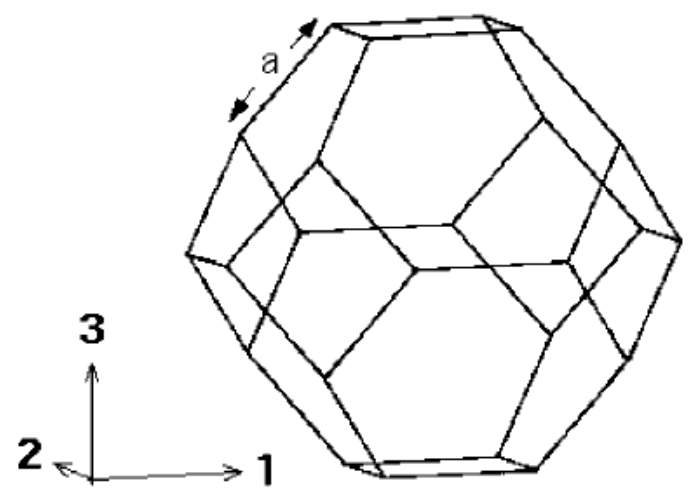

Figure 8.6: Tetrakaidecahedron shape of grains. 


$$
\begin{gathered}
\frac{S_{V}}{S_{V_{0}}}=\frac{\left[8 S_{33}+\frac{4}{S_{33}^{2}}\right]^{\frac{1}{2}}+\frac{1}{3}\left[\frac{1}{S_{33}}+2 S_{33}^{\frac{1}{2}}\right]}{1+2 \sqrt{3}} \\
\frac{S_{V}}{S_{V_{0}}}=\frac{1}{2}\left(0.429 \exp \left\{-\epsilon_{11}\right\}+0.571 \exp \left\{-\epsilon_{22}\right\}+\exp \left\{-\epsilon_{33}\right\}\right)
\end{gathered}
$$

where $S_{V}=$ grain boundary per unit volume after deformation (un-recrystallised grains); $S_{V_{0}}=$ grain boundary per unit volume before deformation; $S_{33}=$ principal distortion along direction 3 (compression direction). The percentage reduction $(p)$ is related to $S_{33}$ by:

$$
\frac{p}{100}=1-S_{33}
$$

For axisymmetric compression, $\epsilon_{11}=\epsilon_{22}=$ true strain along directions 1 and $2=$ $-0.5 \epsilon_{33}$ where $\epsilon_{33}=$ true strain along direction 3 (compression direction) $=\ln \left(S_{33}\right)$.

The experimentally measured mean linear intercepts of austenite grains are related to the directional strains by the equation $8.5, \overline{L_{0}}$ is mean linear intercept of equiaxed austenite grains before deformation and $\overline{L_{1}}, \overline{L_{2}}$ and $\overline{L_{3}}$ are mean linear intercepts along direction 1, 2, 3 respectively for un-recrystallised austenite grains after deformation. For axisymmetric deformations, $\overline{L_{1}}=\overline{L_{2}}$ as $\epsilon_{11}=\epsilon_{22}$.

$$
\begin{gathered}
\overline{L_{0}}=2 / S_{V_{0}} \\
\overline{L_{1}}=\overline{L_{0}} \exp \left\{\epsilon_{11}\right\} \\
\overline{L_{2}}=\overline{L_{0}} \exp \left\{\epsilon_{22}\right\} \\
\overline{L_{3}}=\overline{L_{0}} \exp \left\{\epsilon_{33}\right\}
\end{gathered}
$$

So the experimental $S_{V} / S_{V_{0}}$ can be calculated from the mean linear intercept measurement of the austenite grain sizes as 35 152]:

$$
\left.\frac{S_{V}}{S_{V_{0}}}\right|_{\exp }=\frac{\overline{L_{0}}}{2}\left(0.429 / \overline{L_{1}}+0.571 / \overline{L_{2}}+1 / \overline{L_{3}}\right)
$$

Also, the aspect ratio $\left(E=\overline{L_{1}} / \overline{L_{3}}\right)$ of the un-recrystallised grains can be calculated from the percentage reduction $(p)$ as:

$$
E=\frac{\overline{L_{1}}}{\overline{L_{3}}}=\frac{\exp \left\{\epsilon_{11}\right\}}{\exp \left\{\epsilon_{33}\right\}}=\frac{1}{\left(S_{33}\right)^{\frac{3}{2}}}=\frac{1}{\left(1-\frac{p}{100}\right)^{\frac{3}{2}}}
$$




\subsection{Two-stage compression tests}

Two-stage compression tests are carried out on the water-quenched cylindrical samples at temperatures above and below the possible no-recrystallisation temperatures. During industrial scale rolling, the roughing passes reduce the large grain sizes which formed during the reheating. The following reheating temperature and time combination (Table 8.1) were selected to develop similar prior austenite grain size of about $200 \mu \mathrm{m}$ (in terms of mean linear intercept $\overline{L_{\gamma}}$ ) before the two-stage deformation schedule (Figure 8.7a). A 6-pass compression schedule with $20 \%$ deformation per pass was carried out to understand the effect of multi-pass schedules (Figure 8.7b).

Table 8.1: Reheating temperature and time and corresponding austenite grain size

\begin{tabular}{cccc}
\hline Steel & Temperature $/{ }^{\circ} \mathrm{C}$ & Time $/ \mathrm{s}$ & $\overline{L_{\gamma}} / \mu \mathrm{m}$ \\
\hline P7901 & 1200 & 120 & $208 \pm 16$ \\
$\mathrm{~B} 2102$ & 1200 & 120 & $218 \pm 13$ \\
\hline
\end{tabular}
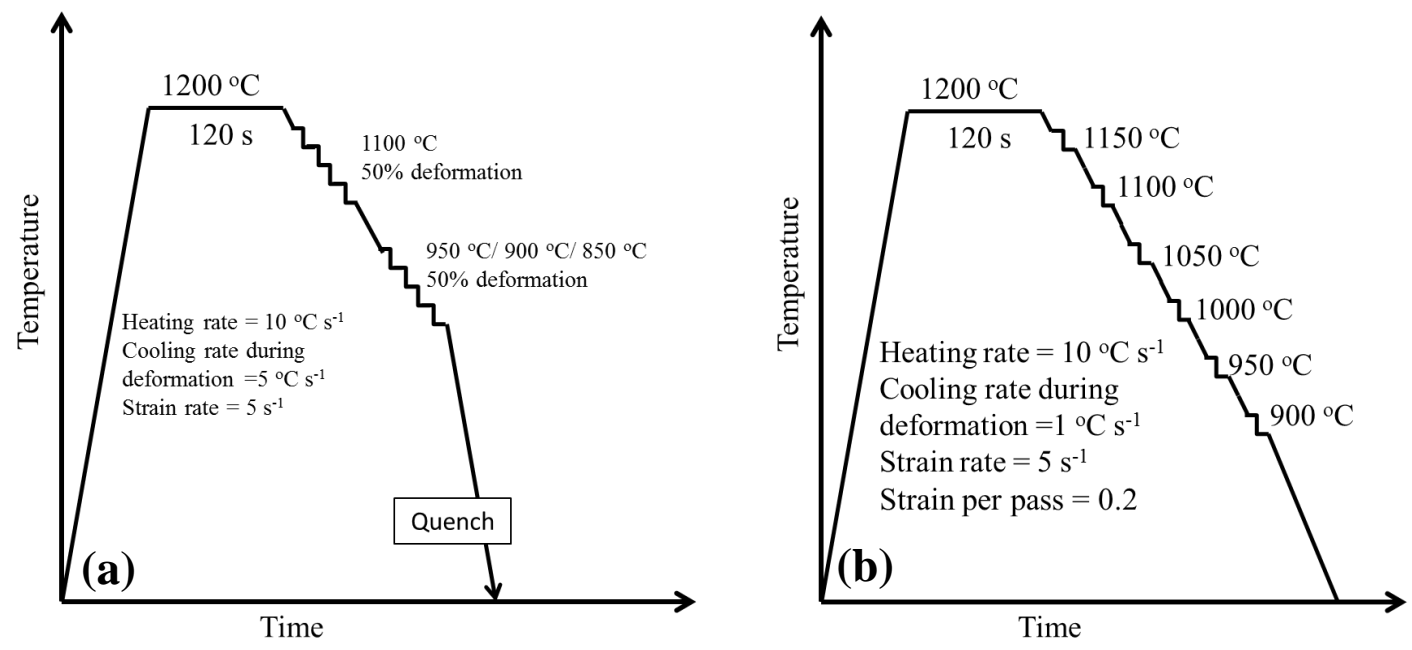

Figure 8.7: (a) Two-stage comprsession schedule, (b)multi-pass compression schedule.

Figure 8.8 summarises the microstructures of hot deformed prior austenite grains for the two-stage compression schedules of Figure $8.7 \mathrm{a}$. The prior austenite grains from the multi-pass schedule of Figure $8.7 \mathrm{~b}$ are shown in Figure 8.9. The mean linear intercepts $\left(\overline{L_{0}}, \overline{L_{1}}, \overline{L_{3}}\right.$ as defined in section 8.3 and corresponding aspect ratio $(E)$ and $S_{V} / S_{V_{0}}$, both predicted and experimentally calculated values, are summarised in Table 8.2. A minimum of 20 measurements were taken for each condition and the standard deviations are reported together with the average values. 

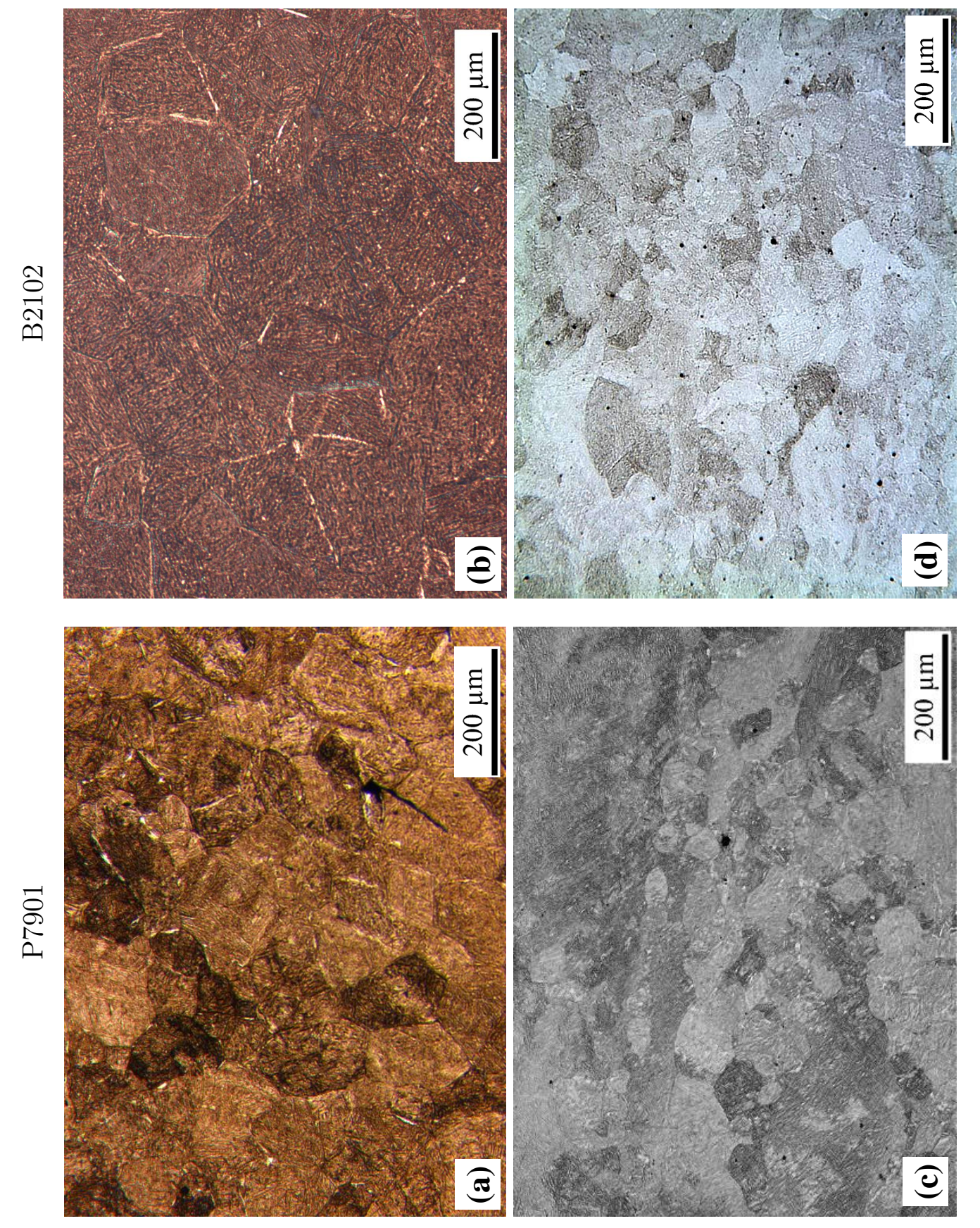

$\left[\begin{array}{c}5 \\ 15 \\ 0 \\ 0\end{array}\right.$

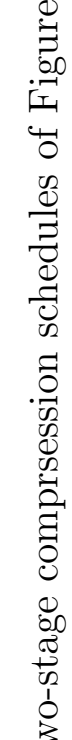

0
के
0
1
1
3
3 

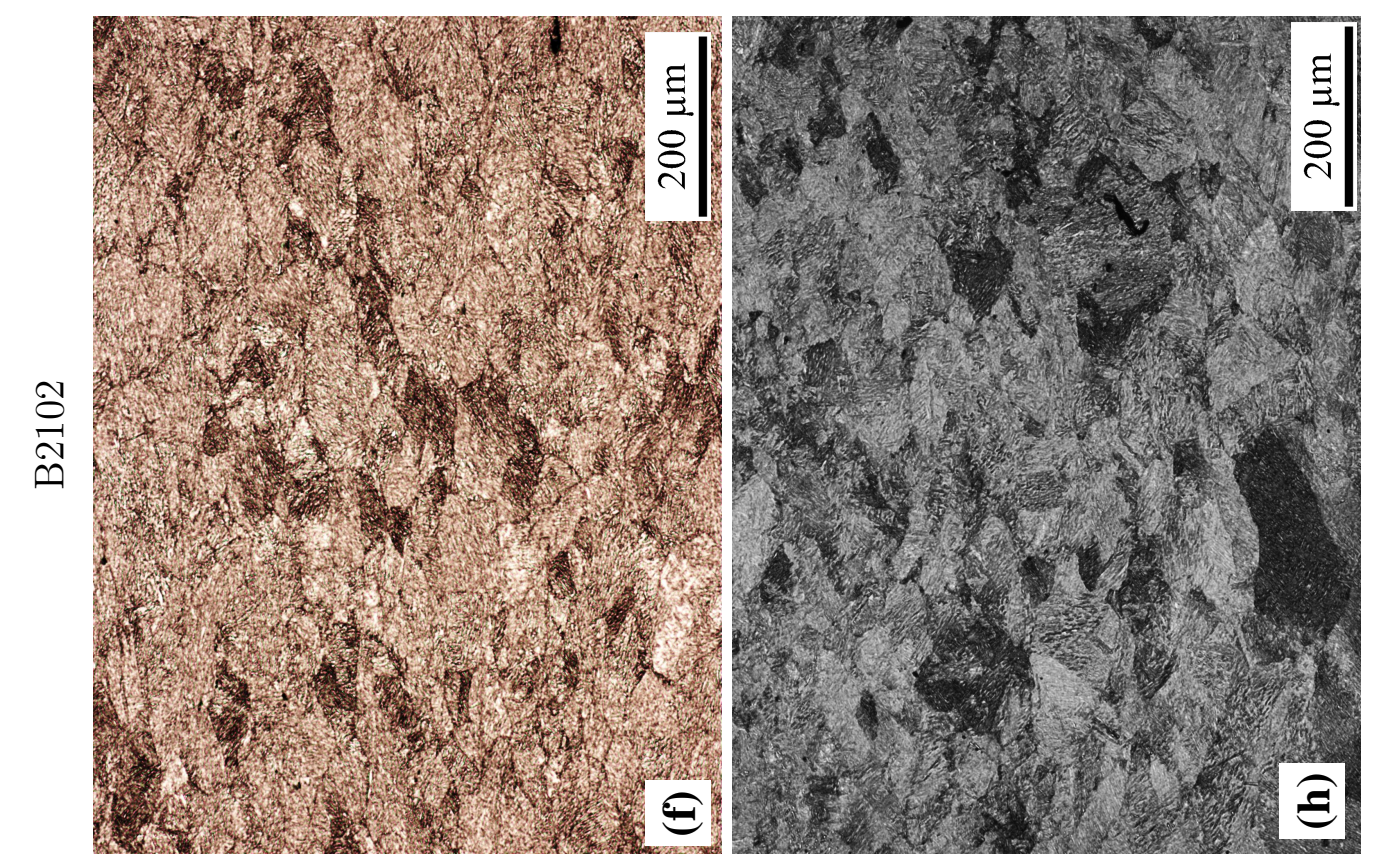

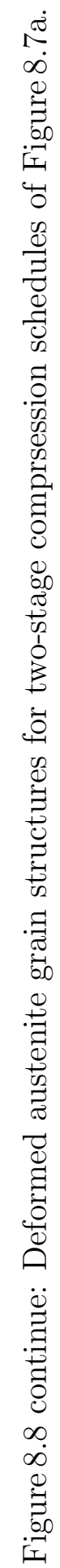
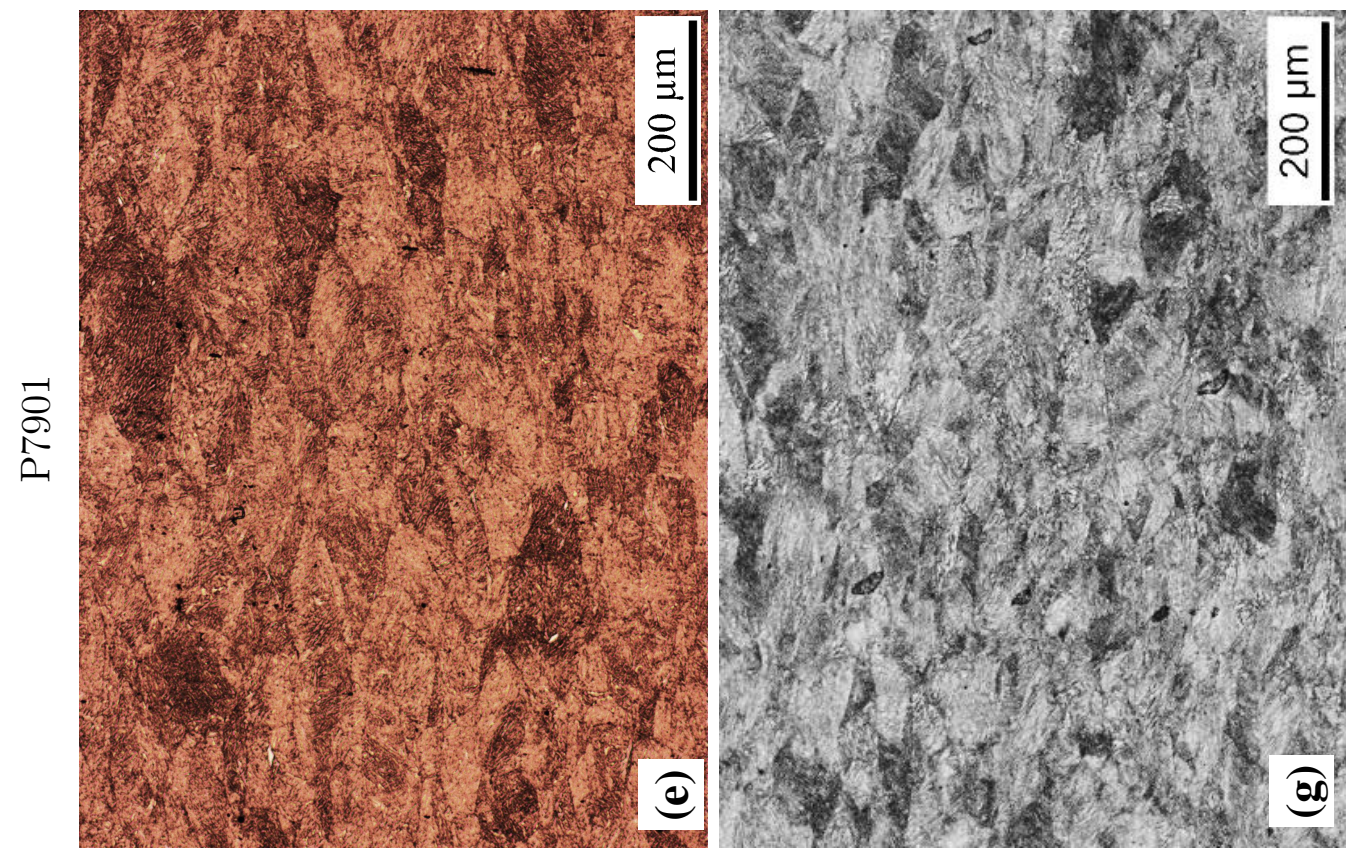

完总

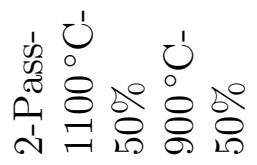

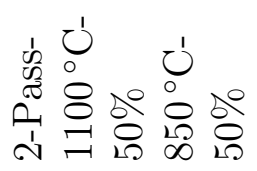



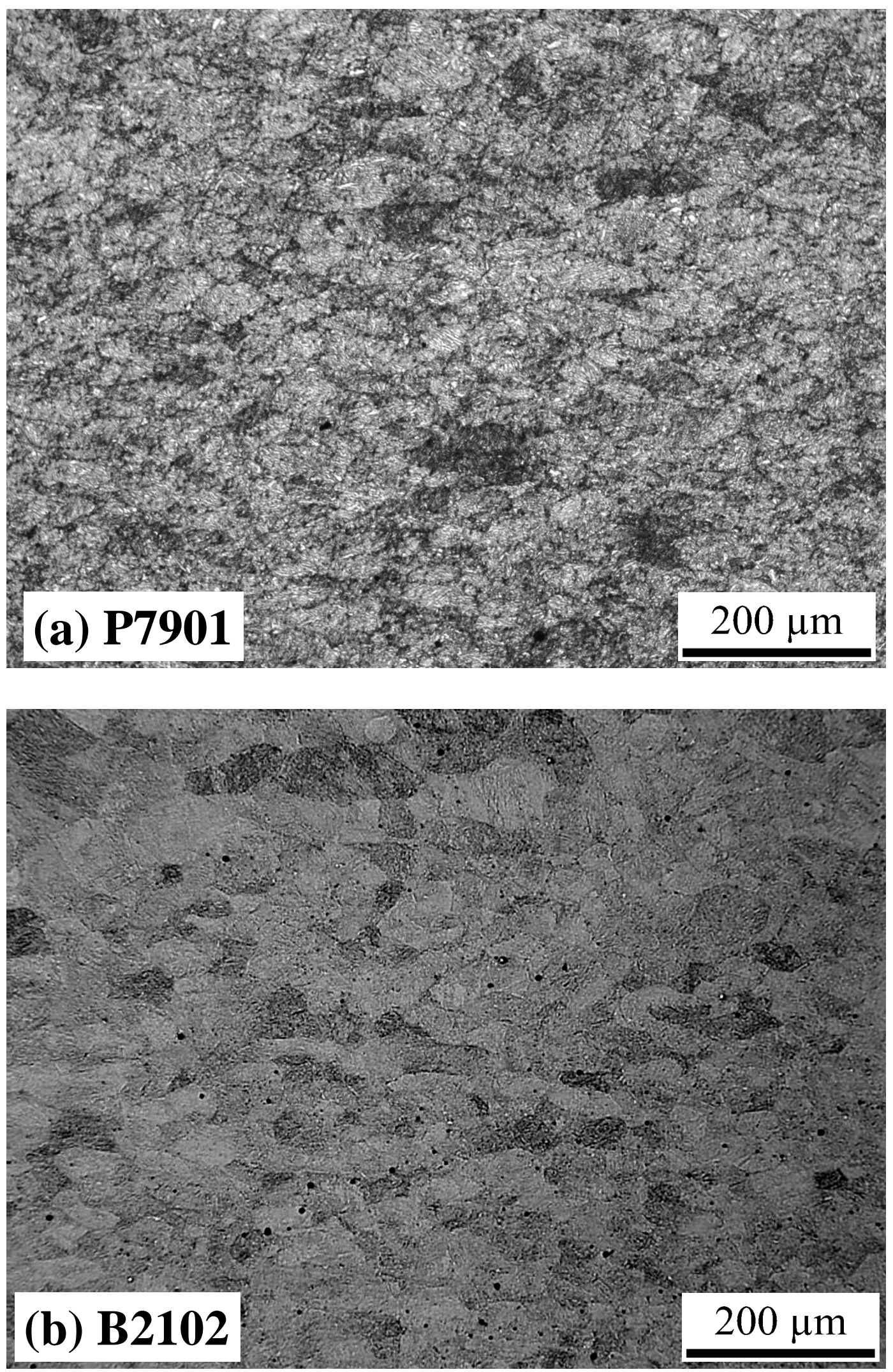

Figure 8.9: Deformed austenite grain structures for multi-pass comprsession schedules of Figure $8.7 \mathrm{~b}$. 


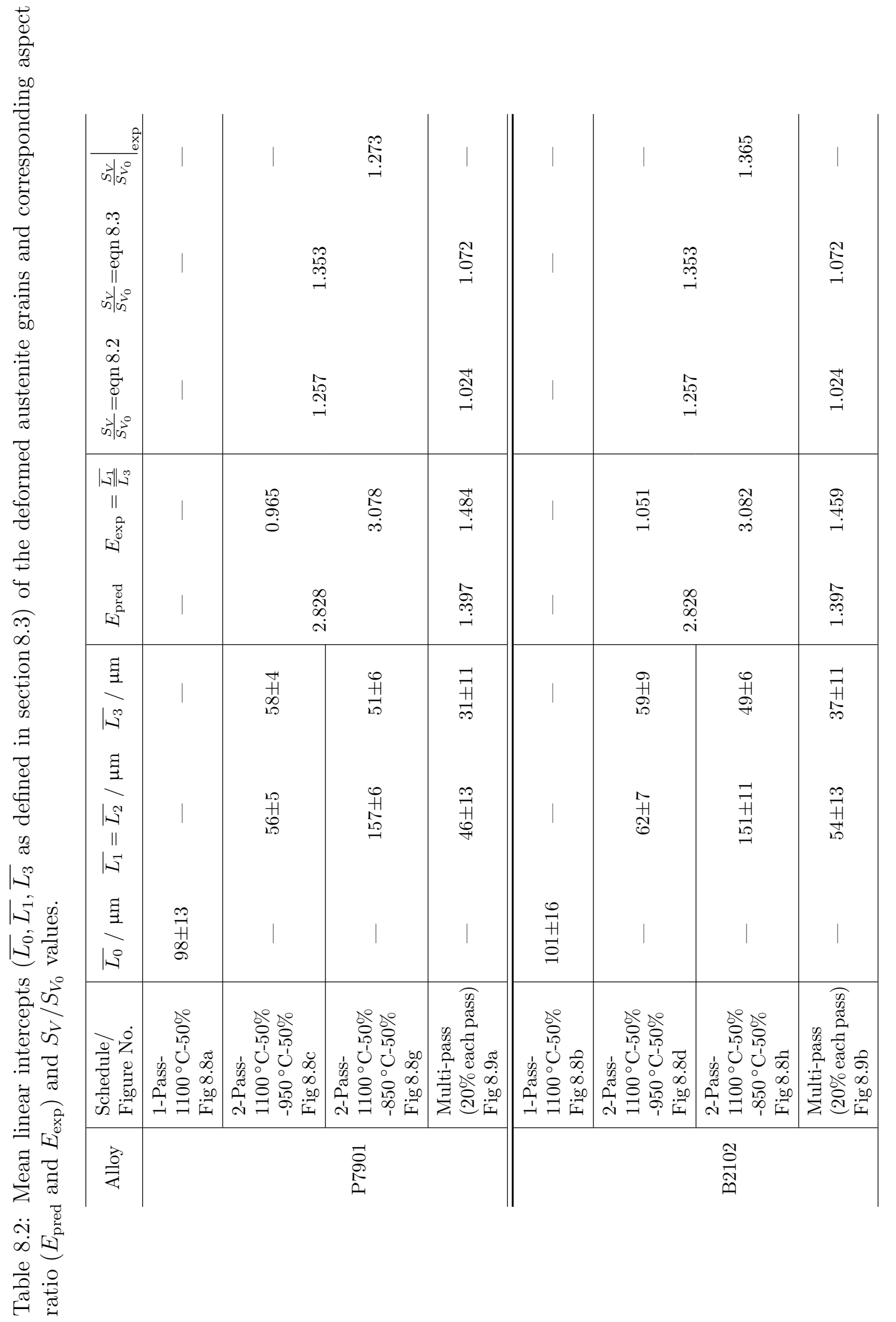


From both Figure 8.8 and Table 8.2 , it is clear that the deformed austenite grains recrystallise when finish deformed by $50 \%$ at $950{ }^{\circ} \mathrm{C}$ during the two-stage compression for both the Nb-microalloyed pearlitic (P7901) and bainitic (B2102) alloys. When the finish deformation temperature decreased to $900^{\circ} \mathrm{C}$ and $850{ }^{\circ} \mathrm{C}$, the austenite grains remain un-recrystallised and both the experimentally calculated aspect ratio and $S_{V} / S_{V_{0}}$ values are close to the values predicted by the analytical equations 8.2 , 8.3 and 8.7 . If the austenite grains do not recrystallise when the deformation is less than $50 \%$, it can be assumed that they will remain un-recrystallised under a $20 \%$ finish deformation which is typical in rail-head during rolling of rails. This is because $20 \%$ deformation will have a lower driving force for recrystallisation compared to $50 \%$ deformation.

For the multi-pass deformations with $20 \%$ reduction at each pass and finish deformed at $900{ }^{\circ} \mathrm{C}$ (Figure 8.9 and Table 8.2), the austenite also remain un-recrystallised. The $E_{\text {pred }}$ and $E_{\text {exp }}$ are quite similar but the $S_{V} / S_{V_{0}}$ cannot be calculated experimentally at the moment as this would require the measurement of $\overline{L_{0}}$ of the deformed austenite grains at the preceding deformation step. But equations 8.2 and 8.3 can be used to calculate $S_{V} / S_{V_{0}}$ analytically which yield lower $S_{V} / S_{V_{0}}$ values. This indicates a lower degree of increase in grain boundary per unit volume compared to that during $50 \%$ finish deformation.

\subsection{Transformation temperature}

The transformation kinetics in the Nb-microalloyed pearlitic (P7901) and bainitic (B2102) alloys for different finish deformation temperature $\left(950{ }^{\circ} \mathrm{C}, 900^{\circ} \mathrm{C}, 850{ }^{\circ} \mathrm{C}\right)$ at $20 \%$ finish deformation during the two-stage compression tests are compared in Figure 8.10 for a typical rail-head cooling rate of $0.6^{\circ} \mathrm{C} \mathrm{s}^{-1}$. The effects of the amount of finish deformation $(20 \%$ and $50 \%)$ are also studied at $900{ }^{\circ} \mathrm{C}$ finish deformation temperature. The transformation temperatures were calculated by an offset method as described by Yang et al. 153] [Figure8.11. 

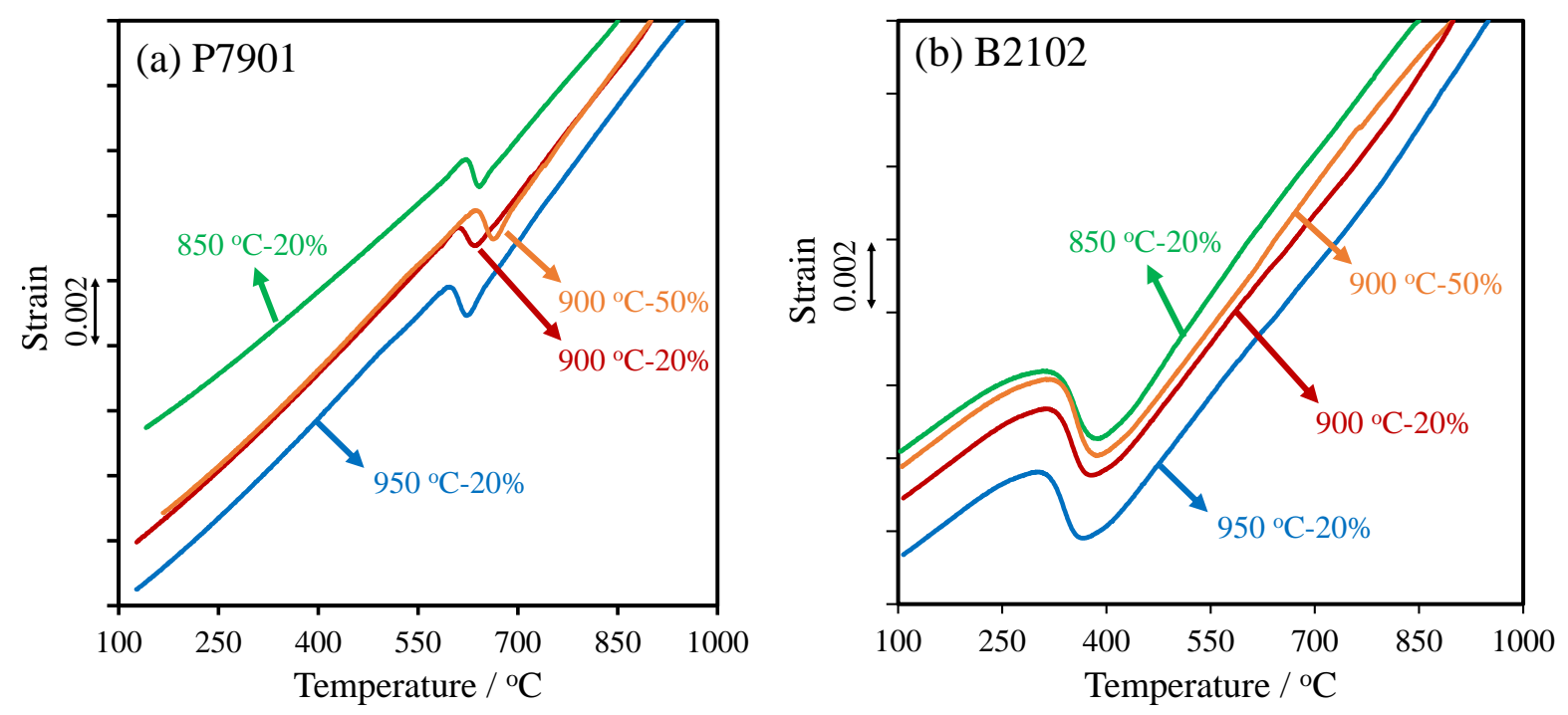

Figure 8.10: Dilatation curves during cooling at $0.6^{\circ} \mathrm{Cs}^{-1}$ after different finish deformation schedule during two-stage compression tests: (a) P7901, (b) B2102.

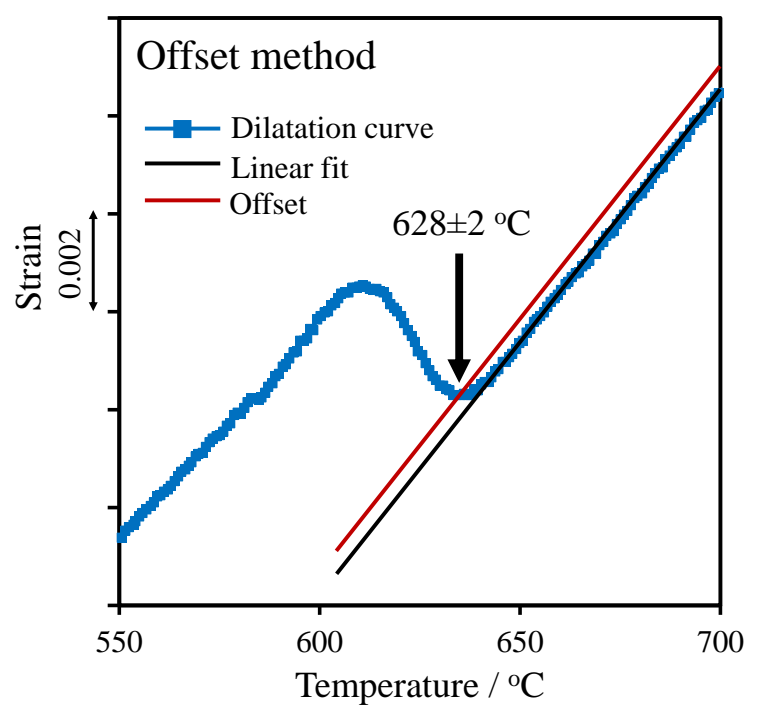

Figure 8.11: Determination of transformation temperature by offset method [153].

The pearlite transformation temperatures in alloy P7901, calculated by the offset method are summarised in Figure 8.12 along with the hardness of the transformed pearlite. The pearlite appeared similar under optical and scanning electron microscopes for different deformation conditions. Representative optical and scanning electron micrographs of the transformed pearlite are shown in Figure $8.12 \mathrm{~b}-\mathrm{c}$. At a constant finish deformation of $20 \%$, the transformation temperature tends to increase by about $10^{\circ} \mathrm{C}$ when the finish deformation temperature decreased from $950^{\circ} \mathrm{C}$ to $900^{\circ} \mathrm{C}$ and $850^{\circ} \mathrm{C}$. The corresponding average hardness value decreased 
with increasing transformation temperature but both hardness and transformation change are not significant. This is because at $20 \%$ finish deformation, the prior austenite grain boundary area per unit volume does not increase significantly in case of no-recrystallisation. If the finish deformation amount is increased upto 50\%, the transformation temperature increase significantly (by $\sim 30^{\circ} \mathrm{C}$ ) because of a greater nucleation site density. The corresponding hardness value decrease, probably because of a coarser pearlite structure due to increased transformation temperature.
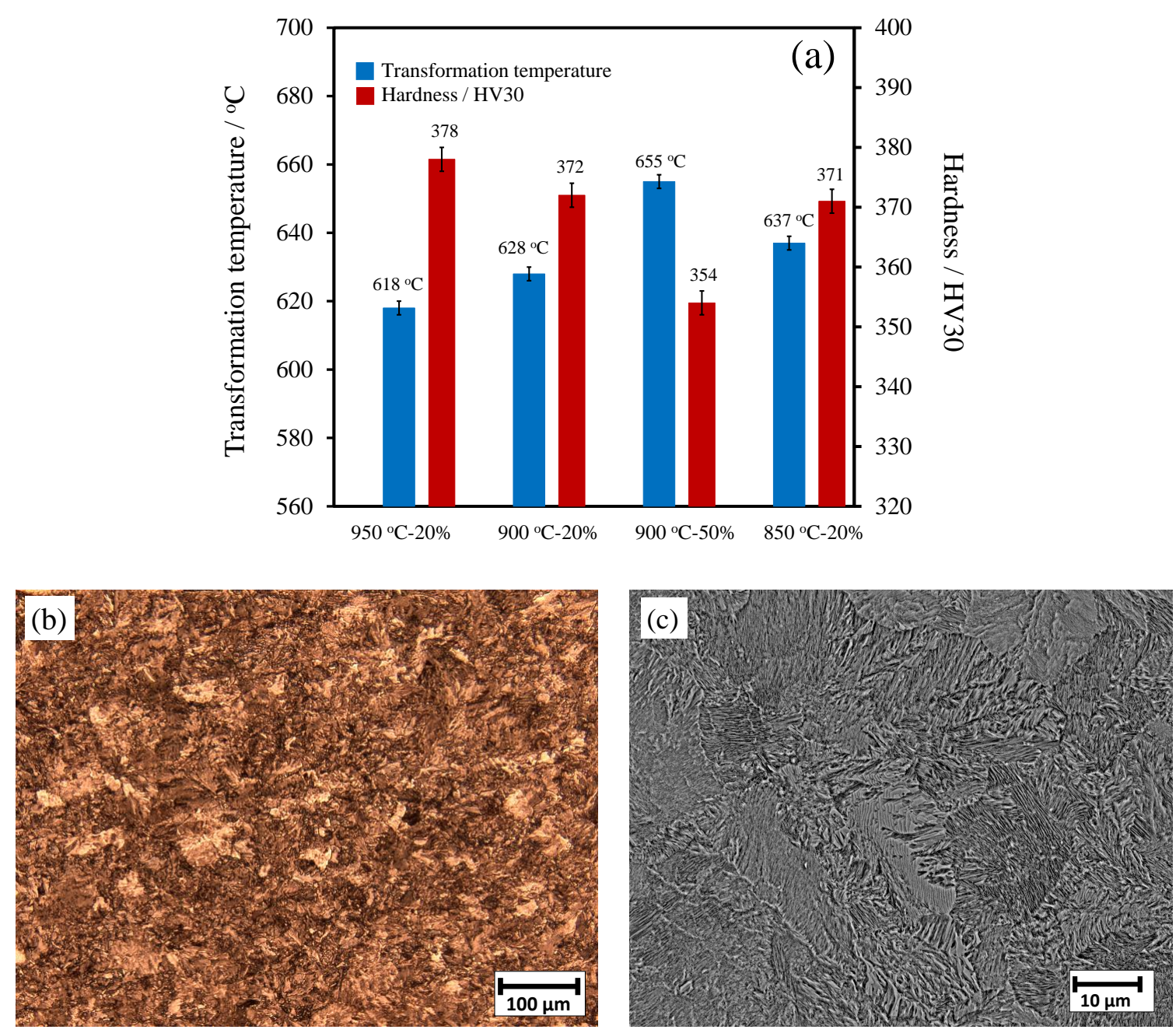

Figure 8.12: (a) Variation of transformation temperature and corresponding hardness for different finish deformation schedule for P7901 alloy. Optical micrograph in (b) and scanning electron micrograph in (c) are for $850^{\circ} \mathrm{C}-20 \%$ finish deformation schedule. 
The bainite transformation temperatures in alloy B2102, calculated by the offset method are summarised in Figure 8.13 along with the hardness of the transformed microstructure.

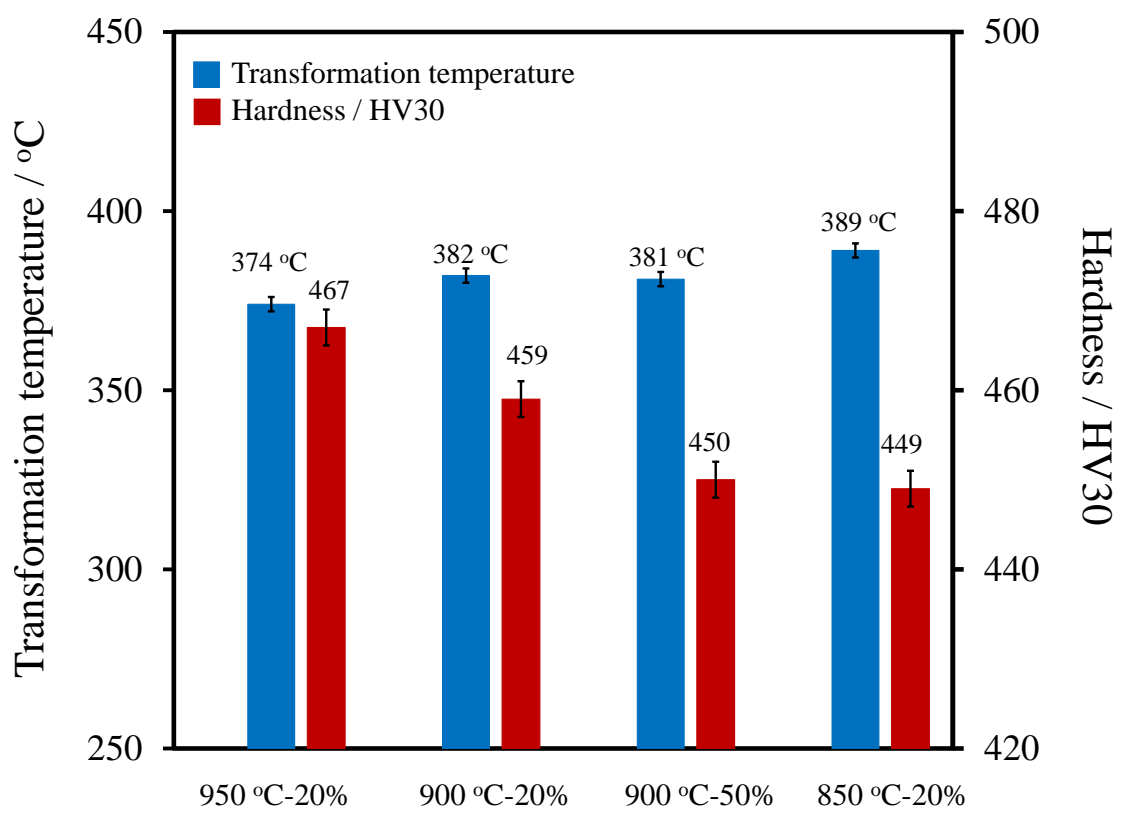

Figure 8.13: Variation of transformation temperature and corresponding hardness for different finish deformation schedule for B2102 alloy.

Representative optical and scanning electron micrographs of the transformed microstructure are shown in Figure 8.14. At a constant finish deformation of $20 \%$, the transformation temperature tends to increase by about $8^{\circ} \mathrm{C}$ when the finish deformation temperature decreased from $950{ }^{\circ} \mathrm{C}$ to $900^{\circ} \mathrm{C}$ and $850^{\circ} \mathrm{C}$. The corresponding average hardness value decreased with increasing transformation temperature. When the finish deformation amount is increased upto $50 \%$ at $900{ }^{\circ} \mathrm{C}$, the bainite transformation temperature does not change significantly but the hardness of the transformed microstructure decreases due to a mixed ferrite-bainite microstructure (Figure 8.14c-d). For $850{ }^{\circ} \mathrm{C}-20 \%$ deformation condition also, ferrite formation can be observed at prior austenite grain boundaries (Figure 8.14 ). This ferrite may be formed due to either of the following reasons:

(i) due to increased deformation amount and low deformation temperature, the dislocation density in austenite as well as the grain boundary area per unit volume are increased which reduce the incubation time for diffusional ferrite transformation during cooling in Si-rich cementite-free bainitic alloys. But the dilatation curves (Figure 8.10p) do not show any deviation from linearity until 
bainitic transformation starts. This may be due to small amount of ferrite formation during cooling which does not result in detectable dilatation.

(ii) another possibility is the formation of deformation induced ferrite during deformation itself prior to cooling. The $A_{e_{3}}$ temperature for $\mathrm{B} 2102$ is $846^{\circ} \mathrm{C}$ and the deformation temperatures where ferrite formation has been observed, are quite close. So it is quite possible that during deformation at temperatures close to $A_{e_{3}}$, austenite may transform to ferrite and the transformed ferrite itself may undergo further deformation. 

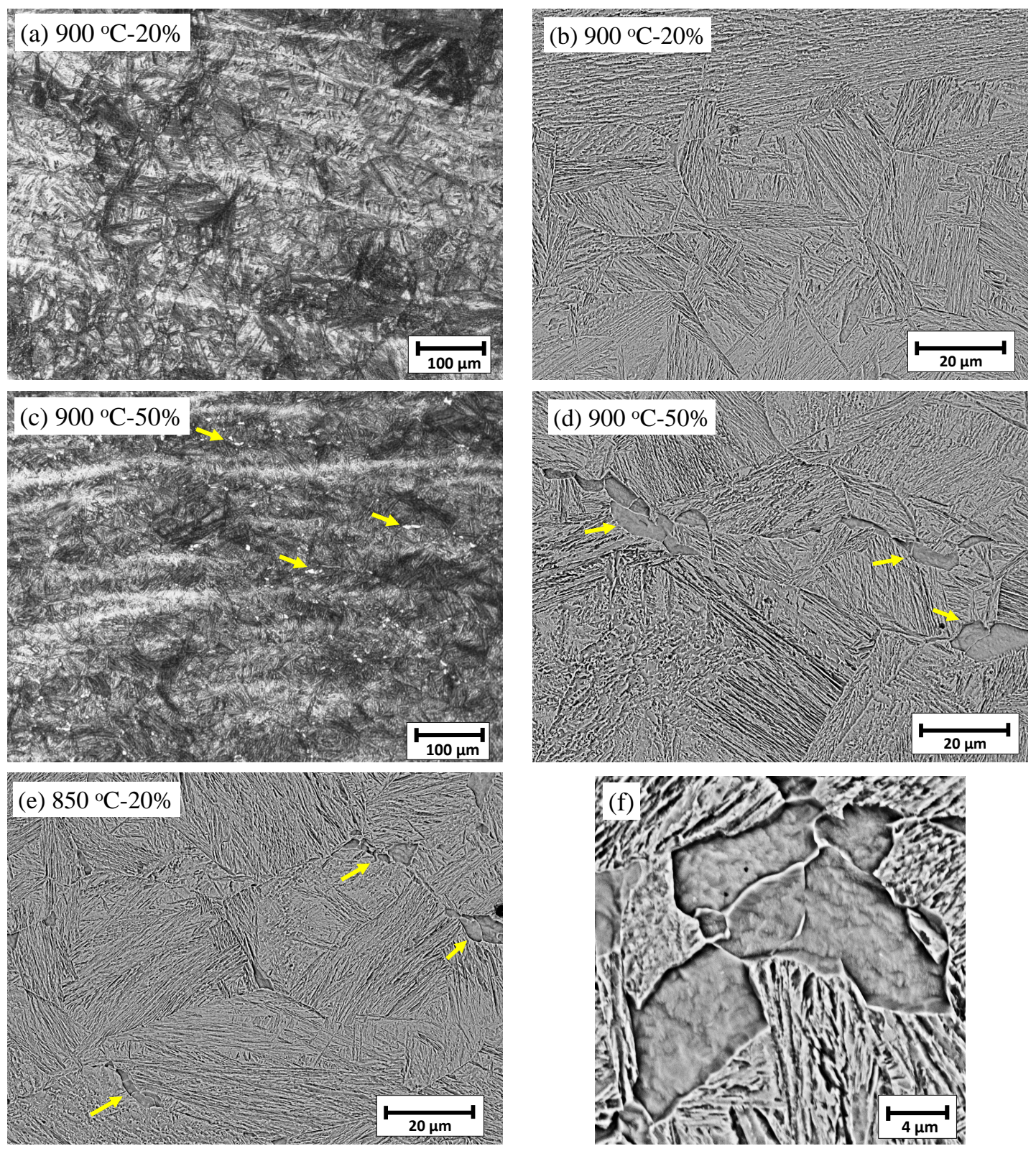

Figure 8.14: Transformed microstructures for different deformation schedules in B2102 alloy. Arrows indicate ferrite at prior austenite grin boundaries. (a), (b) $900{ }^{\circ} \mathrm{C}-20 \%$ finish deformation. (c), (d) $900{ }^{\circ} \mathrm{C}-50 \%$ finish deformation. (a) and (c) are optical micrographs while (b) and (d) are SEM micrographs. (e) SEM micrograph for $850^{\circ} \mathrm{C}-20 \%$ finish deformation. (f) SEM micrograph showing ferrite at prior austenite grain boundary. 


\subsection{Summary}

The important findings from this study are:

(i) Niobium microalloying certainly affects the recrystallisation kinetics of high carbon $(0.8 \mathrm{wt} \% \mathrm{C})$ austenite and low carbon $(0.2 \mathrm{wt} \% \mathrm{C})$ Si-rich austenite in pearlitic and cementite-free bainitic alloys, respectively, by increasing the norecrystallisation temperature. Austenite tends to remain un-recrystallised below $900-950^{\circ} \mathrm{C}$ for the investigated Nb-microalloyed alloys.

(ii) The topology of the deformed austenite can be approximated by the stereological calculations provided the grains are not recrystallised. In case of recrystallised austenite grains, experiments with variable strain and strain rates, need to be carried out to develop equations for recrystallisation kinetics for these Nb-microalloyed alloys.

(iii) The pearlite transformation kinetics tend to accelerate when deformed below the no-recrystallisation temperature but the effect is low until the amount of deformation is significant.

(iv) The bainite transformation kinetics also tend to accelerate with decreasing deformation temperature. But during heavy deformation near $A_{e_{3}}$ temperature for the Si-rich bainitic alloys, ferrite transformation may occur which reduce the effective hardness in the final microstructure. 


\section{Chapter 9}

\section{Microstructure and mechanical properties of as-rolled material}

\subsection{Introduction}

The as-rolled microstructure and mechanical properties (tensile, impact toughness and wear) of the alloys listed in Tables 9.1 and 9.2 are analysed. The experimental methodology is detailed in Chapter 5.

Table 9.1: Composition for alloys (wt\%)

\begin{tabular}{ccccccccc}
\hline Alloy & C & Mn & Si & Cr & Mo & Nb & P & S \\
\hline B2102 & 0.21 & 2.0 & 1.9 & 0.54 & 0.52 & 0.019 & 0.0023 & 0.0007 \\
B2200 & 0.22 & 2.0 & 1.9 & 0.54 & 0.47 & - & 0.0026 & 0.001 \\
\hline P7901 & 0.79 & 0.98 & 0.41 & 0.57 & - & 0.011 & 0.0022 & 0.0005 \\
P7600 & 0.76 & 1.0 & 0.42 & 0.53 & - & - & 0.0023 & 0.0007 \\
\hline
\end{tabular}

Table 9.2: Hot rolling schedule

\begin{tabular}{lclccccccc}
\hline Alloy & $\begin{array}{c}\text { Reheating } \\
\text { temperature } \\
\text { and time }\end{array}$ & Hot Rolling & Initial & Pass 1 & Pass 2 & Pass 3 & Pass 4 & Pass 5 & \\
\hline B2102 & & Reduction/ $\%$ & - & 11 & 24 & 24 & 22 & 22 & Air \\
B2200 & $1200^{\circ} \mathrm{C}$ & Temperature $/{ }^{\circ} \mathrm{C}$ & 1200 & 1180 & 1150 & 1100 & 1020 & 870 & cooling \\
P7901 & $-2 \mathrm{~h}$ & Thickness/ mm & 95 & 85 & 64 & 49 & 38 & 30 & \\
P7600 & & & & & & & & \\
\hline
\end{tabular}




\subsection{Results and discussion}

\subsubsection{Microstructure and tensile properties}

The optical and SEM micrographs of the bainitic alloys (B2200 and B2102) are shown in Figure 9.1 along with the hardness values. The inverse-pole figure (IPF) maps by EBSD are shown in Figure $9.2 \mathrm{a}$-b with corresponding colour keys. The $\{100\}$ stereographic pole figures of ferrite and intensity contour plots are shown in Figure $9.2 \mathrm{~d}-\mathrm{e}$. The prior austenite grain size measurements were carried out by delineating approximately the continuous retained austenite networks at austenite grain boundaries as shown in Figure 9.3. Figure 9.4 compares the prior austenite grain sizes (PAGS) in terms of mean linear intercepts along the rolling direction $\left(\overline{L_{\mathrm{RD}}}\right)$ and along the normal direction $\left(\overline{L_{\mathrm{ND}}}\right)$. 

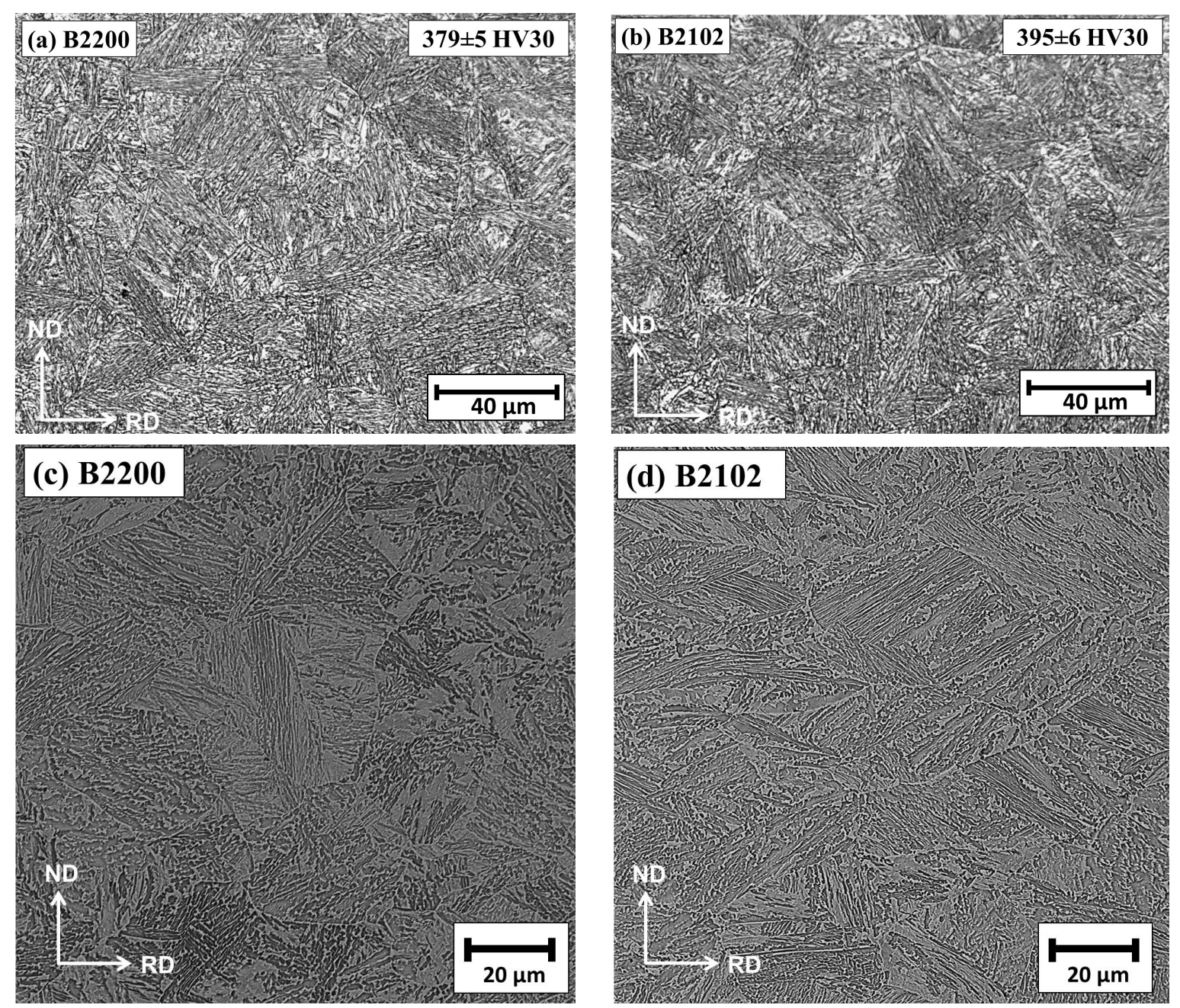

Figure 9.1: Optical micrograph of B2200 (a) and B2102 (b) and corresponding hardness values; SEM micrograph of B2200 (c) and B2102 (d) 

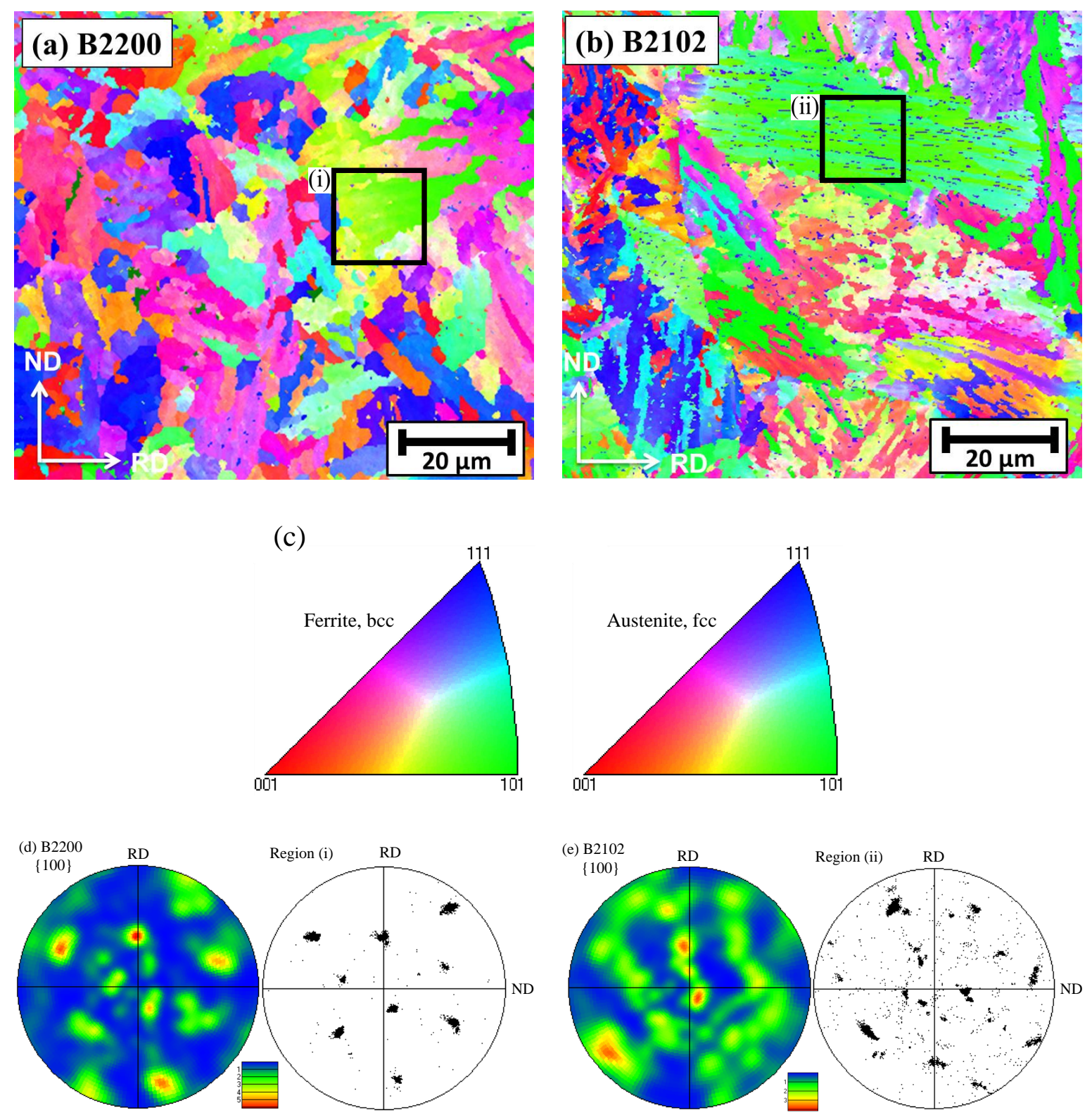

Figure 9.2: IPF map of B2200 (a) and B2102 (b) and the corresponding colour key in (c). $\{100\}$ pole figure intensity contour plots of ferrite in B2200 (d) and B2102 (e) with the corresponding individual $\{100\}$ poles from regions (i) and (ii) as marked in (a) and (b) respectively. 


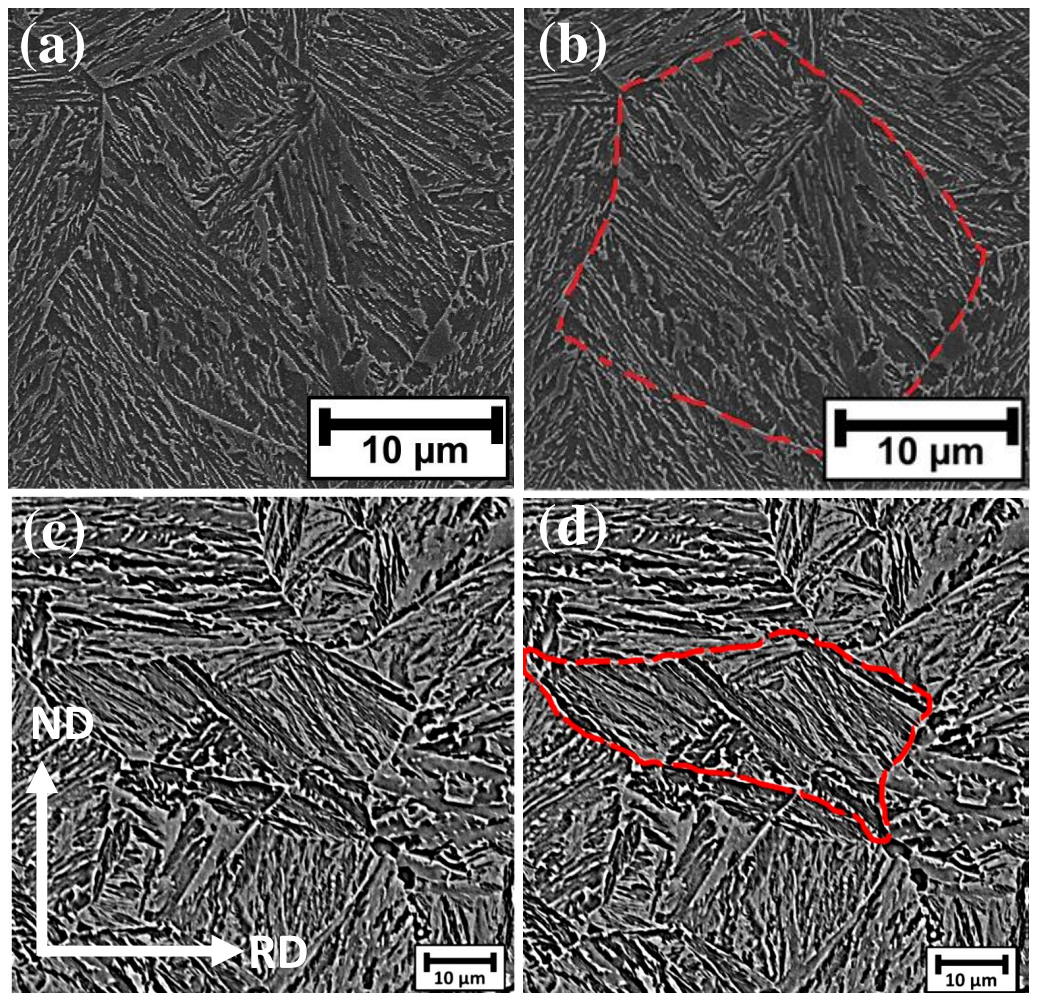

Figure 9.3: Representative austenite grain boundary delineation in bainitic microstructures: (a),(b) equiaxed grains in B2200 and (c),(d) elongated grains in B2102.

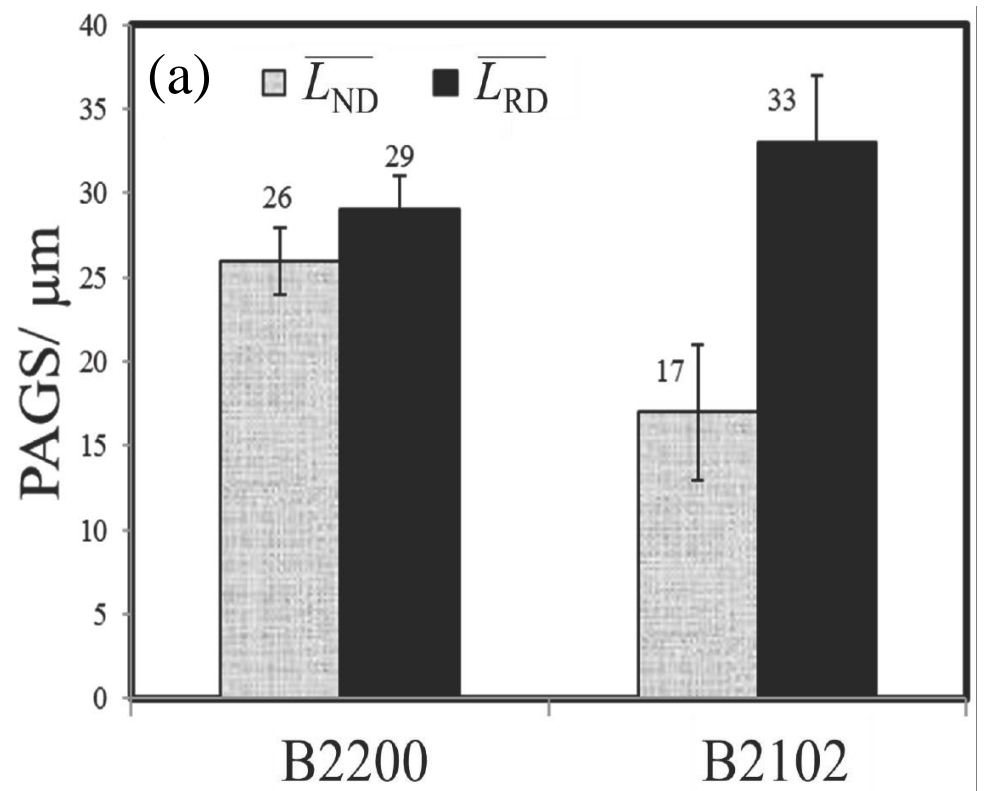

Figure 9.4: Comparsion of prior austenite grain size (PAGS) in terms of mean linear intercept along rolling direction $\left(\overline{L_{\mathrm{RD}}}\right)$ and along the normal direction $\left(\overline{L_{\mathrm{ND}}}\right)$ 
Both SEM and EBSD maps along with the average aspect ratio $\left(E=\overline{L_{\mathrm{RD}}} / \overline{L_{\mathrm{ND}}}\right)$ calculation show that the austenite grains in B2102 $\left(E_{\mathrm{B} 2102}=1.98\right)$ have not recrystallised while those in B2200 $\left(E_{\mathrm{B} 2200}=1.11\right)$ have. The stereographic projection of $\{100\}$ poles for B2102 (Figure 9.2 ), tend to be more homogeneously distributed compared to a relatively more scattered distribution of $\{100\}$ poles for B2200 in Figure 9.2 . There will be gradients of orientation in the un-recrystallised austenite in B2102 caused by defects introduced by the deformation, which in turn lead to more random orientation of bainite during transformation. This is reflected into a more homogeneous distribution of poles in B2102.

X-ray diffraction spectra for the bainitic alloys are illustrated in Figure 9.53 . The retained austenite volume fraction $\left(V_{\gamma}\right)$ was calculated from the integrated austenite $(\gamma)$ and ferrite ( $\alpha$ peaks by Rietveld refinement in both MAUD and HighScore Plus software for X-ray diffraction analysis. $V_{\gamma}$ is more for Nb-microalloyed B2102, probably because of increased prior austenite grain boundary area due to un-recrystallised grains and mechanical stabilisation of bainite growth due to increased dislocation density in prior austenite. Individual $\gamma(200)$ and $\alpha(200)$ peaks of B2200 and B2102 are normalized with respect to their respective peak intensity and superimposed in Figure 9.5b-c. Substantial peak broadening of both austenite $(\gamma)$ and ferrite $(\alpha)$ peaks can be observed for B2102 where bainite transformation occur from un-recrystallised austenite.

The longitudinal (L) and transverse $(\mathrm{T})$ tensile properties are plotted in Figure 9.6. The change in tensile strength is negligible but the ductility, particularly reduction of area, tends to improve for the niobium containing B2102 compared to the steel B2200 which is not microalloyed. Because the elongation is not uniform along the entire gauge length and is greatest at the at the center of the neck, the percent elongation is not an absolute measure of ductility and also gauge length dependent. The reduction in area, being measured at the minimum diameter of the neck, is a better indicator of ductility. The increased retained austenite volume fraction in B2102 can be attributed to the increased ductility. According to the percolation model proposed by Bhadeshia [154], failure during a tensile test occurs when the retained austenite in the microstructure loses continuity due to progressive transformation during deformation. This percolation threshold being 0.1 (10\%), below which continuity in austenite is lost and failure is initiated. More is the retained austenite volume fraction, more plastic strain will be required for failure which increases ductility. 

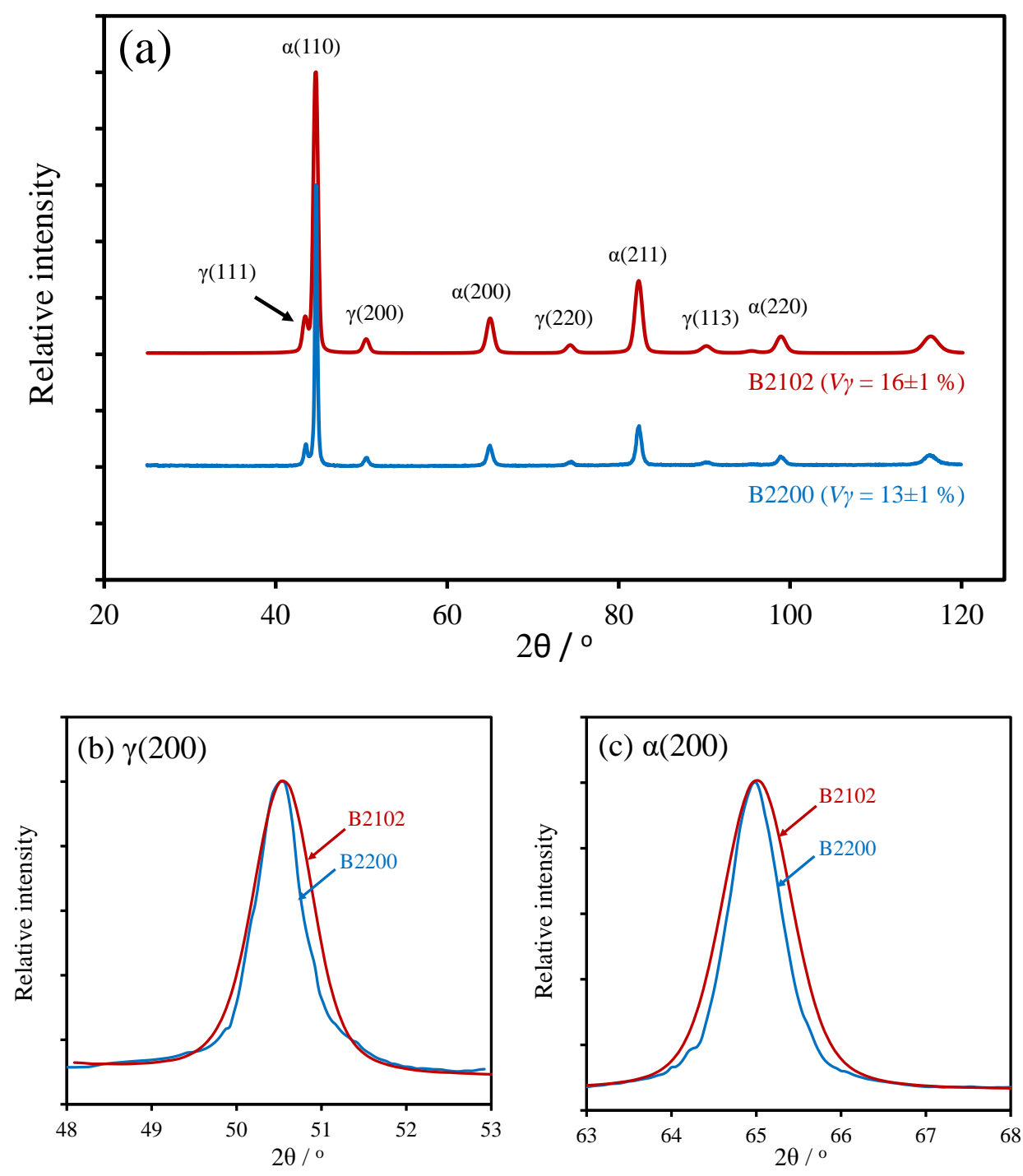

Figure 9.5: (a) X-ray diffraction spectra and measured retained austenite volume fraction $V_{\gamma}$ for B2200 and B2102 steels. (b) $\gamma(200)$ peak and (c) $\alpha(200)$ peak. Each $\gamma(200)$ and $\alpha(200)$ peak from B2200 and B2102 is normalized with respect to their respective peak intensity and superimposed. 

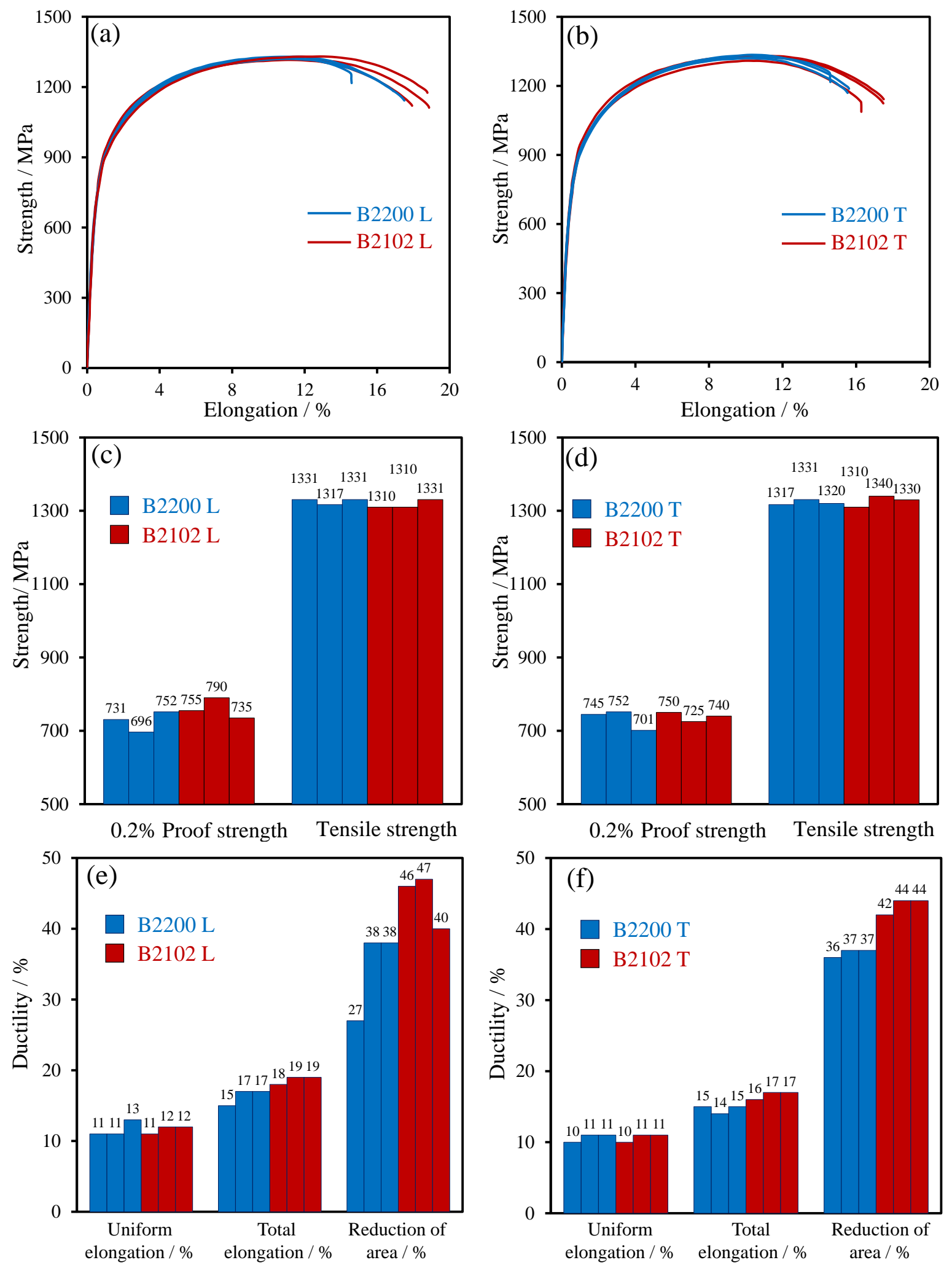

Figure 9.6: Tensile properties of bainitic alloys B2200 and B2102 in longitudinal (L) orientation in (a), (c), (e) and in tranverse (T) orientation in (b), (d), (f). 
The optical and SEM micrographs of the pearlitic alloys (P7600 and P7901) are shown in Figure 9.7. The inverse-pole figure maps by EBSD and corresponding pole figures are shown in Figure 9.8. The change in crystallographic unit size with critical orientation angle is plotted in Figure 9.9. At small misorientation angles $\left(<10^{\circ}\right)$, the crystallographic unit sizes are comparable in both alloys but at higher misorientation angles, the crystallographic unit size tends to refine in the Nb-microalloyed P7901, possibly due to refinement in prior austenite grain size due to Nb-microalloying. But this refinement is unlikely to have significantly affected the pearlite transformation temperature because as seen from Figure 9.10, the interlamellar spacing and hardness values are comparable in both the alloys.
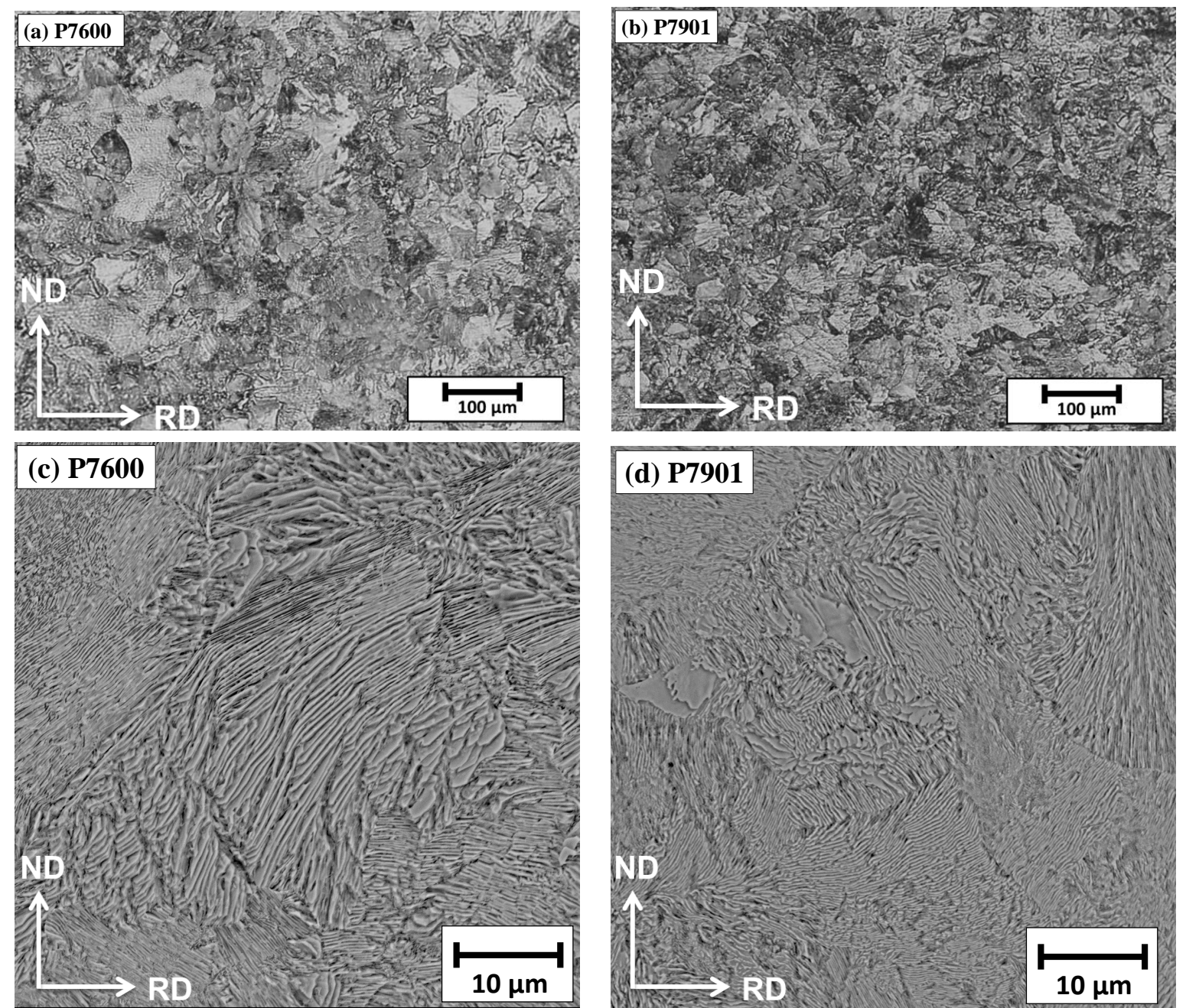

Figure 9.7: Optical micrograph of P7600 (a) and P7901 (b); SEM micrograph of P7600 (c) and P7901. 

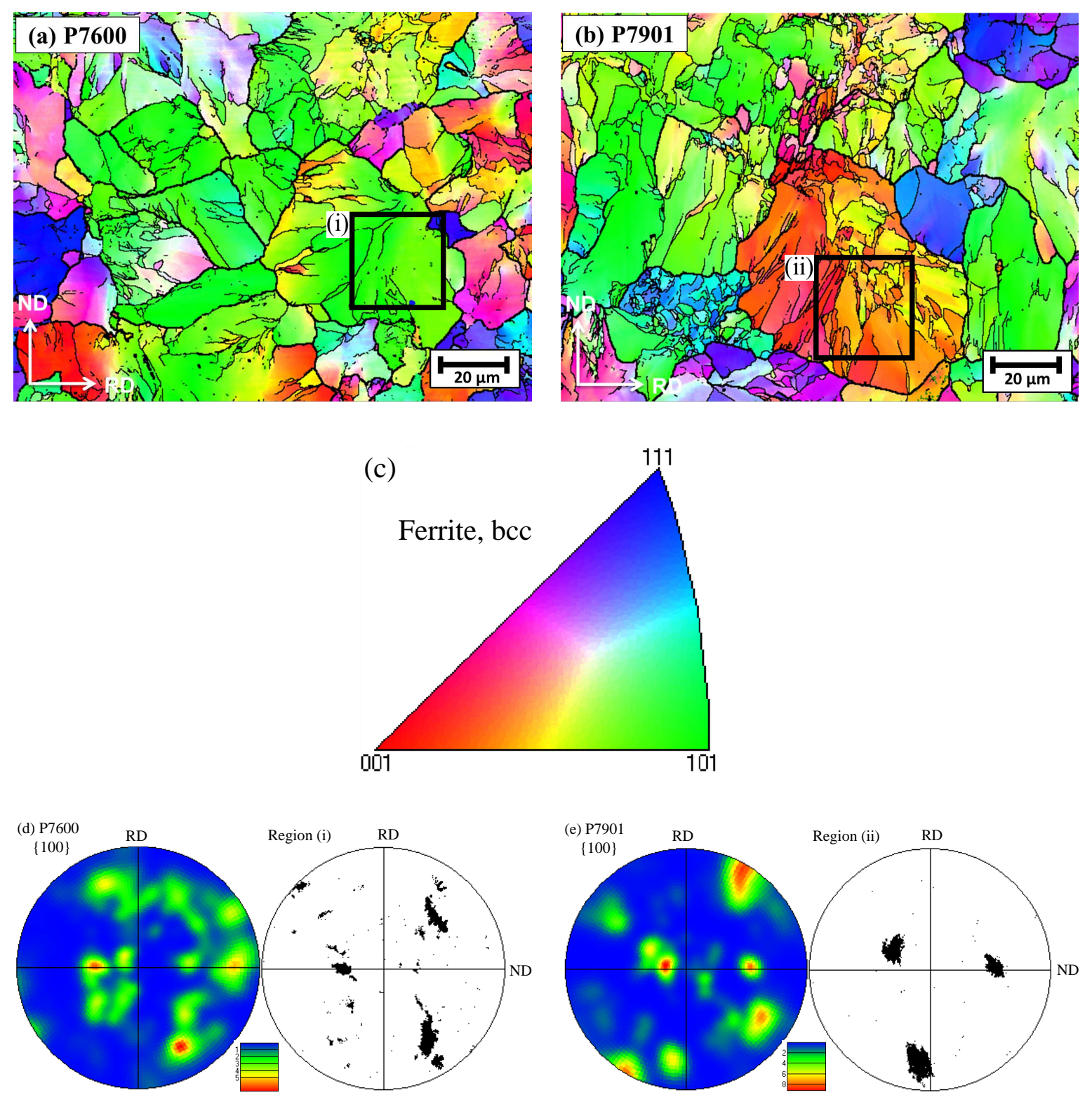

Figure 9.8: IPF map of P7600 (a) and P7901 (b) and the corresponding colour key in (c). Thick lines indicate high angle boundaries $\left(>15^{\circ}\right)$ and thin lines indicate low angle boundaries $\left(3^{\circ}-15^{\circ}\right)$. $\{100\}$ pole figure intensity contour plots of ferrite in P7600 (d) and P7901 (e) with the corresponding individual $\{100\}$ poles from regions (i) and (ii) as marked in (a) and (b) respectively. 


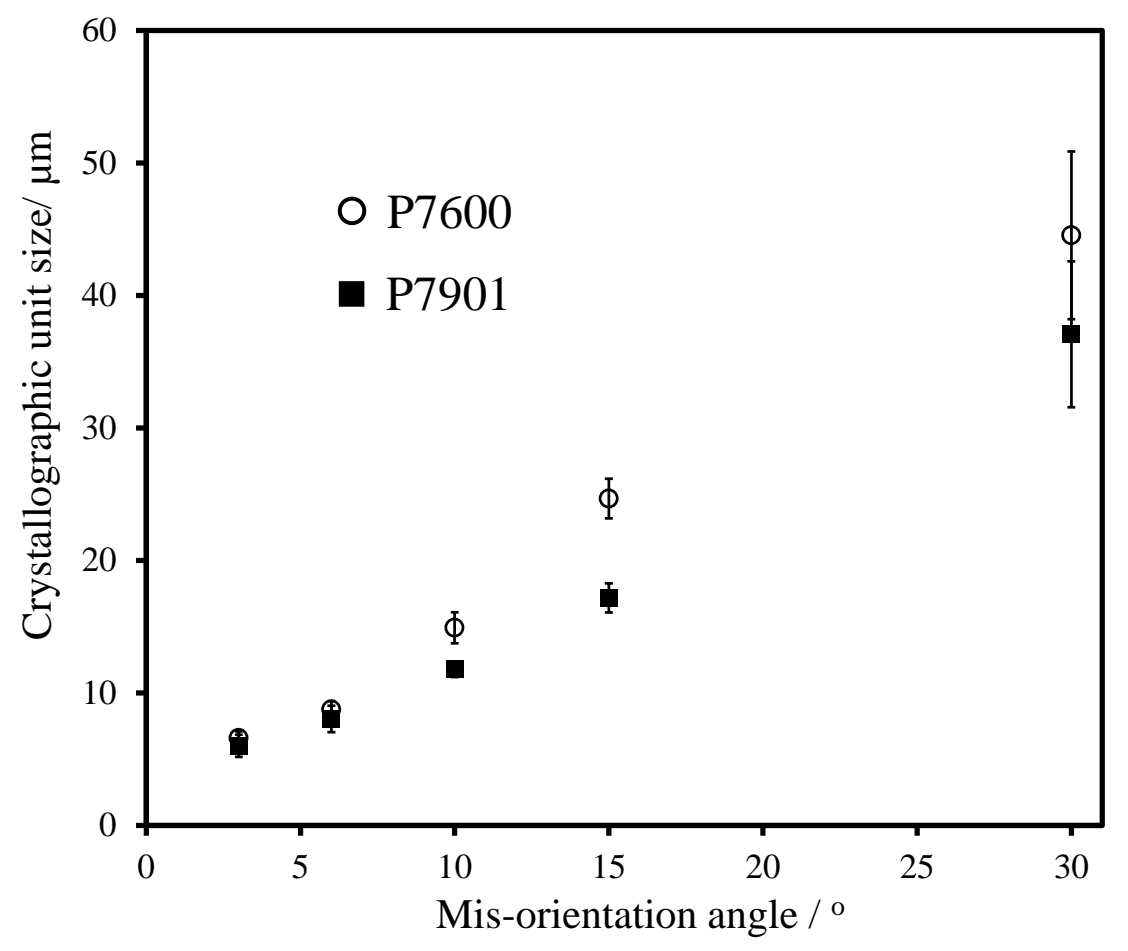

Figure 9.9: Variation of crystallographic unit size with critical misorientation angle

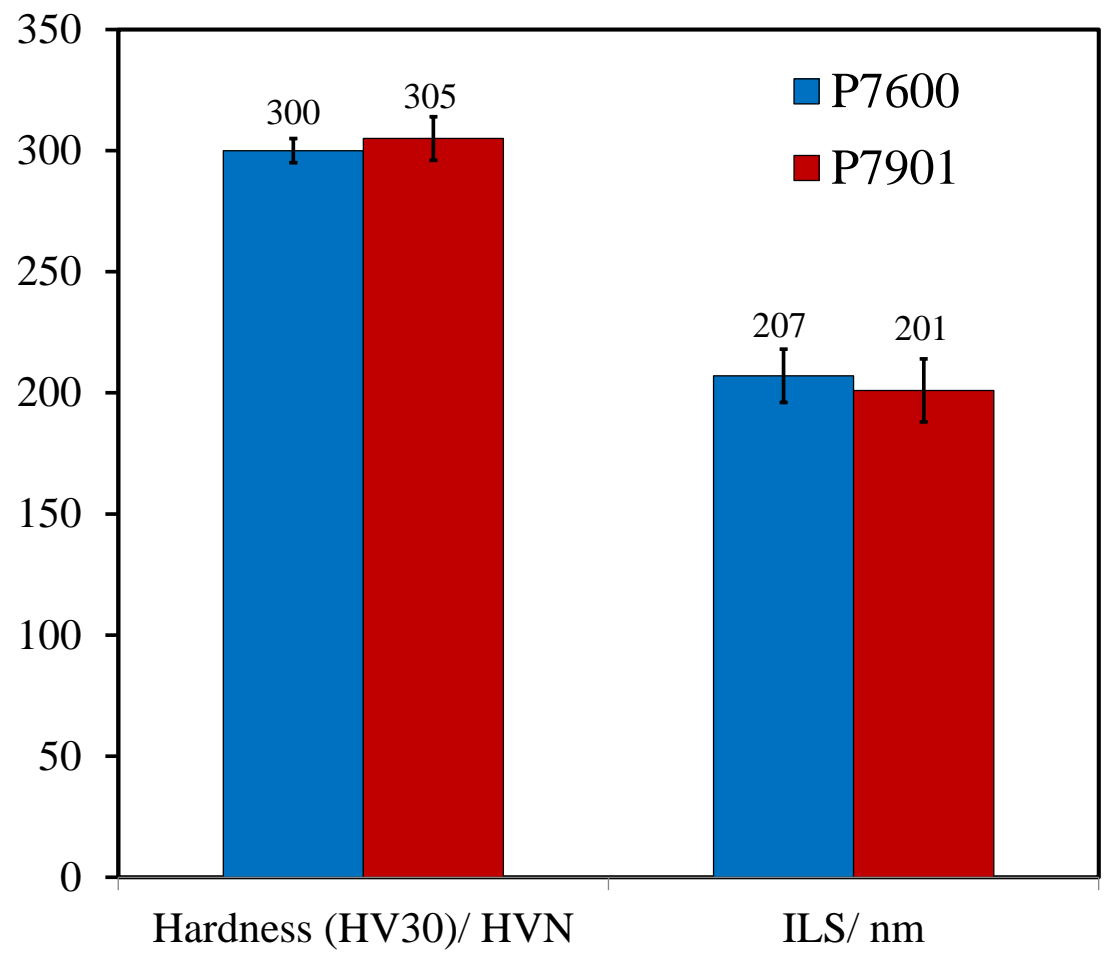

Figure 9.10: Comparison of hardness (HV30) and mean random interlamellar spacing (ILS) for P7600 and P7901. 
The longitudinal and transverse tensile properties are plotted in Figure9.11. The tensile strength improves by $\sim 30 \mathrm{MPa}$ in the Nb-microalloyed P7901 alloy despite having similar interlamellar spacing and hardness values compared to P7600. The small refinement in crystallographic unit size in Nb-microalloyed P7901 may be attributed to the improved tensile strength. Unlike the bainitic steels, the ductility, particularly the reduction in area tends to decrease in the Nb-microalloyed pearlitic steels due to increased strength. Here also, change in reduction in area is more significant than total elongation.
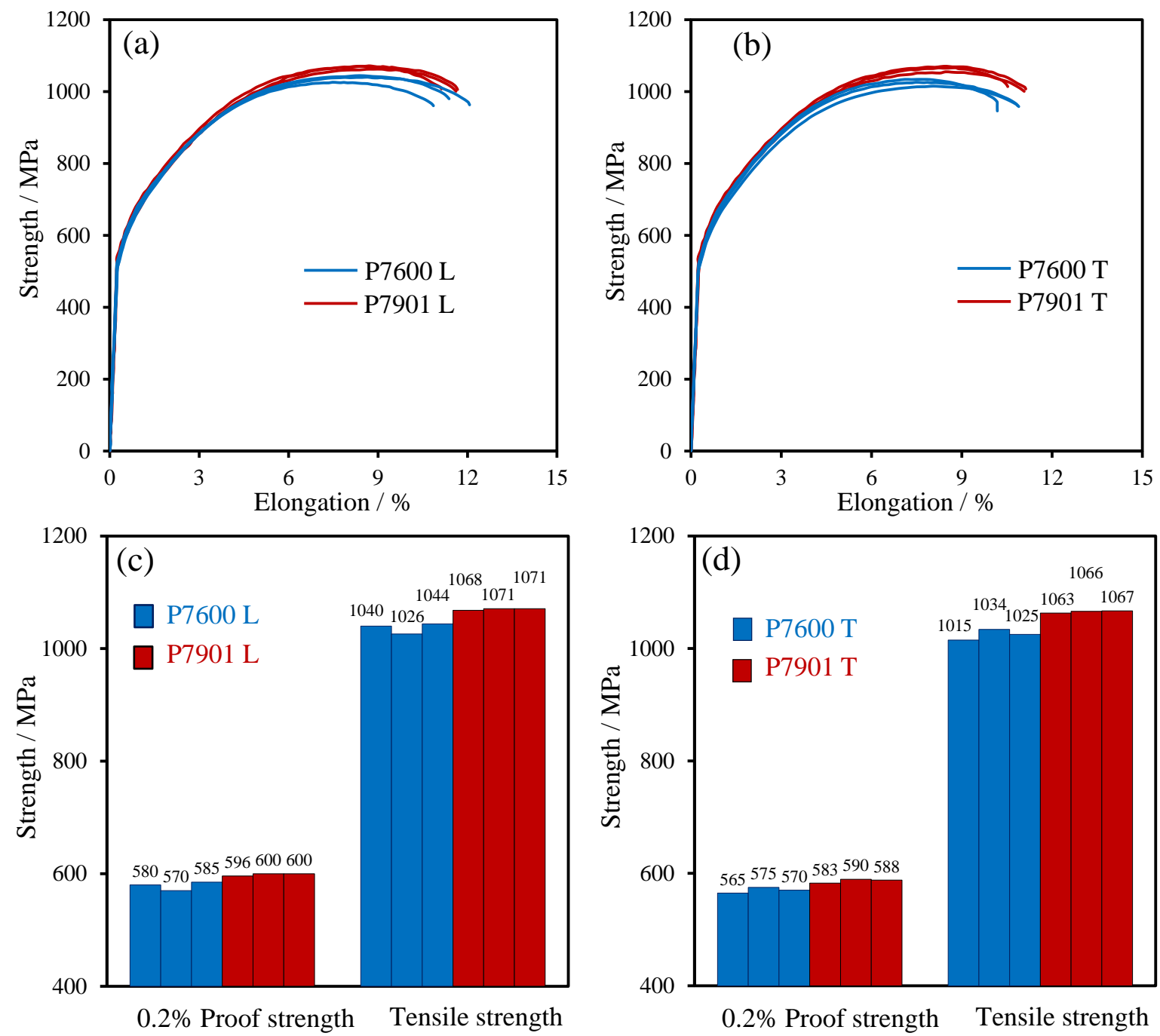

Figure 9.11: Tensile properties of pearlitic alloys P7600 and P7901 in longitudinal (L) orientation in (a), (c) and in tranverse (T) orientation in (b), (d). 

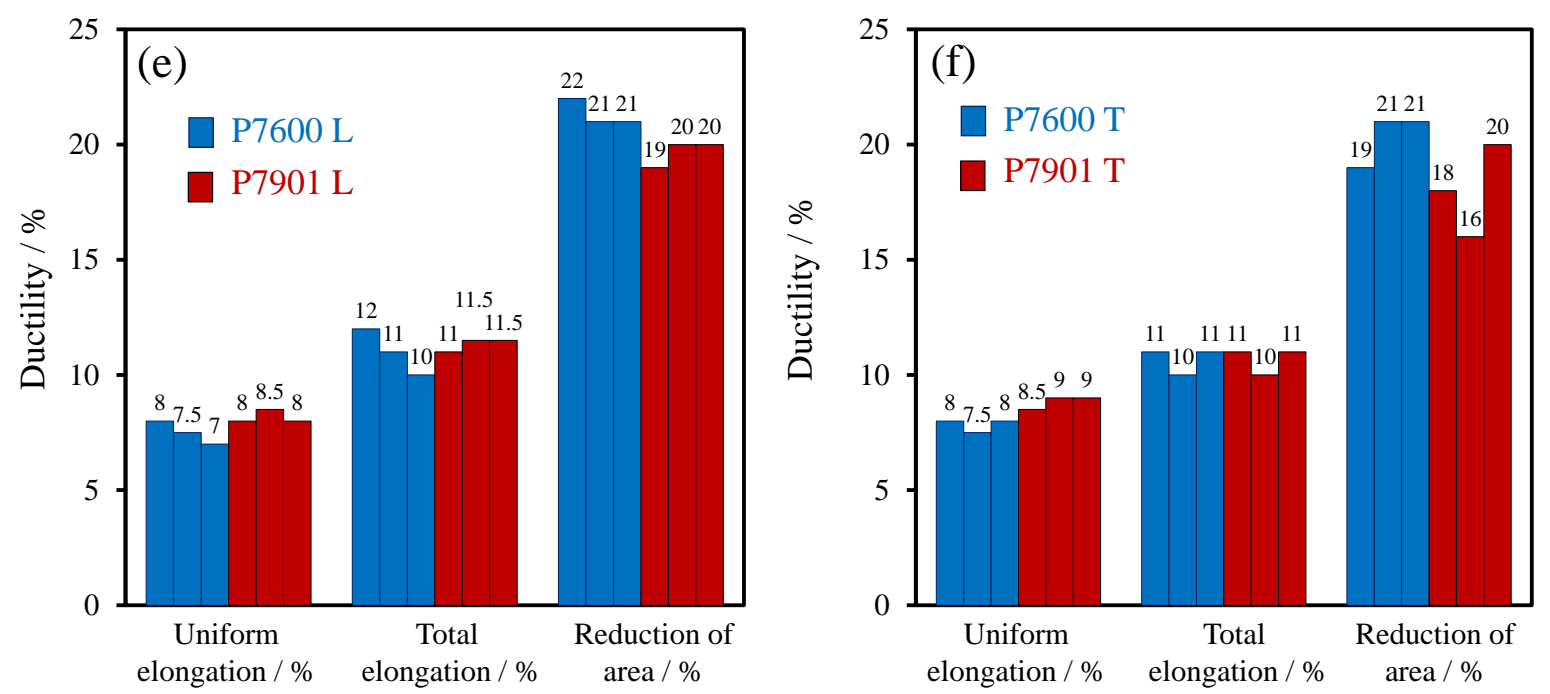

Figure 9.11 continued: Tensile properties of pearlitic alloys P7600 and P7901 in longitudinal $(\mathrm{L})$ orientation in (e) and in tranverse $(\mathrm{T})$ orientation in (f).

\subsubsection{Charpy impact toughness}

The Charpy impact toughness properties at room temperature in L and T orientation are summarised in Figures 9.12 and 9.13 for bainitic and pearlitic alloys respectively. For the bainitic alloys, the toughness tends to improve by $\sim 24 \%$ in the $\mathrm{L}$ orientation for the niobium containing B2102 compared to the steel B2200 which is not microalloyed. The transverse toughness is about similar for both steels. The cementite in pearlite microstructure makes this kind of steel inherently brittle and the small refinement in crystallographic unit size (by $\sim 5 \mu \mathrm{m}$ with an average size of $\sim 22 \mu \mathrm{m}$ ) is not sufficient to improve the toughness significantly in the Nb-microalloyed P7901. But due to possible rolling anisotropy, the toughness in transverse $(\mathrm{T})$ orientation decreases in P7901. 


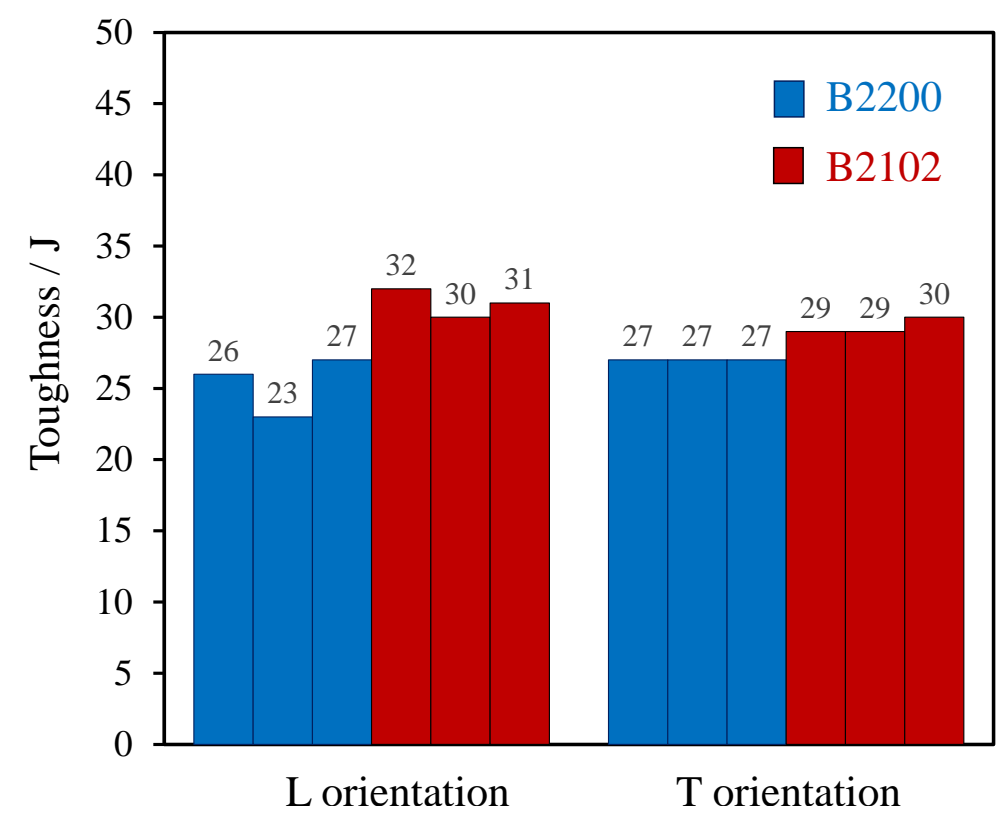

Figure 9.12: Charpy impact toughness in longitudinal (L) and transverse (T) orientation for B2200 and B2102 alloys.

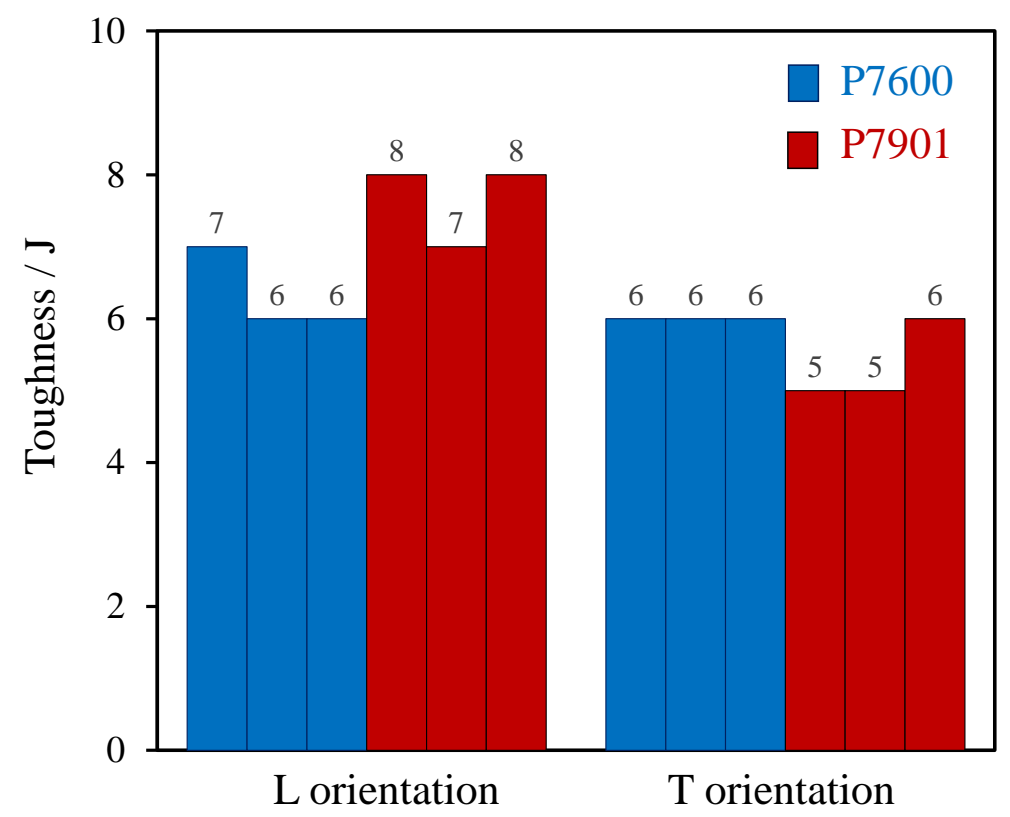

Figure 9.13: Charpy impact toughness in longitudinal (L) and transverse (T) orientation for P7600 and P7901 alloys.

The fracture surfaces of the impact tested samples were observed using SEM. Representative fractographs for the bainitic and pearlitic alloys are shown in Figures 9.14 and 9.15, respectively. The river lines in the fracture surface are traced back to find the origin of cleavage initiation. No coarse NbC particles can be observed at the 
initiation sites. The cleavage fracture facet boundaries were identified and delineated as shown in Figure 9.16. The facet size distribution was measured in terms of equivalent circle diameter and compared in Figure 9.17. Approximately 50 facets were identified and measured for each value quoted. The decrease in the cleavage facet size in the Nb-microalloyed B2102 indicates improvement in toughness.
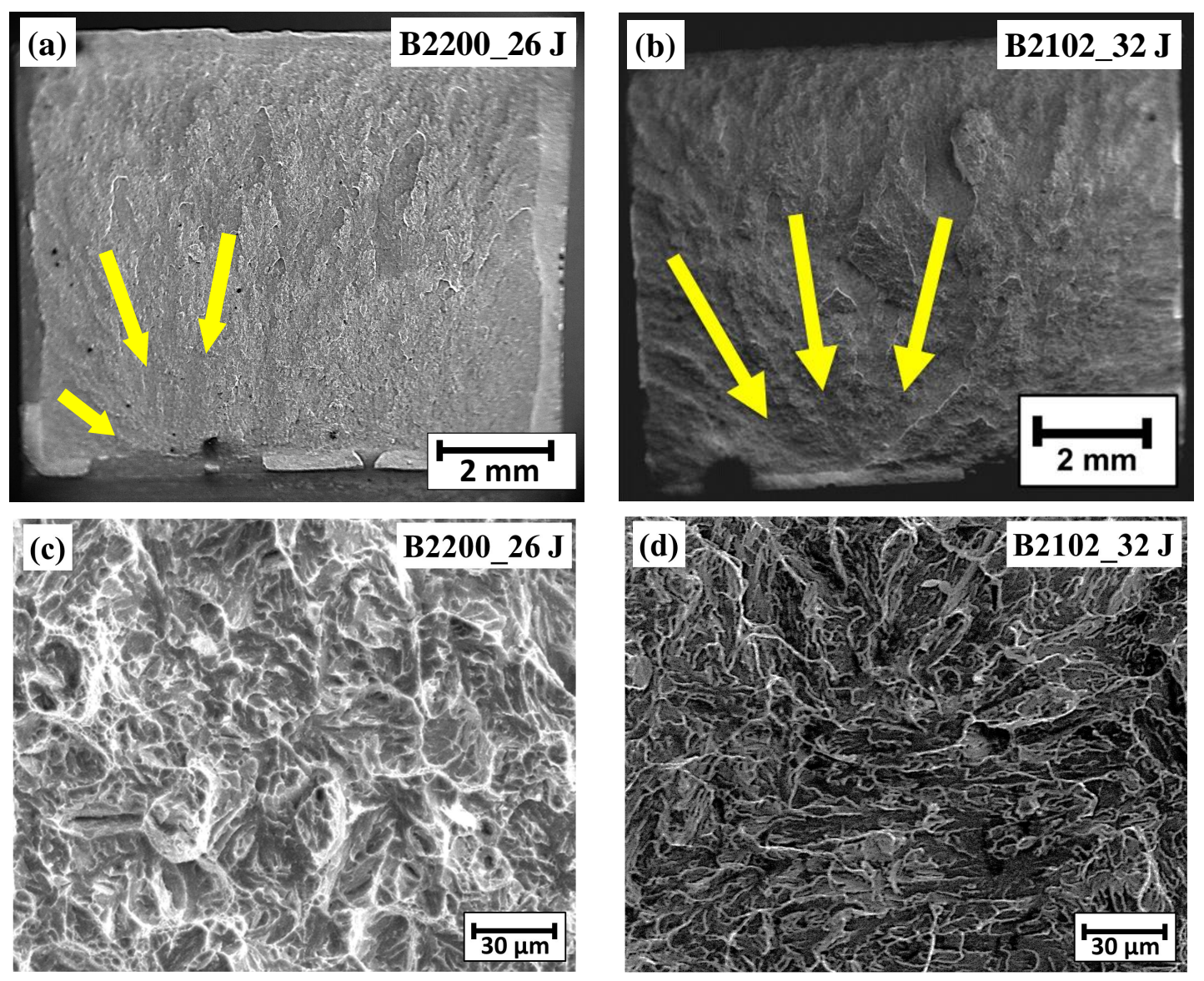

Figure 9.14: Fracture surface morphology of the impact tested samples at room temperature: (a), (c) B2200 (toughness 26 J); (b), (d) B2102 (toughness $32 \mathrm{~J}$ ). Yellow arrows trace the river lines back to the cleavage fracture initiation points. 

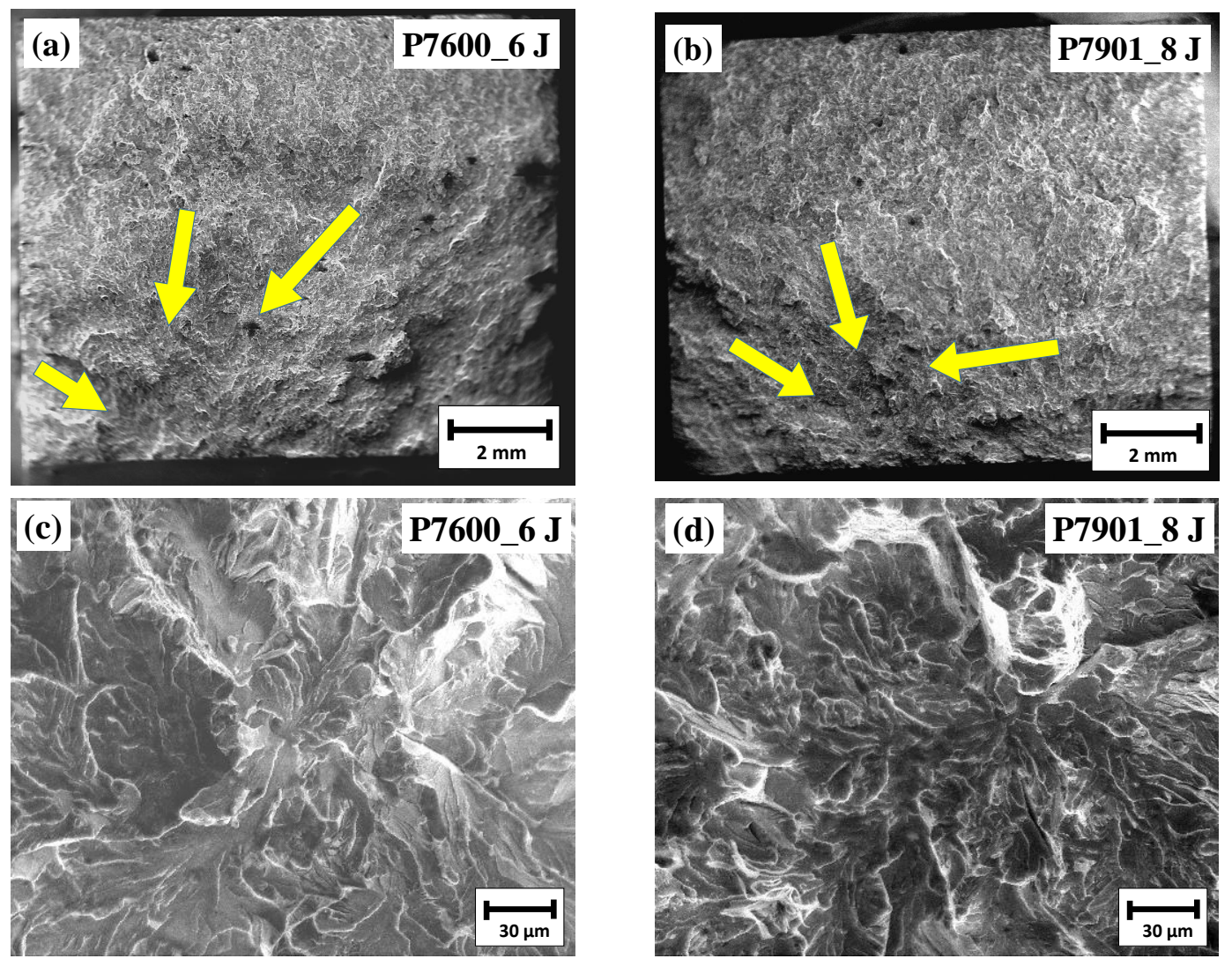

Figure 9.15: Fracture surface morphology of the impact tested samples at room temperature: (a), (c) P7600 (toughness 6 J); (b), (d) P7901 (toughness 8 J). Yellow arrows trace the river lines back to the cleavage fracture initiation points. 

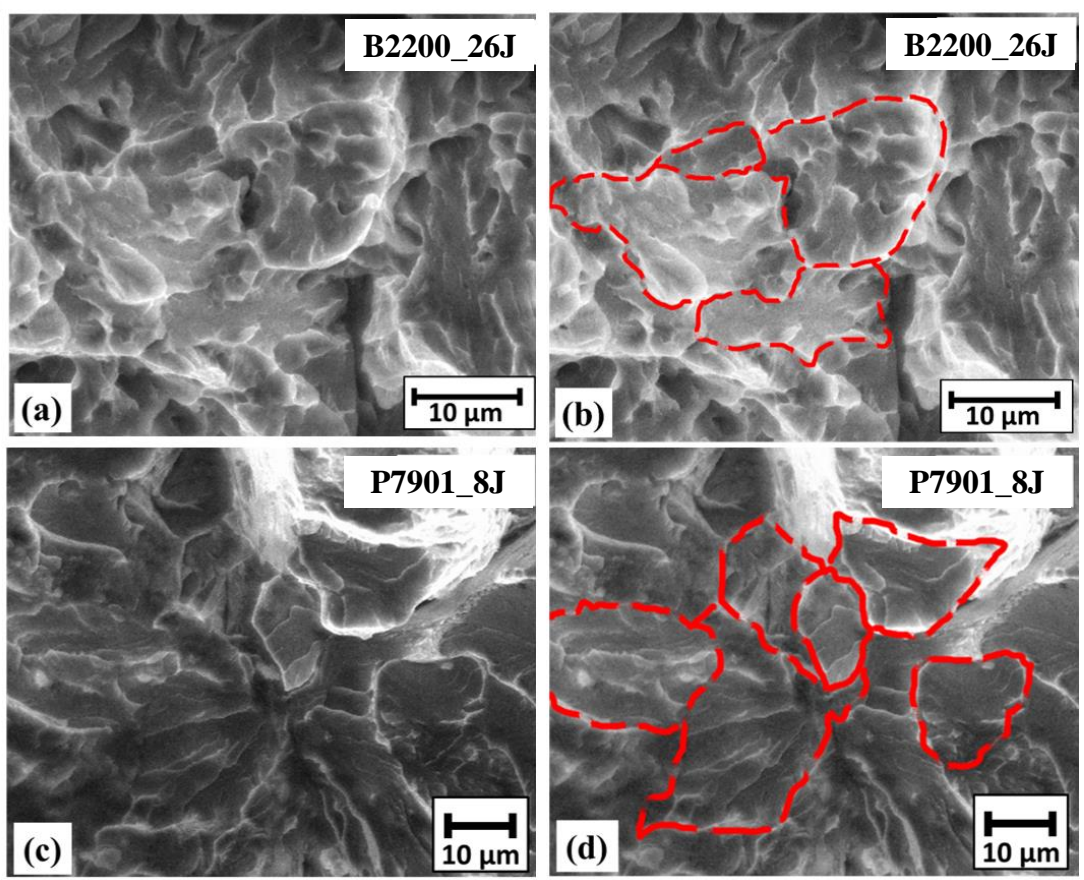

Figure 9.16: Representative cleavage fracture facet delineation for impact tested samples: (a), (b) Bainitic; (c), (d) Pearlitic.

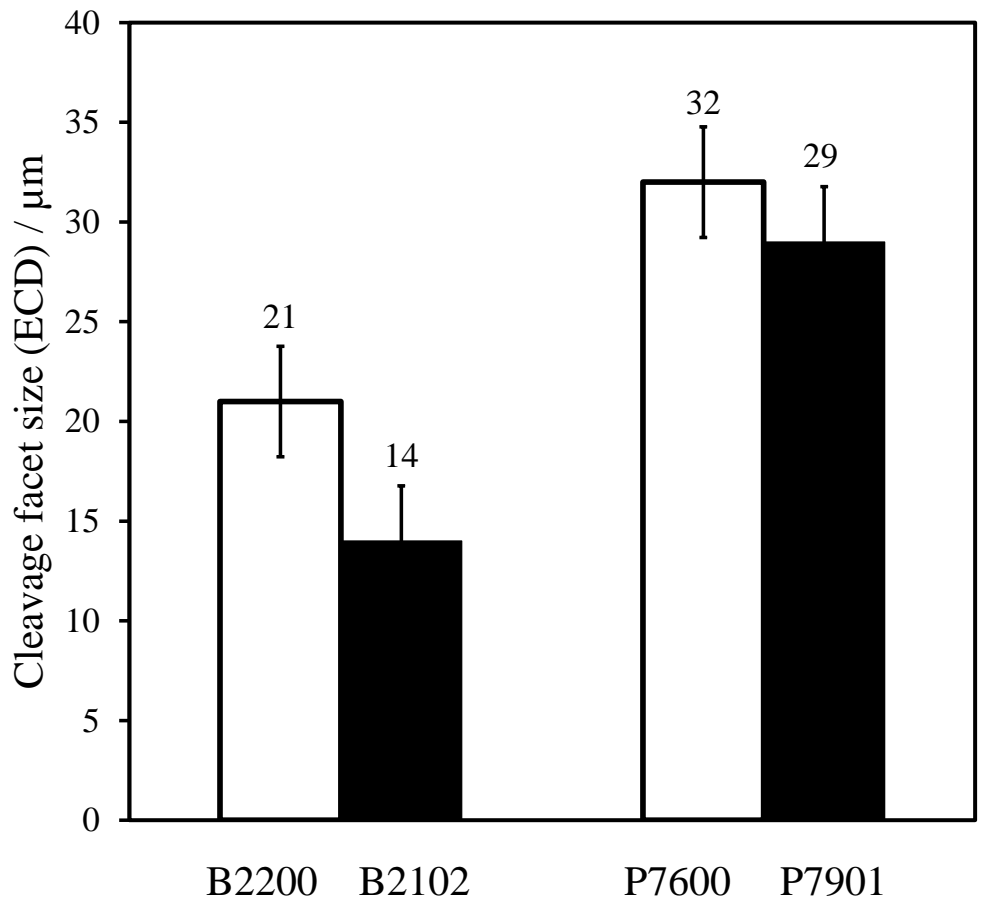

Figure 9.17: Cleavage fracture facet size in terms of equivalent circle diameter (ECD) comparison for the investigated alloys. 
The impact tested samples were cut perpendicular to the main fracture surface and non-propagating secondary microcracks were studied in the vicinity of the main fracture surface as shown in Figure 9.18. Pearlite is inherently brittle as the number density and size of the microcracks are both significantly high compared to the bainitic steels. The cracks in the bainitic alloys tend to be blunted or deviate at the retained austenite networks. There is a slightly greater volume fraction of retained austenite in the Nb-microalloyed B2102, which contributes to its improved toughness compared to B2200 which is not microalloyed. Low angle grain boundaries $\left(<15^{\circ}\right)$ in pearlitic microstructures cannot arrest crack while high angle boundaries can deflect the crack, thus contributing to toughness as shown in Figure9.19. In an instance, primary niobium carbide can be found in the vicinity of the notch as observed in Figure 9.20 for P7901 steel. For the B2102 steel, no such observation of niobium carbides in the vicinity of the notch is found.
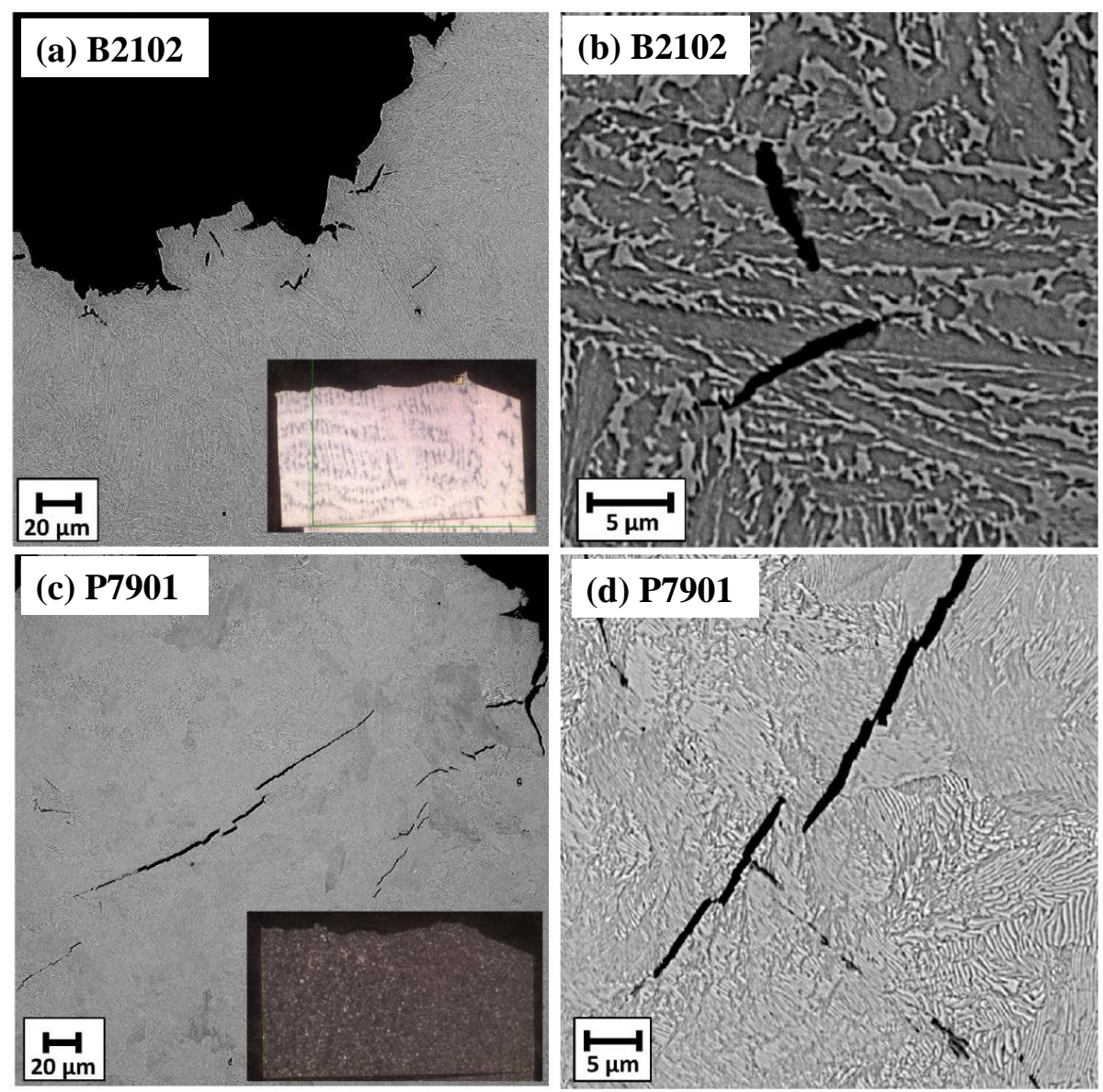

Figure 9.18: Non-propagating secondary microcracks in (a),(b) B2102 and (c),(d) P7901. The insets in (a) and (c) show the observation plane which is perpendicular to the main cleavage plane. 

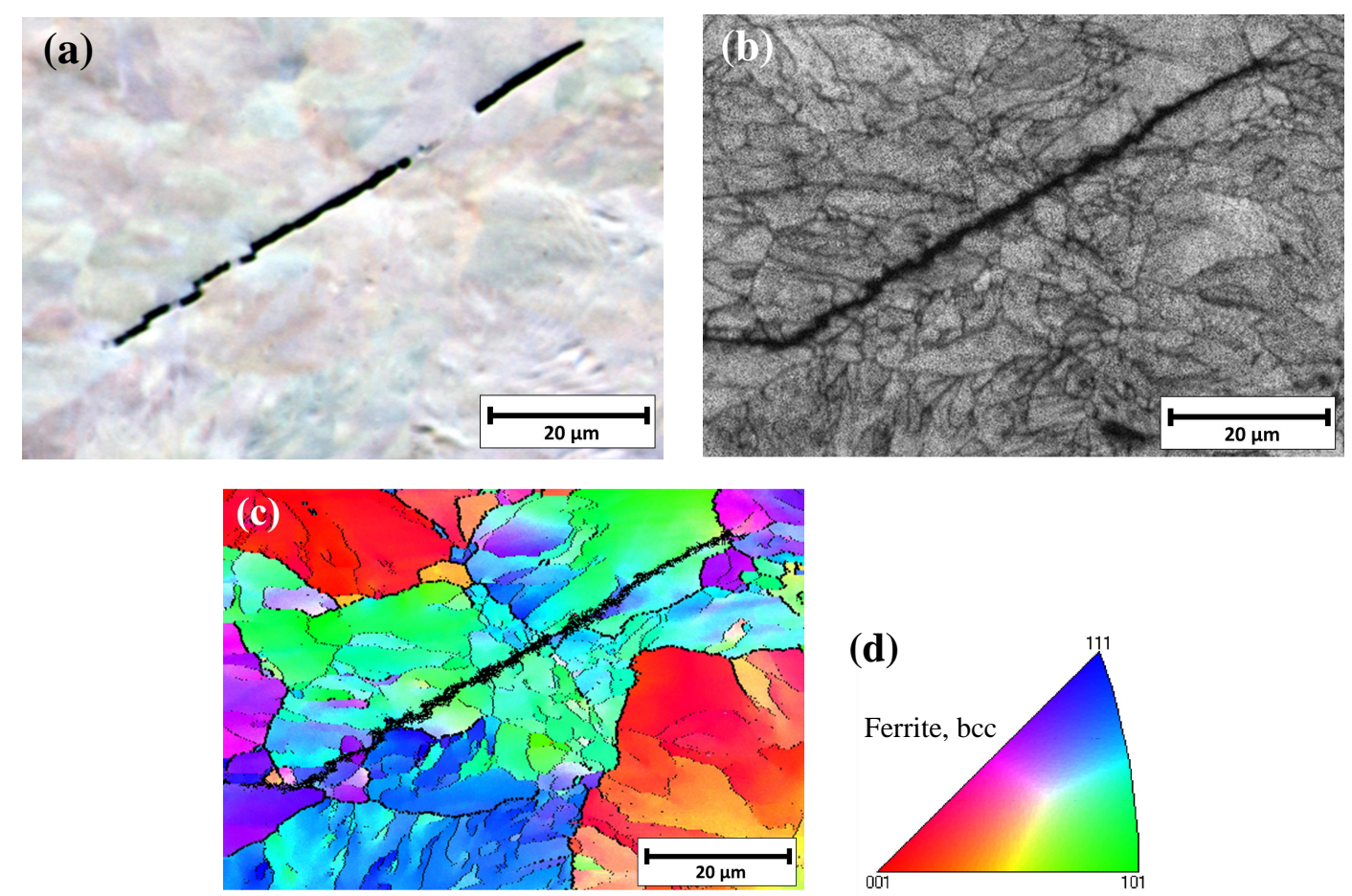

Figure 9.19: EBSD (step size $=0.16 \mu \mathrm{m}$ ) of a secondary microcrack perpendicular to main cleavage plane in a pearlitic alloy: (a) back-scattered electron image, (b) band contrast map, (c) inverse pole figure (IPF) map and (d) corresponding colour key. Thick lines indicate high angle boundaries $\left(>15^{\circ}\right)$ and thin lines indicate low angle boundaries $\left(3^{\circ}-15^{\circ}\right)$.

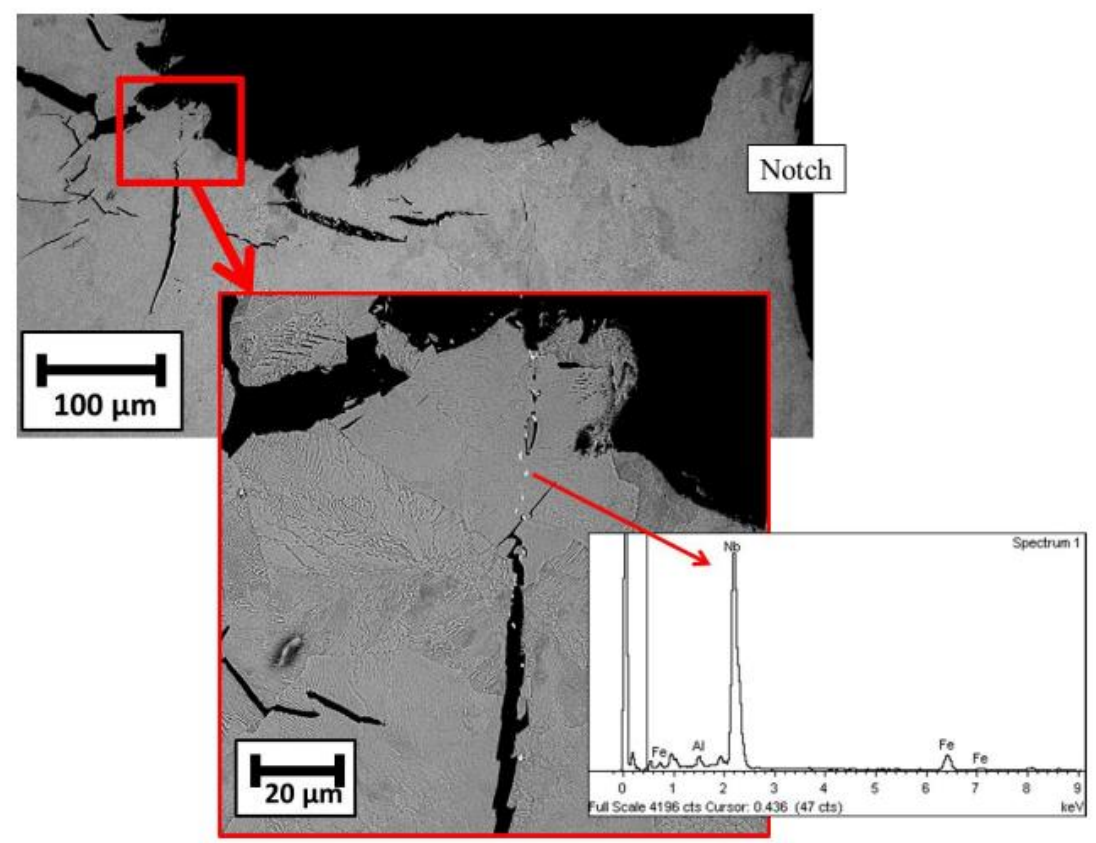

Figure 9.20: Primary niobium carbides in the vicinity of the notch for P7901 steels. 


\subsubsection{Wear performance}

The wear testing methodology is detailed in the Chapter 5 on experimental methodology. Figure 9.21 compares the wear performance of the investigated alloys along with the hardness values. The Vickers hardness (HV 30) of each disc was measured at three positions just below the disc surface and the average of these measurements is used as the disc hardness. Bainitic alloys (hardness $>320 \mathrm{HV}$ ) were tested at $750 \mathrm{MPa}$ stress whereas the pearlitic alloys (hardness $<320 \mathrm{HV}$ ) were tested at stress $560 \mathrm{MPa}$. The error in each experimental wear rate data is calculated from a neural network model perceived noise in a collection of 758 other wear test results from earlier experiments on different compositions using the identical test setup at STC, Tata Steel, UK. The details of the neural network model are summarised in Chapter 10.
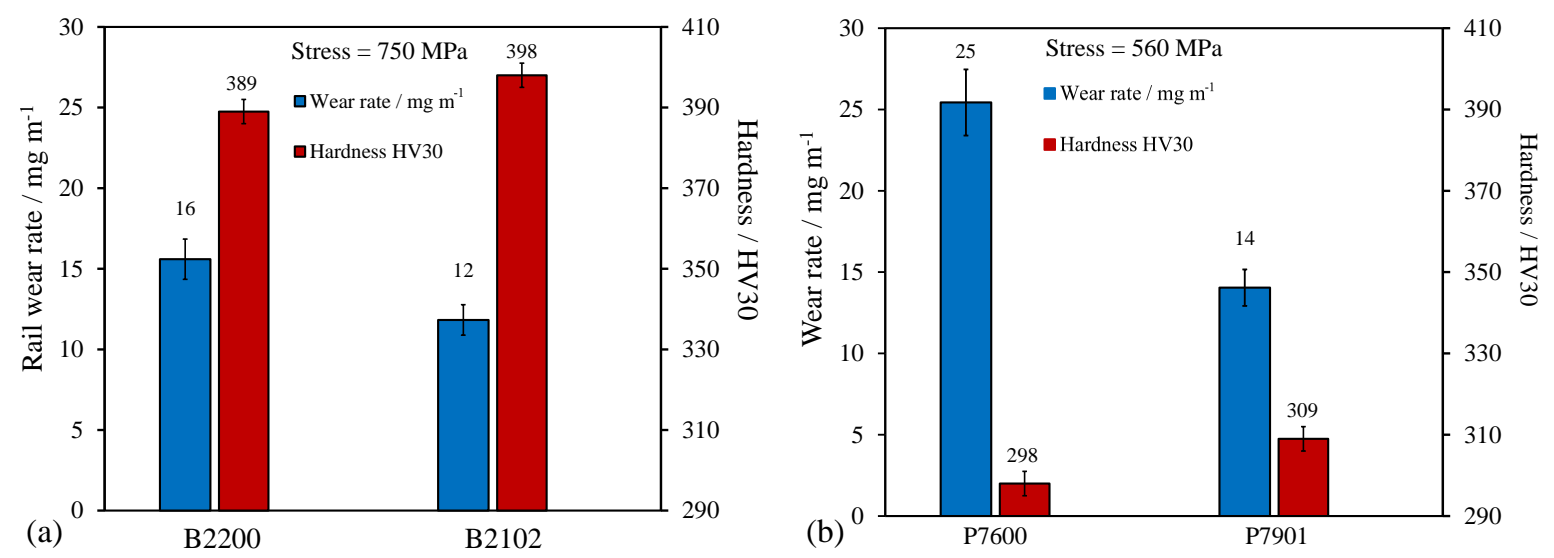

Figure 9.21: Wear rates and hardness for (a) bainitic alloys B2200 and B2102, (b) pearlitic alloys P7600 and P7901. The error in each experimental wear rate data is calculated from a neural network model perceived noise and reflect the repeatability error for each experiment.

Even though the bainite steels were tested at a higher contact stress, their wear resistance was better or comparable to the pearlitic alloys which were tested at a lower contact stress of $560 \mathrm{MPa}$. This is because the bainitic microstructures are generally more wear resistant than pearlite of the same strength levels. The wear rate decreased in the $\mathrm{Nb}$-microalloyed alloys compared to their non-microalloyed counterparts essentially due to increased hardness. The decrease in wear rate is less in the bainitic alloys, presumably because the wear rate itself is low to begin with, but significant for pearlitic alloys. The addition of $0.01 \mathrm{wt} \% \mathrm{Nb}$ in pearlitic com- 
positions increased the hardness by $\sim 10 \mathrm{HV}$ and the mean yield strength (averaged over both $\mathrm{L}$ and $\mathrm{T}$ orientation from Figure 9.11) by $\sim 20 \mathrm{MPa}$, but approximately doubles the wear resistance.

The wear tested samples were cut parallel and also perpendicular to the wear direction and the subsurface cross-sections were observed using SEM. The wear mechanism for both the bainitic alloys are similar. Some regions contain a plastically deformed layer containing numerous voids and microcracks as shown in Figures $9.22 \mathrm{a}$ and $\mathrm{b}$. The orientation of the samples are shown in the inset. Whereas in some areas, the deformed layer is worn out as shown in Figure9.22 c indicating nonuniform wear along the circumference of the discs. Solano et al. observed similar kind of damage mechanism under rolling contact stresses in nanostructured bainitic steels 155 and in cementite-free bainite rails 156 where ductile micro-void initiation was attributed to the strain incompatibility at interfaces between bainitic-ferrite and blocky retained-austenite regions transformed into martensite or, between ferrite and austenite layers due to dislocation pile-up. Voids coalesce and form cracks. For the Nb-microalloyed B2102, sometimes NbC can be observed associated with the microcracks as shown in Figure $9.22 \mathrm{~d}$. 

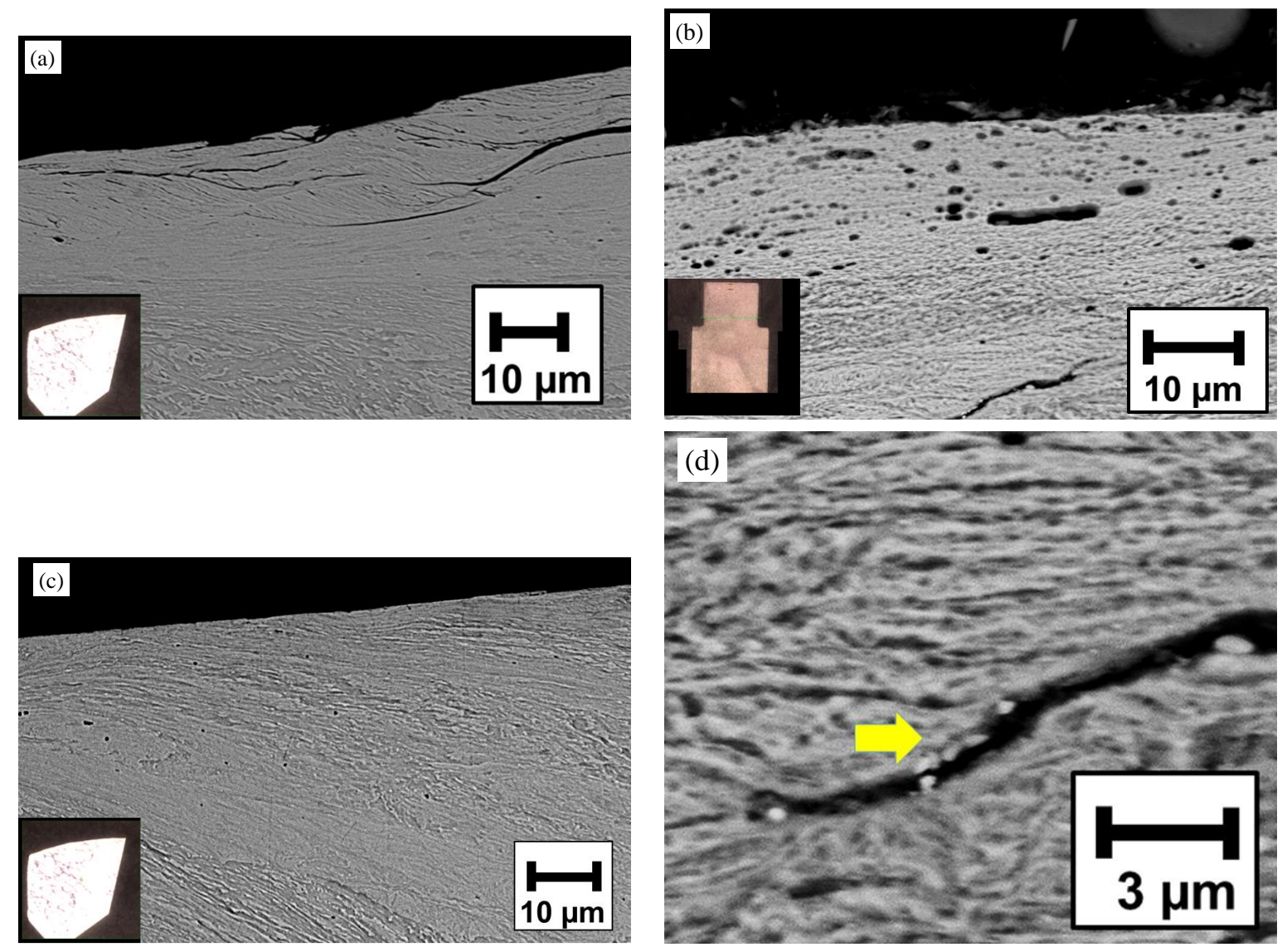

Figure 9.22: Deformed subsurface layer containing voids and microcracks in (a) parallel to wear direction, (b) perpendicular to wear direction. (c) Worn out deformed layer in a region parallel to wear direction. The observation planes are shown in the insets. (d) Yellow arrow indicating NbC particles associated with a microacrack. 
For the pearlitic alloys, P7600, which is non-microalloyed undergoes gross plastic deformation as observed from the lip formation at the corners in Figure 9.23 a due to increased plastic side flow as compared to microalloyed P7901 (Figure 9.23b). The mean yield stress (averaged for both $\mathrm{L}$ and $\mathrm{T}$ orientation) for P7600 is $574 \mathrm{MPa}$ which is quite close to the $560 \mathrm{MPa}$ contact stress whereas mean yield stress for P7901 is $593 \mathrm{MPa}$ (Figure 9.11). Figures 9.24 and b shows depth of the plastically deformed layer parallel to the wear direction. Once the plasticity is exhausted, cracks form and eventually the layer is removed by flaking. Sub-surface voids and cracks can be observed as indicated by yellow arrows. The sub-surface cracks tends to be confined within a crystallographic unit grain i.e. arrested by high-angle boundaries as shown in Figure 9.24c. In P7901, sometimes NbC can be observed associated with the microcracks as shown in Figure $9.24 \mathrm{~d}$.
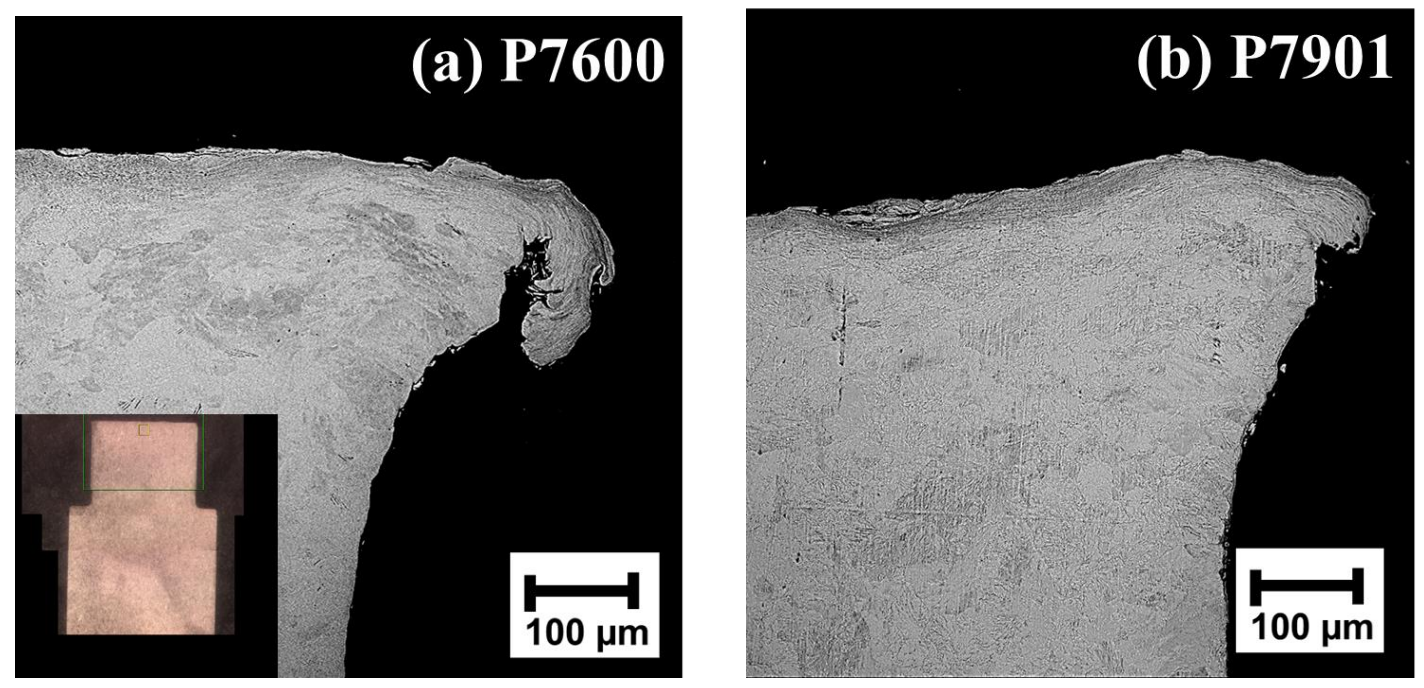

Figure 9.23: Plastic deformation in identically tested wear specimens (a) P7600, (b) P7901. The observation plane is shown in the inset in (a). 

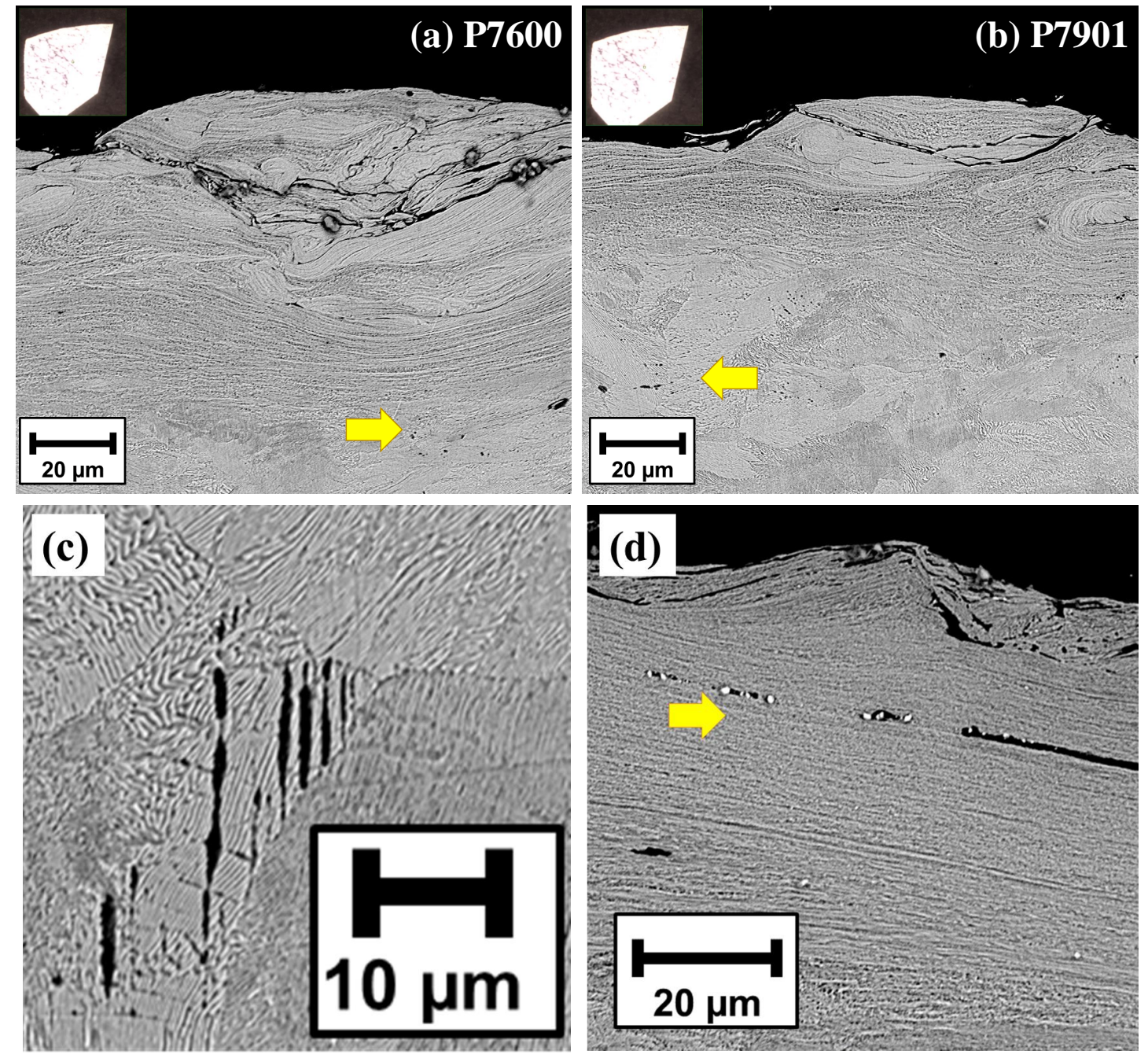

Figure 9.24: Deformed layer parallel to wear direction containing microcracks and sub-surface voids in (a) P7600, (b) P7901. (c) Microcracks arrested at high angle boundaries, (d) yellow arrow indicating NbC particles associated with a crack. 


\subsection{Summary}

The important findings from this study are:

(i) Niobium microalloying certainly affects the austenite recrystallisation kinetics of low carbon $(0.2 \mathrm{wt} \% \mathrm{C})$ Si-rich cementite-free bainitic alloys. Austenite tends to remain un-recrystallised and develop a pancaked morphology in the Nb-microalloyed alloy when finish rolled at $870{ }^{\circ} \mathrm{C}$; in contrast, the austenite in the non-microalloyed steel recrystallises and hence has an equi-axed grain shape.

(ii) Increased austenite grain boundary area and increased dislocation activity, hinder bainite growth and the retained austenite volume fraction increase which leads to slightly improved ductility and toughness.

(iii) Nb-microalloying improves the hardness and in turn the wear resistance properties of cementite-free bainitic steels. The bainitic microstructures are generally more wear resistant than pearlite of the same strength levels. Bainite with higher hardness than pearlite, when subjected to a higher contact stress $(750 \mathrm{MPa})$, have comparable or better wear resistance than the less hard pearlite under a lower contact stress $(560 \mathrm{MPa})$.

(iv) For the pearlitic alloys, $0.01 \mathrm{wt} \% \mathrm{Nb}$ addition refine the crystallographic unit size in the microstructure. The effect of this refinement improves the tensile strength and toughness negligibly, but the wear resistance improves significantly. Nb-microalloying minimizes the gross plastic deformation of pearlite, leading to low wear rate.

(v) The undissolved primary niobium carbide sizes are fine enough to not trigger any cleavage fracture initiation. But brittle cementite in pearlite microstructure makes this kind of steels inherently brittle while the fineness in bainitic microstructures provide good toughness which can also be improved by niobium microalloying. 


\section{Chapter 10}

\section{Neural network modelling of wear}

\subsection{Introduction}

A Bayesian neural network model can be constructed to estimate the wear performance of rail compositions. The perceived noise in the experimental data can also be analysed to ascertain the repeatability of an experiment. Details of the neural networks have been given by numerous authors $157-170$ and relevant applications in materials science field have been comprehensively reviewed by Bhadeshia et al. [171 172]. The neural network models applied in a Bayesian framework [157 160], are implemented in 'Neuromat's Model Manager' 173 174 which provides a graphical interface to MacKay's 'bigback' program [175], used extensively in the Phase Transformations and Complex Properties group at the University of Cambridge.

\subsection{The technique}

In brief, a typical neural network consists of an input layer, a hidden layer and an output layer as illustrated in Figure 10.1. The output variable $y$ is expressed as a linear summation of activation functions, $h_{i}$, with weights $w_{i}$ and the bias $\theta$.

$$
\begin{gathered}
y=\sum_{i} w_{i} h_{i}+\theta \\
h_{i}=\tanh \left(\sum_{j} w_{i j} x_{j}+\theta_{i}\right)
\end{gathered}
$$

The weightings are simplified for interpretation purposes by normalising the data within the range \pm 0.5 . 


$$
x_{j}=\frac{x-x_{\min }}{x_{\max }-x_{\min }}-0.5
$$

where $x$ is the input value and $x_{j}$ is the normalised value $171 \quad 172$ 174].

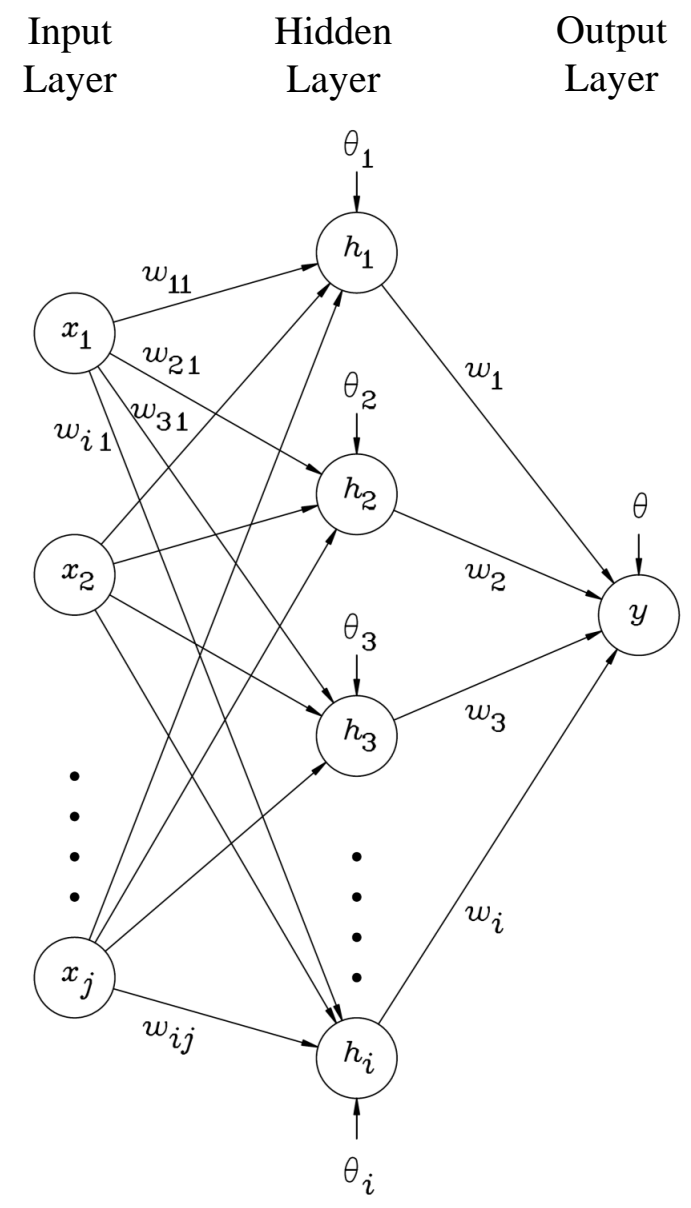

Figure 10.1: Sturcture of a three layer neural network [174].

The input data are divided into two sets, a training and a test data set to avoid overfitting of data. The model is produced using only the training data. The test data are then used to determine the optimum complexity of the model by assessing its ability to model previously unseen data.

In the Bayesian neural network [157], the 'training' is achieved by altering the parameters to fit the functions to the data using 'back-propagation' gradient descent optimisation procedures [176]. The purpose is to optimise an objective function which combines an overall error term $\left(E_{D}\right)$ to assess how good the fitting is and a regularisation term $\left(E_{W}\right)$ to force the network to use appropriately small weights.

$$
M(w)=\beta E_{D}+\alpha E_{W}
$$




$$
\begin{gathered}
E_{D}=\frac{1}{2} \sum_{k}\left(t^{k}-y^{k}\right)^{2} \\
E_{W}=\frac{1}{2} \sum_{i} w_{i}^{2}
\end{gathered}
$$

where $\beta$ and $\alpha$ are complexity parameters which greatly influence the complexity of the model, $t^{k}$ and $y^{k}$ are the target and corresponding output values respectively, for one example input from the training data $x^{k}$. This automatically infers overcomplex and underregularised models to be less probable, even though the flexibility of equation 10.1 allows them to fit the data better 174 .

\subsubsection{Noise and uncertainty}

It is important to distinguish between two kinds of error: noise and uncertainty [171 172]. Noise is when the outcome of an experiment which is repeated a number of times results is slightly different results. A term $\sigma_{\mathrm{v}}\left(=\beta^{-\frac{1}{2}}\right)$ is used as the framework estimate of the noise level of the training data [175]. The second kind of error is the uncertainty which originates from the ambiguity in the mathematical functions capable of representing the same experimental data. Assuming that the uncertainty about the output $y^{k}$ has a Gaussian distribution, the size of the error bars i.e. variance $\left(\sigma_{y}^{k}\right)^{2}$ can be calculated from the Hessian of the parameters by,

$$
\left(\sigma_{y}^{k}\right)^{2}=G_{k}^{T} A^{-1} g_{k}
$$

where $g_{k}$ is $\partial y / \partial w$ evaluated at $x^{k} 177,178$.

\subsubsection{Log predictive error}

The final values of the weights depend upon the initial guess made for the probability distribution of the weights and the number of hidden units. Therefore a large number of separate models are trained with different starting conditions. These sub-models are best evaluated using the log predictive error (LPE), in comparison to calculating the test error (TE). LPE penalises wild predictions less when they are accompanied by large uncertainties. Splitting the data into a training and testing set, allows alternative submodels to be compared by their performance in predicting the unseen data using equation 10.5 .

$$
\mathrm{LPE}=\sum_{k}\left[\frac{1}{2} \frac{\left(t^{k}-y^{k}\right)^{2}}{\left(\sigma_{y}^{k}\right)^{2}}+\log \left(\sqrt{2 \pi} \sigma_{y}^{k}\right)\right]
$$




$$
\mathrm{TE}=\frac{1}{2} \sum_{k}\left(t^{k}-y^{k}\right)^{2}
$$

\subsubsection{Committee}

The best $n$ models as ranked by the LPE (or TE) are combined to make a committee model in the hope of attaining more reliable results. The final prediction $(\bar{y})$ being the average of the predictions of the submodels and the variance of the committee's predictive distribution plus the mean of the variances are given by:

$$
\begin{gathered}
\bar{y}=\frac{1}{n} \sum_{l} y^{l} \\
\text { Variance } \sigma^{2}=\frac{1}{n} \sum_{l}\left(\sigma_{y}^{l}\right)^{2}+\frac{1}{n} \sum_{l}\left(y^{l}-\bar{y}\right)^{2}
\end{gathered}
$$

where $n$ is the number of submodels in the committee and $\bar{y} \pm \sigma_{y}^{l}$ is the estimate of a particular model $l$. The test errors of the predictions made by the different committees, are calculated in a similar manner to the test error of a single model and the one with the lowest perceived predictive error used.

$$
\left.\mathrm{TE}\right|_{\text {committee }}=\frac{1}{2} \sum_{n}\left(t_{n}-\bar{y}_{n}\right)^{2}
$$

Once trained, the network captures interactions between the inputs because of the nonlinearity of the activation function. The nature of the interactions are stored in the weights, however, in comparison to linear regression they are difficult to interpret directly, the best way to identify trends is to make predictions using the model. Predictions are accompanied by an indication of the uncertainty which depends upon the confidence of the model for that prediction, and also the level of noise perceived in the data which is assumed to have a Gaussian distribution.

\subsection{The variables}

The variables included in the dataset accumulated for analysis are listed in Table 10.1 along with the ranges, means and standard deviations. The full set consisted of some 758 experiments collected from TATA Steel, UK and the same rolling-sliding wear testing machine was utilised to evaluate the wear performance of the Nb-microalloyed alloys in the previous chapter. 
Table 10.1: Variables and corresponding statistics. Compositions are in weight percent.

\begin{tabular}{lcccc}
\hline Variables & Minimum & Maximum & Average & Standard deviation \\
\hline Rail hardness $\left(\mathrm{H}_{\mathrm{R}}\right) / \mathrm{HV}$ & 194 & 556 & 336.1609 & 75.3736 \\
Wheel hardness $\left(\mathrm{H}_{\mathrm{W}}\right) / \mathrm{HV}$ & 217 & 467 & 284.9776 & 32.5606 \\
Contact stress / MPa & 560 & 750 & 640.9631 & 94.0193 \\
$\mathrm{C}$ & 0.035 & 1.1 & 0.563 & 0.2194 \\
$\mathrm{Si}$ & 0.06 & 2.11 & 0.4569 & 0.4723 \\
$\mathrm{Mn}$ & 0.46 & 13 & 1.3366 & 1.7482 \\
$\mathrm{P}$ & 0.005 & 0.057 & 0.0186 & 0.0081 \\
$\mathrm{~S}$ & 0.003 & 0.17 & 0.0243 & 0.0136 \\
$\mathrm{Cr}$ & 0 & 2.04 & 0.4567 & 0.5514 \\
$\mathrm{Mo}$ & 0 & 2.29 & 0.1149 & 0.3101 \\
$\mathrm{Ni}$ & 0 & 8.86 & 0.4287 & 1.2887 \\
$\mathrm{Nb}$ & 0 & 0.044 & 0.0006 & 0.0043 \\
$\mathrm{Cu}$ & 0 & 0.52 & 0.0418 & 0.1025 \\
$\mathrm{~V}$ & 0 & 0.16 & 0.0046 & 0.0213 \\
$\mathrm{Al}$ & 0 & 0.72 & 0.0049 & 0.0381 \\
$\mathrm{~B}$ & 0 & 0.0036 & 0.0002 & 0.0007 \\
$\mathrm{Ti}$ & 0 & 0.04 & 0.0016 & 0.0063 \\
\hline
\end{tabular}

\subsection{Model training}

The wear rate of rails were modelled directly as a raw value, rather than as a functional form which would bound its values leading to bias [170]. This is particularly the case when training the model with logarithmic values, which induces an upper and a lower limit for the predicted values and hence biases the model, this becomes extremely obvious when extrapolating over long ranges. The input dataset is equally divided into a training and a test dataset randomly 8 . The networks are trained with the training dataset starting with 25 hidden networks and 9 seeds 9 . Once the training is completed, the model performances in terms of LPE, TE and $\sigma_{\mathrm{v}}$, are analysed as function of model complexity (Figure 10.2).

\footnotetext{
${ }^{8}$ This randomness will affect the training each time the data is randomly divided for training and testing, and in turn affect the final model parameters and the output.

${ }^{9}$ The seeds are for the pseudorandom number generator generating the initial guesses at the network weights.
} 

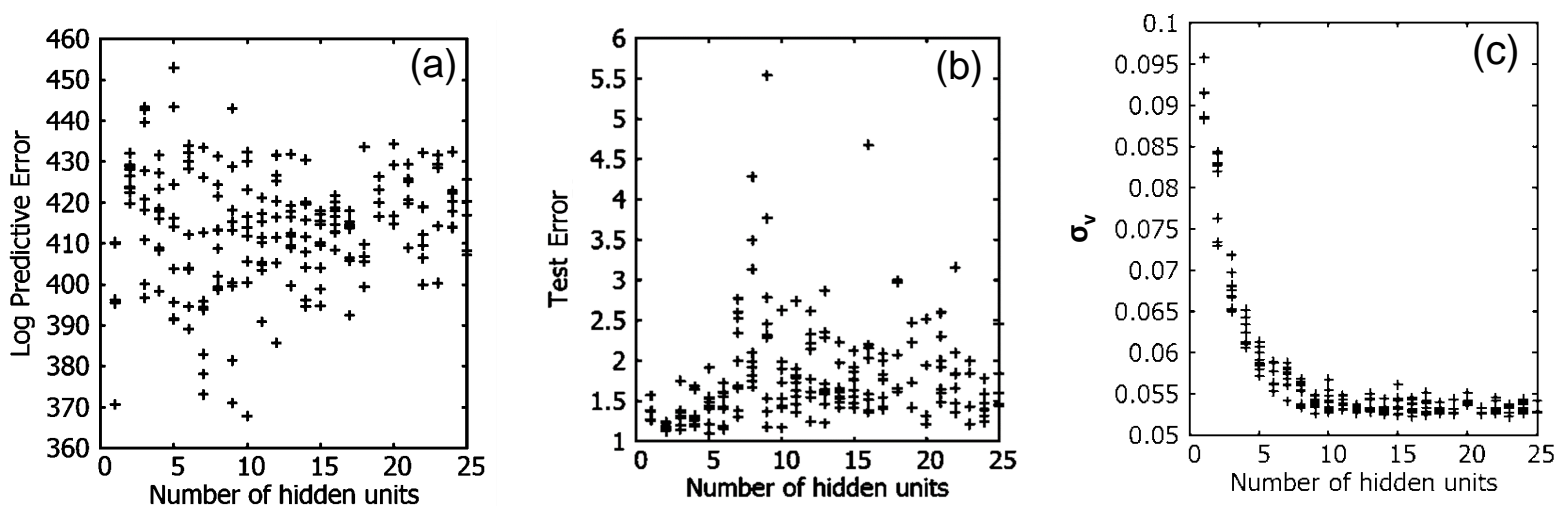

Figure 10.2: Variation in (a) log predictive error, (b) test error, and (c) $\sigma_{\mathrm{v}}$, the perceived noise in the output as function of the number of hidden units.

\subsection{Committee formation and testing}

Predictions are averaged over a number of best-performing networks which are ranked by decreasing LPE. As discussed earlier, LPE penalises wild predictions less when they are accompanied by large uncertainties. The performance of the committees is tested against the unseen test data and the cumulative test errors are plotted against the number of submodels in the committee in Figure10.3. The one giving the least cumulative error is selected as the best network for prediction which is in this case, is the committee comprising first 7 submodels ranked by decreasing LPE. Once the optimum committee is chosen, it is retrained on the entire dataset without changing the complexity of each model, with the exception of the inevitable and relatively small adjustments to the weights. Figure $10.4 \mathrm{a}-\mathrm{b}$ shows normalised predicted values versus experimental values for the best model in the training and test datasets, respectively. The predictions made using the optimum committee of models are illustrated in Figure 10.4 . 


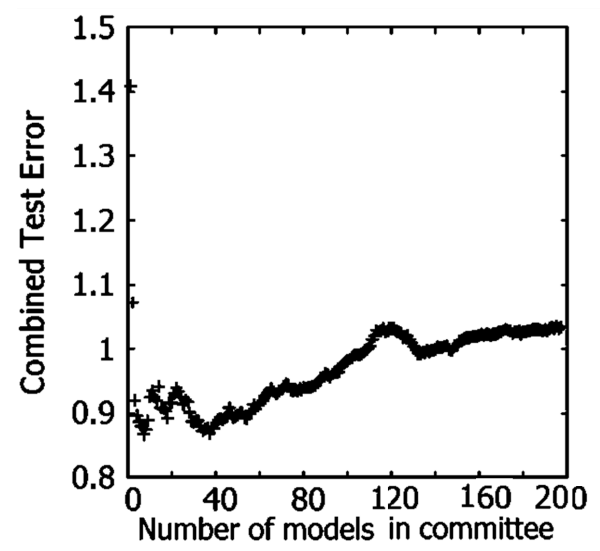

Figure 10.3: Cumulative test error with increasing number of submodels (ranked by decreasing log predictive error) in a committee.
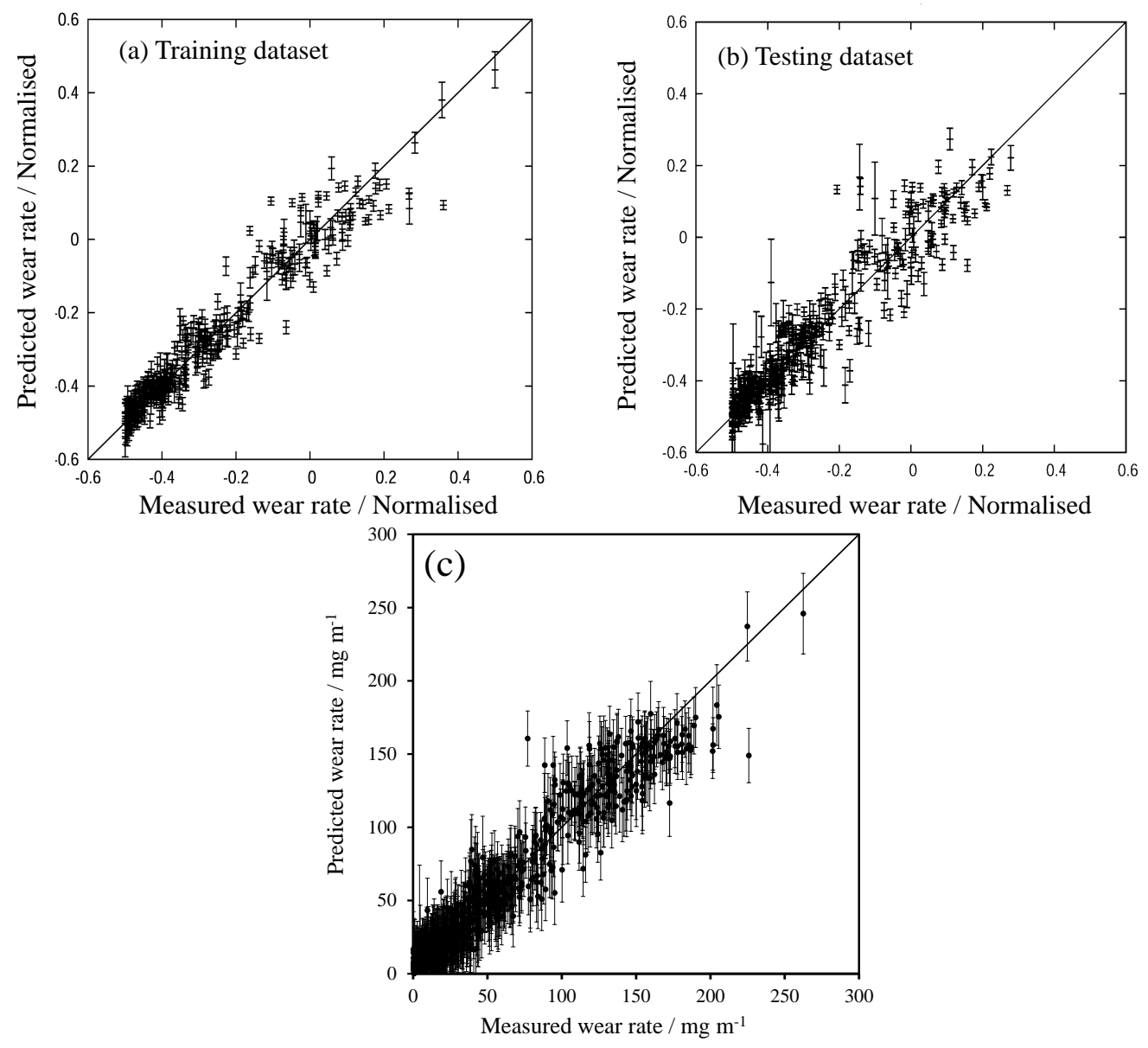

Figure 10.4: Predictions made using the best model, selected as the one having the largest log predictive error: (a) training data set, (b) test data set. (c) Predictions made on the entire dataset using the optimum committee. All the error bars contain both noise and uncertainty. 


\subsection{Maximum noise}

The $\sigma_{\mathrm{v}}$ values of the 7 sub-models used to form the committee, are plotted in Figure 10.5. The maximum $\sigma_{\mathrm{v}}$ is 0.073 . This noise, when multiplied to an experimental datum, can approximate the error in repeatability of that experimental datum. Similar concept has been used to find the error in the experimental wear data for the niobium microalloyed rails in Chapter 9. As discussed earlier, this noise is a constant and different from the uncertainty in prediction, which can be larger. The associated error will contain both the uncertainty and noise.

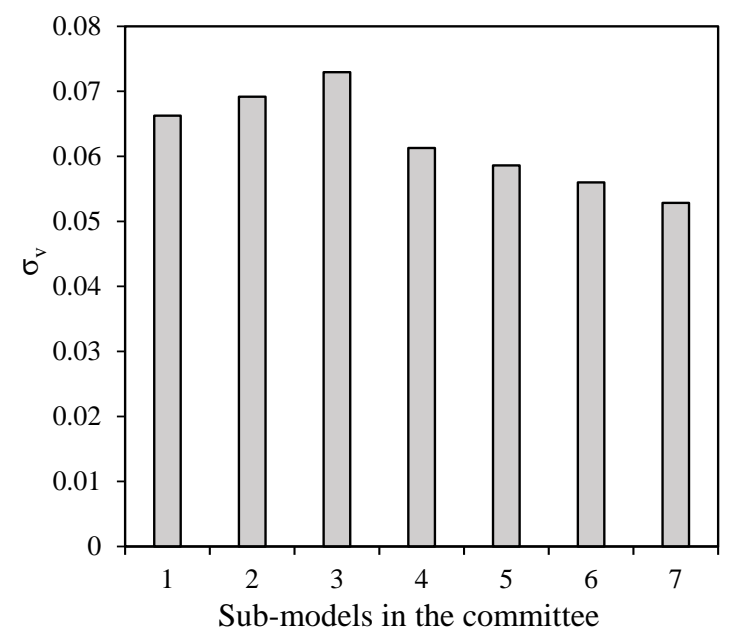

Figure 10.5: Cumulative test error with increasing number of submodels (ranked by decreasing log predictive error) in a committee.

\subsection{Significance}

For every input, it is possible to calculate a significance, which is a measure of the ability of an input to explain variations in the output. The significance is rather like a partial correlation coefficient, which is a function of the regularisation constants for the weights associated with the input 157 158. Consequently the significance of each input, as perceived by the neural network model, in influencing the output wear rate can be compared against metallurgical experience. Fig. 5 illustrates the significance of each input in terms of mean of the significance from the 7 submodels in the committee and error bars represent the standard error. As expected, rail hardness $\left(H_{R}\right)$ and wheel hardness $\left(W_{R}\right)$ are the most important factors in controlling wear rate of rails. Among the alloying elements, Mn and S have some effect on the wear performance probably due to $\mathrm{MnS}$ inclusions in high sulphur steels. 


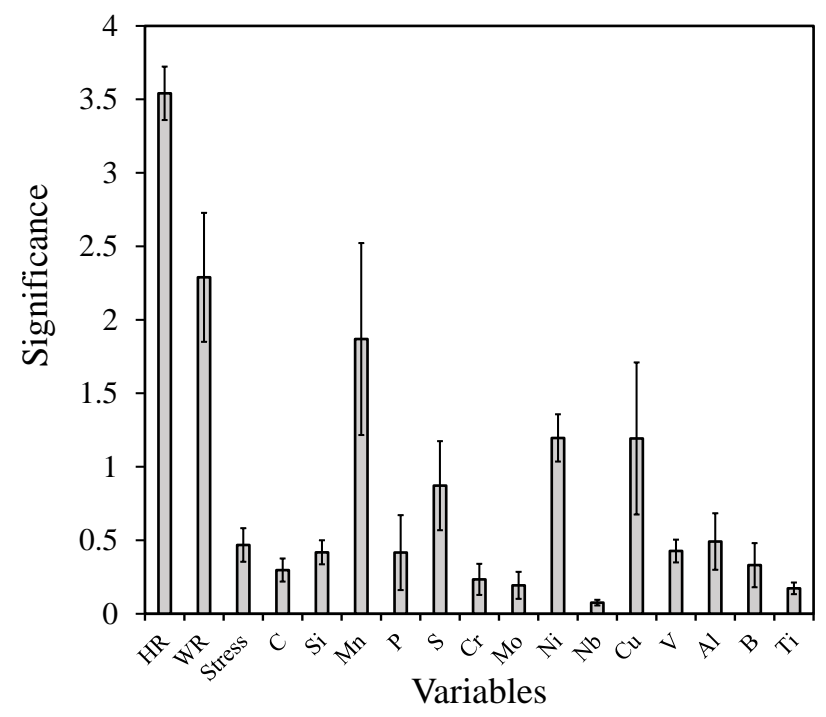

Figure 10.6: Network perceived significance of the input variables for the models in the committee.

Unlike linear regression analysis, the range of applicability of a neural network model cannot be defined in terms of the range of the data used to create the model (Table 10.1). This is because the network is non-linear so the inputs will in general be expected to interact. It is the Bayesian framework of the present method which resolves this problem because it allows the calculation of error bars which define the range of useful applicability of the trained network. The model can therefore be used in extrapolation given that it indicates appropriately large uncertainties when knowledge is sparse.

\subsection{Predictions}

To determine the sensitivity of the model to individual input variables, predictions are made by changing one variable whilst keeping all the others constant. The constant values for the variables are given in Table 10.2 . Figure 10.7 demonstrates the effect of individual inputs on rail wear rates.

Table 10.2: Constant values for variables in Figure 10.7. Compositions are in wt\%.

\begin{tabular}{ccccccccc}
\hline $\begin{array}{c}\text { Rail hardness } \\
\left(\mathrm{H}_{\mathrm{R}}\right)\end{array}$ & $\begin{array}{c}\text { Wheel hardness } \\
\left(\mathrm{H}_{\mathrm{W}}\right)\end{array}$ & $\mathrm{C}$ & $\mathrm{Si}$ & $\mathrm{Mn}$ & $\mathrm{P}$ & $\mathrm{S}$ & $\mathrm{Cr}$ & Mo-Ni-Nb-Cu-V-Al-B-Ti \\
\hline $310 \mathrm{HV}$ & $210 \mathrm{HV}$ & 0.78 & 0.42 & 1.0 & 0.0021 & 0.0005 & 0.55 & 0 \\
\hline
\end{tabular}



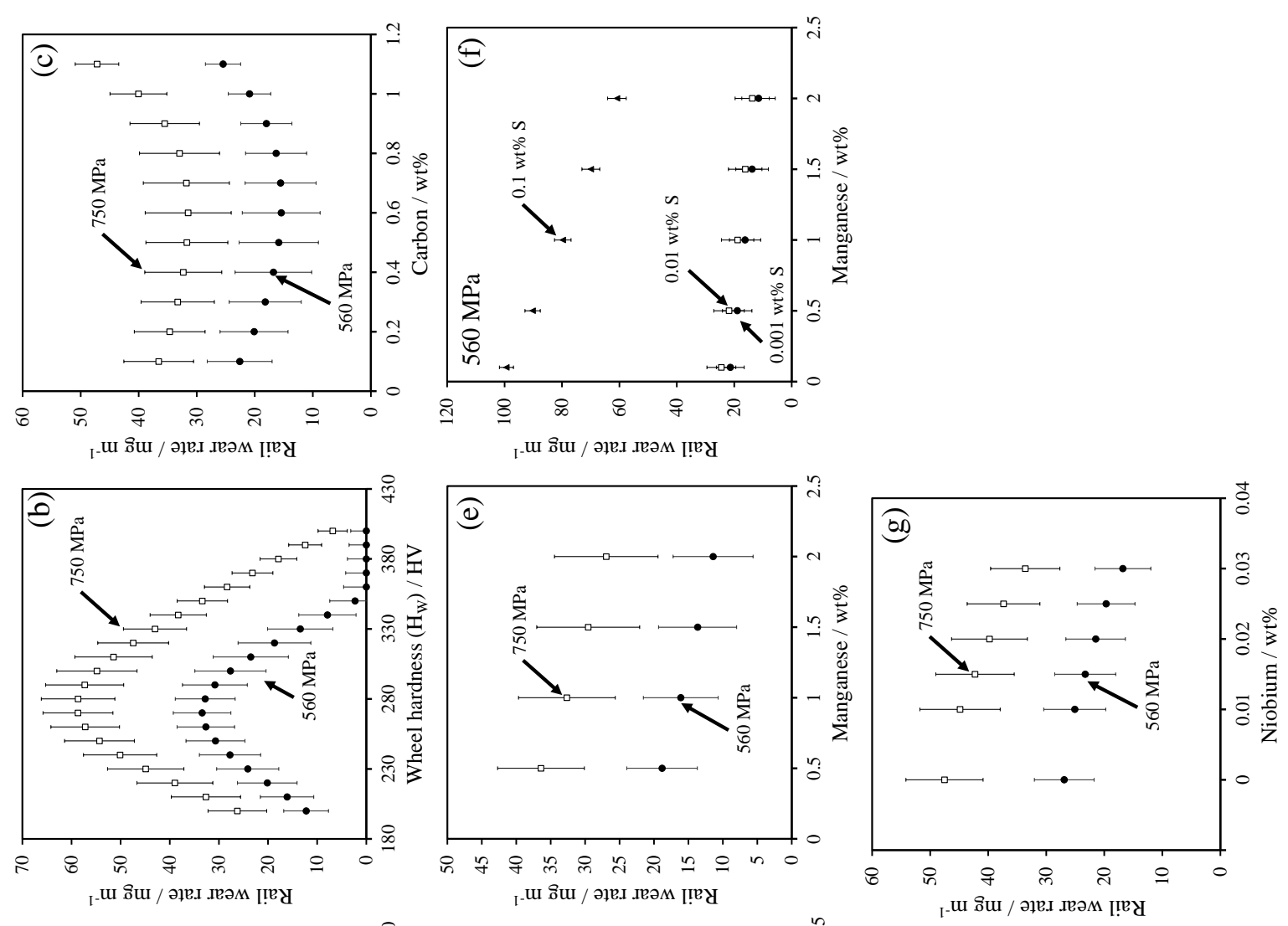

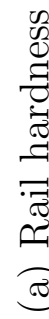

菡

ठ

党

क

武

青

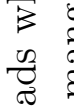

๘

过

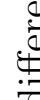

密

\%

苛 (2)

.

苞

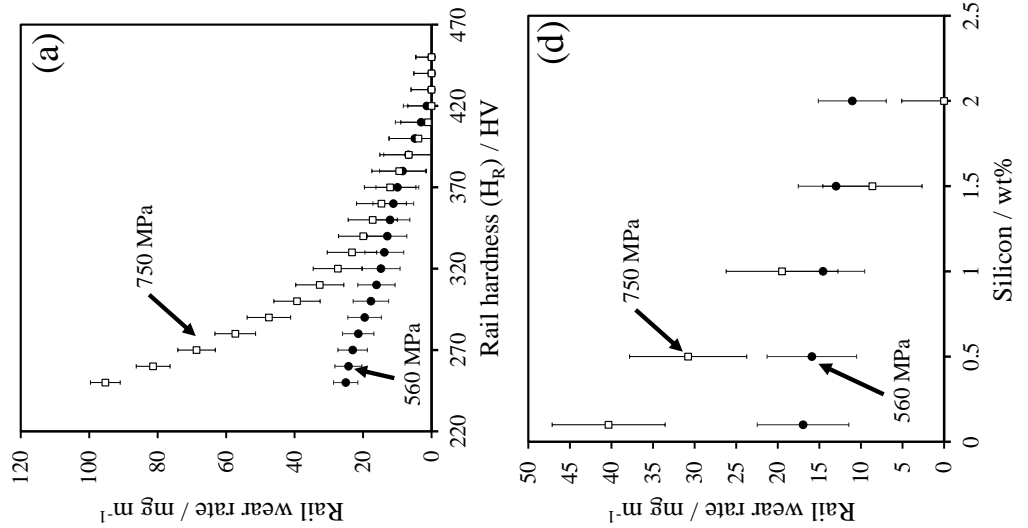

.

돈

๑

\%

ธิ

3

我莡

.$\exists$

등

.

츨

.

$\ddot{\sim} B$

0

$\because$

臭 
For Figure 10.7 a, at a constant wheel hardness of $210 \mathrm{HV}$ and constant rail composition, the wear rate of rails decrease sharply with increasing rail hardness and the rate of decrease is higher at higher contact stress. At very high hardness of rails, variation in contact stress seems to have no effect on rail wear performance.

At a constant rail hardness of $310 \mathrm{HV}$, wear rate increase with increasing wheel hardness upto about $270 \mathrm{HV}$ wheel hardness in Figure 10.7b. After that, rail wear decrease with increasing wheel hardness, probably due to less generation of abrasive debris due to harder wheels.

Carbon controls the microstructure of rails which generally varies from bainitic microstructures at low carbon $(0.1-0.4 \mathrm{wt} \% \mathrm{C})$ contents to ferrite-pearlite or, fully pearlite at $0.4-0.8 \mathrm{wt} \% \mathrm{C}$ to pro-eutectoid cementite-pearlite microstructure in hypereutectoid carbon $(>0.8 \mathrm{wt} \% \mathrm{C})$ compositions. The rail wear decrease with increasing carbon concentration in Figure 10.7 because of gradually increasing pearlite volume fraction. At same hardness level, pearlite is more wear resistant to ferrite. Beyond 0.6-0.7 wt\% C, wear rate increase with increasing carbon probably due to brittle pro-eutectoid cementite in the microstructure which are detrimental to mechanical properties.

With constant carbon $(0.78 \mathrm{wt} \% \mathrm{C})$, silicon decreases wear rate for rails (Figure $10.7 \mathrm{~d})$ because high silicon ( $\geq 1 \mathrm{wt} \%$ ) indicates cementite-free bainitic microstructure which is more-wear resistant than pearlite. Manganese (Figure 10.7) has an independent effect on decreasing the wear rate but, in presence of high sulphur contents, wear rates increase (Figure 10.7F) due to $\mathrm{MnS}$ related rolling contact fatigue issues. Niobium addition also tend to decrease the wear rate of rails (Figure $10.7 \mathrm{~g}$ ).

The similar exercise can be carried out for a bainite based composition in Table 10.3 and the results are demonstrated in Figure 10.8 .

Table 10.3: Constant values for variables in Figure 10.8. Compositions are in wt\%.

\begin{tabular}{cccccccccc}
\hline $\begin{array}{c}\text { Rail hardness } \\
\left(\mathrm{H}_{\mathrm{R}}\right)\end{array}$ & $\begin{array}{c}\text { Wheel hardness } \\
\left(\mathrm{H}_{\mathrm{W}}\right)\end{array}$ & $\mathrm{C}$ & $\mathrm{Si}$ & $\mathrm{Mn}$ & $\mathrm{P}$ & $\mathrm{S}$ & $\mathrm{Cr}$ & $\mathrm{Mo}$ & Ni-Nb-Cu-V-Al-B-Ti \\
\hline $390 \mathrm{HV}$ & $240 \mathrm{HV}$ & 0.2 & 2.0 & 2.0 & 0.015 & 0.03 & 0.55 & 0.5 & 0 \\
\hline
\end{tabular}



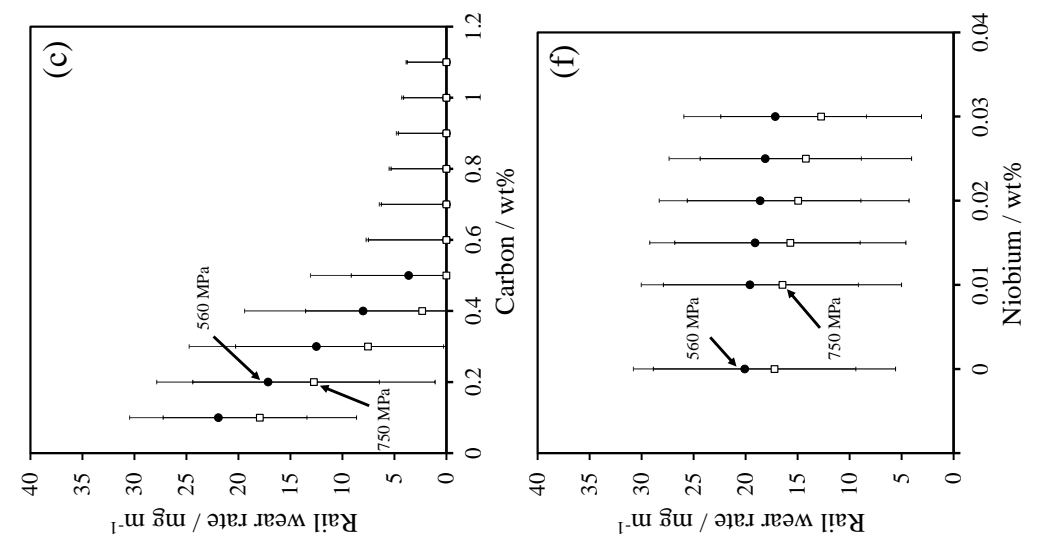

$\frac{\overrightarrow{0}}{0}$

$\frac{0}{3}$

$\frac{\pi}{0}$

苟

$\because \cdot \frac{1}{\exists}$

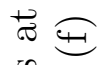

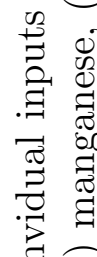
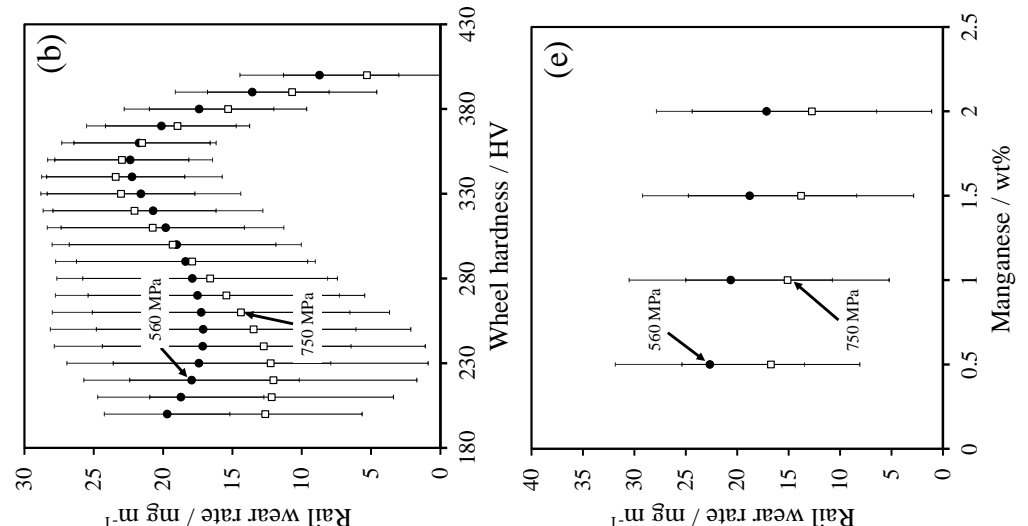

寻

击

$3 \stackrel{0}{0}$

प्:

帚无

0

苜

ठृ

政
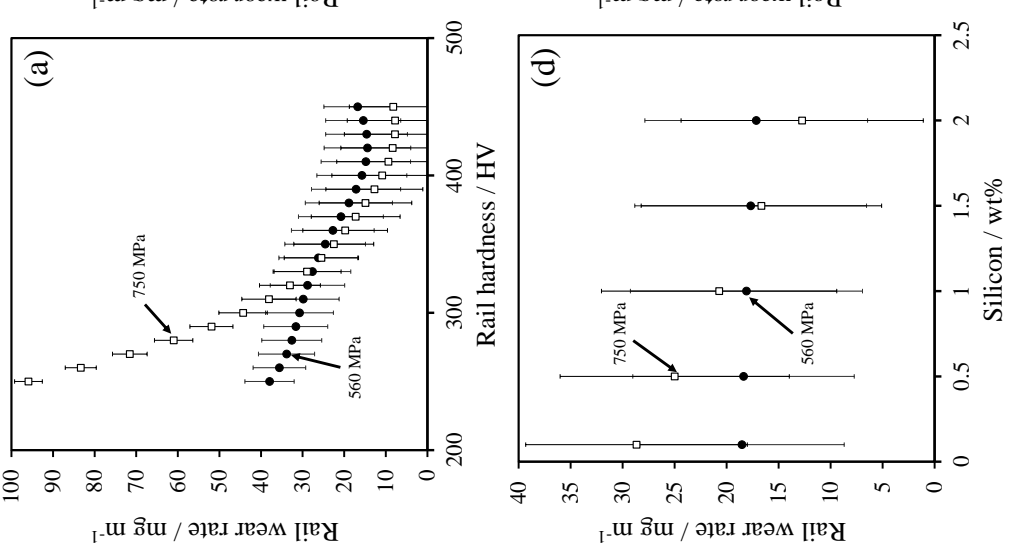

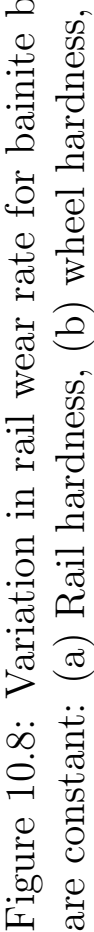

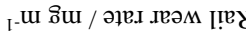

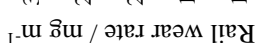




\subsection{Summary}

A neural network model has been developed to estimate the wear performance of rails and the perceived noise in experimental data to ascertain the repeatability of an experiment. Hardness of the rails and wheels are the most important variables in controlling the wear of rails. Predicted trends have been found consistent with metallurgical experiences and the perceived noise in the experimental data ascertain reasonable repeatability with an experiment with the concerned wear testing rig. The model can be applied widely to predict wear because of its capacity to indicate uncertainty, including both an estimate of the perceived level of noise in the output, and an uncertainty associated with fitting the function in the local region of input space. 


\section{Chapter 11}

\section{Conclusions and future work}

The following conclusions can be drawn about the work presented in this thesis:

(i) Pearlitic steels with fine interlamellar spacings, are hard but not necessarily tough as the pearlite colony size controls toughness. Cementite-free bainitic rails are hard as-well-as tough owing to fine bainitic ferrite plates and cementitefree retained austenite films. The solubility of niobium decreases with increasing carbon concentrations even at higher carbon levels $(>0.8 \mathrm{wt} \% \mathrm{C})$ in austenite in contradiction to some analysis reporting increased niobium solubility at high carbon levels. Silicon decreases niobium solubility in austenite which affect high silicon cementite-free bainitic compositions.

(ii) Niobium additions are limited by the maximum concentration that can be soluble in austenite at reheating temperatures. Any niobium concentration beyond that, will form carbides that cannot be dissolved in austenite at typical reheating temperatures. Even when the niobium addition is less than the maximum soluble niobium in austenite, microsegregation leads to solute enrichment in liquid and eventually formation of primary niobium carbides that precipitate from liquid. To dissolve these primary carbides in the segregated austenite, the dissolution temperature required is way higher than the standard $1200-1300{ }^{\circ} \mathrm{C}$ reheating temperatures and the carbides will remain undissolved.

(iii) Coarse primary niobium carbides as large as $\sim 10 \mu \mathrm{m}$ can be observed in the ascast high carbon pearlitic steels and Si-rich cementite-free low carbon bainitic steels. The largest observed precipitate size decrease with decreasing niobium concentration. To dissolve these primary precipitates in austenite, the reheating temperatures must be atleast greater than the equilibrium $\mathrm{NbC}$ solution 
temperatures. But due to the coarse nature of the primary NbC precipitates, the diffusion controlled dissolution kinetics is slow and the standard reheating time of $2 \mathrm{~h}$ is not sufficient to dissolve all the precipitates. The dendritic morphology of the precipitates breaks down into spherical shape during reheating and hot rolling and the average diameter of such carbides in as-rolled alloys are 2-4 $\mu \mathrm{m}$. Dissolved niobium in reheated austenite precipitate during hot deformation as strain-induced fine niobium carbides $(<50 \mathrm{~nm})$ which are suitable to affect recrystallisation kinetics of deformed austenite.

(iv) Nb-microalloying increases the no-recrystallisation temperature of deformed austenite in high carbon pearlitic and low carbon Si-rich bainitic alloys. Nbmicroalloyed austenite tends to remain unrecrystallised below $900-950^{\circ} \mathrm{C}$ and the topology of the deformed austenite can be approximated by the stereological calculations. The pearlite transformation kinetics tend to accelerate when the austenite is deformed below the no-recrystallisation temperature but the effect is low until the amount of deformation is significant. The bainite transformation kinetics also tend to accelerate with decreasing deformation temperature. But during heavy deformation near $A_{e_{3}}$ temperature for the Si-rich bainitic alloys, ferrite transformation occur at prior austenite grain boundaries which reduce the effective hardness in the final microstructure.

(v) During hot rolling, $0.02 \mathrm{wt} \% \mathrm{Nb}$ addition in cementite-free bainitic alloy leads to un-recrystallised austenite after finish rolling at $870{ }^{\circ} \mathrm{C}$. Increased austenite grain boundary area and increased dislocation activity, hinder bainite growth which leads to increased retained austenite volume fraction. This leads to slightly improved ductility, improved toughness and improved wear resistance in the Nb-microalloyed alloy compared to the non-microalloyed one. For the as-rolled pearlitic alloys, $0.01 \mathrm{wt} \% \mathrm{Nb}$ addition refine the crystallographic unit size in the as-rolled microstructure after finish rolling at $870^{\circ} \mathrm{C}$, but does not have any significant effect on the pearlite transformation temperature as the interlamellar spacing and hardness values are comparable in both microalloyed and non-microalloyed alloys. The toughness is comparable and the tensile strength improves slightly but the wear resistance improves significantly in Nb-microalloyed pearlitic alloys.

(vi) Neural network analysis of wear data identify rail and wheel hardness to be the most important parameters in affecting wear performance of rails as well as indicating that niobium microalloying can lead to improved wear resistance. 


\subsection{Scope for future work}

Knowing the work performed in this thesis and the results obtained, the following work could be relevant for further research on the field:

(i) High resolution synchrotron X-ray experiments can be carried out to accurately measure the $\mathrm{NbC}$ volume fraction and corresponding dissolved $\mathrm{Nb}$ in solution after reheating conditions which is otherwise difficult to measure by electron microscopy or conventional X-ray diffraction because of very low volume fraction (about 0.0001-0.0002) of niobium carbide precipitates in the investigated alloys.

(ii) Hot compression experiments with variable strain and strain rates can be carried out to develop equations for recrystallisation kinetics of deformed austenite in the investigated Nb-microalloyed rail steels. Also, the effect of plane-strain compression and other complex deformation schedules on the recrystallisation kinetics can be studied.

(iii) A more in-depth study of non-propagating secondary cracks in various pearlitic and bainitic microstructures would provide valuable insight, and complement existing results.

(iv) Effect of Nb-microalloying on other important rail properties like rolling contact fatigue performance, weldability, hydrogen embrittlement etc needs to be investigated. 


\section{Bibliography}

[1] H. K. D. H. Bhadeshia. Steels for rails, in: Encyclopedia of Materials Science: Science and Technology. Pergamon Press, Oxford, Elsevier Science, ISBN 0-08-0431526, 2007.

[2] M. Hillert. The formation of pearlite. Decomposition of austenite by diffusional processes, pages 197-237, 1962.

[3] M. De Graef, M.V. Kral, and M. Hillert. A modern 3-D view of an Old pearlite colony. JOM, 58(12):25-28, 2006.

[4] T. Tanaka. Controlled rolling of steel plate and strip. Int Metals Rev. 2013; 26(1):185212..

[5] K. Nishioka and K. Ichikawa. Progress in thermomechanical control of steel plates and their commercialization. Science and Technology of Advanced Materials, 13(2):023001, 2012.

[6] M. Schilke. Degradation of railway rails from a materials point of view. [PhD Thesis]. Goteborg, Sweden: Chalmers University of Technology, 2013.

[7] R. Ordóñez. Study of the austenite decomposition and formation of proeutectoid cementite in hyper-eutectoid steels. PhD thesis, University of Pittsburgh, 2012.

[8] B. Bramfitt, AM Steelton, and F. Fletcher. A perspective on the manufacture of modern-day high-strength steel rail. In: Proceedings of the AREMA 2013 Annual Conference.

[9] L. Xiao-fei, P. Langenberg, S. Münstermann, and W. Bleck. Recent developments of modern rail steels. In: The 5th International Conference on HSLA Steels. 2005, Sanya, Hainan, China; pp. 775-782. 
[10] W. Heller and H. Schmedders. Steel. a handbook for materials research and engineering. (Berlin, Heidelberg, New York, Tokyo: Springer - Verlag and Dsseldorf: Verlag Stahleisen), vol. 2:593-601, 1993.

[11] H. de Boer, H. Bienzeisler, B. Müsgen, H. Schmedders, and K. Wick. Verbesserung des betriebsverhaltens von eisenbahnschienen durch feinperlitisieren des schienenkopfes. Stahl und Eisen, 112:101-107, 1992.

[12] M Sato, PM Anderson, and DA Rigney. Rolling-sliding behavior of rail steels. Wear, 162:159-172, 1993.

[13] Martin Schilke, Johan Ahlström, and Birger Karlsson. Low cycle fatigue and deformation behaviour of austenitic manganese steel in rolled and in as-cast conditions. Procedia Engineering, 2(1):623-628, 2010.

[14] P. Folgarait, A. Saccocco, A. De Ro, and B. Eisenkolb. Bainitic steels for new rail materials. EUR, (22081):1-189, 2006.

[15] H. K. D. H. Bhadeshia. Bainite in steels. Inst. of Metals, 1992.

[16] H. Ghonem, J. Kalousek, and D. Stone. On the fracture and wear characteristics of chromium-molybdenum bainitic steel. Specialty Steels and Hard Materials, pages 259-265, 1982.

[17] W. Heller and R. Schweitzer. High-strength pearlitic steel does well in comparative tests of alloy rails. Railway Gazette International, 136(10), 1980.

[18] W. Heller and R. Schweitzer. Hardness, microstructure and wear behaviour of rail steels. In 2nd Int. Conf. Heavy Haul Railways, pages 282-286, Colorado, USA, 1982.

[19] H. Ichinose, J. Takehara, and M. Ueda. In 2nd Int. Conf. on Heavy Haul Railways, page 178182, Colorado Springs, USA, 1982.

[20] J. Kalousek, D.M. Fegredo, and E.E. Laufer. The wear resistance and worn metallography of pearlite, bainite and tempered martensite rail steel microstructures of high hardness. Wear, 105(3):199-222, 1985.

[21] P. Clayton, K.J. Sawley, P.J. Bolton, and G.M. Pell. Wear behavior of bainitic steels. Wear, 120(2):199-220, 1987.

[22] R. Devanathan and P. Clayton. Rolling-sliding wear behavior of three bainitic steels. Wear, 151(2):255-267, 1991. 
[23] H.K.D.H. Bhadeshia and D.V. Edmonds. Bainite in silicon steels: new composition-property approach part 1 and 2. Metal Science, 17(9):411-425, 1983.

[24] H. K. D. H. Bhadeshia and V. Jerath. Relating to carbide-free bainitic steels and method of producing such steels, March 9 1999. US Patent 5,879,474.

[25] B. Sladojević, M. Jelić, and M. Puzić. New requirements for the quality of steel rails. Metalurgija, 17(4):213-219, 2011.

[26] H. Yokoyama, S. Mitao, S. Yamamoto, Y. Kataoka, and T. Sugiyama. High strength bainitic steel rails for heavy haul railways with superior damage resistance. NKK Technical Report-Japanese Edition-, pages 17-23, 2000.

[27] D. A. Curry and J. F. Knott. Effects of microstructure on cleavage fracture stress in steel. Metal Science, 12(11):511-514, 1978.

[28] K. Sawley and J. Kristan. Development of bainitic rail steels with potential resistance to rolling contact fatigue. Fatigue \& Fracture of Engineering Materials \& Structures, 26(10):1019-1029, 2003.

[29] J. Herian, K. Aniołek, M. Cieśla, and G. Skotnicki. Shaping the structure during rolling and isothermal annealing, and its influence on the mechanical characteristics of high-carbon steel. Materials Science and Engineering: A, 608:149-154, 2014.

[30] D. M. Fegredo, M. T. Shehata, A. Palmer, and J. Kalousek. The effect of sulphide and oxide inclusions on the wear rates of a standard C-Mn and a Cr-Mo alloy rail steel. Wear, 126(3):285-306, 1988.

[31] C. Liu, Y. Huang, and M. Jiang. Effects and mechanisms of RE on impact toughness and fracture toughness of clean heavy rail steel. Journal of Iron and Steel Research, International, 18(3):52-58, 2011.

[32] Chapter 4. American Railway Engineering and Maintenance-of-the-Way Association (AREMA), Rail Specifications 4-2-1, 2006.

[33] M. Glowacki, R. Kuziak, Z. Malinowski, and M. Pietrzyk. Modelling of heat transfer, plastic flow and microstructural evolution during shape rolling. Journal of materials processing technology, 53(1):159-166, 1995.

[34] G. Smyk, M. Frantzke, R. Kuziak, and M. Pietrzyk. Coupling microstructure evolution model with FE code for numerical simulation of rolling-cooling 
sequence for rails. In: 23rd International Conference on Metallurgy and Materials METAL 2014, May 2014, Brno, Czech Republic, EU.

[35] S.B. Singh and H.K.D.H. Bhadeshia. Topology of grain deformation. Materials Science and Technology, 14(8):832-834, 1998.

[36] S.S. Hansen, J.B. Vander Sande, and M. Cohen. Niobium carbonitride precipitation and austenite recrystallization in hot-rolled microalloyed steels. Metallurgical Transactions A, 11(3):387-402, 1980.

[37] JG Williams, ID Simpson, and JK MacDonald. Niobium in rail steels. In Niobium-Proceedings of the international symposium, 1984.

[38] H. De Boer and H. Masumoto. Niobium in rail steel. In International Symposium on Niobium 2001, pages 821-844, 2001.

[39] T. Tanaka H. Ohtani, T. Nishizawa and H. Hasebe. In Proc. Japan-Canada Seminar on Secondary Steelmaking, 1985.

[40] K. Balasubramanian. Thermodynamics of microalloyed austenites and nonstoichiometric carbides and nitrides. [PhD thesis]. Hamilton, Ontario, Canada: McMaster University; 1988.

[41] F. De Kazinczy, A. Axnas, and P. Pachleitner. Some properties of niobium treated mild steel. Jernkont Ann, 147:408, 1963.

[42] T Mori et al. Behavior of niobium carbides and nitrides in steel. Journal Iron and Steel Institute Japan, 50:911-917, 1964.

[43] K. Narita and S. Koyama. The physical chemistry of steels containing vanadium, niobium, and tantalum. Tetsu To Hagane, 52(4):788, 1966.

[44] L. Meyer. Dissertation Clausthal Berg. Hulten. PhD thesis, 1966.

[45] R. P. Smith. The solubility of niobium/columbium/ carbide in gamma iron (solubility of niobium carbide in gamma iron from carbon content of series of iron-niobium alloys equilibrated with hydrogen-methane mixtures). AIME, Transactions, 236:220, 1966.

[46] B. Augland, N. Christensen, and T. H. Johansen. The solubility of niobium/columbium/ carbide in gamma iron (solubility of niobium carbide in gamma iron determined from experiments using $\mathrm{Fe}-\mathrm{Nb}$ alloy in equilibrium with hydrogen-methane mixtures). AIME, Transactions, 239:1651-1654, 1967. 
[47] H. Nordberg and B. Aronsson. Solubility of niobium carbide in austenite. $J$ Iron Steel Inst, 206(12):1263-1266, 1968.

[48] S. Koyama, T. Ishii, and K. Narita. Effects of $\mathrm{Mn}, \mathrm{Si}, \mathrm{Cr}$, and $\mathrm{Ni}$ on the solution and precipitation of niobium carbide in iron austenite. Technical report, Kobe Steel Ltd., Japan, 1971.

[49] V. K. Lakshmanan. Thermodynamics of the interstitial phases of niobium in iron austenite. Open Dissertations and Thesis, page 364, 1977.

[50] R. C. Sharma, V. K. Lakshmanan, and J. S. Kirkaldy. Solubility of niobium carbide and niobium carbonitride in alloyed austenite and ferrite. Metallurgical Transactions A, 15(3):545-553, 1984.

[51] W. Huang. A thermodynamic evaluation of the Fe-Nb-C system. Z. Metallkd., 81(6):397-404, 1990.

[52] B. Lee. Thermodynamic assessment of the Fe-Nb-Ti-CN system. Metallurgical and Materials Transactions A, 32(10):2423-2439, 2001.

[53] K. Balasubramanian and J. S. Kirkaldy. Austenite-nonstoichiometric precipitate equilibria in microalloyed steels: Part I: Fe-Ti-C and Fe-Nb-C systems. Calphad, 10(2):187-202, 1986.

[54] M. Hasebe T. Nishizawa, H. Ohtani. Presentation, CALPHAD XIV, Boston, Mass. 1985.

[55] M. Hasebe H. Ohtani and T. Nishizawa. to be contributed to Met. Trans. A; Cited in 53.

[56] P. Gustafson. A thermodynamic evaluation of the Fe-C system. Scand. J. Metall., 14(5):259-267, 1985.

[57] K Balasubramanian, A Kroupa, and JS Kirkaldy. Experimental investigation of the thermodynamics of $\mathrm{Fe}-\mathrm{Nb}-\mathrm{C}$ austenite and nonstoichiometric niobium and titanium carbides $(\mathrm{T}=1273$ to $1473 \mathrm{~K}$ ). Metallurgical Transactions A, 23(3):729-744, 1992.

[58] R. H. Davies, A. T. Dinsdale, J. A. Gisby, J. A. J. Robinson, and S. M. Martin. MTDATA-thermodynamic and phase equilibrium software from the national physical laboratory. Calphad, 26(2):229-271, 2002. 
[59] MatCalc The Materials Calculator. (2011). Databases. Available: http://matcalc.wkmp.tuwien.ac.at/databases.htm. Last accessed 5th April, 2014.

[60] H-J Kestenbach, A Itman, AM Nishi, IB Roca, and C Valentin. Metallographic studies of eutectics carbides in high niobium microalloyed steels. In Proceedings 4 CEBECIMAT UFSC, Florianopolis - SC/Brazil, December 1980.

[61] J Bernetič, B Bradaškja, G Kosec, E Bricelj, B Kosec, F Vodopivec, and L Kosec. Centreline formation of $\mathrm{Nb}(\mathrm{C}, \mathrm{N})$ eutectic in structural steel. Metalurgija, 49(1), 2010.

[62] F Vodopivec, M Gahrovšek, and B Ralič. Solution of eutectic niobium carbonitride in austenite in mild steel. Metal Science, 9(1):324-326, 1975.

[63] S. Zamberger, M. Pudar, K. Spiradek-Hahn, M. Reischl, and E. Kozeschnik. Numerical simulation of the evolution of primary and secondary $\mathrm{Nb}(\mathrm{CN})$, $\mathrm{Ti}(\mathrm{CN})$ and $\mathrm{AlN}$ in Nb-microalloyed steel during continuous casting. International Journal of Materials Research, 103(6):680-687, 2012.

[64] S. Kumar, S. Shukla, S. De, A. Saxena, B. Jha, B. Mishra, A. Verma, and S. Mallik. API X 70 grade HR coils for ERW pipes. International Journal of Metallurgical Engineering, 2(2):179-187, 2013.

[65] C. Davis and M. Strangwood. Segregation behaviour in nb microalloyed steels. Materials Science and Technology, 25(9):1126-1133, 2009.

[66] W. Ming, M.A. Dangshen, L. Zhentian, Z. Jian, C. Hongxiao, and D. Jianqing. Effect of nb on segregation, primary carbides and toughness of h13 steel. Acta Metall Sin, 50(3):285-293, 2014.

[67] A.W.B. Den. Characterization of ferroniobium and the thermodynamics and kinetics of dissolution of niobium compounds in liquid iron. [Masters' Thesis]. Hamilton, Ontario, Canada: McMaster University; 2013.

[68] C. Liu, Y. Huang, H. Liu, and M. Jiang. Effects and mechanisms of niobium on the fracture toughness of heavy rail steel. Advanced Materials Research, 163:110-116, 2011.

[69] R. Coladas, J. Masounave, G. Guerin, and J.P. Baïlon. Austenite grain growth in medium and high-carbon steels microalloyed with niobium. Metal science, 2013. 
[70] A. Nolasco, E.Q. Oliveira, G. Leonardos, and P.J.P. Bordignon. Niobium in Si-Mn rail steel. In Proceedings of the Int. Symposium Niobium, volume 81, pages 1041-1060, 1984.

[71] M.D.G.M. da Fonseca, L.H. de Almeida, L.C.F. Gomes, and I. Le May. Effects of microstructural parameters on the mechanical properties of eutectoid rail steels. Materials Characterization, 39(1):1-14, 1997.

[72] H.J. Kestenbach and G.S. Martins. Effect of niobium on austenite recrystallization and pearlite colony size in a microalloyed eutectoid steel. Metallurgical and Materials Transactions A, 15(7):1496-1499, 1984.

[73] S. Jansto. Niobium-bearing structural steels for the 21st centruy. Niobium Bearing Structural Steels, pages 1-27, 2010.

[74] S. Jansto. Current development in niobium high carbon applications. In MSET 2011, Materials Science \& Technology 2011 Conference and Exhibition (MS\&T Partner Societies), Columbus, Ohio; 2011. p. 642653.

[75] S. Jansto. Applied metallurgy of the microniobium $囚$ alloy approach in long and plate products. In METAL, Brno, Czech Republic, EU, 2012.

[76] S. Jansto. Microniobium alloy approach in medium and high carbon steel bar, plate and sheet products. Metallurgical and Materials Transactions B, 45(2):438-444, 2014.

[77] S. Jansto. Metallurgical mechanism and niobium effects on improved mechanical properties in high carbon steels. In HSLA Steels 2015, Microalloying 2015 E Offshore Engineering Steels 2015: Conference Proceedings, pages 981-986. Wiley Online Library.

[78] R. Coladas, J. Masounave, and J.P. Ballon. The hot deformation of austenite, ed. Balance, JB, New York: AIME; 1977 pages 341-383.

[79] Z. Cui, J. Patel, and E.J. Palmiere. Thermomechanical processing of structural steels with dilute niobium additions. In HSLA Steels 2015, Microalloying 2015 \& Offshore Engineering Steels 2015: Conference Proceedings, pages 281-287. Wiley Online Library.

[80] T. Wada and K. Fukuda. Effect of rolling in low temperature austenite region on strength, ductility and toughness of rail steels. Tetsu-to-Hagane, 73(9):1162-1169, 1987. 
[81] E. Cotrina, B. López, and J.M. Rodriguez-Ibabe. Influence of thermomechanical treatment on the austenite-pearlite transformation in a high carbon nb-microalloyed steel. In Symposium on the Thermodynamics, Kinetics, Characterization and Modeling of: Austenite Formation and Decomposition, pages 213-225, 2003.

[82] K. Sugino, H. Kageyama, and H. Masumoto. Development of weldable highstrength steel rails. In Proc. Second Heavy Haul Railway Conference, Paper, pages 187-196, 1982.

[83] Z. Yang, H. Wang, and Y. Ji. Study on nb microalloying in high carbon pearlite steels for rails. In HSLA Steels 2015, Microalloying $2015 \mathscr{E}$ Offshore Engineering Steels 2015: Conference Proceedings, pages 987-993. Wiley Online Library.

[84] L. Mauritczat K. Groß K. Hulka, E. Koerfer and E. Kudielka. Niob als mikrolegierungselement in eutektoiden sthlen am beispiel der schienensthle. Berg- und Httenmnnische Monatshefte, 129:25-34, 1984.

[85] U. P. Singh, R. Singh, and S. Jha. Influence of microalloying on fracture toughness and wear resistance of rail steel. Scandinavian journal of metallurgy, 24(4):180-186, 1995.

[86] S.L. Miller. Effect of microalloying on pearlite transformation of high carbon wire steels. [PhD thesis]. Golden, CO: Colorado School of Mines; 2007.

[87] N. Guo and Q. Liu. Back-scattered electron imaging combined with ebsd technique for characterization of pearlitic steels. Journal of microscopy, 246(3):221-228, 2012.

[88] H.K.D.H. Bhadeshia and R. Honeycombe. Steels: microstructure and properties. Butterworth-Heinemann, 2011.

[89] F.B. Pickering and B. Garbarz. The effect of transformation temperature and prior austenite grain size on the pearlite colony size in vanadium treated pearlitic steels. Scripta metallurgica, 21(3):249-253, 1987.

[90] J.M. Rodriguez-Ibabe and B. López. Thermomechanical processing and role of microalloying in eutectoid steels. In Advanced Steels, pages 475-484. Springer, 2011. 
[91] Y.J. Park and I.M. Bernstein. The process of crack initiation and effective grain size for cleavage fracture in pearlitic eutectoid steel. Metallurgical Transactions A, 10(11):1653-1664, 1979.

[92] L. Mendizabal, A. Iza-Mendia, B. López, and J.M. Rodriguez-Ibabe. Influence of vanadium microaddition on the microstructure and mechanical properties of high strength large diameter wire-rods. In Materials Science Forum, volume 500, pages 761-770. Trans Tech Publ, 2005.

[93] R. K. Steele and R. P. Reiff. Rail: its behavior and relationship to total system wear. 1982.

[94] L.E. Daniels and N. Blume. Rail corrugation growth performance. In Second International Heavy Haul Railway Conference, pages 294-318, 1982.

[95] G.I. Rees, J. Perdrix, T. Maurickx, and H.K.D.H. Bhadeshia. The effect of niobium in solid solution on the transformation kinetics of bainite. Materials Science and Engineering: A, 194(2):179-186, 1995.

[96] I.A. Yakubtsov and J.D. Boyd. Bainite transformation during continuous cooling of low carbon microalloyed steel. Materials science and technology, 17(3):296-301, 2001.

[97] K. Tsuzaki, T. Ueda, K. Fujiwara, and T. Maki. Increase in retained austenite by ausforming in an austempered silicon steel. New Materials and Processes for the Future, pages 799-804, 1989.

[98] A. Matsuzaki and H.K.D.H. Bhadeshia. Effect of austenite grain size and bainite morphology on overall kinetics of bainite transformation in steels. $M a$ terials Science and Technology, 15(5):518-522, 1999.

[99] P.H. Shipway and H.K.D.H. Bhadeshia. Mechanical stabilisation of bainite. Materials Science and Technology, 11(11):1116-1128, 1995.

[100] H.K.D.H. Bhadeshia. Effect of stress \& strain on formation of bainite in steels. Hot Workability of Steels and Light Alloys-Composites, pages 543-556, 1996.

[101] Y. Won and B. G. Thomas. Simple model of microsegregation during solidification of steels. Metallurgical and Materials Transactions A, 32(7):1755-1767, 2001.

[102] MatCalc The Materials Calculator. (2012). Example E20: Continuous casting of micro-alloyed Fe-Al-C-N-Nb-Ti steel, part 
2: Scheil-Gulliver analysis of primary precipitation. Available: http://matcalc.tuwien.ac.at/wiki/doku.php?id=examples:equilib:e20:e20_2. Last accessed 10th August, 2016.

[103] H. D. Brody and M. C. Flemings. Trans. TMS-AIME, 236:615-624, 1966.

[104] MatCalc The Materials Calculator. (2012). Example E20: Continuous casting of micro-alloyed Fe-Al-C-N-Nb-Ti steel, part 4: Scheil-Gulliver analysis of microsegregation. Available: http://matcalc.tuwien.ac.at/wiki/doku.php?id=examples:equilib:e20:e20_4. Last accessed 10th August, 2016.

[105] J. Kunze, C. Mickel, M. Leonhardt, and S. Oswald. Precipitation of titanium nitride in low-alloyed steel during solidification. Steel research, 68(9):403-408, 1997.

[106] S. Roy, S. Patra, S. Neogy, A. Laik, S.K. Choudhary, and D. Chakrabarti. Prediction of inhomogeneous distribution of microalloy precipitates in continuouscast high-strength, low-alloy steel slab. Metallurgical and Materials Transactions A, 43(6):1845-1860, 2012.

[107] M. Strangwood, D.Y. Zhang, and C.L. Davis. A comparison of analytical and calphad-based modelling for simulation of segregation during casting of steels. E-Proceedings of Science and Technology of Ironmaking and Steelmaking (STIS 2013), 2013.

[108] E. N. Norma. 13674-1. Railway applications-Track-Rail-Part, 1.

[109] ASTM Standard. E23-09: Standard test method for notched bar impact testing of metallic materials. Annual Book of ASTM Standards, ASTM, West Conshohocken, PA, 2009.

[110] Y.M. Han, A.M. Samuel, F.H. Samuel, and H.W. Doty. Dissolution of $\mathrm{Al}_{2} \mathrm{Cu}$ phase in non-modified and Sr modified 319 type alloys. International Journal of Cast Metals Research, 2013.

[111] N. Fujita and H. K. D. H. Bhadeshia. Modelling precipitation of niobium carbide in austenite: multicomponent diffusion, capillarity, and coarsening. Materials science and technology, 17(4):403-408, 2001.

[112] R.G. Baker and J. Nutting. Precipitation processes in steels. ISI Special Report, 64, 1959. 
[113] T. Gladman. The physical metallurgy of microalloyed steels, volume 615. Maney Pub, 1997.

[114] H. Kestenbach and E. V. Morales. Transmission electron microscopy of carbonitride precipitation in microalloyed steels. Acta Microscopica, 7(1):22-33, 1998.

[115] J. Gallego, A. R. Rodrigues, C.L.F. de Assis, and L. Montanari. Second phase precipitation in ultrafine-grained ferrite steel. Materials Research, 17(2):527534, 2014.

[116] H. Lee, K. Park, J. H. Lee, Y. Heo, D.W. Suh, and H. K. D. H. Bhadeshia. Dissolution behaviour of $\mathrm{NbC}$ during slab reheating. ISIJ International, 54(7):1677-1681, 2014.

[117] G. Thomas and M. J. Whelan. Observations of precipitation in thin foils of aluminium+ 4\% copper alloy. Philosophical Magazine, 6(69):1103-1114, 1961.

[118] M. J. Whelan. On the kinetics of precipitate dissolution. Metal Science, 3(1):95-97, 1969.

[119] H. B. Aaron. On the kinetics of precipitate dissolution. Metal Science, 2(1):192-193, 1968.

[120] H.B. Aaron and G.R. Kotler. Second phase dissolution. Metallurgical transactions, 2(2):393-408, 1971.

[121] H.B. Aaron, D. Fainstein, and G.R. Kotler. Diffusion-limited phase transformations: A comparison and critical evaluation of the mathematical approximations. Journal of applied physics, 41(11):4404-4410, 1970.

[122] F.V. Nol Jr, P.G. Shewmon, and J.S. Foster. The dissolution and growth kinetics of spherical precipitates. Transactions of the Metallurgical Society of AIME, 245:1427-1433, 1969.

[123] L. M. Cheng, E. B. Hawbolt, and T. R. Meadowcroft. Modeling of dissolution, growth, and coarsening of aluminum nitride in low-carbon steels. Metallurgical and Materials Transactions A, 31(8):1907-1916, 2000.

[124] N. Fujita. Modelling carbide precipitation in alloy steels. PhD thesis, University of Cambridge, 2000. 
[125] J. Robson. Modelling of carbide and laves phase precipitation in 9-12 wt\% Chromium steels. PhD thesis, University of Cambridge, 1996.

[126] T. Sourmail and H. K. D. H. Bhadeshia. Modelling simultaneous precipitation reactions in austenitic stainless steels. Calphad, 27(2):169-175, 2003.

[127] Metals Data Book, 1993, Tokyo, The Japan Institute of Metals.

[128] D. San Martín, F. García Caballero, C. Capdevila, and C. García de Andrés. Austenite grain coarsening under the influence of niobium carbonitrides. $M a$ terials transactions, 45:2797-2804, 2004.

[129] H. Oikawa. Lattice diffusion in iron - a review. Tetsu-To-Hagane, 68:14891497, 1982.

[130] S. Subramanian, S. Shima, and G. Ocampo. The effect of nitrogen content on the evolution of precipitates and on the processing of $\mathrm{Ti}-\mathrm{Nb}$ bearing HSLA steel slabs. HSLA Steels: Metallurgy and Applications, pages 151-161, 1985.

[131] S. J. Lechuk. A study of austenite grain growth in a Ti-Nb HSLA steel. PhD thesis, University of British Columbia, 2000.

[132] S. Kurokawa, J. E. Ruzzante, A. M. Hey, and F. Dyment. Diffusion of niobium in iron and iron alloys. Met. Sci., 17(9):433-438, 1983.

[133] K. Xu, B. G. Thomas, C. J. Gauthier, M. S. Dyer, J. G. Speer, D. K. Matlock, and G. S. Ansell. Model of microalloy precipitation during continuous casting and reheating. Iron \& Steel Technology, 8(10):59-68, 2011.

[134] C. Homsher. Determination of the non-recrystallization temperature (tnr) in multiple microalloyed steels. 2007.

[135] F. Boratto, R. Barbosa, S. Yue, and J. Jonas. Effect of chemical composition on the critical temperatures of microalloyed steels. In International Conference on Physical Metallurgy of Thermomechanical Processing of Steels and Other Metals. THERMEC-88., volume 1, pages 383-390, 1988.

[136] F. Fletcher. Meta-analysis of tnr measurements: Determining new empirical models based on composition and strain. In Austenite Processing Symposium (Internal company presentation), pages 1-14, 2008.

[137] D. Bai, R. Bodnar, J. Ward, J. Dorricott, and S. Sanders. Development of discrete X80 line pipe plate at SSAB Americas. In Proceedings of AIST 2011 International Symposium on the Recent Developments in Plate Steels, 2011. 
[138] R. Kuziak, Y. Cheng, M. Glowacki, and M. Pietrzyk. Modeling of the microstructure and mechanical properties of steels during thermomechanical processing. NIST Technical Note(USA), 1393:72, 1997.

[139] S. Kim, Y. Lee, D. Lee, and Y. Yoo. Modeling of AGS and recrystallized fraction of microalloyed medium carbon steel during hot deformation. Materials Science and Engineering: A, 355(1):384-393, 2003.

[140] W. Roberts, A. Sandberg, T. Siwecki, and T. Werlefors. Prediction of microstructure development during recrystallization hot rolling of $\mathrm{Ti}-\mathrm{V}$ steels. HSLA Steels, Technology and Applications, pages 67-84, 1983.

[141] S. Medina and V. Lopez. Static recrystallization in austenite and its influence on microstructural changes in C-Mn steel and vanadium microalloyed steel at the hot strip mill. ISIJ international, 33(5):605-614, 1993.

[142] P. Choquet, A. Bon, and C. Perdrix. Mathematical model for precision of austenite and ferrite microstructures in hot rolling processes. Strength of Metals and Alloys(ICSMA 7)., 2:1025-1030, 1985.

[143] D. Bai, S. Yue, W. Sun, and J. Jonas. Effect of deformation parameters on the. Metallurgical Transactions A, 24(10):2151-2159, 1993.

[144] S. Vervynckt, K. Verbeken, P. Thibaux, M. Liebeherr, and Y. Houbaert. Control of the austenite recrystallization in niobium microalloyed steels. In $\mathrm{Ma}$ terials Science Forum, volume 638, pages 3567-3572. Trans Tech Publ, 2010.

[145] S. Vervynckt, K. Verbeken, B. Lopez, and J. Jonas. Modern HSLA steels and role of non-recrystallisation temperature. International Materials Reviews, 57(4):187-207, 2012.

[146] F. Samuel, S. Yue, J. Jonas, and K. Barnes. Effect of dynamic recrystallization on microstructural evolution during strip rolling. ISIJ international, 30(3):216-225, 1990.

[147] S. Medina, A. Quispe, P. Valles, and J. Banos. Recrystallisation-precipitation interaction study of two medium carbon niobium microalloyed steels. ISIJ international, 39(9):913-922, 1999.

[148] Y. Xu, Y. Yu, B. Xiao, Z. Liu, and G. Wang. Modelling of microstructure evolution during hot rolling of a high-Nb HSLA steel. Journal of materials science, 45(10):2580-2590, 2010. 
[149] E. Palmiere, C. Garcia, and A. DeArdo. The influence of niobium supersaturation in austenite on the static recrystallization behavior of low carbon microalloyed steels. Metallurgical and Materials Transactions A, 27(4):951960, 1996.

[150] S. Patra, S. Neogy, V. Kumar, D. Chakrabarti, and A. Haldar. Refinement of ferrite grain size near the ultrafine range by multipass, thermomechanical compression. Metallurgical and Materials Transactions A, 43(11):4296-4310, 2012.

[151] G.E. Dieter and D.J. Bacon. Mechanical metallurgy, volume 3. McGraw-Hill New York, 1986.

[152] Q. Zhu, C.M. Sellars, and H.K.D.H. Bhadeshia. Quantitative metallography of deformed grains. Materials science and technology, 23(7):757-766, 2007.

[153] H. Yang and H.K.D.H. Bhadeshia. Uncertainties in dilatometric determination of martensite start temperature. Materials Science and Technology, 23(5):556$560,2007$.

[154] H.K.D.H. Bhadeshia. Properties of fine-grained steels generated by displacive transformation. Materials Science and Engineering: A, 481:36-39, 2008.

[155] W. Solano-Alvarez, E. Pickering, and H.K.D.H. Bhadeshia. Degradation of nanostructured bainitic steel under rolling contact fatigue. Materials Science and Engineering: A, 617:156-164, 2014.

[156] W. Solano-Alvarez, E. Pickering, M. Peet, K. Moore, J. Jaiswal, A. Bevan, and H.K.D.H. Bhadeshia. Soft novel form of white-etching matter and ductile failure of carbide-free bainitic steels under rolling contact stresses. Acta Materialia, 121:215-226, 2016.

[157] D. MacKay. Bayesian interpolation. Neural computation, 4(3):415-447, 1992.

[158] D. MacKay. A practical bayesian framework for backpropagation networks. Neural computation, 4(3):448-472, 1992.

[159] D. MacKay. Bayesian nonlinear modeling for the prediction competition. ASHRAE transactions, 100(2):1053-1062, 1994.

[160] D. MacKay. Probable networks and plausible predictionsa review of practical bayesian methods for supervised neural networks. Network: Computation in Neural Systems, 6(3):469-505, 1995. 
[161] H.K.D.H. Bhadeshia, D. MacKay, and L. Svensson. Impact toughness of CMn steel arc welds-bayesian neural network analysis. Materials Science and Technology, 11(10):1046-1051, 1995.

[162] H. Fujii, D. MacKay, and H.K.D.H. Bhadeshia. Bayesian neural network analysis of fatigue crack growth rate in nickel base superalloys. ISIJ international, 36(11):1373-1382, 1996.

[163] L. Gavard, H.K.D.H. Bhadeshia, D. MacKay, and S. Suzuki. Bayesian neural network model for austenite formation in steels. Materials Science and Technology, 12(6):453-463, 1996.

[164] S. Yoshitake, V. Narayan, H. Harada, H.K.D.H. Bhadeshia, and D. Mackay. Estimation of the $\gamma$ and $\gamma^{\prime}$ lattice parameters in nickel-base superalloys using neural network analysis. ISIJ international, 38(5):495-502, 1998.

[165] S.B. Singh, H.K.D.H. Bhadeshia, D. MacKay, H. Carey and I. Martin. Neural network analysis of steel plate processing. Ironmaking and Steelmaking, 25(5):355-365, 1998.

[166] A. Badmos, H.K.D.H. Bhadeshia, and D. MacKay. Tensile properties of mechanically alloyed oxide dispersion strengthened iron alloys Part 1 - Neural network models. Materials Science and Technology, 14(8):793-809, 1998.

[167] V. Narayan, R. Abad, B. Lopez, H.K.D.H. Bhadeshia, and D. MacKay. Estimation of hot torsion stress strain curves in iron alloys using a neural network analysis. ISIJ international, 39(10):999-1005, 1999.

[168] M. Yescas. Prediction of the vickers hardness in austempered ductile irons using neural networks. International Journal of Cast Metals Research(UK), 15(5):513-521, 2003.

[169] G. Cottrell, R. Kemp, H.K.D.H. Bhadeshia, G. Odette, and T. Yamamoto. Neural network analysis of charpy transition temperature of irradiated lowactivation martensitic steels. Journal of Nuclear Materials, 367:603-609, 2007.

[170] J. Pak, J. Jang, H.K.D.H. Bhadeshia, and L. Karlsson. Optimization of neural network for charpy toughness of steel welds. Materials and Manufacturing Processes, 24(1):16-21, 2008.

[171] H.K.D.H. Bhadeshia. Neural networks in materials science. ISIJ international, 39(10):966-979, 1999. 
[172] H.K.D.H Bhadeshia, R. Dimitriu, S. Forsik, J. Pak, and J. Ryu. Performance of neural networks in materials science. Materials Science and Technology, 25(4):504-510, 2009.

[173] T. Sourmail. Models manager: Tutorial. 2016. [online] Msm.cam.ac.uk. Available at: http://www.msm.cam.ac.uk/phase-trans/2001/mm_doc/ [Accessed 22 Nov. 2016].

[174] Mathew Peet. Technical note, bayesian neural networks as implemented in model manager. 2015. [online] Mathewpeet.org. Available at: http://mathewpeet.org/notes/BNNMM/ [Accessed 23 Nov. 2016].

[175] D. MacKay. Information theory, inference and learning algorithms. Cambridge university press, 2003. Materials Algorithms Project Program Library http://www.msm.cam.ac.uk/ map/utilities/modules/nnecode.html.

[176] D. Williams and G. Hinton. Learning representations by back-propagating errors. Nature, 323:533-536, 1986.

[177] D. MacKay. Information-based objective functions for active data selection. Neural computation, 4(4):590-604, 1992.

[178] M. Peet and H. Hasan. Neural network model for thermal conductivity of steels. [online] Mathewpeet.org. Available at: http://mathewpeet.org/publications/posters/thermalcond/thermalcondposter.pdf [Accessed 21 April. 2017]. 